\title{
DESIGN AND OPERATION
} OF AN ADVANCED HYDRAULIC PISTON CORER

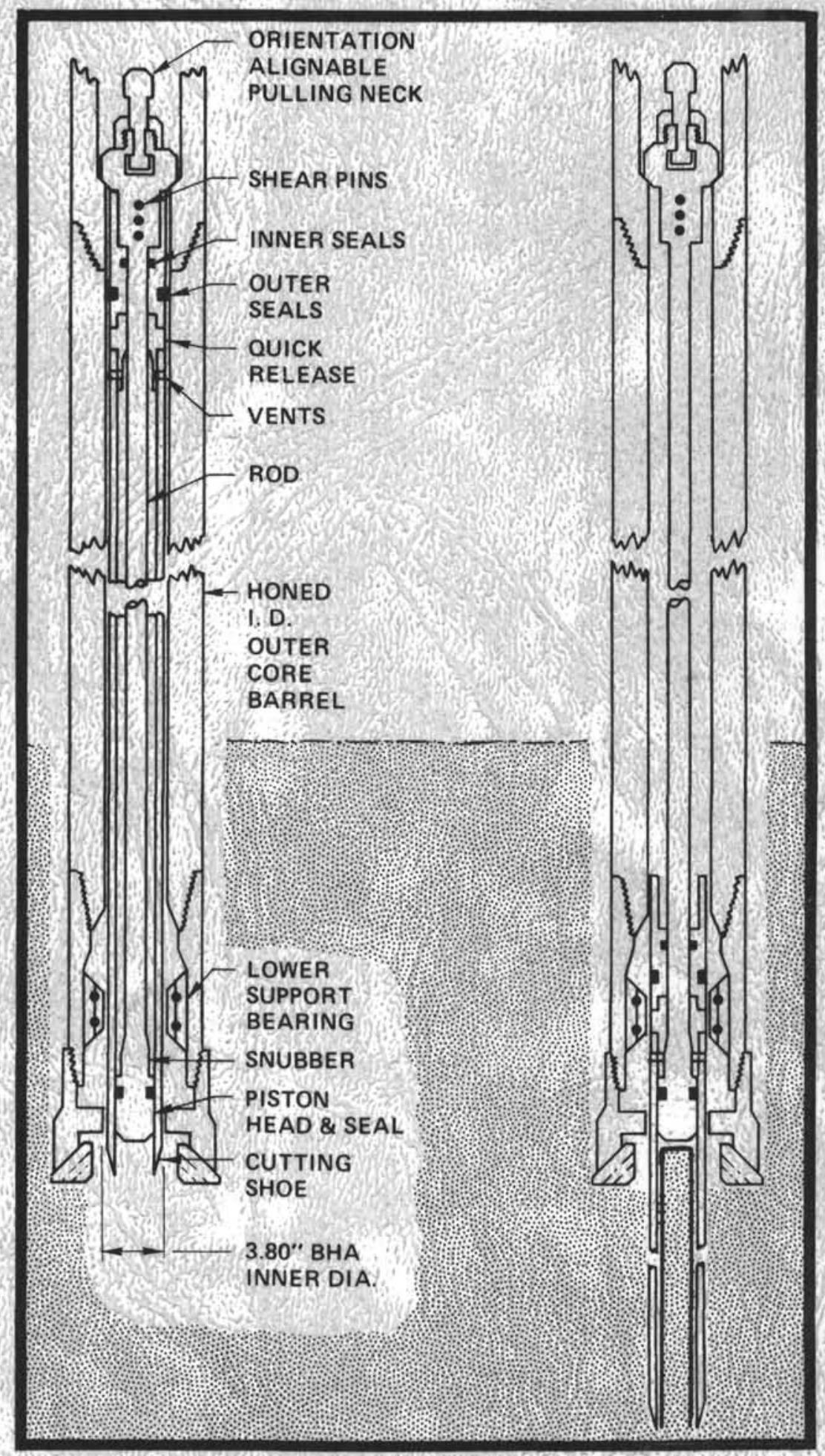

SCRIPPS INSTITUTION OF OCEANOGRAPHY UNIVERSITY OF CALIFORNIA AT SAN DIEGO 


\section{DISCLAIMER}

This report was prepared by the Deep Sea Drilling Project, University of Californ1a, San Diego as an account of work sponsored by the United States Government's National Science Foundation. Neither the University nor any of their empoyees, nor any of their contractors, subcontractors, or their employees, makes any warranty, express or implied, or assumes any legal liability or responsibility for the accuracy, completeness or usefulness of any information, apparatus, product or process disclosed, or represents that its use would not infringe privately owned rights. 


\section{The Cover Illustration}

A simplified version of the Advanced Piston Corer (APC) in action is depicted. At left, the corer has been landed in the bottomhole assembly so that the outer seals are activated against the bore of the Outer Core Barrel. At the right, the core has been taken by pressuring up to shear the pins and drive the scoping section of tool into the sediment. 
TECHNICAL REPORT NO. 21

Design and Operation of An Advanced

Hydraulic Piston Corer

\author{
Prepared for the \\ National Science Foundation \\ National Ocean Sediment Coring Program \\ Under Contract C-482
}

by the

University of California

Scripps Institution of Oceanography

Prime Contractor for the Project

July 1984

W.A. Nierenberg, Director

Scripps Institution of Oceanography
M. N. A. Peterson

Principal Investigator and Project Manager

Scripps Institution of Oceanography 


\section{INTRODUCTION}

\section{DEEP SEA DRILLING PROJECT}

The Deep Sea Drilling Project (DSDP) began coring in August, 1968, under the auspices of the National Science Foundations's (NSF) Ocean Sediment Coring Program to increase man's knowledge of the earth's development through the exploration of the ocean floor. The prime contract for the Project was executed in 1966 between NSF and the Board of Regents of the University of California (UC). Scripps Institution of Oceanography in La Jolla, California, which is part of the UC system, is responsible for the management and operation of the Project. Global Marine, Inc. (GMI) of Los Angeles, owner, designer, and builder of the GLOMAR CHALLENGER, subcontracted with Scripps to provide the drilling vessel for the drilling and coring program.

To plan the scientific objectives of the program, major oceanography institutions in the United States (including Woods Hole Oceanographic Institution, Lamont-Doherty Geological Observatory of Columbia University, Rosenstiel School of Marine Sciences of the University of Miami, the University of Washington and Scripps), joined in an agreement to mutually support such a program of deep ocean drilling. This association is called the Joint Oceanographic Institutions for Deep Earth Sampling (JOIDES) and provides scientific guidance for the Deep Sea Drilling Project. The group was later enlarged to include nine American institutions.

\section{INTERNATIONAL PHASE OF OCEAN DRILLING}

Prompted by the vast scientific and technical successes of the first seven years, the Project increased the scope of the coring program to include even deeper penetrations into the ocean floor. International interest in the Project increased. Several foreign scientific institutions, excited by past scientific results and confident of future successes, were interested in becoming members of JOIDES. These institutions were willing to contribute financially to the Projection exchange for a greater role in the scientific planning. In 1975, the "International Phase of Ocean Drilling ", known as IPOD, was born. IPOD was an initial three year Deep Crustal coring Porgram supported both scientifically and financially by the governments of France, Germany, Japan, England, and Russia.

\section{D/V GLOMAR CHALLENGER}

The GLOMAR CHALLENGER, with its unique coring procedures, has long been recognized as a major technical achievement in its own right. The 10,500 metric ton drill ship utilizes an advanced on board computer and dual bow and stern thrusters to dynamically position itself. The CHALLENGER has operated as far north as 76 degrees latitude; as far south as 77 degrees latitude and has the capability to maintain its station in 30-knot winds and 7-10 foot seas. Similar to conventional drillships, the vessel 
incorporates a 43-meter derrick amidship with a hookload capacity of 450 metric tons and can deploy a $7000 \mathrm{~m}$ drill string. The CHALLENGER utilizes an automatic pipe racker capable of handling 7,300 meters of 5-inch S-135 drill pipe, and is equipped with a drill pipe heave compensation system.

Most coring operations are conducted in very deep water and all sites are carefully screened to ensure that there is no possibility of encountering gas or hydrocarbons. For these reasons no riser or blow prevention equipment is used. Circulation while coring is provided by two National 1600 mud pumps and consists of seawater without return circulation. Core barrels are retrieved by wireline utilizing a coring winch equipped with up to $7900 \mathrm{~m}$ of $6 \times 16$ wire rope. Well equipped shipboard scientific laboratories are utilized to conduct comprehensive core analyses.

\section{ABSTRACT/TECHNICAL REPORT NO. 21}

This Deep Sea Drilling Project Technical Report documents the history, incentives, development and testing of the Advanced Piston Corer (APC) - the third generation in the wireline retrievable, piston coring technology in DSDP. Description and operational guidelines of the latest design iteration, APC Mod. II, are included. Operational sea trials of the Mod. I version are summarized. Appendices are included with related reports, design calculations and machine drawings.

The hydraulic piston corer technology developed by the DSDP engineering staff was successful from the first sea trials of the first 15-ft prototype model. Soon thereafter the Variable Length Hydraulic Piston Corer (VLHPC) was introduced and quickly revolutionized the science of coring in soft marine sediments. The VLHPC could take cores up to 9.5 meters in length but in doing so required a total tool length of nearly 100 feet in the extended condition when retrieved. The APC was developed to achieve equivalent length and quality piston cores using a tool only 60-plus feet long in the retrieved condition and about half as mechanically complex as the VLHPC. By employing the inside of the outer core barrel as a seal surface the hydraulic working area and available coring force were increased by $76 \%$ over the VLHPC.

The APC was designed for greater tolerance to overpull tensile loads when extracting the tool from sticky formations as well as more control of selected coring force and velocity. Sea trials of the prototype version were successfully completed during Legs 94, 95, and 96. Design modifications pointed up by the sea trials were incorporated into the current Mod. II version. 


\section{ACKNOWLEDGEMENTS}

The Advanced Piston Corer was originally conceived by Mr. Michael Storms and Mr. David Huey, DSDP Development Engineers. The idea was to achieve a significant simplification over the VLHPC developed by Mr. Storms and others. Mr. Huey was the APC project engineer, acted as Cruise Operations Manager during Leg 95 sea trials of the tool and prepared this report. Mr. Donald Cameron and Mr. Glen Foss were the Cruise Operations Managers during Legs 94 and 96, respectively, and oversaw sea trial testing during those cruises. The Development Engineering Department of DSDP was under the direction of Mr. Stanley Serocki.

M. N. A. Peterson

Principal Investigator

and Project Manager 
I. Background

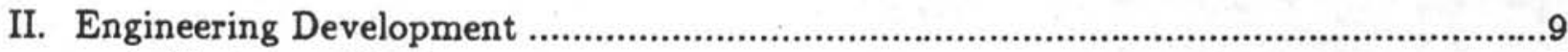

A. Prototype Design ..........................................................................................

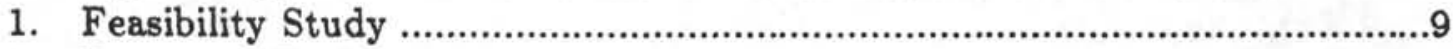

2. Prototype Design Goals ..............................................................................10

3. Seal Bore Outer Core Barrel (Drill Collar) ......................................................11

4. Compatibility with the Extended Core Barrel (XCB) ...................................12

5. Designing for Pullout Loads ..........................................................................12

6. Piston Rod Tensile Tests \& Failure Analysis ..................................................16

7. Release Mechanism - Shear Pins ……………..............................................19

8. Piston Corer Performance Analysis ............................................................20

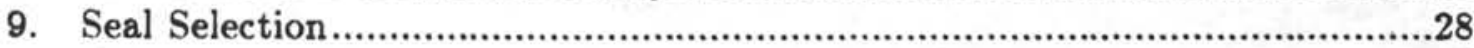

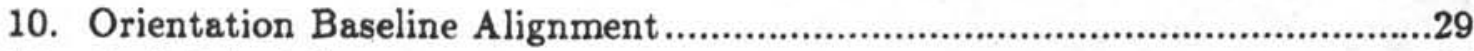

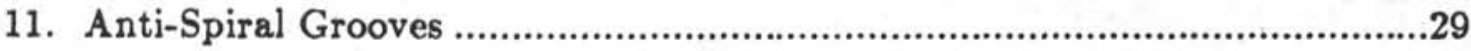

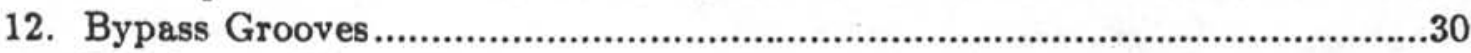

13. Breakaway Piston Head .................................................................................30

14. Compatibility with Heave Compensator ...........................................................31

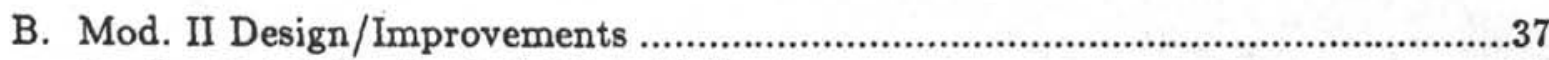

1. Sea Trial Feedback \& Mod. II Goals ................................................................37

2. Redesign Analysis and Changes.....................................................................38

III. System Description and Operation

Advanced Piston Corer - Mod. II .................................................................................

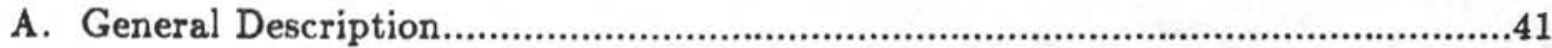

1. Outer Barrel (BHA) Components...............................................................41

2. Care and Handling of the Seal Bore Outer Core Barrel .................................42

B. Orientation Alignment Procedure ……….............................................................43

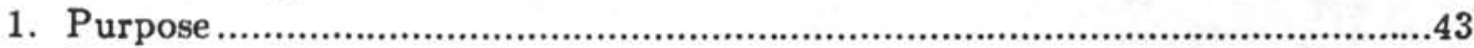

2. Procedure

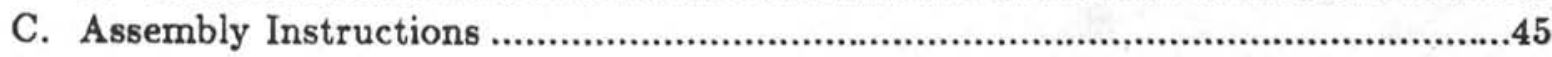

D. Typical Operation Instructions

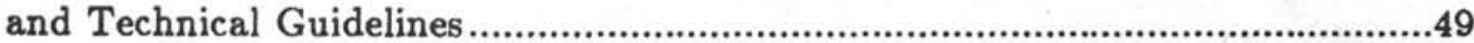

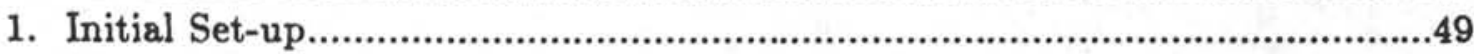

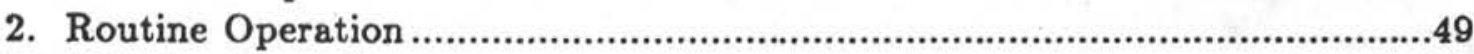

3. Velocity Control ..........................................................................................

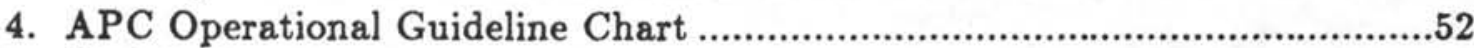

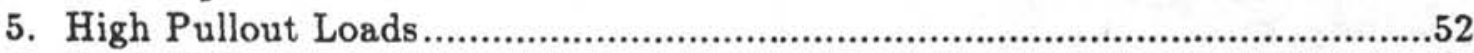

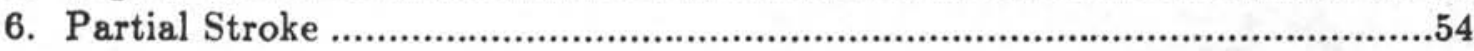

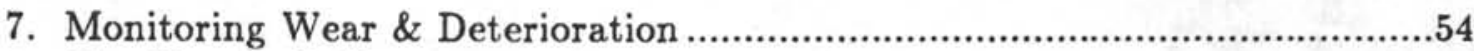

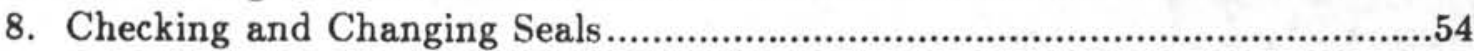




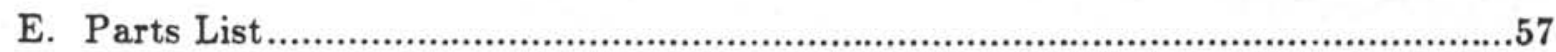

IV. Operational Synopsis - Sea Trials .......................................................................59

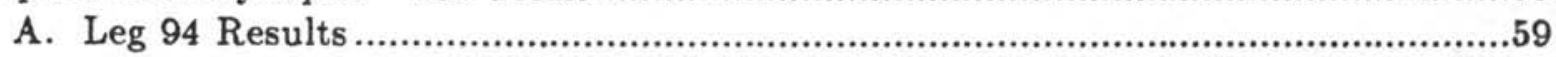

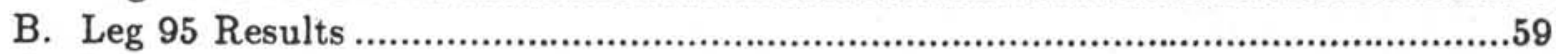

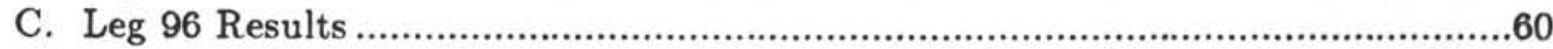

V. Appendices

A. Initial Feasibility Study Report......................................................................63

B. Piston Rod Failure Report ........................................................................97

C. Piston Corer Performance Computer Program.....................................................103

D. Design Calculations ..............................................................................................111

E. Excerpts From Cruise Operation Manager's Reports

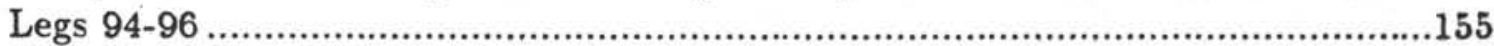

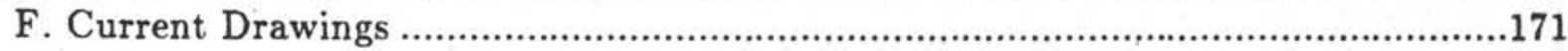

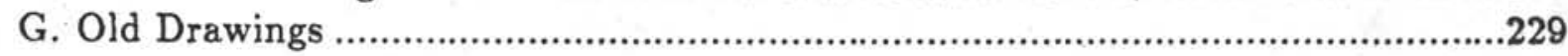


1. A Non-telescoping Hydraulic Piston Corer ......................................................2

2. Potential Coring Force Comparison for Candidate Piston Corer Concepts ........4

3. Stored Energy Comparison for Candidate Piston Corer Concepts......................5

4. Bottomhole Assembly Layout............................................................................

5. Advanced Piston Corer Schematic..................................................................15

6. Cross-section of Piston Rod Threaded Connection with Anti-Spiral Groove …..................................................................................17

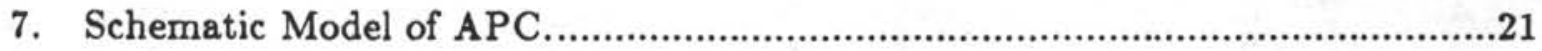

8. Advanced Piston Corer Performance Prediction Program..................................24

9. Sample Output of " APC Performance " Computer Program.............................25

10. " Disturbance Layer " model for evaluation of sediment drag resistance...........27

11. Breakaway Piston Head Schematic.....................................................................32

12. Piston Corer Shear Pin Protection Concept.....................................................34

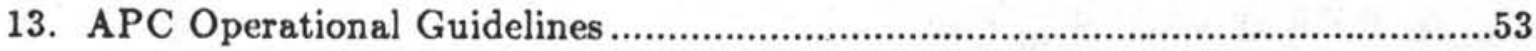




\section{LIST OF TABLES}

1. Decision Factor Comparison Chart. .......................................................................

2. Prototype Sea Trial Deployment Summary ..................................................................61 


\section{BACKGROUND}

The Deep Sea Drilling Project's two original piston corers - the HPC-15 and Variable Length Hydraulic Piston Corer (VLHPC) - were phenomenal successes in making possible an entirely new realm of wireline coring in non-indurated sediments from below the ocean floor. The VLHPC represented a quantum advance in design over the prototype HPC-15 with its variable length capability (from 3.5 to $9.5 \mathrm{~m}$ cores), but optimization of the concept came in jumps and spurts over a period of several years because the immediate success of the tool led to a demand for a high usage rate with little or no time allotted for field engineering experimentation or shipboard analyses.

One of the features added in the VLHPC was a Quick Disconnect mechanism in the middle of the assembly which allowed the long tool to be readily separated into two (approximately 30 -ft long) sections to facilitate handling on deck during routine core removal. The Quick Disconnect experienced a series of failures when overstressed during the process of pulling the extended corer out of sticky sediments. The design of the Quick Disconnect led to an unavoidable weak link in the overall tool design in spite of attempts to optimize tensile "pull-out" load carrying capability.

During a design analysis to devise alternate means of carrying the problematic pull-out loads the concept was suggested of a corer which traveled down the inside of the Outer Core Barrel (the lowest drill collar) and landed at the Support Bearing located just above the core bit. Fig. 1 illustrates this initial concept. Such a tool would not telescope out as the HPC-15 and VLHPC did and thus would not need to be over 60-ft. long in order to take a $30-\mathrm{ft}$. core. Thus, no Quick Disconnect weak link would be used. This tool concept involved abandoning many of the principal functional components proven in the VLHPC design. The entire upper working section of the VLHPC, for example, would have to be discarded. In its place would have to be components to serve the same purposes, i.e. achieve an initial landing point in the bottomhole assembly (BHA) relative to the core bit, achieve an initial hydraulic seal, store hydraulic energy and release it suddenly for the coring action, and land again at the bottom of the stroke.

It was not immediately obvious if the initial seal and consequent build-up and release of hydraulic energy would be sufficient to power the tool. If not, a dynamic seal might be required to continue imparting driving thrust to the corer until the end of the stroke. It was, also, not clear if the internal piston used in the VLHPC could be deleted. If the piston was later determined to be necessary, the question was how exactly it could be incorporated in the shorter - concept tool.

Each of these questions and many others raised doubts about the feasibility of the concept, but the potential advantages of a hydraulic piston corer about half as long, complex and expensive as the VLHPC made the concept well worth pursuing. 


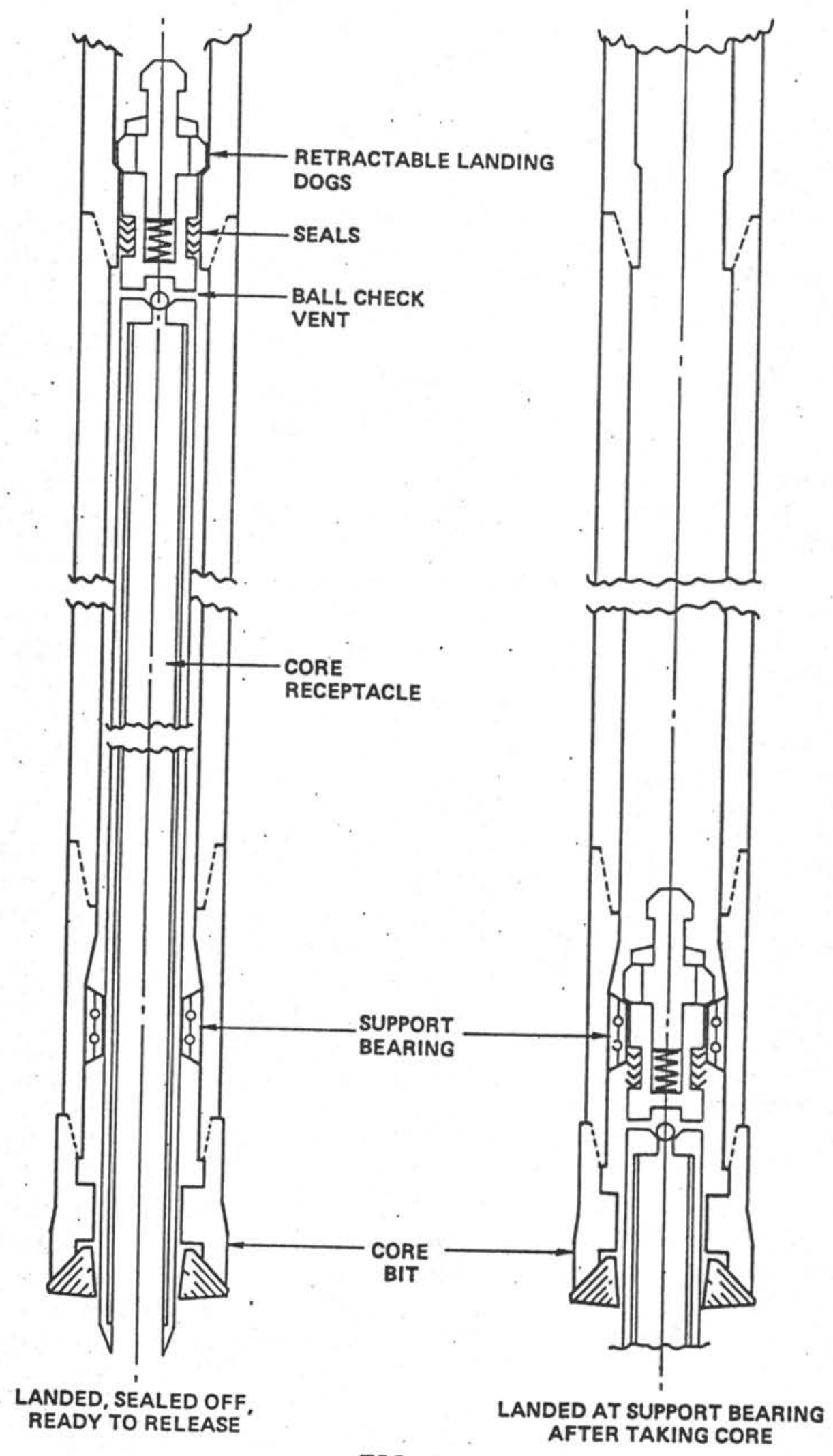

FIG. 1.

Initial concept of a non-telescoping hydraulic piston corer which would travel down the Outer Core Barrel. 
At the same time the DSDP Development Engineering Dept. was busy evaluating the potential of an hypothetical Air Chamber Piston Corer (ACPC). It had been established that one of the secrets of success of the VLHPC had been the utilization of stored energy in the form of compressed sea water in the drill string. However, the potential $\mathrm{pV}$ energy available in a collapsible atmospheric chamber at great depths was far greater than the maximum stored energy produced hydraulically from the ship's mud pumps and could be much more efficiently converted to mechanical thrust. A piston corer operated by the atmospheric chamber principle would offer coring forces up to three times greater than the VLHPC limit.

Since the best overall piston corer was sought, a comparative analysis of the three competing concepts (VLHPC, APC, ACPC) was performed. Fig. 2 is a graphical comparison of coring forces possible with each of the concepts. The VLHPC and APC offered variable coring forces dependent upon the pressure built up before the shear pins were overcome and the stored energy was released. The force to drive the ACPC, on the other hand, would be dependent on hydrostatic pressure, a function only of depth of operation. Fig. 2 shows how this factor could work for or against the choice of the $\mathrm{ACPC}$ as an optimum coring tool. The ability to be able to select the coring force of any piston corer, regardless of operation depth, was thought to be a significant advantage, however.

Another meaningful comparison was utilization of total available stored energy for each of the candidate systems. In all three cases, available stored energy would be a function of operation depth. The Air Chamber tool stored potential energy in the form $\mathrm{E}=\mathrm{pV}$. With working volume, V, constant the energy available would be strictly a function of hydrostatic pressure, $\mathrm{p}$, or depth. All of the available energy would be converted to useful energy when the corer "fired" since the working volume would decrease to essentially zero. The VLHPC and APC tools would also store energy before "firing" by means of a very small but significant quantity of compressed sea water within the drill string as well as the slight elastic expansion of the drill string elements themselves. The magnitude of this stored energy would be a function of the length of the drill string, or the depth of operation. Unlike the ACPC, all of the potential energy would not be effectively used by the VLHPC or APC. In both tools the expanding sea water would drive the telescoping portion of the corer but total effective expansion would be limited to the working volume within the tools. When the working volumes reached their physical limits any excess compressed water would expand out the bottom of the pipe without doing any useful work. Fig. 3 is a graphical presentation of this information for several different operating depths.

It can be seen from Figures 2 and 3 that both the APC and ACPC offered real advantages over the VLHPC while retaining the best features of hydraulic piston coring in general. The Air Chamber tool offered the greatest possible coring force, up to 49,000 lbs. thrust, as well as the most efficient utilization of stored energy and the greatest potential stored energy. Its prime drawback in these comparisons was depth-sensitivity. The APC did not approach the ACPC in efficiency or power potential at great depths but significantly surpassed the VLHPC in all categories and was not depth-sensitive. 


\section{CORING FORCE COMPARISON}

APC: $3.80^{\prime \prime}$ SEAL BORE THRU D.C. $0.75^{\prime \prime}$ PISTON ROD

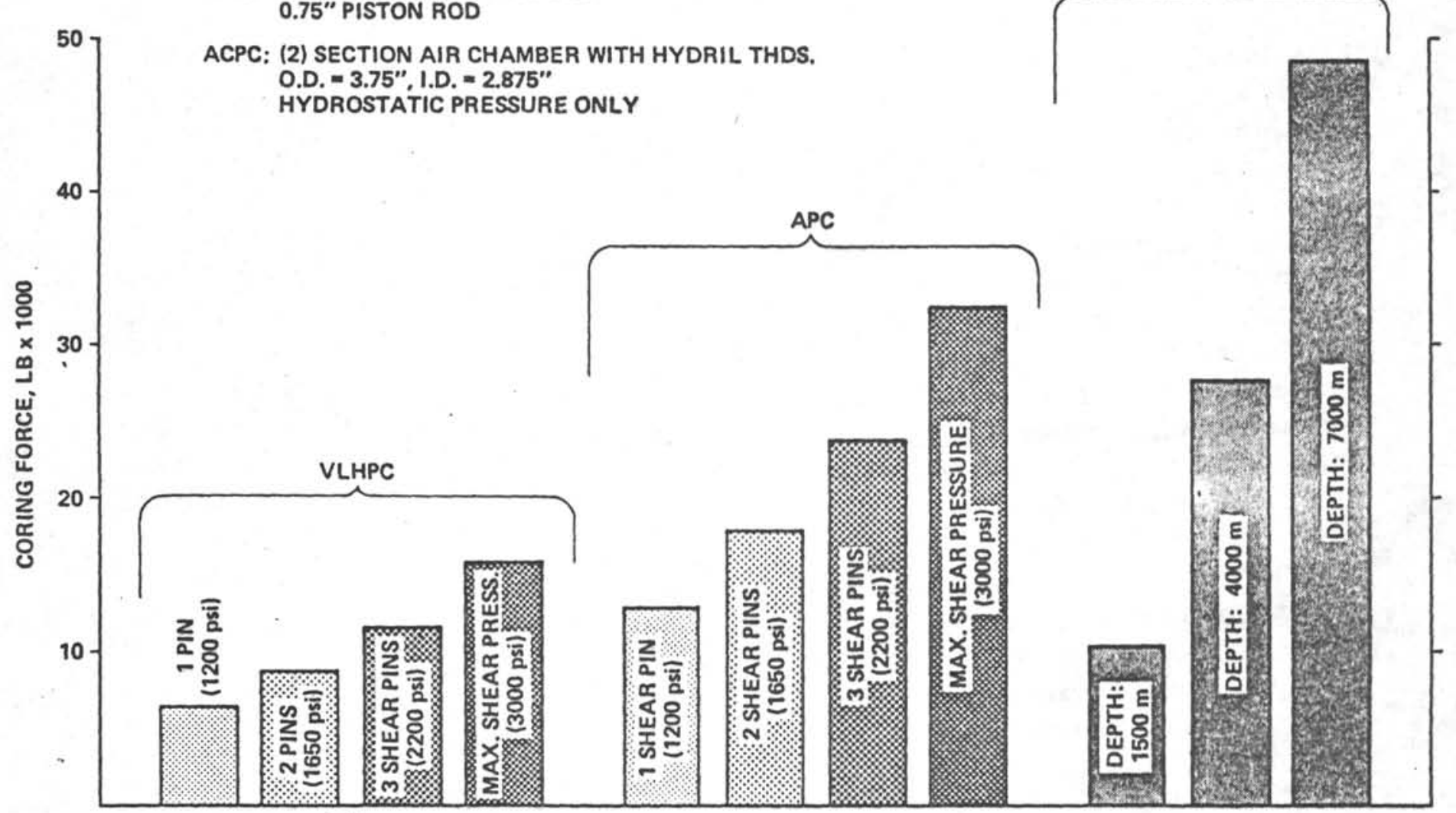

FIG. 2.

Potential Coring Force Comparison for candidate piston corer concepts (VLHPC = Variable Length Hydraulic Piston Corer, $\mathrm{APC}=$ Advanced Piston Corer, $\mathrm{ACPC}=$ Air Chamber Piston Corer) 


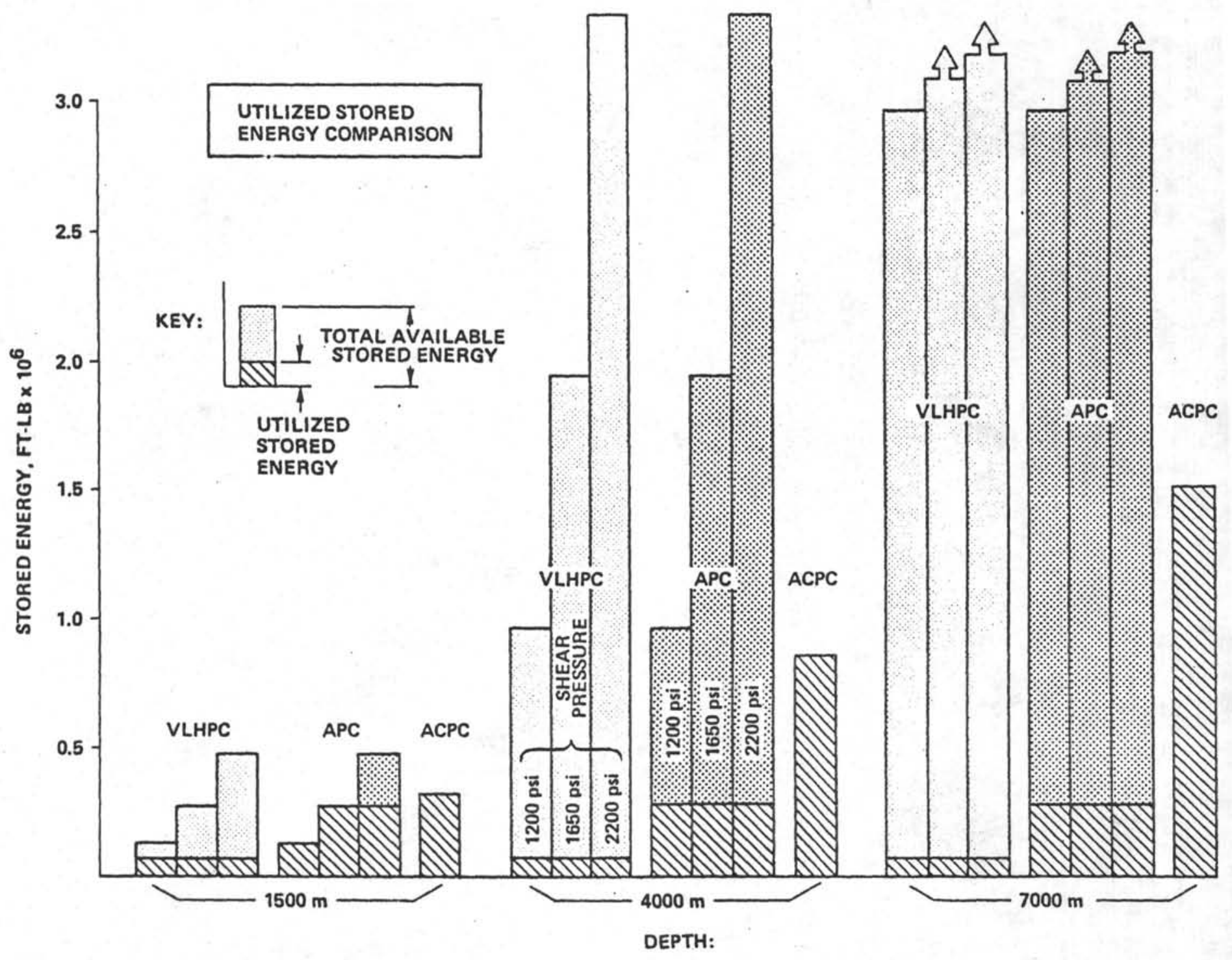

FIG. 3 .

Stored Energy Comparison for candidate piston corer concepts.

(VLHPC = Varible Length Hydraulic Piston Corer, $\mathrm{APC}=$ Advanced Piston Corer, $\mathrm{ACPC}=$ Air Chamber Piston Corer) 
In Table 1 the force and energy comparisons. are listed along with other to proceed with a full APC concept. This decision was made on the basis hydraulic piston corer based on the existing VLHPC in cost, mechanical com the basis of potential improvements over the being quite a significant factor in roughlexity and ease of on-deck handling (the latter safety). The extra force aval in saved and personnel to offset the high costs and un $\mathrm{ACPC}$ was not considered enough advantage nal thought which prompted thown technological difficulties. It is ironic that the origiQuick Disconnect mechanism the APC concept - elimination of a tension-vulnerable develop the tool. 
TABLE I

ADVANCED PISTON CORING SYSTEM

ADVANTAGE/DISADVANTAGE MATRIX

\begin{tabular}{|c|c|c|c|}
\hline & VLHPC & $\overline{A P C}$ & $\overline{A C P C}$ \\
\hline $\begin{array}{c}\text { Max. Length For } \\
\text { Rig Floor Handling } \\
\text { - Collapsed } \\
\text { - Scoped Out }\end{array}$ & $\begin{array}{l}\sim 60^{\prime} \\
\sim 62^{\prime} \\
\end{array}$ & $\begin{array}{l}\sim 32 \\
\sim 32 \\
\end{array}$ & $\begin{array}{l}\sim 60^{\prime} \\
\sim 62^{\prime} \\
\end{array}$ \\
\hline Mech. Complexity & - & $1 / 2$ of VLHPC & $20 \%$ More \\
\hline Reliability & Proven & $\begin{array}{l}\text { Same as } \\
\text { VLHPC }\end{array}$ & $\begin{array}{c}\text { No Core if } \\
\text { Main Seals Fail }\end{array}$ \\
\hline Coring Force & $15.8 \mathrm{k} \mathrm{lb} p \max$. & $32.7 \mathrm{k} \mathrm{lb}_{\mathrm{p}} \max$. & Varies with Depth \\
\hline Stored Energy Used & Low & $4 \times$ VLHPC & $\begin{array}{c}\text { Very High ? } \\
10.3 \mathrm{k}-48.8 \mathrm{k} \text { ft- } \mathrm{lb}_{\mathrm{f}}\end{array}$ \\
\hline Estim. Cost Per Tool & $\$ 20,000$ & $\simeq \$ 9,000$ & $\simeq \$ 25,000$ \\
\hline Development Cost & - & $\simeq \$ 20,000$ & $\simeq \$ 35,000$ \\
\hline Use With Heave Comp? & No & Yes & No \\
\hline Primary Disadvantage & $\begin{array}{l}\text { - Long, Hard to } \\
\text { Handle } \\
\text { - Low Coring } \\
\text { Force \& } \\
\text { Energy } \\
\text { Utization } \\
\text { - Excessive } \\
\text { Complexity }\end{array}$ & $\begin{array}{l}\text { Probably } \\
\text { Requires } \\
\text { Seal Bore } \\
\text { Thru D.C. }\end{array}$ & $\begin{array}{l}\text { - Long, Hard to } \\
\text { Handle } \\
\text { - Expensive } \\
\text { - Unproven Seals }\end{array}$ \\
\hline Primary Advantages & $\begin{array}{l}\text { - Track } \\
\text { Record } \\
\text { - Excellent } \\
\text { Cores }\end{array}$ & $\begin{array}{l}\text { - Low Cost, } \\
\text { Complexity } \\
\text { Easy To Handle } \\
\text { - Heave Comp. } \\
\text { In Adds To } \\
\text { HF/PW Work } \\
\text { - Improved Force }\end{array}$ & $\begin{array}{l}\text { - Max. Coring } \\
\text { Force at } \\
\text { Deep Sites } \\
\text { - Leads To } \\
\text { Future } \\
\text { Technology }\end{array}$ \\
\hline
\end{tabular}




\section{ENGINEERING DEVELOPMENT}

\section{A. PROTOTYPE DESIGN}

\section{Feasibility Study}

The first step in development of the APC after making the decision to proceed was to initiate a technical feasibility analysis to assess the following questions:

a) Determine if the concept was viable in the form sketched in Fig. 1 where the main seals were essentially static and sealed only to build up the initial "shoot off" energy. In this scenario the entire tool would travel down the Outer Core Barrel and extend into the sediment,

b) Determine if, atlernatively, a dynamic seal would be necessary to maintain a driving thrust over the entire stroke,

c) Analyze the feasibility of venting the trapped sea water above the incoming core material and determine the net effect of such required venting on corer performance.

To accomplish this first step the John E. Halkyard Co., private engineering consultants, was engaged to perform a formal Feasibility Analysis. Their report appears in Appendix A The approach in the Halkyard Study was to first generate an approximate expression for penetration resistance of a piston corer working in "medium clay". This was done by modeling the cored material as a viscous, non-newtonian fluid and using fluid dynamic relationships to relate coring resistance, sediment shear strength and velocity of the corer. The tentative mathematical model established was compared to actual shore-test results of the prototype HPC-15 to establish a generalized penetration resistance factor to be used for corer concept comparison. The Halkyard Study then went on to calculate performance curves (penetration depth vs. time) for the APC concepts. Also, the problem of back pressure generated by fluid venting paths was integrated into the analysis. 
The conclusions of the analysis were that,

a) a dynamic seal providing coring force for the entire stroke of the tool was necessary to achieve full (or maximum possible) penetration in firm sediments; a simple "shoot off" system did not effectively utilize the stored energy available;

b) a very advantageous by - product of using a continuous seal in the Outer Core Barrel was a large increase in piston working area as compared to the working surface of the VLHPC (approximately $76 \%$ increase) which would yield higher coring thrust at any given operating pressure;

c) a piston head fixed in place by a rod assembly was recommended following analysis of back pressures exerted on the cored material; the piston head/ rod arrangement used in the VLHPC would have to be incorporated into the APC design;

d) specific, incremental performance analyses of any design to determine probable penetration vs. velocity was not only possible but essential; a relatively simple computer program should be used to predict performance and enable design parameters to be varied and evaluated.

\section{Prototype Design Goals}

Following the encouraging results of the Feasibility Analysis, a design phase was begun with establishment of the following goals:

a) Determine a means of producing a Drill Collar (Outer Core Barrel) 30-ft long, 8-1/4" O.D., with a honed, close-tolerance, step free seal bore;

b) Select an appropriate release mechanism to hold the scoping portion of the tool while running down the drill string, store the builtup hydraulic energy, and then release it suddenly to propel the tool into the sediment (the shears pins used with the VLHPC had experienced some shortcomings of pre-shearing and irregular shootoff pressures);

c) Layout the tool components to determine if a quick release means of shortening the tool on deck would be required for ease of core removal or rig floor handling; if so, determine whether an inner barrel component or Piston Rod disconnect be better; 
d) Design the overall system to safely accomodate pull-out loads up to 100,000 lbs. for extracting the extended core barrel from sticky sediment;

e) Determine the optimum means of connection to the tool for a (paleomagnetic) orientation tool;

f) Ensure that the tool was capable of operating in a BHA which could also accept an Extended Core Barrel (XCB).

\section{Seal Bore Outer Core Barrel (Drill Collar)}

The success of the APC concept with its dynamic outer seals depended to a great degree on the ability to produce a drill collar with a controlled inner diameter to act as the seal surface. Standard drill collars produced for the oil industry do not have seal surface quality requirements and the fabrication technology necessary is not common.

Two designs for the Outer Core Barrel were considered: one piece construction with a honed bore, and two piece, using a finished I.D. liner in a conventional drill collar. The liner technique was questionable in the details of how to fix the liner rigidly in place and how to prevent crevice corrosion between the liner and drill collar body. The liner plan was eventually abandoned when the single piece collar proved feasible, both technically and economically.

Corrosion resistant alloys for the drill collar were considered briefly since pitting or severe scale corrosion on the seal surface would render the part useless. The technology to produce, procure and fabricate drill collars in lengths exceeding thirty feet in materials such as Type 316 stainless or Monel was either non-existant or very expensive (up to 4 times the cost alloy steel). Alloy steel was selected.

The Outer Core Barrels ultimately specified were produced by Chance Collar Co. of Pearland, Texas using some recently developed fabrication techniques. The inside diameter was made by trepanning from one end only to produce a stepless rough bore. The outside, $8-1 / 4$ " diameter was then turned to be concentric with the bore. Finally, the inside diameter was honed over the full length to produce an RMS 32-63 finish with a diameter tolerance of + $0.040 "$ - 0.000". The Outer Core Barrels were made of fully heat treated, AISI $4145 \mathrm{H}$ alloy steel and had $6-5 / 8 \mathrm{FH}$ threaded connections on the ends. To preserve the upper threaded, box connection a Landing/Saver Sub was included in the overall BHA plan. This sub was designed to be semipermanently attached to the top of the Outer Core Barrel so that the box thread connection on the drill collar itself would not be made and broken with every usage. The Sub also provided a landing shoulder for the tool that could more easily be re-machined when worn. The problem of corrosion of 
the seal surfaces was designated as a maintenance priority, especially during periods of storage after deployment in sea water.

\section{Compatibility with the Extended Core Barrel (XCB)}

Second and third generation development of the $\mathrm{XCB}$ coring tool system was concurrent with the APC development. Because these two tools were seen as the probable coring systems of the future, serious consideration was given to maintaining compatibility between them in the design of the APC. Prior to the advent of the $\mathrm{XCB}$, rotary coring could not follow piston coring without a pipe round trip to change the $\mathrm{BHA}$ and core bit.

The XCB was initially made compatible with the longer, VLHPC by including a special Seal/Latch/Landing Sleeve which was installed in the BHA, where both tools landed, the VLHPC sealed off and the XCB latched down. The APC was a shorter tool, intentionally, than the XCB and landed at a point in the BHA lower than the latch sleeve required to hold down the $\mathrm{XCB}$. Several critical dimensions for both tool systems were established to insure full compatibility in a common BHA (refer to Fig. 4):

1) the APC seal bore $=3.800 / 3.840^{\prime \prime}$ dia.;

2) The APC landing shoulder $=4.000 / 4.005^{\prime \prime}$ dia.; this was the maximum drift diameter of the drill pipe;

3) maximum O.D. for any XCB component which was to be located within the 3.8" APC Outer Core Barrel bore = 3-1/2" dia.; this was necessary to avoid excessively high pressure drops within the flow annulus around the XCB asembly through which the sea water was pumped to the bit jets; the $\mathrm{XCB}$ would land at the $\mathrm{APC}$ Landing/Saver Sub;

4) XCB Latch Sleeve I.D. = 4-1/8" dia.; a special, dead-bolt type latch was designed for the XCB.

\section{Designing for Pullout Loads}

One of the major problems encountered in using the VLHPC was the high tension loads imposed on the various components of the tool assembly when pulling the core barrel free from high traction formations. A combination of wall friction and suction tended to hold the barrels firmly in certain types of sediment, requiring pullout loads at times exceeding 100,000 lbs. The VLHPC had not been originally designed with this problem in mind and component overload failures at loads as low as $30,000 \mathrm{lbs}$. had been experienced all too frequently. Attempts to beef up the weak links were only partially successful largely due to the restrictions imposed on retrofit designing. 


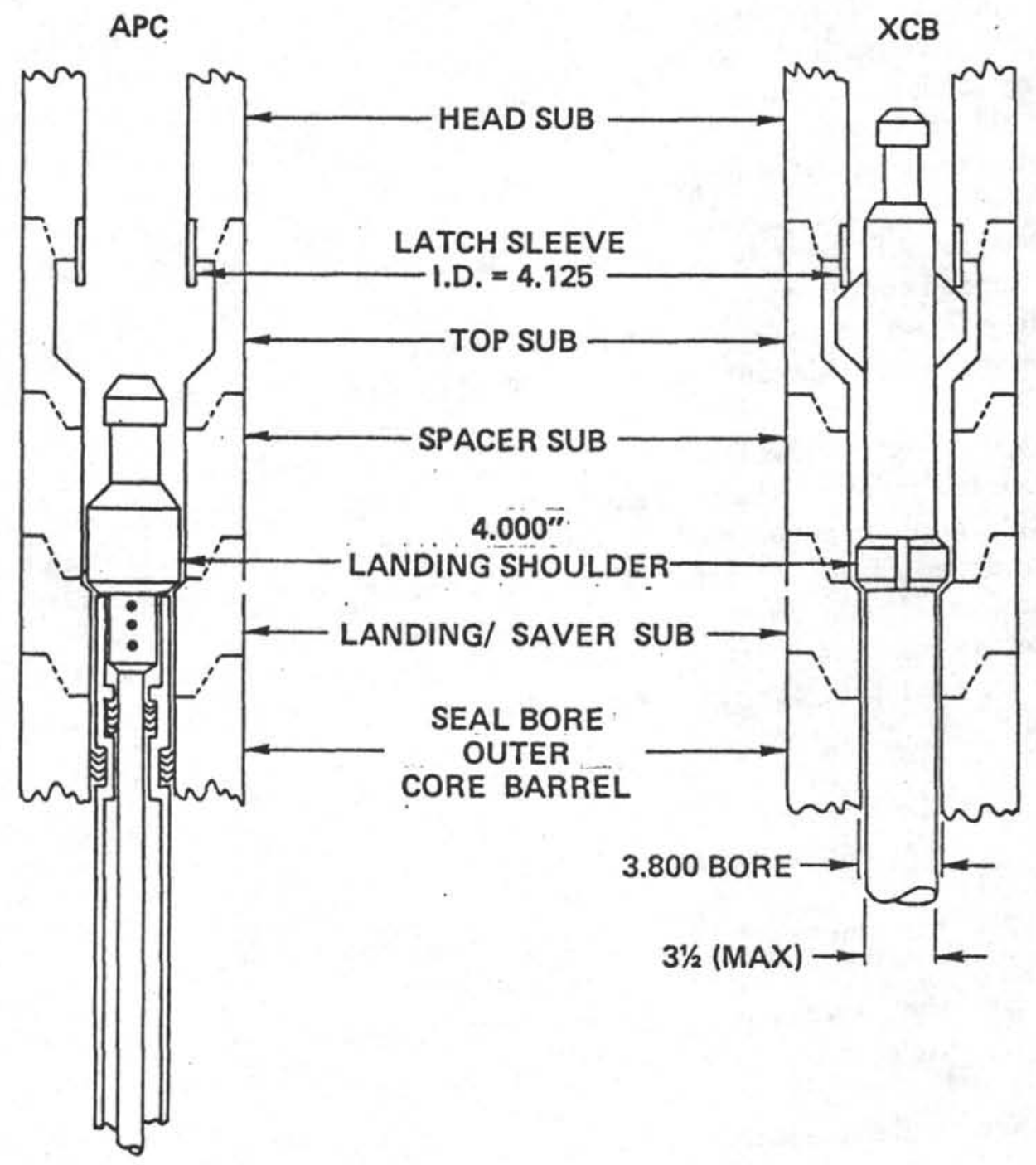

FIG. 4.

Bottomhole Assembly Layout for compatibility between the XCB and APC. 
In the early design stages of the APC this problem was not only expected to be significant but, if anything, to be more severe as a result of the $76 \%$ greater driving force that would be available (as compared to the VLHPC). A balanced design was sought so that all natural weak links in the system could be sized to tolerate an equal tensile load. The layout of the APC called for pullout to be accomplished by pulling the drill string with the drawworks until the core barrel was free as indicated by absence of overpull. The limit of overpull was arbitrarily selected to be $100,000 \mathrm{lbs}$. for two reasons. First, for long drill strings $100,000 \mathrm{lbs}$. overpull was the safe limit designed into the drill string deployment plan to avoid overloading the uppermost pipe joints. Second, overpulls in excess of 100,000 lbs. were not considered safe for the traveling block, power sub or rig floor personnel even when short drill strings would have eliminated the pipe overstress problem. Any inadvertent, sudden release of overpull tension at loads over 100,000 lbs. would cause a highly undesireable rebound of the above-deck rig hardware with the potential of equipment damage or injury to personnel.

Thus the APC was to be operationally limited to $100,000 \mathrm{lbs}$. overpull with all loaded components to be designed to tolerate that load level plus as much safety factor as could practically be included. Fig. 5 is a schematic illustration of the APC layout showing critically loaded components.

Initial layout of the tool assembly had dictated that an inner barrel Quick Release similar to that developed for the VLHPC would best suit the ondeck handling problems. A piston Rod Assembly Quick Disconnect was abandoned since it would overly weaken the Rod or require an excessive Rod diameter. In the right half of Fig. 5 the core barrel has been extended to take the core and is ready for extraction by raising the entire drill string. It can be seen that the three most vulverable components to the tensile load would be

1) the threaded Piston Rod connections (since a 33-ft single piece Rod was impractical),

2) the inner barrel Quick Release mechanism and,

3) the several Inner Barrel threaded connections below the Quick Release.

The Quick Release mechanism employed with the VLHPC carried tension loads on two rectangular "lugs" engaged in windows (J-slots). Past failures of these parts revealed that bearing stress overload of these lugs was the initial step in ultimate failure. By increasing the total area of the load carrying surface of the lugs the load limit of the mechanism could be correspondingly increased. For the APC maximum lug surface area was achieved within the geometric limits imposed and a third lug was added to the two used on the VLHPC. This brought the minimum tensile failure load up to a calculated 

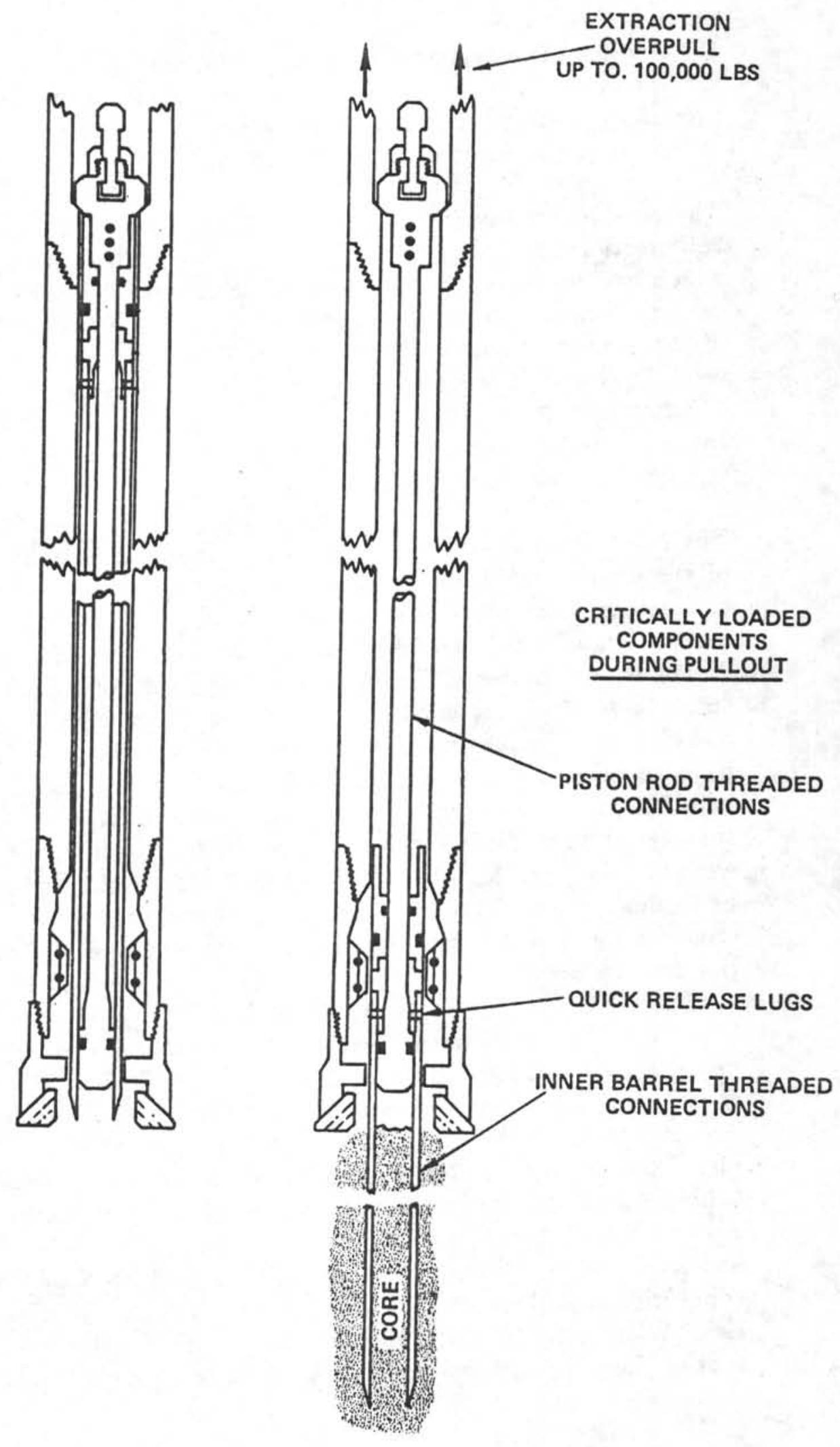

FIG. 5.

ADVANCED PISTON CORER SCHEMATIC.

At left, landed in the BHA.

At right, hydraulically " shot off "into the sediment.

Critically loaded components during extraction overpulls are indicated. 
139,500 lbs. The asymetrical design (two lugs on one side, one on the other) also aided in assuring correct assembly of the Quick Release halves for proper paleomagnetic core orientation each time the core barrel was redressed and reassembled.

The core barrel assembly below the Quick Release was made up of several tube sections, 3-1/2" O.D. x 2-7/8" I.D. A tapered, Stub Acme thread form, which had been standardized for all DSDP core barrels for many years, was used to connect the various sections. During high pullout situations several of these connections would be required to carry the full tensile load. The weak links were the pin connections which were rated in various analyses at 133,200 to $159,600 \mathrm{lbs}$. yield strength. No changes to the standard DSDP Inner Barrel Thread was expected to be necessary to match the required strength for $100,000 \mathrm{lb}$. overpulls.

The most sensitive design problem in achieving a complete assembly capable of sustaining high pullout loads was the selection of Piston Rod threaded connections. The process required an iterative procedure involving the interaction of four variables: details of the type and size of threads, rod diameter, rod material (limited by commercial availability), and heat-treat strength level of the chosen material (to balance yield strength, toughness and ductility). The initial tool layout showed that the Piston Rod would have to be about 33 -ft long overall. For ease of fabrication, shipping and handling the Rod assembly was to be made of three, eleven foot sections thus two intermediate connections would be required. Since the inner seals were to travel the length of the Piston Rod assembly the connections had to be flush on the O.D. Minimum acceptable rod diameter was sought since the cross-sectional area of the rod sacrificed "working area " and reduced potential driving force.

With these restrictions in mind a rod connection design was established using a rod of $1-5 / 8$ " diameter, 15-5 PH stainless steel. The rod material could be readily heat treated to Condition H1025 which would develop a yield strength of $165,000 \mathrm{psi}$ and a Charpy V-notch impact strength of $35 \mathrm{ft}$ lbs. The ideal box-and-pin-balanced connection would have been 1-3/16"- 8 Stub Acme but this was reduced to a 1-1/8"- 8 Stub Acme to make room for an Anti-Spiral Groove which would run the length of the Rod Assembly and had to cross the threaded connections. Fig. 6 shows a cross-section of the connection and illustrates how the Anti-Spiral Groove affects the connection size. With the groove installed in this connection the weak spot became the root of the pin which was calculated to have a yield strength of $139,000 \mathrm{lbs}$.

\section{Piston Rod Tensile Tests \& Failure Analysis}

During sea trials of the prototype APC on Leg 94 a Piston Rod failed in tension during a series of high overpull situations. The actual load at failure was read at the rig floor to be 40,000 lbs., although on the two previous 


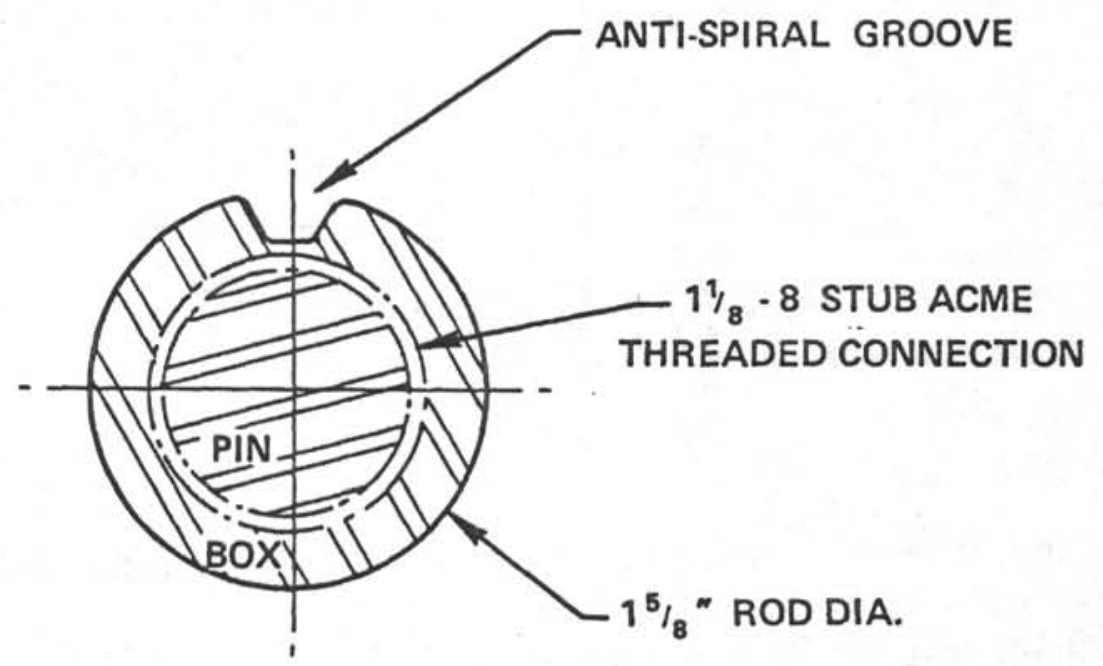

FIG. 6.

CROSS-SECTION OF PISTON ROD THREADED CONNECTION WITH ANTI-SPIRAL GROOVE. 
cores overpulls of 100,000 and 20,000 lbs. had been recorded. The location of the failure was at the last thread of the pin of an intermediate Rod connection.

Further investigation of the failure was indicated because the load at failure was supposed to have been well within safe tension load design limits. To verify theoretical strength calculations a set of full size samples were made of Piston Rod and Std. Inner Barrel Threaded connections. These were pulled to failure on a large tensile test machine with the following results:

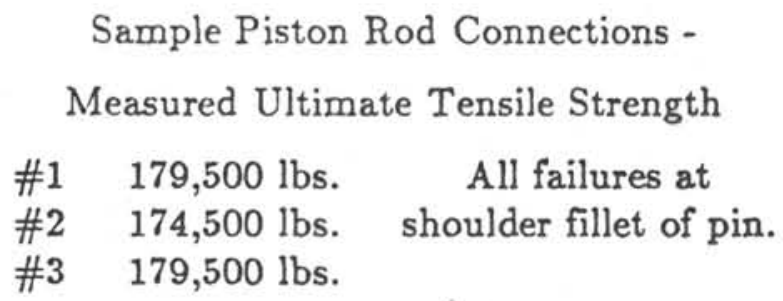

Sample Inner Barrel Connections -

Measured Ultimate Tensile Strength

$\begin{array}{lll}\text { \#1 } & 204,500 \text { lbs. } & \text { Box failure } \\ \text { \#2 } & 201,000 \text { lbs. } & \text { Box failure } \\ \text { \#3 } & 203,000 \text { lbs. } & \text { Pin failure } \\ \# 4 & 206,000 \text { lbs. } & \text { Pin failure }\end{array}$

The test results demonstrated that the theoretical calculations of connection strengths for both Rods and Inner Barrels had been about $27 \%$ conservative for the case of simple tensile overload - believed to be the only mechanism of failure possible in high pullout load situations. This suggested that a very different failure mode must have prevailed in the case of the Leg 94 Rod failure. This was augmented by inspection of both the field and lab failed pieces - a distinct difference could readily be seen in the character of the failure surfaces. After verifying that the field rod had been made of the correct specified material and heat treated properly the remaining portion of the pin connection was sent to Battelle Petroleum Technology Center for a formal failure analysis. Their letter-report appears in Appendix B and concludes that failure of the Piston Rod was due to pure torsional overload - not axial tensile overload. Since no torque of any kind is applied to the Piston Rod (or core barrel) during routine deployment the overload was assumed to have been caused during initial assembly of the Rod. It is possible that severe thread galling in the Rod connection may have occured forcing the assemblers to use considerably more than the specified $400 \mathrm{ft}-\mathrm{lbs}$ make-up torque in order to shoulder the connection (15-5 PH stainless steel has a high tendency to gall). If this did, indeed, occur a partial torsion failure at the last thread would have resulted and ultimately complete failure would have occurred during pullout of a stuck barrel. 


\section{Release Mechanism - Shear Pins}

One of the shortcomings of the VLHPC design was erratic behavior of the shear pins. This was attributed to a variety of causes, the most significant being a tendency to pre-shear the pin or pins as the core barrel traveled down the drill string. Additional premature damage would occur if the tool landed with any impact, although operational procedures called for this to be avoided as much as possible. In an attempt to achieve real improvement with the new APC the shear pin design was analyzed. Alternate release mechanisms were considered but eventually abandoned on the basis of being unnecessarily experimental. Also, the APC would enjoy a natural advantage in the strength of the shear pins to be used versus the weight of the portion of the tool acting to cause pre-shear.

When the tool is being run into the hole on the sandline the shear pins hold the scoping and stationary halves of the assembly together. Each time the protrusions on the Piston Corer contact a tool joint or Bumper Sub shoulder the impact is transmitted to the shear pins. In many cases using the VLHPC the cumulative damage had been enough to partially (or even totally) preshear the pins. Thus the hydraulic energy was not stored and suddenly released as designed and the tool was not able to take a proper core. The impact damage to the pins is a function of, 1) the weight of the scoping portion of the assembly which is being held and, 2) the shear strength of the pins. With the APC the weight of the scoping components would be about half that of the VLHPC assembly. In addition, the shear strength of the pins used in the APC would have to be $76 \%$ greater for a given "shoot-off" pressure to account for the greater hydraulic working area between the inner and outer seals. In combination, these two factors would make the APC shear pins considerably less susceptible to premature damage than the VLHPC pins. Under these conditions it was thought that conventional shear pin technology would provide adequate service until proven otherwise in operations at sea.

The shear pins selected were $1 / 4^{\prime \prime}$ diameter, 17-4 $\mathrm{PH}$ stainless steel, heat treated to condition H1150-M. Lab tests were performed to determine the actual loads required to shear one, two and three pins with the following average results for five, room temperature tests of each combination:

Ave.

No. of pins Load, lb.

Equiv. APC shoot-off

$$
1
$$

9,835

pressure, psi

$2 \quad 18,869$

1060

328,421

2063

3067

It was desired to achieve a maximum shoot-off pressure for three pins of 2800 psi. This was safely within the approximate 3000 psi relief valve limit of the rig pump system yet still effectively utilized the available hydraulic 
energy. The lab tests indicatd that three pins averaged in excess of $3000 \mathrm{psi}$ but this fact was tempered with much at-sea operational experience which indicated that in-service shoot-off pressures were regularily 5-10\% less than lab test results. As a further safety factor for prototype sea trials a quantity of $1 / 4$ " diameter mild steel (1018) shear pins were made available to be used as "half strength" pins in case maximum rig pressure was not sufficient to shear three pins. (These "half strength" pins proved popular and were later incorporated as a regular part of APC operations.) Results of prototype sea trials showed that rig pressures to shear the pins closely approximated lab tests and that pre-shear while running the tool down hole was minimal or non-existent.

\section{Piston Corer Performance Analysis}

Early testing and use of the HPC-15 and VLHPC had led to the conclusion that piston coring could produce remarkably undisturbed cores in soft sediments without the use of a Heave Compensator, if the coring action could be made to take place fast enough to effectively decouple the corer motion from the heave motions of the ship and drill string. Common spectrums of ocean waves which produce heave of the drillship have periods on the order of 5 to 17 seconds or more. The lower end of the drill string follows a different oscillation pattern but with similar periods. To decouple from these motions the piston corer had to complete its $9.5 \mathrm{~m}$ stroke in about two seconds. This was the design goal for the APC.

Two significant questions arose in connection with this goal. First, could the stored hydraulic energy which was released when the shear pins failed effect the acceleration of the core barrel to complete the full stroke in two seconds or less? Second, what would the end-of-stroke velocity be and could the mechanism withstand the impact when the traveling mass came to a sudden stop? The problem was considered more acute with the APC concept due to the significantly increased driving force over the VLHPC.

To assist in analyzing the perfomance of the tool a computer program was written based on the model which appears in Fig. 7. In the figure, the hydraulic pressures and significant forces acting on the core barrel are denoted. The hydraulic pressure, $P$, is built up until the shear pins fail and release the core barrel. The volume of compressed water in the total drill string in most cases far exceeds the volume required to totally stroke the tool, thus the pressure, $P$, is assumed constant from an "infinite" reservoir above the Landing Shoulder. The pressure which reaches the seals on the scoping portion and drives the tool is not constant, however. The actual driving pressue is $\mathrm{P}-\Delta \mathrm{P}$, where the pressure drop, $\Delta \mathrm{P}$, is a function of the geometry of the Landing Shoulder and its fluid passages and a function of the velocity of the scoping section of the tool. The driving force, $F$, is derived by multiplying the working area between the inner and outer seals by the pressure felt at the top of the scoping section at any given point in 


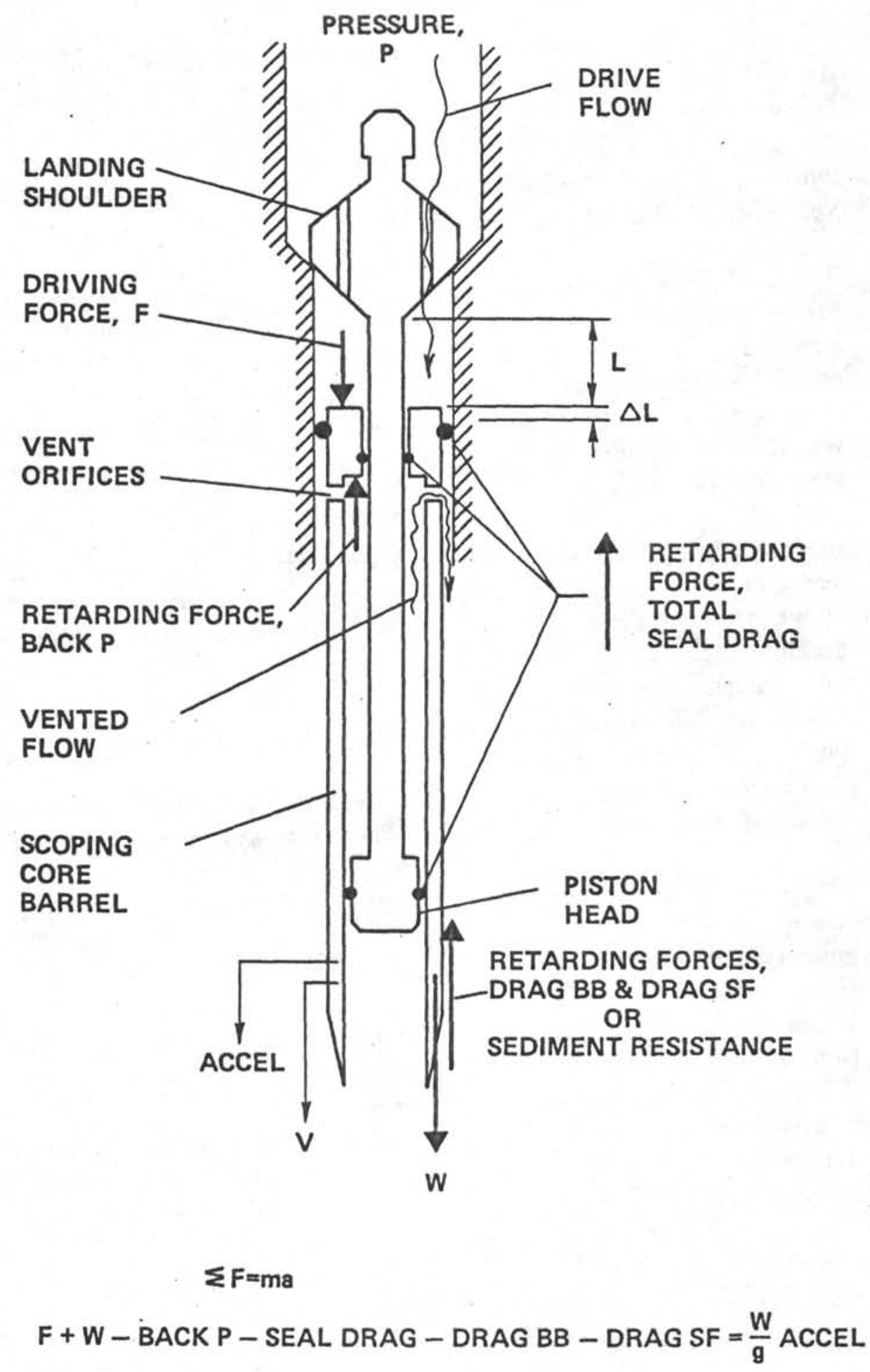

FIG. 7.

Schematic model of APC used for computer program showing forces which determine velocity and performance. 
the stroke. The acceleration of the tool at any given point in the stroke is derived from $\Sigma F=$ ma, where the summation of the forces is the driving forces minus the retarding forces. The driving forces are $\mathrm{F}$ plus the weight of the traveling section, W. The retarding forces are seal drag, sediment or water drag resistance and the force resulting from the back pressure of the vented fluid above the Piston Head.

The seal drag relationship is a complicated function of seal type, surface area, pressure, etc. and can only be determined empirically. It is known, however, that for seals of the type and size of interest here, the total drag could be expected to be on the order of hundreds of pounds whereas the driving forces are one or two orders of magnitude greater. No great error was then introduced by simply assuming total seal drag to be equal to a constant 300 lbs.

In determining the potential for impact damage at the end of the stroke the worst case is that of an inadvertent water core (where the tool is fired off above the mudline and no sediment is penetrated). In this case, the decelerating potential of sediment drag would be nil. The retarding drag force for this condition can be calculated by application of conventional fluid mechanics relationships. Appendix D contains the derivation for the function which defines skin friction and bluff body drag of the corer in sea water as a function of velocity. (The derivations for the other force relationships, velocities, accelerations and impact loads also appear in Appendix D.)

The force caused by the back pressure of the vented fluid is a function of the size of the orifices, the fixed geometry of the core barrel and BHA, and the velocity of the corer at any given instant as it strokes out.

When all of these driving and retarding forces are combined by vector addition the result is a net driving force at any given instant in time. Applying $F=$ ma yields an instantaneous acceleration at that point. If this acceleration is then assumed constant for a short interval, $\Delta \mathrm{L}$, of travel of the scoping section a velocity at the end of the interval can be calculated directly from

$$
V_{1}=\sqrt{V_{0}^{2}+2 a \Delta l}
$$

Using the new velocity to re-evaluate each of the driving and retarding forces the process can be repeated for a series of short intervals until the entire stroke is evaluated. It is then possible to examme maximum coring velocities, velocity at the end of the stroke, elapsed time for a full stroke and so on. 
The flowchart for Fortran and Basic computer programs is shown in Fig. 8. Using a computer to make these repetive calculations allows the stroke intervals to be made very small $-0.05 \mathrm{ft}$. was commonly used. The program was employed first as a design tool to "see" the effects of changing the size and shape of the vent orifices, flow passages in the Landing Shoulder and so on. The design of the overall tool was, thus, optimized to meet the design goals.

Early application of the computer program demonstrated that the end-ofstroke velocity would be excessively high if no provisions were made to decelerate the core barrel near the end of its stroke. Using less pressure to shear the pins or reducing the vent orifice or Landing Shoulder flow passage sizes could reduce end-of-stroke velocity but, also, handicapped the useful coring power of the entire stroke. It was deemed better to utilize the available force as efficiently as possible throughout the majority of the stroke and then include a snubbing device to brake the core barrel and bring the endof-stroke velocity to within safe limits. The stroking portion of the tool would be stopped (and pulled out) by an upset shoulder on the Piston Rod. Impact analysis of the Rod connections determined a safe impact velocity to be $15 \mathrm{ft} / \mathrm{sec}$ or less. Therefore, a Snubber was designed to achieve this additional design goal.

One part of the Snubber was an upset at the lower 18 inches of the Piston Rod assembly. When the vent orifices encountered the Snubber upset the primary (large) vent orifices would be closed leaving only four, very small orifices for venting the sea water above the Piston Head. This would result in a sudden increase of back pressure in the vented fluid and a corresponding sudden increase in retarding (or braking) force on the core barrel. Again, the computer program was used as a design tool to optimize the length of the Snubber and the size of the reduced vent orifices. Back pressure above the Piston Head was limited by design to 3000 psi during the high pressure snubbing action to avoid overpowering the Piston Head seals.

Fig. 9 is an example of the hundreds of outputs of the computer program used during the design phase. The stroke length increment used was $0.05 \mathrm{ft}$. although only results at selected stroke intervals were printed out for brevity. The total elapsed time at the end can be seen to be $1.79 \mathrm{sec}$ - well within the two second goal. Final velocity is $12.7 \mathrm{ft} / \mathrm{sec}$ - within the 15 $\mathrm{ft} / \mathrm{sec}$ limit. Maximum back pressure force is $5026 \mathrm{lb}$. which corresponds to an acceptable maximum pressure against the Piston Head seals of less than 1000 psi. 


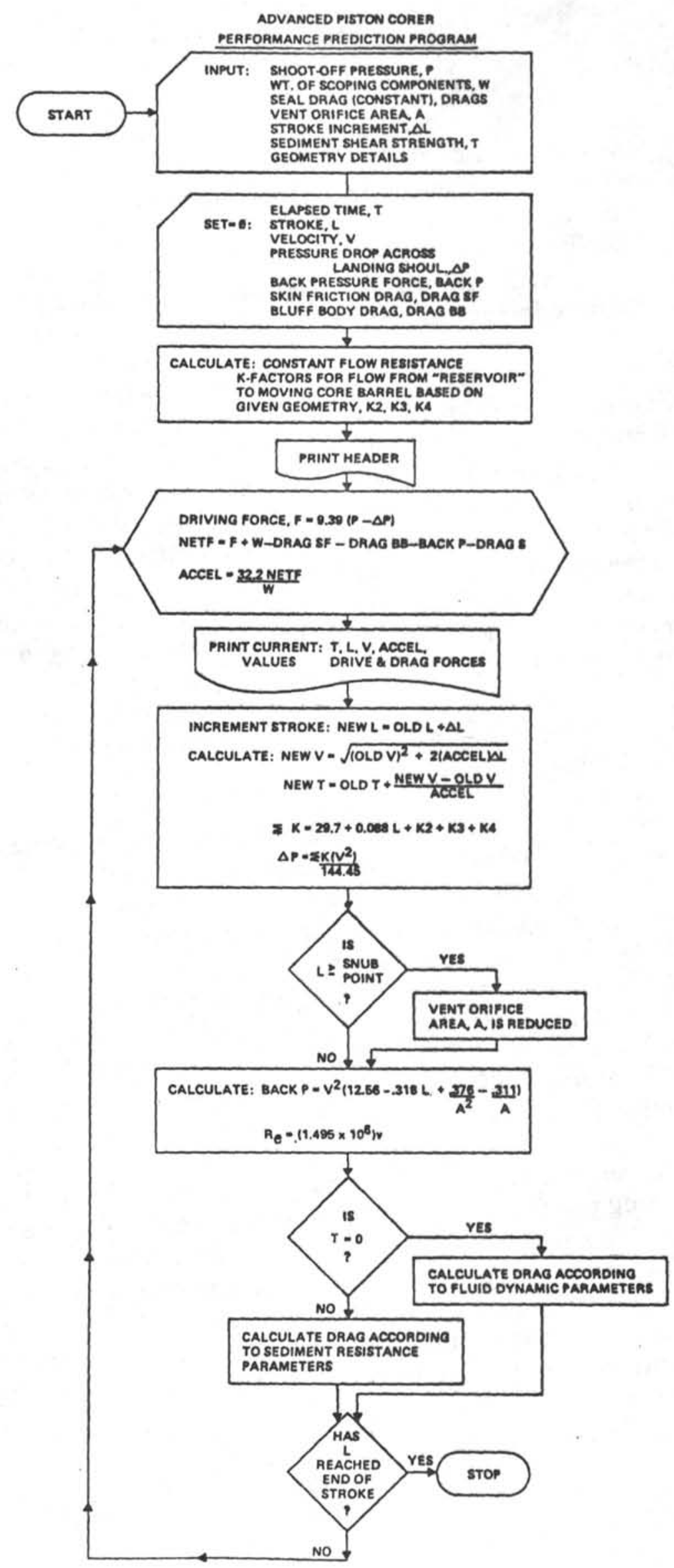

FIG. 8 . 


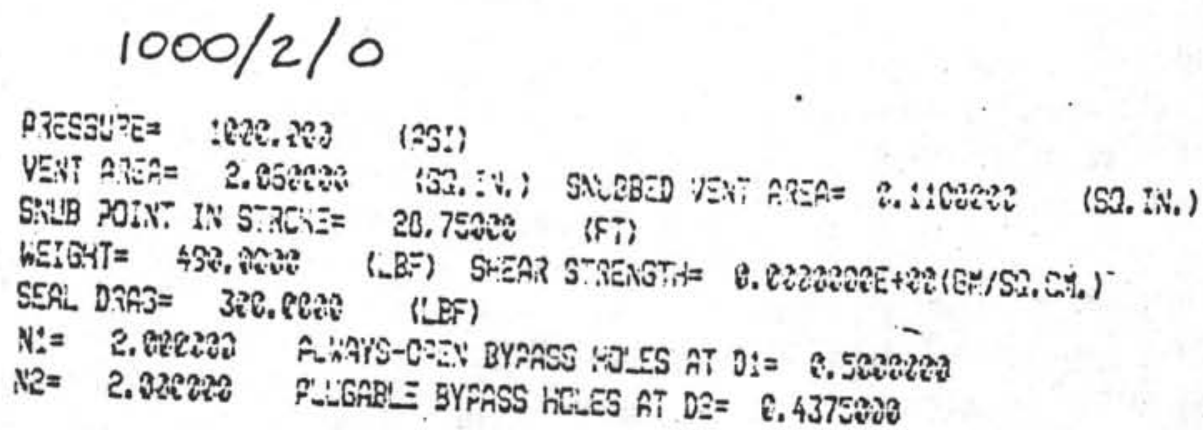

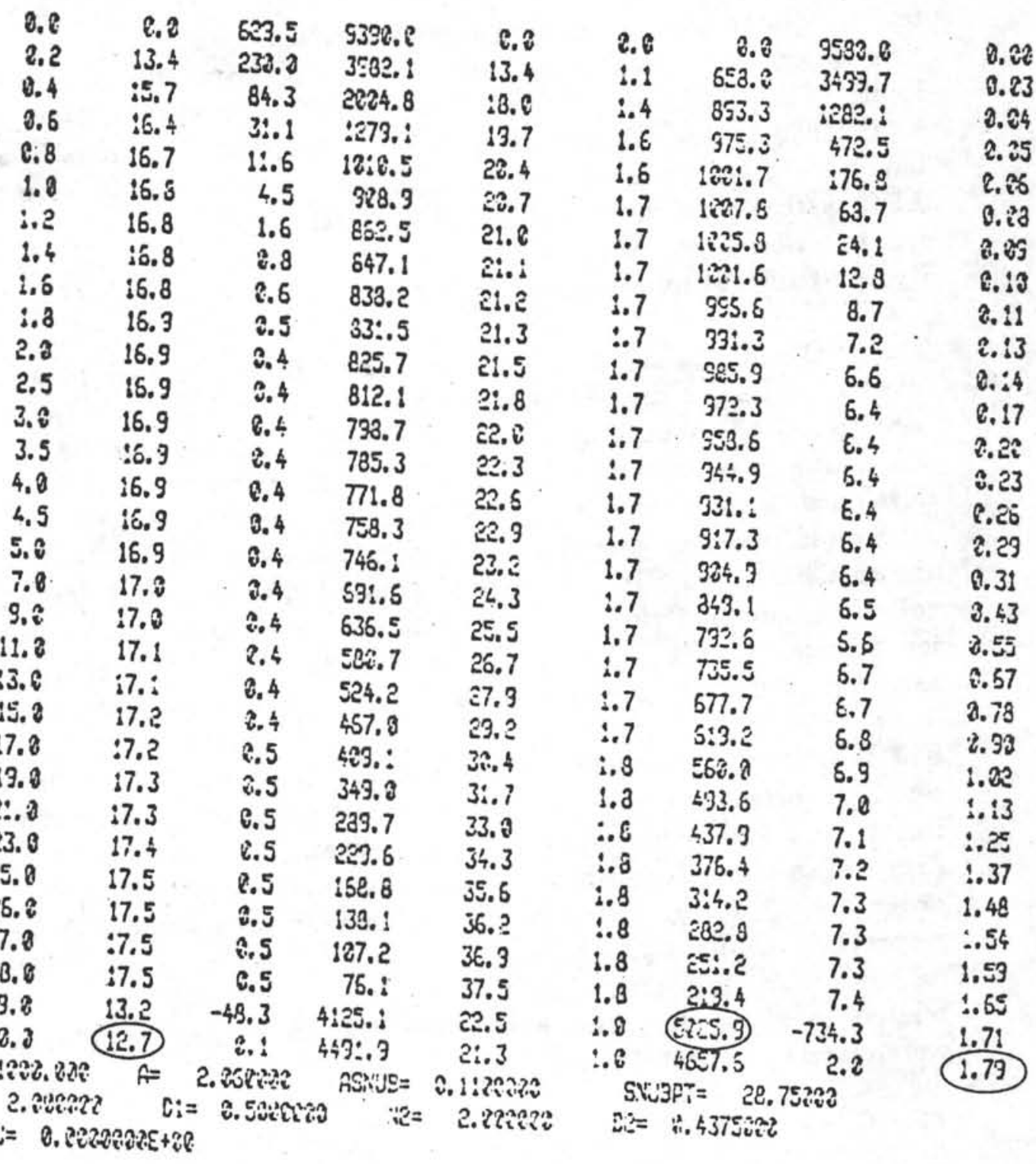

FIG. 9. 
The performance predictions generated by the computer program showed that the Snubber system could safely brake the moving corer when shoot-off pressures up to 2000 psi were used. However, for water core situations fired off at pressures from 2000 to 3000 psi the end-of-stroke velocity would be excessive despite any reasonable Snubber action. The computer runs also demonstrated that performance was quite sensitive to the flow passage area through and around the Landing Shoulder. Manipulation of the flow orifice sizes could be used to easily control maximum (and, thus, final) velocity of the core barrel. A flow system was, therefore, added to the Landing Shoulder which included threaded ports which could be closed with large set screws. These Speed Control Set Screws provided for a vernier-type maximum speed control for the purpose of controlling both end-of-stroke impact and actual penetration velocity. Previous experience with the VLHPC system suggested that relationships exist between optimum coring velocity and lack of core disturbance for different sediment types. Although the only flexibility of coring velocity offered with the VLHPC was shoot-off pressure (as established by the number of shear pins used) the differences in core disturbance were at times evident when different coring speeds were tried. The APC system provides a much more sophisticated approach to the speed control question which, with adequate at-sea experimentation, offers the capability of significant improvement in the control of core quality.

The final problem evaluated via the computer performance program was the effect of sediment drag resistance on corer performance. In the past, piston corer penetration capability had been loosely assumed to be a function of sediment shear strength, but no formal functional relationship was ever developed theoretically and/or verified empirically. A new approach was attempted based on assuming that the sediment in contact with the walls of the core barrel was "fluidized" to the extent that it could be treated analytically as a viscous fluid undergoing laminar flow and subject to fluid mechanics principles. Fig. 10 shows how the "fluidized disturbance layer" was assumed to exist during the one to two seconds of corer penetration.

The functional relationship which was developed was entered into the computer performance program and used to evaluate performance at various sediment shear strengths and shoot-off pressures. The results indicated that the drag resistance relationship was not accurate since shear strengths on the order of $100,000 \mathrm{gm} / \mathrm{sq}$. cm had to be used to significantly model corer response in moderately resistant sediments. The math model was quite useful, however, in demonstrating how sediment drag resistance generally related to shoot-off pressure and velocity even though actual magnitudes were clearly erroneous.

The following is a summary of the analytical approach (the full details appear in Appendix D). 


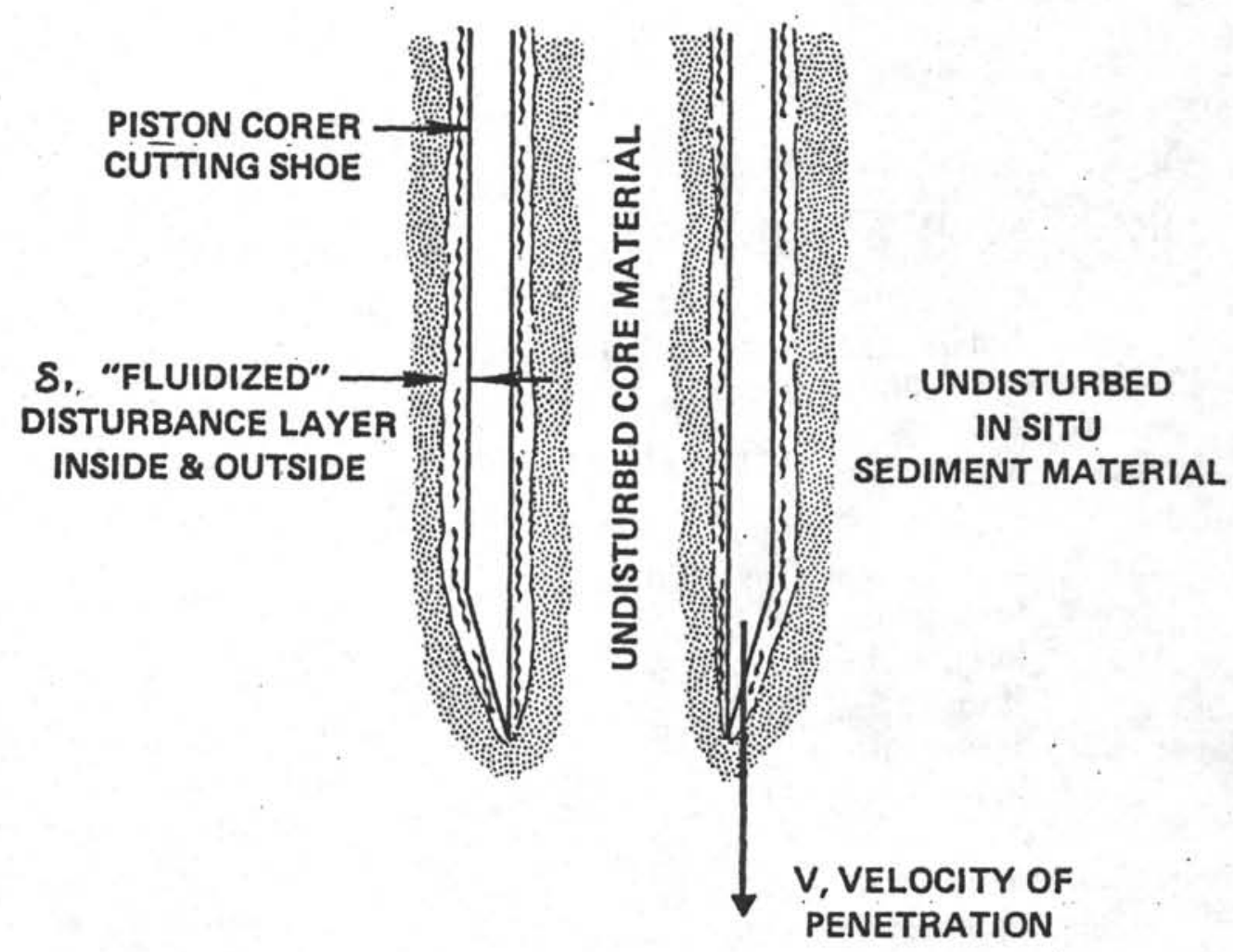

FIG. 10.

" Disturbance Layer " model for evaluation of sediment drag resistance. 
Assume the existence of a fluidized disturbance layer as described above and in Fig. 10. Also, assume that the only known physical properties of the sediment are shear strength, $\tau$ and density, $\rho$. Thus a relationship describing coring resistance (drag) must be developed which is a function of $\tau$ and $\rho$ plus variables resulting from the core barrel dimensions but independent of the cored material. If conditions within the fluidized disturbance layer simulate laminar flow of a viscous fluid, skin friction can be derived from the drag equation,

$$
\text { Drag }=c_{D} \frac{\rho V^{2} A}{2 g_{e}}
$$

where $\rho=$ density of the fluidized material (assumed)

$\mathrm{V}=$ velocity of penetration

$A=$ affected surface area

The friction drag coeffient, $c_{D f}$, can be determined using the Blasius equation for laminar flow in a boundary layer over a flat plate with adjustments made for the shape and size of the cylindrical core barrel. An approximation of "fluid" viscosity, $\mu$, is required for use in calculating the Reynolds number needed in the Blasius equations. The definition of $\mu$ is a function of $\tau$ for a Newtonian fluid and therefore can be calculated. (It is highly doubtful that the theoretical "fluidized" layer behaves as a Newtonian fluid and this may be the source of significant inaccuracy in this derivation. It does, however, represent some form of approximation and is not the sole parameter of interest.)

Besides skin friction drag, the other major source of penetration resistance results from actual compressive displacement of sediment to make room for the walls of the core barrel as it penetrates. A theoretical compressive strength related to the shear strength is thus used and is multiplied by the frontal area of the core barrel to achieve the compressive displacement factor.

A total sediment drag relationship can then be derived which is a function of shear strength and density of the sediment plus length, velocity and crosssectional dimensions of the core barrel.

\section{Seal Selection}

The APC design, which called for fully dynamic outer seals acting against the Outer Core Barrel, necessitated a comprehensive evaluation to determine the best seals to be used. A variety of options were suggested by seal 
manufacturers and distributors, from which two candidates were chosen, both of which had been proven on the VLHPC. The two were: single Type $\mathrm{B}$, molythane Polypaks and conventional molythane V-packings in a triple stack separated by metal V-spacers.

The APC seal glands for the prototype assemblies were set up to accept either type of seal if appropriate shim washers and assembly order was employed. Sea trials demonstrated that either type of seal system would function for both inner and outer seals. The Polypaks, however, proved to be excessively vulnerable to damage by snagging when the tool was removed from the BHA. The V-packings, which were initially questionable as dynamic seals, especially when retracted thru the tight bores in reverse, proved to be wholly adequate although they were observed to wear considerably faster than the static version used on the VLHPC - which had been expected.

\section{Orientation Baseline Alignment}

Paleomagnetic core orientation of piston core samples requires knowing the relative angle between the fixed point of attachment of the Kuster (or other) Orientation tool and a reference line on the core liner. Since this angle varies randomly from one tool assembly to the next, a rotating swivel must be included which enables rotation for baseline alignment and then can be locked. The system used on the VLHPC was always cumbersome due mainly to the fact that the two points which required alignment were approximately 38-ft apart. A special telescopic sighting system was needed to perform the alignment operation and accuracy was never guaranteed.

The shorter design of the APC led to a reduction of the distance between the Pulling Neck (the attachment point for any orientation measuring device) and the Liner reference screw to about 5 feet. This meant that the VLHPC telescopic alignment system could be abandoned. In addition, the bulky VLHPC Swivel was discarded in favor of a Split Bushing which allowed the Pulling Neck to be rotated for alignment then locked securely in place.

\section{Anti-Spiral System}

A recurring complaint by paleomagnetic investigators using VLHPC cores for their research was a lack of assurance that the cores entered the core liners without twisting, or conversely, that the core barrels did not rotate (spiral) into the sediment while cutting the cores. In fact, some specific data on orientation baseline drift within single cores suggested that this was actually happening, at least in sporadic cases.

For the APC design, a mechanical Anti-Spiral system was devised which would constrain the scoping portion of the core barrel from rotating. The system was composed of a key-in-groove. The groove was milled into the 
Piston Rod assembly of one of the two prototype APC's after all three Rod sections were assembled. This guaranteed proper groove alignment down the length of the Rod Assembly. The Anti-Spiral Key was mounted in a position in the scoping section of the tool between the seals and the Quick Release.

The traveling key - stationary groove arrangement was chosen rather than putting a ridge on the Piston Rod because the inner seals were required to seal on the Rod assembly. Conventional seals could be used on a grooved rod but not an asymmetric rod with a sharp protrusion. The groove in the Rod under the inner seals did provide an undesireable leak path but this was mitigated by two factors. First, the groove did not have to extend far enough up the Rod to include the area occupied by the seals during static pressure build up prior to shearing the pins. Thus, the leakage via the groove would only begin after the core barrel had scoped out about eleven inches. Examination of Fig. 9, the sample computer program output, shows that the majority of the acceleration ( $\sim 90 \%)$ occurs in the first foot of travel. Also, the leakage into the groove was partially blocked by the traveling Anti-Spiral key which would provide a further pressure drop and, consequently, recover some of the lost hydraulic force.

\section{Bypass Grooves}

At the end of the stroke the main outer seals were positioned to break out of the seal bore in the Outer Core Barrel. This would allow the pressure behind the corer to be vented to ambient and provide positive full stroke indication at the rig floor. Upon retrieval the corer would be lifted by the sandline and the outer seals would immediately re-enter the bore of the Outer Core Barrel. It would then be necessary to displace the water column inside the pipe until the main seal exited the top of the sealed bore at the Landing/Saver Sub. Although a manometer effect would prevent the problem of trying to "lift the ocean" with the sandline, the Baker Float Valve and various other fluid restrictions in the BHA would add an unnecessary burden to the sandline load.

To prevent this situation a set of bypass grooves were located strategically in the lower Piston Rod section so that the inner seals were effectively bypassed when the core barrel was at the end of its stroke. The Anti-Spiral Groove also extended into the bypass zone so that the combination of it and the two bypass grooves provided adequate flow area.

\section{Breakaway Piston Head}

Unlike the VLHPC which could be assembled in various lengths, the APC was designed to be operated in only one $9.5 \mathrm{~m}$ version. Thus the problems associated with incomplete strokes in stiff sediments had to be handled by some other technique. When the corer encounters enough sediment 
resistance to come to a halt before completing the full stroke several problems arise. The pressure trapped above the unvented main seals is released at the rig floor and the drill string is raised to pull the corer out of the formation in the normal fashion. The Piston Rod must pull the Piston Head to the top of the core barrel, however, before the upset on the Rod Assembly can begin to put a strain on the embedded core barrel. When the Piston Head is thus stroked up the unstroked section, a zone of low pressure is created above the core. The result is either severe flow-in disturbance of the core, implosion of the Liner wall, or both.

To avoid such undersireable effects a Breakaway Piston Head was designed specifically for use with the APC. Figure 11 depicts the action of the device. The principle of operation is that the assembled halves remain fixed together during the time that the core barrel is cutting the core. Then during the extraction process the low pressure zone beneath the Piston Head causes the Breakaway portion to release and remain on top of the core. This opens a flow path around the Piston Head seals so that the pressure above the core in the Liner can remain equalized - preventing flow in or Liner implosion.

The Breakaway Piston Head was tested along with the APC on Legs 95 and 96. Results were inconclusive. The Breakaway Head was almost always found to be broken away even on complete-stroke cores. Several cases of successful operation were noted but eventually use of the Piston Head was abandoned when it seemed that the Breakaway section was releasing prematurely and getting stuck at the bottom of the Liner. Further design modifications and experimentation will be needed to perfect the Breakaway Piston Head.

\section{Compatibility with Heave Compensator}

Theoretically the speed at which a high pressure, hydraulic piston corer takes a 9.5 meter core decouples the coring motion from the heave motions of the drillship. In practice, however, numerous cores in soft sediments taken with the VLHPC system were observed to have unexplained disturbed sections in the middle of the core with undisturbed sections both above and below. This suggested that undesireable heave motion effects could be affecting piston corer performance and core quality. A logical solution would have been to perform piston coring operations while using the Heave Compensator, thus mitigating heave motions in the $\mathrm{BHA}$ and the piston corer itself. The VLHPC was not compatible with the Heave Compensator, however. The Heave Compensator functioned to hold the drill pipe approximately motionless with respect to the sea floor despite continous heave motions of the drillship. The sandline attached to the Pulling Neck of the VLHPC during the coring process was not attached to the Heave Compensator as it passed through the Traveling Block, Power Sub and other loadcarrying components in the derrick. Thus, the drill pipe was activated to move independently of the sandline which moved with (and was attached to) 

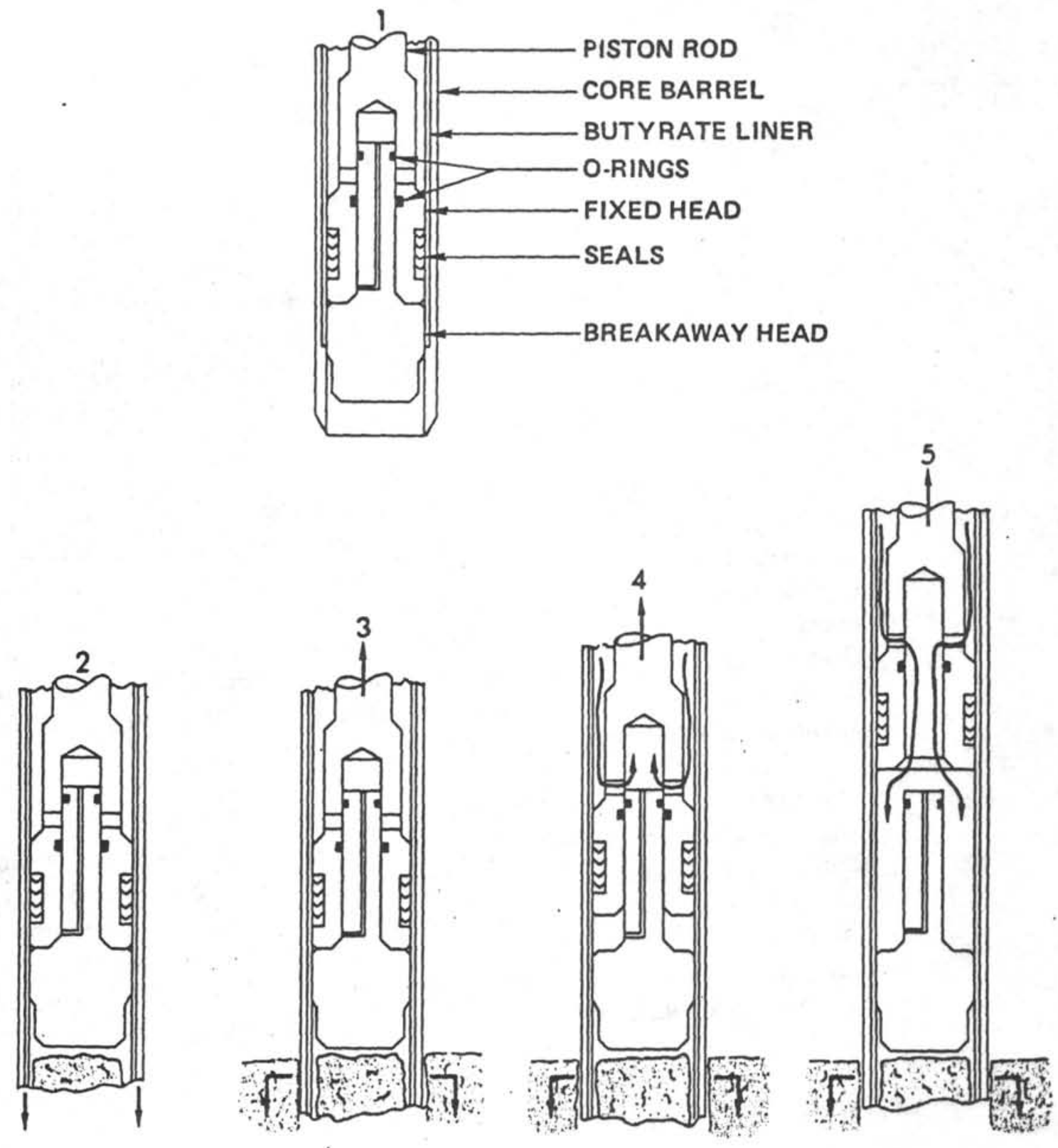

1. Piston head as assembled prior to shooting corer.

2. Pins shear and corer shoots into sediment. Breakaway head remains in place. Seals prevent flow-by, thus protecting core from compression force.

3. After partial stroke core barrel is restrained by sediment, retrieval is initiated by pulling on piston rod.

4. As piston rod is lifted, suction below piston head pulls breakaway section away from fixed section.

5. After breakaway head has fully released flow of water above piston head can bypass seals preventing implosion of liner and flow-in disturbance of cored material.

FIG. 11.

Breakaway Piston Head schematic showing operation sequence. 
the ship. The resulting mismatch of motion would have caused the VLHPC to lift off its landing point in the BHA in synchronization with heave motions during the time when the system was being pressured up to shear the pins. In addition, the Line Wiper which packed off around the sandline to achieve a top end seal during pressure-up would be required to pack off against a continuously moving line - resulting in rapid wear of the wiper seals. The piston coring operation was thus incompatible with heave compensation unless sandline/wireline compensation was also included synchronized to the drill pipe motions - a sophistication significantly beyond the capabilities of the Heave Compensator used on the Glomar Challenger.

One means of overcoming the problem of no sandline heave compensation would be to eliminate the sandline from the picture either by pumping (or free-falling) the piston cores to the BHA without the line attached or by delivering the tool to the $\mathrm{BHA}$ via the sandline and then removing the line by jarring off. Removal of the sandline would effectively double the rig time consumed by sandline trips which was already the dominating time factor in piston coring operations. Running the piston corer to the bit without a line attached was not practical because random impacts en route and the severe landing impact have been proven to partially or completely pre-shear the shear pins of the VLHPC.

Two new approaches to these problems were initiated in the prototype design of the APC. A mechanical device to keep the impact loads from the shear pins was contemplated which would allow the APC to be free-falled to the bit without damage to the pins. A preliminary Shear Pin Protection Device is shown in Fig. 12 which was evaluated during the prototype design phase. The impact loads would be carried on the latch ball (or balls) while the tool was running in the hole. After landing the small piston would be actuated by the pressure being built up and the latch ball(s) would release so that the shear pins would come into play as normal. Frictional analysis suggested that the latch ball would be undesireably sensitive to locking in place even after the small piston had moved. The complexity of a design which would guarantee that friction lock-up could not occur was deemed too much of a problem to be handled during early prototype design and was postponed until sea trials could provide more data abut the need for shear pin protection.

The second approach involved the possibility of free-falling the APC assembly without shear pin protection. Although the magnitude of the impact $\mathrm{g}$ loads in free falling tools had never been measured directly it was considered possible that the APC shear pins might survive the trip to the bit. The APC shear pins were designed to shear at a load level $76 \%$ greater than those of the VLHPC. In addition, the scoping portion of the APC tool which formed the mass which acted against the pins at impact was $41 \%$ lighter than the VLHPC. Thus, the APC shear pins would be able to withstand a landing impact three times greater than the VLHPC. A free - fall 


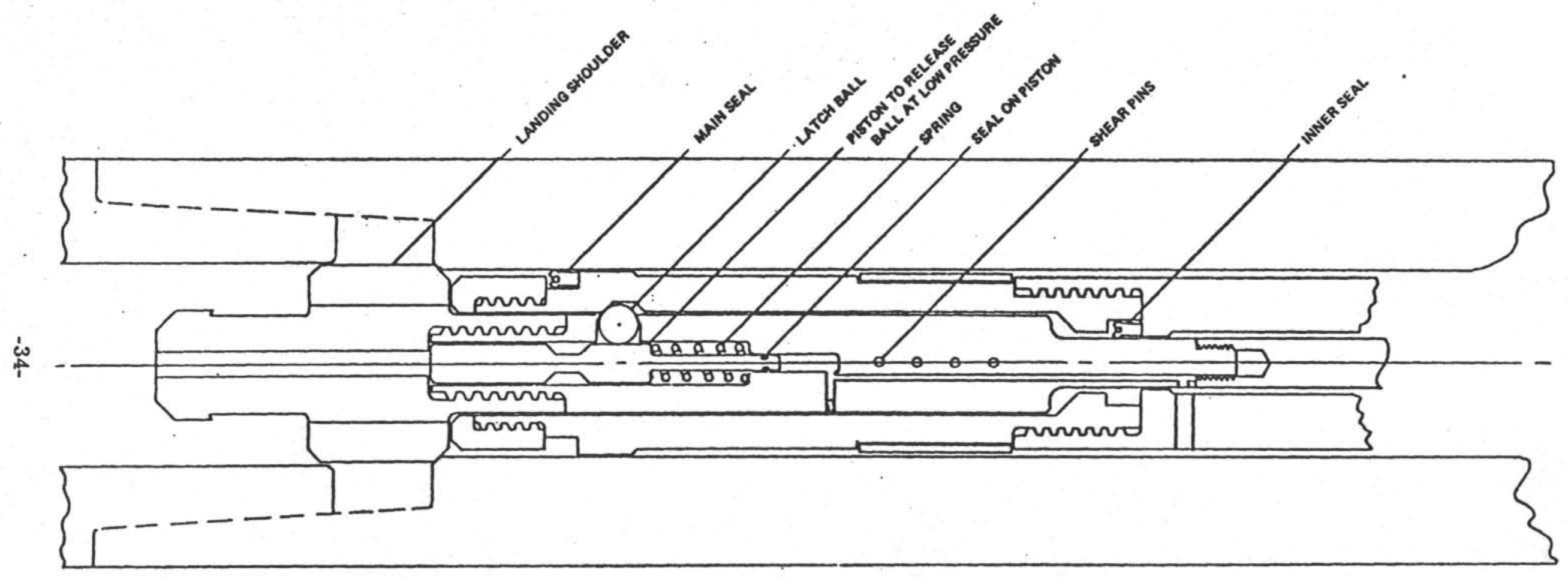

FIG. 12.

PISTON CORER SHEAR PIN PROTECTION CONCEPT.

Never built. 
test of the APC was conducted during Leg 95, at Site 612. The APC was assembled with two, 17-4 $\mathrm{PH}$ shear pins and all speed control holes plugged. (This is the maximum number of shear pins safe to use if a water core is considered possible.) The length of pipe was 2070 meters. The tool was pumped down the pipe using 50 strokes of the mud pumps during the first five minutes and cut back to 25 strokes near the end of the time expected for the tool to reach the BHA. This would have resulted in a relative velocity of the sea water within the pipe of about $9.8 \mathrm{ft} / \mathrm{sec}$ slowing to about $4.9 \mathrm{ft} / \mathrm{sec}$ after five minutes. A pressure kick at seven minutes indicated that the tool had probably landed which would have meant that the tool traveled the 2070 meters to the bit at an average velocity of $16.1 \mathrm{ft} / \mathrm{sec}$. Exact time and velocity at landing was not known. When the tool was retrieved the two shear pins were cleanly sheared. The calculated impact load required to shear the two pins was $18,760 \mathrm{lb}$. which would require an impact deceleration of 39.5 g's. It was thus concluded that compatibility between APC operations and heave compensation (without sandline compensation) could only be accomplished if the shear pins could be protected from the landing impacts inherent in free-falling the tool to the bit. 


\section{B. MOD. II DESIGN/IMPROVEMENTS}

\section{Mod. II Design / Improvements}

The APC prototype assemblies were tested at sea during Legs 94, 95, \& 96. Results were generally very favorable but certain minor problems, typical of prototype designs, were noted. (A full synopsis of prototype operations is included in Section IV of this report.) Following Leg 96 the list of identified problems were evaluated and a Mod. II re-design was undertaken. The specific difficulties and re-design goals were as follows:

a. Shear pin stubs - When the shear pins were double sheared during routine operation of the prototype APC each pin was separated into three pieces, one long section and two end stubs. The stubs had a persistent tendency to then fall into the annular cavity between the Piston Rod and the Outer Shear Pin Sub. These stray stubs would ultimately prevent complete reassembly of the tool when brought back on deck, requiring that they be fished out with a magnet. Mod. II goal - elimination of this problem.

b. Piston Rod Connections - The torsion overload failure of one of the Rod assemblies focused attention on the connection design. The natural galling tendency of $15-5 \mathrm{PH}$ stainless steel called for lubrication of the connections during assembly but this, in turn, would necessitate a mechanical thread lock device to forestall inadvertent back-off of the connections downhole. At the same time, a means of positive alignment between Rod sections was required for the Anti-Spiral groove which ran across all three Rod sections.

c. Outer Seal Replacement - Field testing demonstrated that the dynamic outer seals of the APC were subject to enough wear in routine usage to require regular renewal. The outer seals would last for up to ten deployments but could be worn out on a single core especially when working in sandy formations. The prototype design required a difficult sequence of disassembly steps to change the outer seals. Also, the carefully established internal alignment required to match up the inner and outer holes for the shear pins was disturbed at every seal change. Mod. II goal - Re-design so that seals could be quickly changed with the tool in a vertical position. Elimination of inadequate Piston Rod Jam Nut plus a means to easily re-align shear pin holes.

d. Final Seal Selection - The prototype APC's had been fitted with convertible seal glands to accommodate either separated V-packing or single Polypaks. Field tests indicated that the V-packing was 
preferable for outer seals and double Polypaks would be best for the inner seals.

e. Inner Seal Bypass - Small bypass grooves had been included on the prototype Piston Rod to prevent a complete seal when the tool reentered the seal bore of the outer core barrel during retrieval. Although this bypass area did prevent a complete seal it did not allow enough overall flow to prevent a noticeable increase in drag on the sandline during the entire sandline trip time. Mod. II goal Provide at least as much end-of-stroke, bypass flow area as the VLHPC to reduce sandline drag.

f. Minor Improvements - Some difficulties in rig floor handling pointed out the need for an additional location to attach a core barrel handling clamp in the vicinity of the Pulling Neck. Minor design improvements which could be made to the Quick Release assembly and the Vent Sub were also identified.

\section{Redesign Analysis And Changes}

In concert with general changes being made to the entire DSDP coring tool inventory, the Mod. II APC was designed with a core receptacle capable of taking a full 9.8 meter long core. The need to lengthen the capacity beyond the previous standard of 9.5 meters was brought about by the general increase in length of the individual joints of new S-135 drill pipe purchased for the use on the Challenger. Joints raging in length from 9.5 to slightly over 9.7 meters were common in the newest pipe and, therefore, required coring tool capacities to match.

Sea trials of two APC assemblies - one with and one without the Anti-Spiral system - demonstrated that the Anti-Spiral groove and key were functional and caused no operational problems. The Anti-Spiral option was, thus, included as a standard feature in the Mod. II design. The Key was still installed as a separate, removeable piece, so that damaged keys could be easily replaced and the tool could be operated with the key removed if necessary to avoid other, unforeseen, problems.

An optional Breakaway Piston Head had also been introduced with the prototype APC's to accommodate short cores and incomplete strokes. Test results were not entirely favorable so the Breakaway Head was shelved for later development and a standard, fixed Piston Head was adapted for use with the Mod. II design.

\section{a. Upper Scoping Section Mod. II Design}

The problems involving the shear pin stubs, outer seal replacement and interval alignment to line up shear pin holes called for 
changing the entire upper scoping section of the tool above the Quick Release. The potential for shear pin stubs to become trapped between the Outer Shear Pin Sub and the Rod was eliminated by reducing the annular gap to $3 / 16^{\prime \prime}$ so that a $1 / 4$ " dia. $x$ $5 / 8$ " long stub could not enter. This diameter reduction also eliminated the possibility of using the Jam Nut to align the Piston Rod but it had not been particularily successful in sea trials. A roll pin was introduced instead to lock the Upper Piston Rod section to the Upper Piston Rod section to the Inner Shear Pin Sub in an orientation that was repeatable on each reassembly - required since this connection was part of the overall paleomagnetic baseline alignment and would have to be broken whenever the seals were replaced. To allow the Inner and Outer Shear Pin Subs to align with the Rod locked in place while an Anti-Spiral key prevented rotation of the scoping assembly, a swiveling Outer Shear Pin Sub was introduced. This addition to the original design would allow the rig floor operators to align the shear pin holes by hand each time and eliminated the need for a touchy internal alignment procedure.

The Anti-Spiral key was moved from the bottom of the Outer Seal Sub to the top of the Male Quick Release and the Vent Sub was shortened to be assembled to a Lower Liner Seal Sub. This step was a cost reduction measure for the Vent Sub plus guaranteed interchangeability between Upper tool assembly sections and Lower scoping sections. Since a single Upper section is alternated between two Lower sections in normal operations, full interchangeability is mandatory. The problem is maintaining baseline orientation alignment from the Pulling Neck on the upper section to the Liner Retaining Screw on the Lower section. The Mod. II system establishes a proper alignment at fabrication which would not be not disturbed by interchanging parts.

b. Piston Rod Assembly Mod. II Design

The most significant problem encoutered during sea trials was failure of a Piston Rod under moderate tensile load. Although the failure load was less than the calculated safe limit the failure analysis which followed established that the problem had been torsional overload brought about by inability to deal with the natural galling tendency of $15-5 \mathrm{PH}$ stainless steel during assembly while, at the same time, assuring proper make-up of the Rod sections and alignment of the Anti-Spiral Groove from one section to the next. 
A new connection design was introduced which used roll pins to lock Rod sections together after hand-tight assembly. This would assure Groove alignment, prevent back-off of the connections and allow proper thread lubricants to be used to eliminate the galling problem. The weakest point in the prototype connection was strengthened by eliminating the threading tool runout under cut at the base of the pin. In its place a tapered runout was specified using a $9^{\circ}$ vanish-cone as used on API Sucker Rod connections. A step-by-step fabrication sequence using special thread gages was established to locate the Anti-Spiral Groove in each Rod section relative to the thread orientation so that Rod sections would be interchangeable with sections made singly later while still maintaining proper alignment for the Anti-Spiral Groove. This also eliminated the costly necessity of cutting the Groove only after assembling of a given three Rod sections.

In the Lower Rod section the small Bypass Slots were replaced by flats on three sides of the Rod to provide for about three times the bypass flow area to reduce the sandline drag during retrieval. 


\section{ADVANCED PISTON CORER - MOD. II}

\section{A. General Description}

The Advanced Piston Corer (Mod. II) utilizes the technology of past DSDP Hydraulic Piston Corers while incorporating a simplified seal system which results in a Piston Corer capable of $76 \%$ greater coring force (up to $28,000 \mathrm{lbf}$ ) but about half as mechanically complex as the older VLHPC. The main difference is the use of a dynamic seal acting between the scoping piston corer and a special honed-bore outer core barrel. The inside diameter of the outer core barrel is 3.800 -inches minimum which constitutes the tightest restriction in the $\mathrm{BHA}$.

The lower core-taking section of the APC is essentially the same as the VLHPC. The butyrate liners, core catchers and catcher subs are identical. The nonscoping section of the APC incorporates an adjustable-flow-by Landing Shoulder Sub where Speed Control Sets Screws can be added or removed to control coring velocity. Adjustment for baseline alignment of the magnetic orientation system is reduced to one function of the pulling neck.

The Mod. II version of the APC has incorporated several improvements resulting from the sea trials of the prototype. A more convenient method for changing outer seals has been arranged. Piston Rod connections have been re-designed to lock and align using roll pins so that Baker-lock and/or high torque makeup are not required. The Jam Nut used for shear pin alignment has been deleted. End-of-stroke bypass grooves have been enlarged to reduce drag on the sandline during retrieval: The tool now is capable of taking a full 9.8 meter long core.

The Anti-Spiral system tested out successfully in the prototype and has been added as a permanent feature in the Mod. II version. The system prevents rotation of the scoping section of the corer relative to the piston rod. An Anti-spiral key located in the Male Quick Release tracks down a special groove cut in each of the Piston Rod sections. The grooves are located in the Rod sections during fabrication in such a way that Rod sections are fully interchangeable with other similar parts even if fabricated separately. When assembled and locked, a full set of Piston Rod sections (Upper, Center and Lower) will automatically have a fully aligned Anti-spiral groove running the full required length.

\section{Outer Barrel (BHA) Components}

Several Bottom hole assembly components have been developed specifically for use with the APC. The following BHA arrangement is mandatory, (bottom to top):

XCB/APC Core Bit (with 3.8" min. core guide I.D.)

Long Bit Sub (OL1029)

Seal Bore Outer Core Barrel - 3.8 inch I.D. (OL1044)

Landing/Saver Sub (OL1021) 
NOTE: The possible maximum coring thrust of the tool $(28,000 \mathrm{lbf})$ must be counteracted by an equal mass in the BHA. At the moment this thrust is developed the Bumper Subs cannot close since the internal pressure tends to hold them rigidly open. Thus, to avoid subjecting a hydraulically lockedopen Bumper Sub to static compression loads (plus potential shock loads) it is necessary to place at least six full drill collars between the Landing/Saver Sub and the lowest Bumper Sub. Whether or not to do this must be determined on a case-by-case basis. If only piston coring is to be done, there is no harm to operating with so much weight below the first Bumper Sub. However, if $\mathrm{XCB}$ coring is planned to follow after APC refusal, the lack of a Bumper Sub lower in the BHA may hamper proper weight-on-bit control by the Driller.

It is assumed that the BHA will normally be set up to accommodate both the APC and the XCB interchangeably. Check the XCB Manual for the proper outer barrel components above the APC Landing/Saver Sub to make the BHA compatible to both tools. Always check spacing of coring tools on the rig floor as the $\mathrm{BHA}$ is being run the first time.

\section{Care and Handling of the Seal Bore Outer Core Barrel}

The APC-special Outer Core Barrel and the Landing/Saver Sub that goes with it have honed, seal surface I.D.'s. The quality of these surfaces is critical to the successful operation of the APC. Thus, these components require care and handling beyond the normal for drill collars.

Unused Landing/Saver and Outer Core Barrels should be stored with the inside bores greased to prevent corrosion. Thread protectors should be kept on both ends at all times in storage.

After each site the Landing/Saver Sub and Drill Collar assembly in use should be swabbed with oil or light grease to inhibit corrosion on the inner surface. Between sites they should be stored horizontally on the casing rack filled with fresh water and closed at both ends with sealed thread protectors. The inner surfaces should be inspected before use to determine whether they are in good enough condition to sustain a working seal. 


\section{B. ORIENTATION ALIGNMENT PROCEDURE}

1. Purpose

To achieve baseline alignment between the double reference line on the core liners and the notch in the pulling neck used to key the paleo-magnetic orientation tools.

\section{Procedure}

The tool should be fully assembled from the Pulling Neck (OP4801) to the Vent Sub (OP4829) including the Quick Release Assembly. At least the Upper Piston Rod must be in place. The scoping and non-scoping sections should be scoped together.

a) Lay the assembled tool horizontally so that the Liner Orientation Set Screw (OP4361) in the Vent Sub is facing up. This screw marks the double reference lines on the core liner inside the assembly.

b) Turn the Pulling Neck until its notch aligns with the Set Screw in the Vent Sub. Use a string, rope, straight-edge or line-of-sight to achieve proper orientation. (See Photo G) The Pulling Neck should be pushed in as far as possible.

c) While holding the Pulling Neck to prevent it from inadavertently rotating, tighten the Pulling Neck Lock Nut (OP4704) to lock the Pulling Neck.

This Orientation Alignment should remain valid so long as Vent Subs are used which are Baker-locked to matched Female Quick Releases when they were originally fabricated. If a new Vent Sub or Female Quick Release has been added another Liner Orientation Set Screw hole must be added to the Vent Sub as described in the Vent Sub drawing before the above procedure is performed. 


\section{ASSEMBLY INSTRUCTIONS}

Order of Assembly

Non-Scoping Components:

Step 1. Pulling Neck/Landing Shoulder

Step 2. Upper Rod Components

Step 4. Lower Rod Components \& Piston Head

(standard or breakaway)

Scoping Components:

Step 3. Above Quick Release

Step 5. Below Quick Release

Step 1. Pulling Neck/Landing Shoulder Assembly

a) Slip the Pulling Neck Lock Nut (OP4704) and the Split Bushing (OP4803) onto the Pullng Neck (OP4801). Split Bushing goes narrow end down.

b) Insert this group into the Landing Shoulder Sub (OP4805).

c) Complete the assembly by adding to the threaded end of the Pulling Neck the following: one Support Washer (OP4712), a 3/4-10 UNC Stainless Nut (OD7231), a Stop Washer (OP4713), and a Retaining Ring \#5100-62 (OD7180). (See Assembly Photo A)

d) Do not fully tighten the Lock Nut yet. That is done during the Orientation Alignment procedure.

e) Pack the cavity inside the Landing Sub with Aqua Lube using just enough to cover the $3 / 4^{\prime \prime}$ Nut and Retaining Ring.

Step 2. Upper Rod Components

a) Screw the Inner Shear Pin Sub (OP4809) into the completed Landing Shoulder Assembly. Lock with a 1/2-13 UNC x 1/2 Set Screw.

b) Screw the Upper Piston Rod (OP4817) into the Inner Shear Pin Sub. Wrench flats are provided. Always use anti-sieze compound or grease on Rod Conections to prevent galling the threads. Do not use pipe dope or any zinc-bearing compound. Important: the Piston Rod is screwed in until it shoulders internally then backed off just enough to allow a Roll pin, $3 / 16 \times 1-3 / 4$ (OD7142) to be inserted through the slots in the Inner Shear Pin Sub and the 
matching hole in the Rod. This locates the Anti-spiral groove on the Rod in a position that can be re-established accurately at any time.

Step 3. Scoping Components - Above Quick Release

These components may be assembled to each other first and then installed on the Upper Rod Section, or, each piece may be slipped over the Upper Rod Section individually and fitted together. Take care not to dislodge the inner seals when assembling the Inner Seal Sub on the Piston Rod.

a) Install the Inner Seals into the Inner Seal Sub (OP4815) by inserting two Polypaks \#37501625-625B, lips facing up, into the internal seal gland. (See Photo B)

b) Slip the Shear Pin Sleeve (OP4811) over the Outer Shear Pin Sub (OP4807).

c) Clamp the two halves of the Split Swivel Sub (OP4813) over the notched end of the Outer Shear Pin Sub and hold together while screwing it into the top of the Inner Seal Sub. This step should capture the Sleeve, Outer Shear Pin Sub and inner seals. The Sleeve and Outer Shear Pin Sub should be free to rotate. Lock the Split Swivel Sub in place with a 1/2-13 UNC x 1/2 Set Screw.

d) Grease and install an O-ring \#2-331 (OD2331) in the groove of the Outer Seal Sub (OP4821).

e) Install the outer seals onto the Outer Seal Sub by installing the Outer Seal Female Adaptor (OP4730), a V-Packing \#37503000VP, an Inner Seal V-Spacer (OP4729), another V-Packing, another VSpacer, a third V-Packing and the Outer Seal Male Adaptor (OP4728). (See Photos C \& D)

f) Mate the Outer Seal Sub to the Inner Seal Sub and lock with a 1/2-13 UNC x 1/2 Set Screw.

g) Insert the Anti-Spiral Key (OP4823) in the slot provided in the top end of the Male Quick Release (OP4825). Lock in place with one Roll Pin, $1 / 8 \times 5 / 8$ (OD7111). (See Photo E)

h) Assemble two Quick Release Dogs (OP4753) into the grooves of the Male Quick Release and screw on the Knurled Quick Release Nut (OP4752) so that it captures the Dogs. 
i) Attach the Male Quick Release to the Outer Seal Sub. The AntiSpiral Key engages in the groove in the Piston rod. The connection must be made up by screwing the assembly above the Quick Release onto the Male Quick Release while holding it stationary on the Rod.

j) Slide the Vent Snubber (OP4756) over the Rod with the vent holes down. (See Photo F)

Step 4. Lower Rod Components

a) Attach a Center Piston Rod section (OP4818) to the Upper Rod Section. Attach a Lower Piston Rod section (OP4819) to the Center Rod. Always use anti-sieze compound or grease on the Rod connections to prevent galling the threads. Do not use pipe dope or zinc-bearing compounds. Be sure to carefully remove any wrench marks or burrs on the Piston Rod sections after assembly. Lock both connections with Roll Pins, $3 / 16 \times 1-3 / 8$ (OD7140). The Anti-Spiral groove should now be aligned from one Rod section to the next.

b) Attach the Piston Rod Snubber (OP4766) to the Lower Piston Rod using a Roll Pin, $3 / 16 \times 1-3 / 8 \cdot(O D 7140)$ in the connection. Use anti-sieze compound or thread lubricant on the Rod Thread.

c) Attach the Piston Rod Extension (OP4769) to the bottom of the Piston Rod Snubber. Lock in place with a Roll Pin, 3/16 x 1-3/8.

Step 5. Scoping Components - Below Quick Release

This is the section which is routinely laid down for core removal and refitting with clean liner sections. Initial assembly is described below.

a) The Vent Sub (OP4829) and Female Quick Release (OP4827) should be assembled with Baker Lock when received and a tapped hole should be located in the Vent Sub as specified on the Vent Sub drawing.

b) Attach a Liner Seal Sub (OP4360) to the Vent Sub. Grease and install two O-rings \#2-232 into the Seal Sub.

c) Attach a 12-1/8 inch Inner Barrel Sub (OP3231) below the Liner Seal Sub. 
d) Assemble two 15-ft. Inner Barrels (OP3210) to the Inner Barrel Sub.

e) Attach a second Liner Seal Sub (OP4360) to the bottom of the last Inner Barrel. Grease and install two O-rings \#2-232 into the Seal Sub.

f) Install a plastic liner and cut off flush with the pin of the Lower Liner Seal Sub. Cap the liner bottom with a short-style Plastic Tube Support (OP4382).

g) Attach a standard Catcher Sub or Heat Flow Catcher Sub with the selected core catchers.

The lower Scoping Components can now be hung off in the Piston Corer working stands by using a clamp below the Female Quick Release. The rod and Upper Scoping Components are assembled by spudding the Piston Head into the Female Quick Release and scoping the Rod Assembly into the Lower Scoping Components. Just before mating the Male and Female Quick Release sections, fit the Vent Snubber into the Female Quick Release (Photo F). Finally, assembly the two Quick Release sections and turn the knurled Quick Release Nut down to engage the Dogs. 


\section{TYPICAL OPERATION INSTRUCTIONS AND TECHNICAL GUIDLINES}

Operation of the APC is very similar to the VLHPC. The rig floor practices that are described below are recommendations for simplicity, speed and efficiency.

\section{Initial Set-Up}

a) Assemble one lower scoping section (below the Quick Release) fully dressed with a liner. Hang it off in the working stand with a handling clamp located on the Vent Sub just below the Female Quick Release.

b) Assemble the second lower scoping section without a liner to be used as a protector for the exposed Piston Rod when the nonscoping assembly is picked up for the first time.

c) When the non-scoping assembly (with the upper scoping assembly above the Quick Release) is safely in the vertical position hand it off in the HPC working stand by a clamp on the Vent Sub.

d) The non-scoping assembly can now be separated from the undressed lower section and spudded into the fully dressed, lower scoping assembly as is normally done in routine coring operations.

2. Routine Operation

a) Assume a redressed, clean lower scoping section (from the Female Quick Release to the Catcher Sub) is hanging off in the working stand by a lifting clamp attached at the Vent Sub just below the Female Quick Release.

b) Assume that a complete APC with a core has been returned to the rig floor and is hanging in the pipe by the sinker bar/overshot assembly.

c) Hang off the tool in the pipe at the elevator by a lifting clamp located at the Landing Shoulder Sub, then release the overshot.

d) Withdraw the scoped out tool with a tugger line until it is clear of the pipe and lower it into a second shuck in the working stand. Hang it off at a clamp located on the Vent Sub just below the Female Quick Release. Leave the tugger line attached. 
e) Break the Quick Release and lift the upper scoping and Rod sections using the tugger until the Piston Head is clear.

f) Swing the Piston Head and Rod assembly over and spud the Head into the redressed lower tool section in the adjacent shuck of the working stand. Scope the tool together. Before the Male Quick Release is made up, the Vent Snubber must be guided into the Female Quick Release. (When the tool is separated, the Piston Head pulls the Vent Snubber out.) Make up the Quick Releasc and completely stroke the tool together.

g) Use the Shear Pin Tool to remove the stubs of the old shear pins, using the magnet as needed. Insert the Shear Pin Tool into one shear pin hole to align the Outer Shear Pin Sub while inserting the desired Shear Pins. The pins are held in place by partially rotating the Shear Pin Sleeve after removing the Shear Pin Tool.

h) Lift the completely assembled and redressed tool out of the working stand and stab it into the drill pipe. Hand it off on the handling clamp attached to the tugger while the overshot and sinker bar assembly is attached for running in the hole, then remove the handling clamp.

While the fresh tool is being run in the hole, the lower section containing the core can be lifted with a tugger line and laid out for core removal and redressing.

i) Break off the Catcher Sub and the Liner Seal Sub to access the plastic core liner. Remove the liner and core.

j) Wash out the empty barrel thoroughly and insert a new liner. Liners (for piston coring only) should be prepared in advance by using jigs to locate the Orientation Set Screw hole and bevel the outer edge so that it does not dislodge the O-rings in the Liner Seal $\mathrm{Sub}(\mathrm{s})$ while being inserted in the core barrel. Take care to feel for the O-rings while inserting the Liner.

k) Rotate the Liner inside the core barrel until the hole marking the double reference line on the Liner appears below the Orientation Set screw hole in the Vent Sub. Install the Set Screw.

1) Check the O-rings in the Liner Seal Sub and make it up, over the Liner, to the bottom core barrel. 
m) Cut off the excess plastic liner flush with the end of the Liner Seal Sub. Add a short Plastic Tube Support (OP4382) to the end of the Liner.

n) Insert the chosen Core Catcher assembly into the Catcher Sub and make up to the Liner Seal Sub.

The redressed lower scoping section is now ready to be lifted with a tugger line and hung off in the working stand.

\section{Velocity Control}

The APC has been designed to operate at various power levels and coring velocities. These operating parameters must be pre-set on deck prior to deployment of the tool in anticipation of the type of sediment about to be cored. The pre-set variables are controlled by:

Number and type of shear pins used, Number of Speed Control Set Screws removed.

\section{a) Shear Pins}

One, two, or three shear pins may be used to vary the amount of maximum thrust developed as the corer " shoots off ". The shear pins used are $1 / 4$ " diameter $17-4 \mathrm{PH}$ (specially heat treated) or mild steel. Both types are magnetic. The mild steel pins can be identified by the fact that they are shorter and tend to be considerably more rust-prone than the $17-4 \mathrm{PH}$ pins. The following approximate rig pressures will be encountered:

$$
\begin{array}{ll}
\text { 17-4PH } & \text { Mild Steel } \\
\text { 1 Pin - 1000 psi } & \text { 1 Pin - 550 psi } \\
\text { 2 Pins - 2000 psi } & \text { 2 Pins - 1100 psi } \\
\text { 3 Pins - 3000 psi } & \text { 3 Pins - 1650 psi }
\end{array}
$$

Any combination of shear pins may be used, for example, two (2) 17-4PH shear pins and one mild steel pin should provide a shoot-off pressure of about 2500-2600 psi.

b) Speed Control Set Screws

The scoping section of the tool is driven by expansion of compressed sea water in the drill string. To reach the moving portion of the tool, the water must first Flow through the ports in the Landing Shoulder Sub (OP4805). Six ports are provided, two of which are always open. The other four can be left open or plugged 
with $5 / 8$ "-11 UNC stainless set screws.

These are the Speed Control Set Screws, which, when used to plug one or more of the ports in the Landing Shoulder Sub, act like governors controlling the maximum speed which the moving portion of the tool can achieve.

When using two or three 17-4 shear pins (pressure greater than $2000 \mathrm{psi})$, it is possible for the tool to develop a top speed high enough to severely damage itself when taking a water core or low resistance sediment core.

Optimum performance is achieved by using the greatest number of shear pins and the least speed control set screws possible while remaining within the safe top speed limits.

\section{APC Operational Guideline Chart}

To help achieve optimum performance, (i.e. greatest penetration depth and minimum core distubance) while protecting the tool from damage, refer to the Operational Guideline Chart (Fig. 13).

The Chart is set up to show which combinations of $17-4 \mathrm{PH}$ shear pins and open speed control holes can be used safely when sediment resistance to penetration is very low. Also, some indications of safe combinations are given for medium and high resistance sediments, although these will remain somewhat vague until field experience provides adequate performance data . Using the charts, the tool should by operated in the A Zone as much as possible. The $\mathrm{B}$ squares are safe but do not adequately utilize the coring force potential of the tool. The C Zone is marginal and the D Zone is where mechanical damage to the corer is definitely possible caused by excessive speed and a sudden stop at the end of the stroke.

Prototype sea trials indicated that the Chart was adequate to prevent damage to the tool when followed. It may prove to be significantly conservative after enough testing at sea.

\section{High Pullout Loads}

The APC has been designed to safely tolerate overpulls up to $100,000 \mathrm{lbs}$ (with about a $70 \%$ safety factor). If 100,000 lbs. is not enough to pull the tool free of the sediment, higher overpulls only risk separating the tool either at an Inner Barrel Thread, a Piston Rod Connection or at the Quick Release.

It is recommended that the highest overpull allowed be limited to 100,000 lbs. Beyond this point, wash carefully over the extended barrel for a meter or 

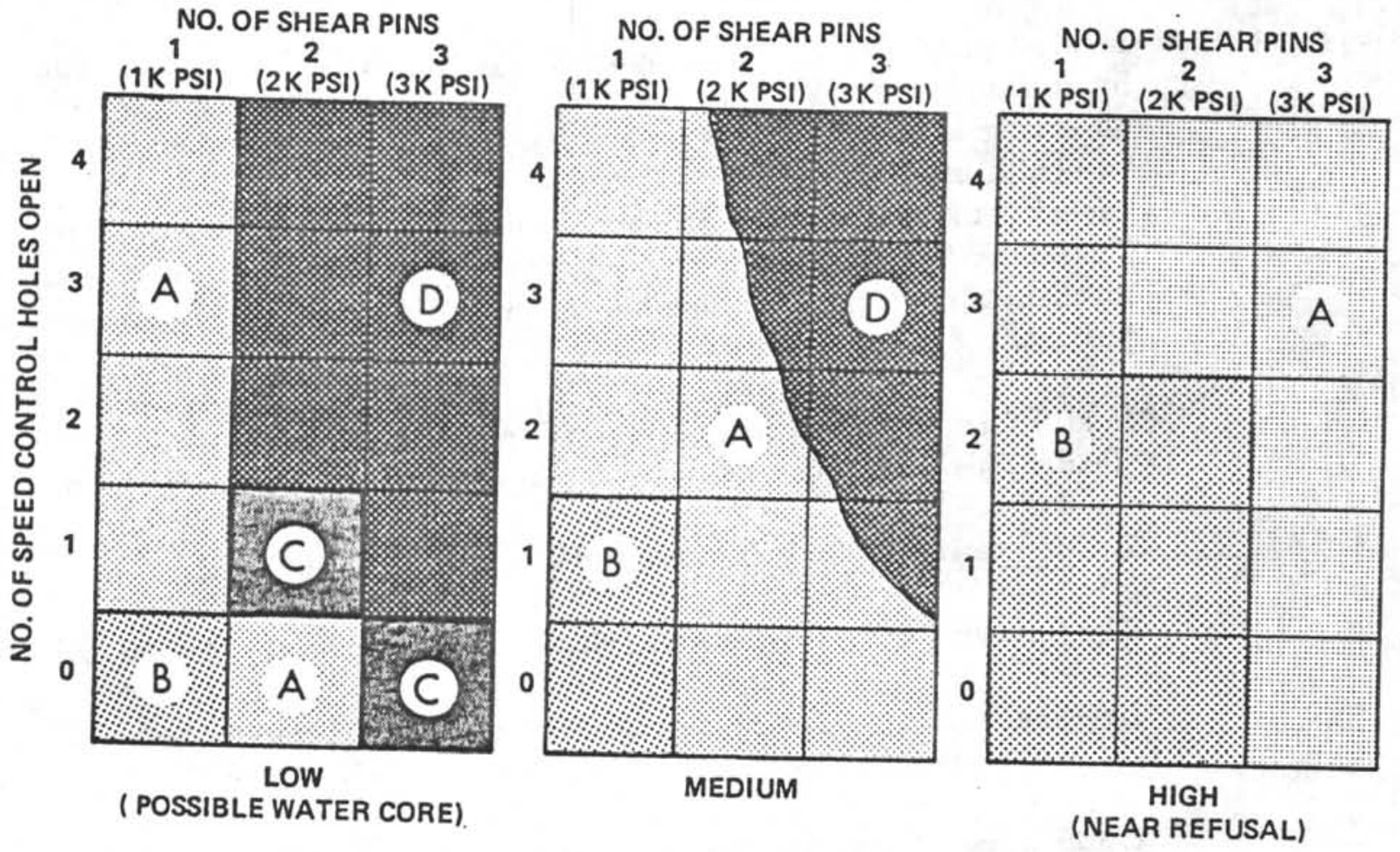

SEDIMENT RESISTANCE

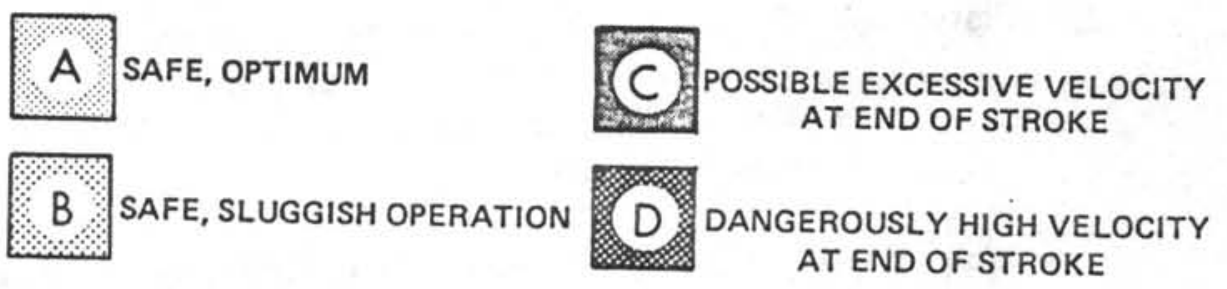

FIG. 13.

- APC OPERAtional gUidelines. 
two and then attempt pulling free again up to 100,000 lbs. Repeat this process until the tool comes loose or is completely washed over. This type of washover process may result in bit gouges on the extended Inner Barrel or Core Catcher Sub.

\section{Partial Stroke}

In most piston-corable formations the onset of APC refusal will be preceeded by incomplete stroking of the tool. This is detectable at the rig floor by observing a distinct difference in the pressure bleed-off characteristics after the build up of pressure to fail the shear pins. The APC does not have the capacity to be assembled in shorter lengths (as the previous VLHPC did). Therefore, flow-in disturbance will probably occur when the piston head is mechanically stroked through the unstroked portion of the core liner during pullout.

In stiff formations the tool can be safely operated with no seals on the Piston Head. This may help to reduce flow-in disturbance after partial strokes.

\section{Monitoring Wear \& Deterioration}

The following critical wear areas should be inspected at every opportunity:

Landing Surfaces - The underside of the Landing Shoulder Sub and the $45^{\circ}$ lead-in taper of the Landing/Saver Sub.

Outer Core Barrel and Landing/Saver Sub - The honed I.D.'s should be inspected regularly for corrosion build-up and pitting.

Piston Rod Snubber - The upper $\left(60^{\circ}\right)$, conical surface is the internal landing shoulder for the scoping portion of the tool at the end of the stroke. Damage will result here if coring velocity is too high (especially after water cores).

Inner Barrel Threads, Piston Rod threaded connections, and Quick Release Lugs - High pullout leads may overstress any or all of these.

\section{Checking \& Changing Seals}

a. Piston Head Seals - The seals should be inspected after each core while reassembling the APC. The tool will function well even if these seals are in poor condition or removed entirely but core quality may suffer, especially in soft formations. 
The seals are changed by backing off the Seal Retainer (OP4345), removing the Lock $\mathrm{Pin}(\mathrm{OP} 4383)$ and then removing the Piston Head Body.

b. Inner (Polypak) Seals - The inner Polypaks cannot be routinely observed but should last the longest of any of the seals on the tool. They should be removed whenever the tool is redressed between sites or put into storage. This will reduce corrosion in the seal gland when the tool is not in service.

c. Outer (V-packing) Seals - The outer seals can be visually inspected after every core and should be changed whenever their appearance indicates the possibility of not achieving a tight seal downhole.

To change Outer Seals:

1) Hang the scoping section off on a clamp located on the Vent Sub just below the Female Quick Release.

2) Scope the Piston Rod into the lower section and make up the Quick Release.

3) Continue scoping the Piston Rod down until the wrench flats on the Upper Rod section approach the top of the Outer Shear Pin Sub.

4) At this point insert the Hang Off Tool (OP4834) into the hole in the Male Quick Release just above the knurled Nut and engage the matching hole in the Piston Rod.

The Piston Rod will be supported by the Hang Off Tool while changing the Outer Seals.

5) Remove the 3/16" Roll Pin and back off the Inner Shear Pin Sub from the Upper Piston Rod.

6) Remove the Set Screw and break the scoping section just above the Outer Seals to gain access to the seal gland.

7) After installing new seals reassemble each of the components in reverse order. When re-assembling the Inner Shear Pin Sub, screw it all the way onto the Upper Piston Rod until it shoulders internally and back off just enough to allow a new $3 / 16^{\prime \prime} \times 1-3 / 4^{\prime \prime}$ Roll Pin to be inserted. This step assures that orientation alignment has been reestablished as before. 


\begin{tabular}{|c|c|c|}
\hline $\mathrm{P} / \mathrm{N}$ & DESCRIPTION & NO. REQ'D \\
\hline OP4800 & Advanced Piston Corer Assy. - Mod. II & - \\
\hline OP4704 & Pulling Neck Lock Nut & 1 \\
\hline OP4710 & Speed Control Set Screw, 5/8-11 UNC x 5/8 SS & $0-4$ \\
\hline OP4712 & Support Washer & 1 \\
\hline OP 4713 & Stop Washer & 1 \\
\hline OP4721 & Shear $\mathrm{Pin}, 1 / 4$ dia $\times 3-7 / 32,17-4 \mathrm{PH}$ & $1-3$ \\
\hline OP 4725 & Shear Pin, $1 / 4$ dia $\times 3-1 / 8$, Mild Steel & $1-3$ \\
\hline OP 4728 & Outer Seal Male Adaptor & 1 \\
\hline OP 4729 & Outer Seal V-Spacer & 2 \\
\hline OP4730 & Outer Seal Female Adaptor & 1 \\
\hline OP4752 & Quick Release Nut & 1 \\
\hline OP 4753 & Quick Release Dog & 2 \\
\hline OP 4756 & Vent Snubber & 1 \\
\hline OP4766 & Piston Rod Snubber & 1 \\
\hline OP4769 & Piston Rod Extension (Std. Hd.) & 1 \\
\hline OP4801 & Pulling Neck & 1 \\
\hline OP 4803 & Split Bushing & 1 \\
\hline OP 4805 & Landing Shoulder Sub & 1 \\
\hline OP 4807 & Outer Shear Pin Sub & 1 \\
\hline OP4809 & Inner Shear Pin Sub & 1 \\
\hline OP4811 & Shear Pin Sleeve & 1 \\
\hline OP 4813 & Split Swivel Sub & 1 \\
\hline OP 4815 & Inner Seal Sub & 1 \\
\hline OP 4817 & Upper Piston Rod & 1 \\
\hline OP 4818 & Center Piston Rod & 1 \\
\hline OP4819 & Lower Piston Rod & 1 \\
\hline OP 4821 & Outer Seal Sub & 1 \\
\hline OP 4823 & Anti-Spiral Key & 1 \\
\hline OP4825 & Male Quick Release & 1 \\
\hline OP 4827 & Female Quick Release & 1 \\
\hline OP 4829 & Vent Sub & 1 \\
\hline OP 4834 & Hang Off Tool & -- \\
\hline OP4836 & Shear Pin Tool & - \\
\hline OP 3210 & Inner Core Barrel, $3-1 / 2 \times 2.87 \times 14^{\prime} 9-1 / 2^{\prime \prime}$ & 2 \\
\hline OP3231 & Inner Barrel Sub, 12-1/8" & 1 \\
\hline OP 3400 & Core Liner, Butyrate, $2.817 \times 32$ ' -6 " & 1 \\
\hline OP4345 & Piston Seal Retainer & 1 \\
\hline OP 4360 & Liner Seal Sub & 2 \\
\hline
\end{tabular}




\begin{tabular}{clc} 
P/N & \multicolumn{1}{c}{ DESCRIPTION } & NO. REQ'D. \\
\hline OP4361 & Core Liner Retainer Screw & 1 \\
OP4362 & Slim Nose Catcher Sub (Alt.) & 1 \\
OP4376 & Catcher Sub & 1 \\
OP4377 & Heat Flow Core Catcher - Body (Alt.) & 1 \\
OP4378 & Heat Flow Core Catcher - Cone (Alt.) & 1 \\
OP4381 & Piston Head Body & 1 \\
OP4382 & Plastic Tube Support & 1 \\
OP4383 & Lock Pin, Piston Head & 1 \\
OP4390 & Male V-packing Adaptor (Piston Hd.) & 1 \\
OP4391 & Female V-packing Adaptor (Piston Hd.) & 1 \\
OP4392 & V-Spacer (Piston Hd.) & 2
\end{tabular}

\section{Fasteners \& Seals}

OD2232

OD2331

OD3150

OD4200

OD4300

OD6555

OD7111

OD7140

OD7142

OD7180

OD7231

OR7010

OR7020

OR7100
O-ring \#2-232, Buna-N, 70D.

O-ring \#2-331, Buna-N, 70D.

Polypak, Molythane, \#37501625-625B

V-packing, Molythane, \#31202000VP

V-packing, Molythane, \#37503000VP

Set Screw, Socket, 1/2-13 UNC x 1/2, Stainless

Roll Pin, $1 / 8 \times 5 / 8$, Stainless

Roll Pin, $3 / 16 \times 1-3 / 8$, Stainless

Roll Pin, $3 / 16 \times 1-3 / 4$, Stainless

Snap Ring, \#5100-62

Hex Nut, Stainless, 3/4-10 UNC

\section{Core Catcher Alternatives}

Core Catcher, Complete, Dog Type "10"

1-2

Core Catcher, Complete, Dog Type "8"

Core Catcher, Complete, Flapper Type

Outer Barrel Components
OL1021 Landing/Saver Sub

OL1029 Long Bit Sub

OL1044 Seal Bore Outer Core Barrel 


\section{OPERATIONAL SYNOPSIS - SEA TRIALS}

The prototype assemblies of the Advanced Piston corer were first introduced to the Glomar Challenger on Leg 94 in June 1983. The two prototypes sent for the initial sea trials were not identical. Several design options were included for evaluation including convertible seals glands capable of accepting either Polypak or separated, V-packing seals, two Piston Rod assemblies (with and without the Anti-Spiral Groove), and two different Piston Heads (conventional-fixed and new, Breakaway version.)

Table 2 capsulizes the results of all prototype deployments during Legs 94,95 and 96. The general performance of the tool was good from the outset. Core quality and functional characteristics were as good or better than the VLHPC. Assembly, maintenance and on-deck handling were considerably better.

\section{A. LEG 94 RESULTS}

The Piston Rod assembly with the Anti-Spiral Groove was used for twelve cores at the first site. The tool functioned as designed but the Anti-Spiral Rod was retired when it allowed shear pin stubs to work their way down the groove and became trapped in the inner seals. The ungrooved Rod assembly was then used successfully for twenty five cores in two different holes until a connection in the Rod assembly failed during a retrieval overpull. The cause of failure was later traced to over-torque during assembly of the ungrooved Rod. (The failure analysis is described in detail in Section II). Shortly thereafter, the bottomhole assembly section containing the sole Seal Bore Outer Core Barrel required for APC work was lost in an unrelated accident involving the failure of a Bumper Sub connection. Further APC usage was thus delayed pending delivery of another set of BHA components during the next port call.

The APC tools were highly successful during these first thirty-seven core attempts. minor problems with shear pins and handling sequences were identified to be improved in the re-design for Mod. II. The Polypak seals were determined to be unacceptable for application as Outer Seals.

\section{B. LEG 95 RESULTS}

The Outer Barrel components lost were replaced along with a set of APC parts to replace those lost when the Rod connection parted during Leg 94 . The APC was used to take only seven cores at Site 612; the remainder of Leg 95 was spent without the need to do any piston coring. Recovery and core qualilty were good. Additional minor shortcomings were identified including the lack of ease of changing outer seals and problems with locking and alignment of the Piston Rod intermediate and upper most connections. 


\section{LEG 96 RESULTS}

An extra set of Outer Barrel Components were provided so that Leg 96 began with duplicate $\mathrm{BHA}$ for $\mathrm{APC}$ work since piston coring was to be the primay work load. The APC was used at 9 holes taking 122 cores before two mishaps resulted in the loss of both sets of APC bottom hole assembly components - thereby abruptly terminating the sea trials of the APC.

The total usage during Legs 94,95 and 96 was adequate to thoroughly establish the viability of the APC concept. The rig floor and operations personnel were unanimous in their opinion that only a few design changes were required and that, with them, the APC would effectively obsolete the VLHPC coring system. Leg 96 usage was in the Mississippi Fan area of the Gulf of Mexico where loose sand was common in the upper sediments - an especially difficult material to piston core successfully. Additional problems requiring design improvements identified during the leg were high sandline drag during retrieval and the need to change outer seals as often as once per core in sand-rich zones. The Breakaway Piston Head was used extensively for about the first half of the APC deployments of Leg 96. It was not, ultimately, deemed ready for full operational acceptance and the final APC runs used the Standard (fixed) Piston Head.

Numerous water cores were inadvertently taken during Leg 96 operations while verifying the location of the mudline at several holes. The lack of mechanical damage from these water cores helped verify the operational guideline limitations. High retrieval overpulls, often in excess of 90,000 lbs., were experienced numerous times on Leg 96 . No damage to the Rods, Quick Releases or Inner Barrel Threads was observed.

Excerpts of the Cruise Operations Managers' Reports for Legs 94, 95 and 96, discussing the results of APC testing, are included in Appendix E. 
TABLE 2

ADVANCED PISTON CORER

PROTOTYPE SEA TRIAL DEPLOYMENT SUMMARY

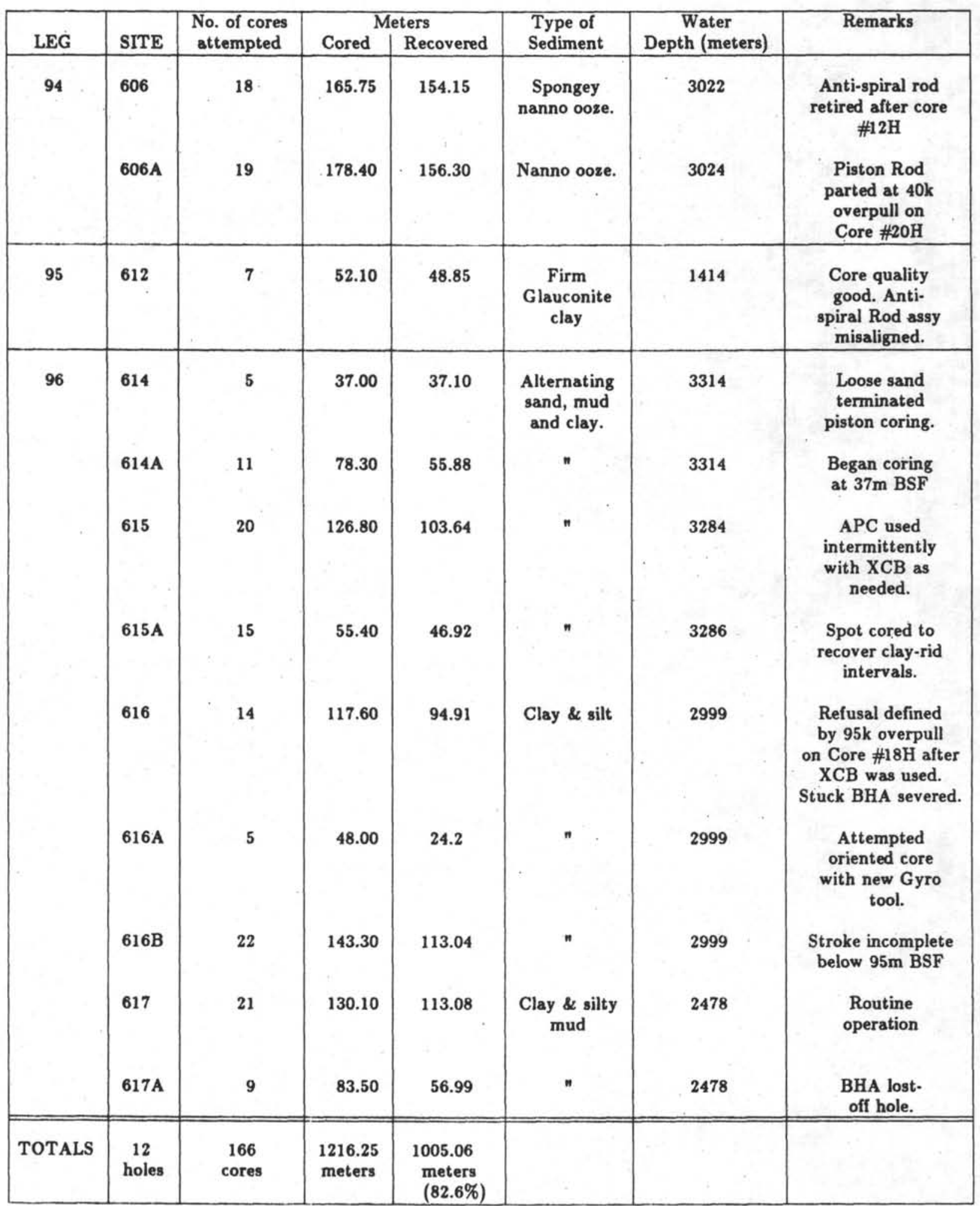


APPENDIX A

INITIAL FEASIBILITY STUDY REPORT 


\section{JOHN E. HALKYARD \& COMPANY}

Consultants in Engineering and Business Development

Specializing in Mechanical Systems, Hydraulics and Ocean Engineering

FEASIBILITY ANALYSIS

OF

PISTON CORE BARREL CONCEPTUAL DESIGN

FOR

DEEP SEA DRILLING PROJECT, A-031

UNIVERSITY OF CALIFORNIA, SAN DIEGO

LA JOLLA, CALIFORNIA 92037

By: O. R. Heine

P. M. Riede

Date: May, 1982 


\section{CONCLUSIONS AND RECOMMENDATIONS}

This analysis indicates the feasibility of designing a piston core barrel provided the Top Sub Body seals are effective throughout the stroke. For the case of using this seal only to shoot off the tool, insufficient stored energy is available to get adequate penetration of the seabottom.

Based on this analysis, it is recommended that primary attention should be placed on the "full length seal" concept (a). In addition, it is recommended that serious consideration be given to including a piston inside the core tube, particularly if samples of low soil shear strength are to be obtained.

We recommend that future efforts include the following:

1. Review a design configuration of the "full length seal".

This should result in a full-scale layout drawing of the complete hydraulic piston corer including all pertinent dimensions.

2. Hydraulic and stress analyses to establish the practicability of the design.

3. Prepare detailed fabrication drawings as required for the manufacture of a prototype unit.

4. Prepare a test plan to allow for verification of the performance of the new corer design.

\section{SUMMARY}

The results of this approximate effort indicate that it will be advisable to utilize concept (a) as defined in the Statement of Work "Full Length Seal" in favor over concept (b) "Shoot off Tool". 
The force balance equation, applying the hydraulic driving forces and hydraulic plus viscous resisting forces acting on the corer, while neglecting secondary terms such as sliding friction and inertial forces, over the full stroke of 30 feet, show that it will be possible to drive the corer into medium clay in about 1.5 to 2.5 seconds with concept (a) relying only on the release of a part of the stored energy and letting the applied pressure thus decay from say 2800 or 2000 psi to about 715 psi at the stored pressurized fluid volume in the pipe string expands during the driving of the tool (see Figure 7).

In contrast, because a flow path is opened to the outside as soon as the piston leaves the seal area (orifice \#3) and the stored fluid volume under the initial pressure exhausts quickly (in less than $.5 \mathrm{sec}$. the pressure would drop to 715 psi or sol, the stored energy can only effect the initial acceleration of the corer to a peak value of about 16 to 24 $\mathrm{ft} / \mathrm{sec}$. but cannot continue to drive the tool.

This initial velocity reached after say 25 feet stroke diminishes rapidly as the pressure generated inside the corer due to headlosses caused by the fluid displaced through restricting orifices tends to decelerate the corer. Because of the distance between the pressure release location and the pump located on the drill ship (1500 $\mathrm{m}$ in this example) the pump can only respond to the fall-off in pressure after the pressure change is noticeable at the surface, which is 1.1 seconds later, the time needed for a signal to propagate at the velocity of sound through the $1500 \mathrm{~m}$ long pipe string.

Thus, at best, 1.1 seconds later the pump can pick up where the initial energy release has leveled off, say at $715 \mathrm{psi}$, and 1 foot of stroke. Since the leakage through the head orifice \#3 continues, the system pressure cannot increase beyond a certain level. Again applying the force balance equa-e 0 it trin. tion, it is estimated that the 30-foot stroke can consequently 
be completed in about 8 seconds by flow provided by the pump at the maximum rate of 600 GPM.

For heavier clay having say three times the viscous shear resistance of medium clay this process would require significantly more time and may not allow full penetration of 30 feet.

\section{CONCLUSION}

While the "shoot-off tool" concept (b) could conceivably work in moderate strength soils, it is questionable whether it would work in heavier or higher strength soils without further performing more detailed analytical effort and subsequent experimental tests.

On the other hand, "the continuous seal" concept (a) should function as well or even better than the present corer inasmuch as more force is initially available due to the larger cross sectional area of the piston compared with the existing one. 
STATEIENT OF WORK

PISTON CORE BARREL FEASIBILITY ANALYSIS

APRIL $27 ; 1982$

Based on a verbal description of the desired new coring tool and the conceptual sketch (Fig. 3) enclosed, the following work items should be accomplished:

1. Review the problem description and tool concept with DSDP engineers and acquire the necessary background and support information including dinensional, test and operational data of current HPC and BtiA components.

2. Outline and report essential requirements for the tool to function according to the principles envisioned.

3. Analyze hydraulic and mechanical feasibility of two proposed concepts.

a) One using Top Sub Body seals throughout the stroke.

b) One using those seals only to shoot off the tool.

4. Analyze hydraulic and mechanical feasibility of check valve or other devices to enable proper venting of the water in the Core Liner when the tool fires.

5. Assess overall feasibility of conceptual design based on above analyses and make recommendations for future efforts both orally and in a summary report with documented concept designs and calculations. 
LIST OF REFERENCES.

(USED IN THIS FEASIBILITT ANACTSIS)

(1) "Theoretical soills mechanics", karl terzaghi JOHN WILEY \& SONS, INC. , NEW YORK.

(2) "PCA SOLL PRIMER"

PoRTLANO CEMENT ASSOCIATION.

(3) "one dimensional two phase fow" graham walls MC GRAW-HILL BOOK CO.

(4) "RUID MECHANICS" " DODVE \& THOMPSON MC GRAW- HIL BOOK CO.

(5) "Handouok of ocean ano underwater enuneering" MIERS, HOCM \& MCAUISTER, MC GRAW-HIL BOOK CO.

(6) DRAWIDGS \& TEST DATA SUPPIED BY DEEP SEA DRUILING PROJELT :

(a) DSDP STD. WIRE IINE CORE BARREI ASIY, R- OP 3000 REV. O

(b) VARIABLE LENGTH HTORAVIK PISTON CORER ASSEMBIY, R- OP 4300

(c) STATEMENT OF WORK, APRIL 27,1962

(d) SHETCH OF CONCECT (b) (AG.3)

(e) ILUSTRATION OE STD. HYORAVIIC PISTON CORER (VLHPR.) (FI6-1.)

(f) D.S.D.P HYDRAULIC PISTON CORER TEST RUN \& (Fb.-2)

(g) VERBAL INF. SUPPliEo BY DAVE HUEY ON $5 / 12 / 62$ :

- Ranber of corer penetration velocity expectio - $10 \div 20$ fi/sel

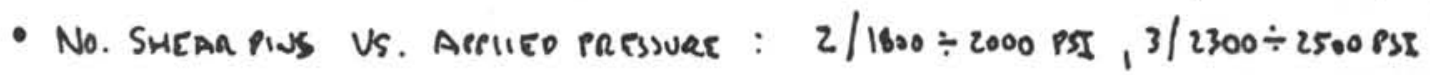

- Workiab DEPTH RANGE : $1500 \div 7000 \mathrm{~m}$

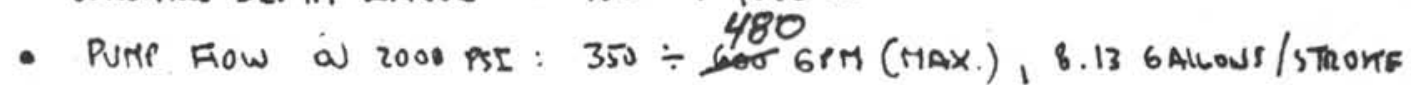

- expecteo ravie of soll shear strentta : $1200 \div 3000 \mathrm{~g} / \mathrm{cm}^{2}$ 
PALE 2 OF 26

Mar 1962

O.R.H.

ESTIMATED CORING RESISTANCE.

CONSIOER : 1. SOIL (CLAY) MAY BE TREATEO AS "NON-NEWTONION" Viscous Ruid (BINGHAM RLAJTIE) bEa. (REF.- -)

2. SPECIFIC GRAJITH OF CLAT IS $2 \mathrm{~g} / \mathrm{cm}^{3}$ (REF.-20)

3. EXTERNAL CORING RESISTANCE IS TREATED AS ADPTIANAL INTERNAS FRICTION LOS:

SHEARINO RESISTANCE OF SOIL : (RRF.-1.)

$$
S=c+\dot{\sigma} \operatorname{tg} \phi=1000 \mathrm{~g} / \mathrm{cm}^{2} \text { (Givew) }
$$

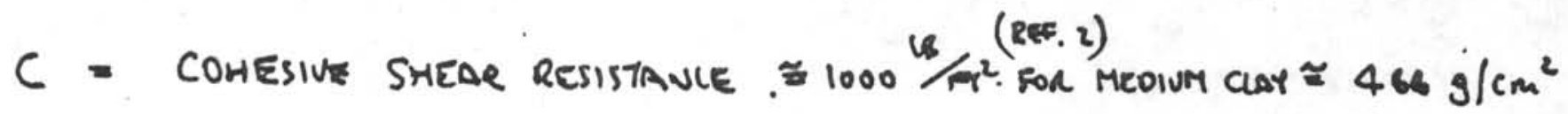
$\sigma=$ Noamar staess $\left(9 / \mathrm{cm}^{2}\right)$ is soll.

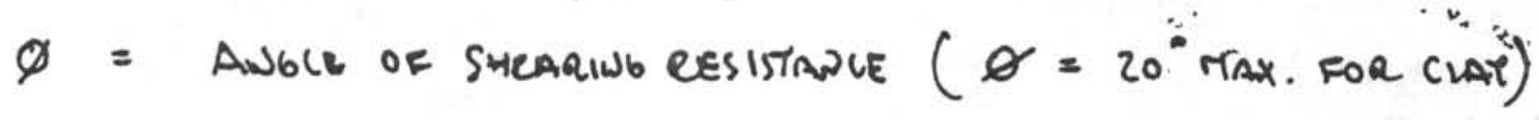

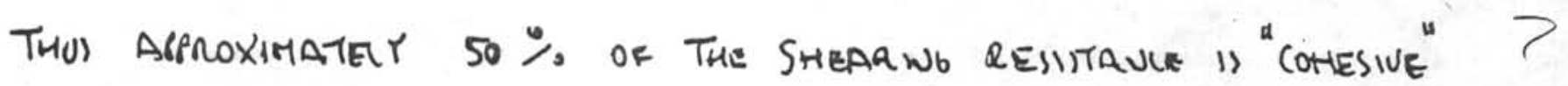
in Treis Assumetiow.

$$
\text { LeT } \quad \begin{aligned}
C & =\tau_{w} \text { (Shear STaess @ conen I.D. WANi) } \\
& =\tau_{\omega}
\end{aligned}
$$

THe EFETTVE VISCOSITH IS FOR NON-NEWTOWIAN RVIOS ASPROXITATELY (JER REF. 3) GIVEN WITH:

$$
\mu_{\text {IEFF. }}=\frac{\sigma_{w}}{8 V_{w}} D
$$


MAY 1482

O.R.H.

WhEAT: $\quad V_{N}=$ VEloctro NEAR PISE WAN (CM/IEC)

$$
D=I . D \text {. Of CONOA }=2.617 \mathrm{NS}=6.647 \mathrm{~cm}
$$

LET: $V_{w}=1.0 \mathrm{~cm} / \mathrm{sEC}$, THEN :

$$
\mu_{\text {EFF. }}=\frac{488}{8 \times 1.0} 6.697 \approx 405 \text { POISE }
$$

$$
\text { (ET: } \begin{aligned}
V_{W}= & .5 \mathrm{~cm} / \text { SEC, THEW : } \\
& \mu_{\text {EFT }}=810 \text { POISE }
\end{aligned}
$$

AT $V_{W}=.25 \mathrm{~cm} / \mathrm{sec}, \mu_{\text {ERT }}=1620$ POISE

Compare THIS WITA TEST resulT:

From D.S. O.P. HYoravili PISTOW Cornea TEST RUN 4

$$
\begin{aligned}
& P_{\text {MAX }}=1500 \text { PSI } \\
& \text { STROKE }=15 \mathrm{FT} \\
& \text { AVG. VELOCITY }=10 \mathrm{FT} / \mathrm{SEC}=304.8 \mathrm{~cm} / \mathrm{seC}
\end{aligned}
$$

Check $\sum$ for approp.

$\mu_{\text {EFF }}$

For LAMUNAR Flow in PIPE: (REF. -4.)

$$
n_{1}-h_{2}=\frac{128 Q v e}{\pi d^{4} g}
$$

Hagen-Porsecille

$\hat{i}$ head loss due to flow $Q$ over length of pipe, $l$ 


$$
\text { FIG-I }
$$

DEEP SEA DRILLING PROJECT

HYDRAULIC PISTON CORER (VLHPC)

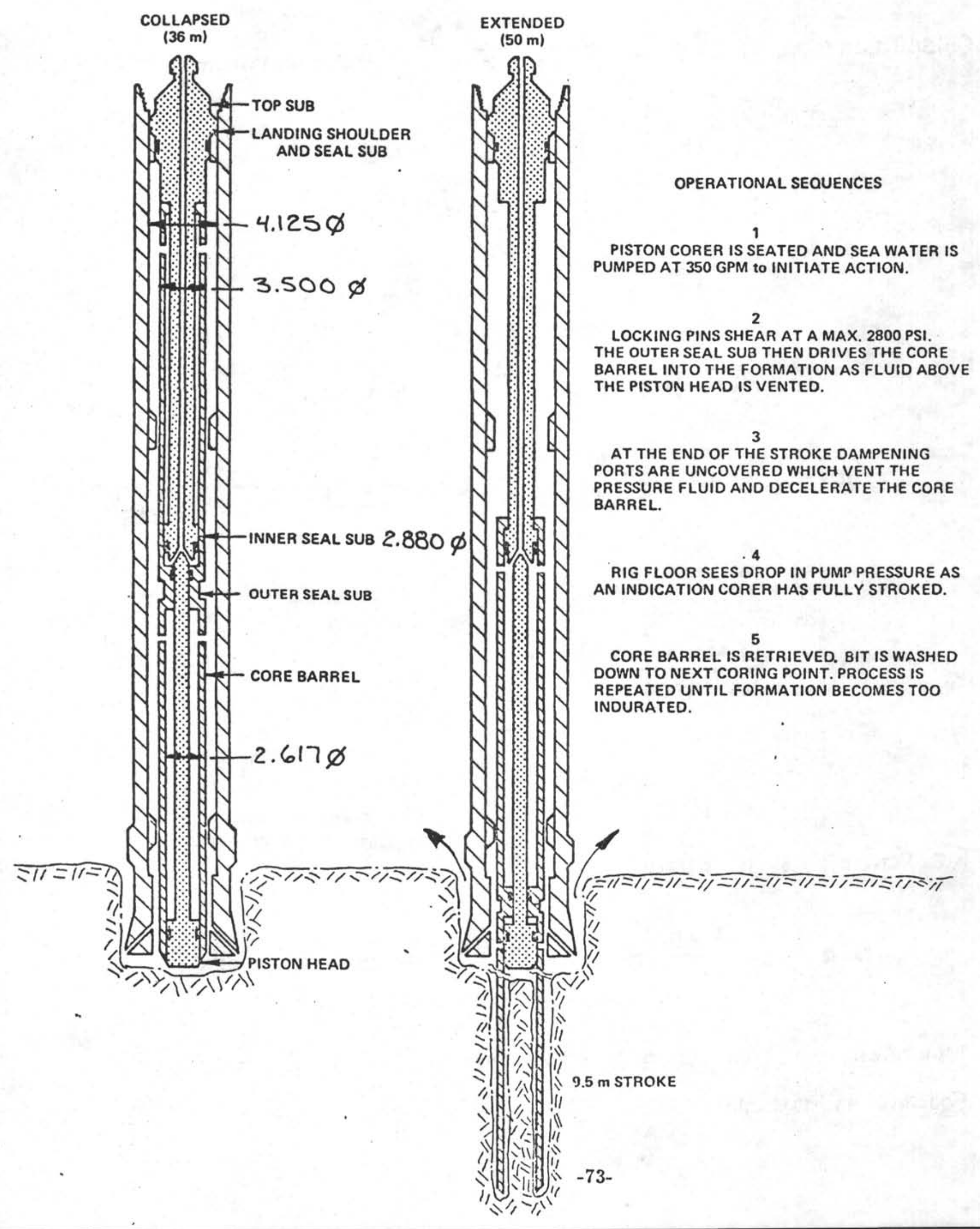


PAGE 5 OF 26 MAY 1982 O.R.M.

Consequeutr : $\quad Y=\frac{\left(h_{1}-h_{2}\right) \pi d^{4} g}{128 Q l}$ (knematic viscosm $\left.-\frac{\mu}{\rho}\right)$

WHEQE:

$$
\begin{aligned}
& \left(h_{1}-h_{2}\right)=\text { HEAD cOSN OF RUID (CM OF AUID) } \\
& Q=\operatorname{Row}\left(\mathrm{cm}^{3} / \mathrm{sec}\right) \\
& \text { g. } 961 \mathrm{~cm} / \mathrm{sec}^{2} \\
& e=15 \mathrm{FT}=457.2 \mathrm{~cm}
\end{aligned}
$$

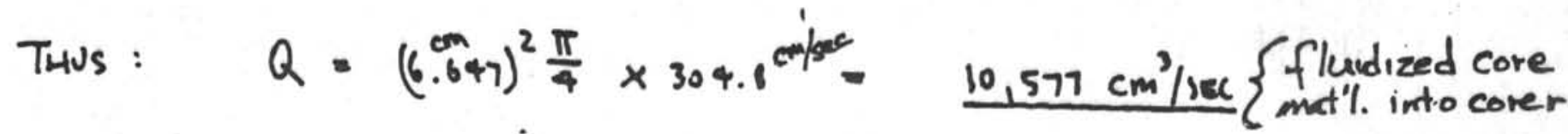

$$
\left.\left(h_{1}-h_{2}\right)={ }_{1500} \frac{\frac{\pi}{4}\left(2.68^{2}-1.28^{2}\right)}{\frac{\pi}{4}(2.617)^{2}}\right) ?=1474 \text { PSI } \longleftarrow \text { ? why this }
$$

$51.639 \mathrm{~cm}$ llQN10 (CLAY)

$$
\begin{aligned}
& Y_{e} \cong \frac{51,639 \pi(6.647)^{4} 961}{128(10,577) 457.2}=504 \mathrm{~cm}^{2} / \mathrm{sec} \\
& \mu_{0} \cong \gamma \rho \cong 504 \times 2=1008 \text { POISE }\left(\frac{9}{\mathrm{cmski}}\right)
\end{aligned}
$$

ESTMATED EFreltive Viscositr on Clay

THE ReYnads No. Is ARPauX.:

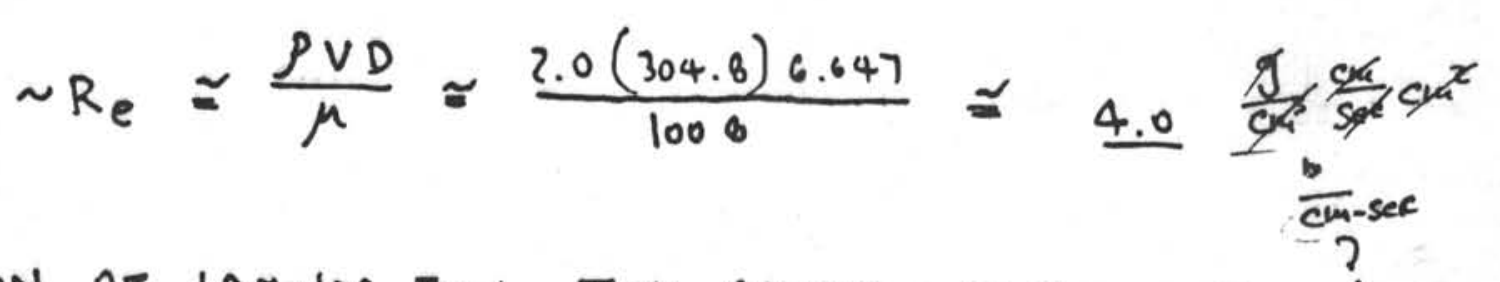

INOICATION OR LAMINAR FLOW, THUS APPLICATION OF VISCOUS Flow? Equation is ESSCNTIAl.

$-74-$ 


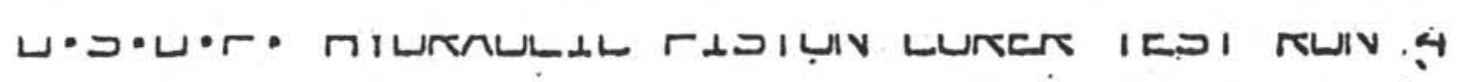

CAN 2 NAX $=-93$ MIN $=-2664$ NSAN $=-956.15$ OATA 1-1024 SCNLEX 7.0 PEESSURE TRANSTUCER. OATA DLYY BATDH B3

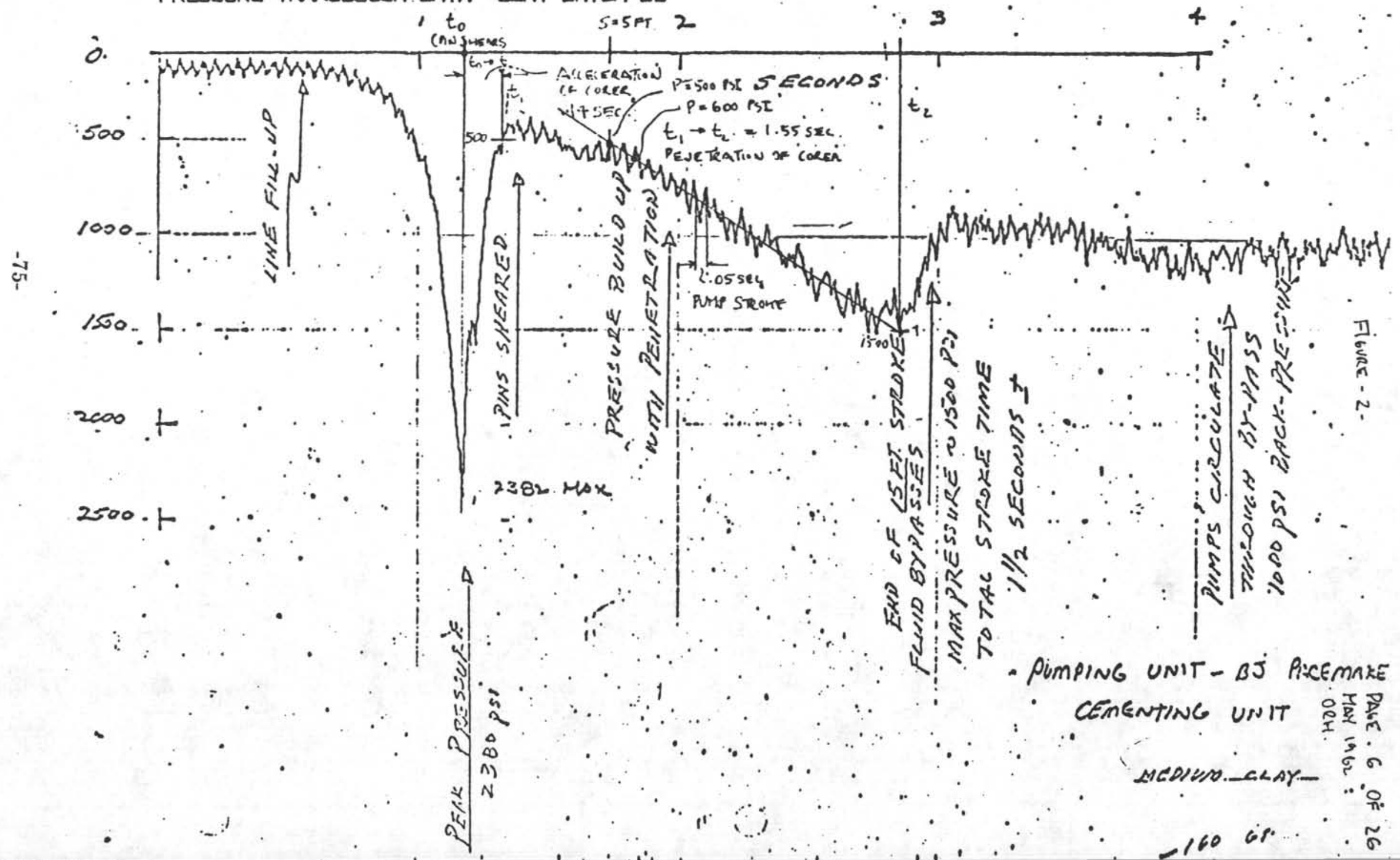


TAOY ISEL

QRH.

The hloqavilic pistow coara test oata (Rin 4) indicales That

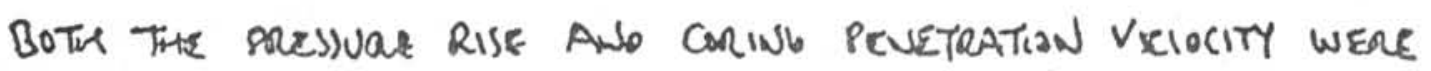
CONITANT DUALWO AT LLAST THE LAST $2 / 3$ OF THE 15 FT. STROKE.

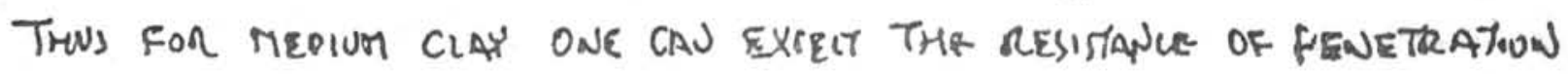
To BE ARSR XIMATEY :

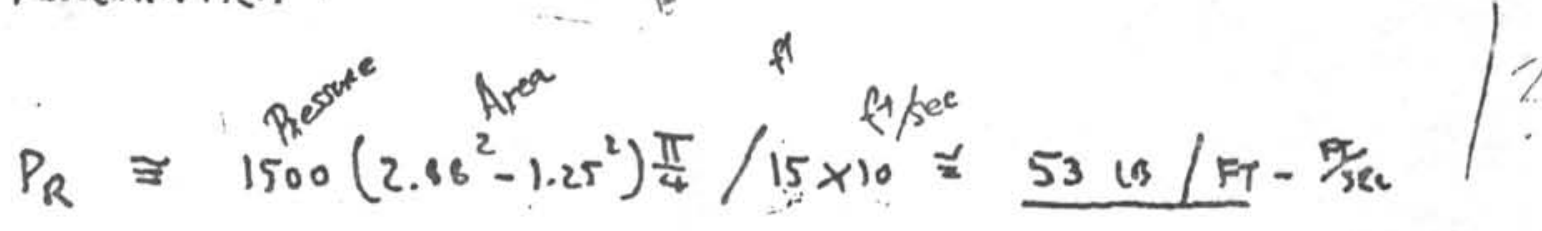

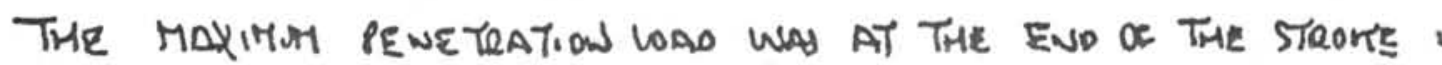

$$
F_{P \max } \approx P_{R}(150) \approx \underline{7}, 95018
$$

The PREs) vare aften 5 'shoke shouro mave bren then: $Q$

$$
P=\frac{53(5 \times 10)}{\frac{\pi}{4}\left(2.68^{2}-1.25^{2}\right)} \approx 500 \text { PSI }
$$

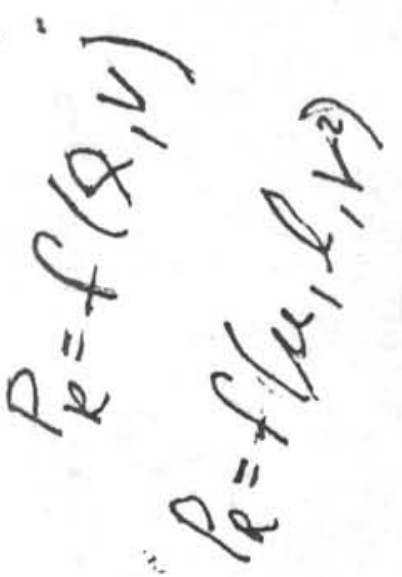

VS ABPROX. 520 PSI NOICATEO, WHICH IS IN 6000 ASREEMENT!

THE THEST dATA (FI6.-2, REF. 6F) COWFIRT THE PRE Sumption that

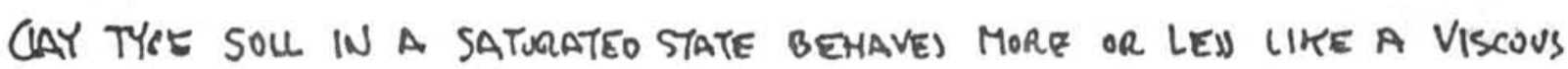

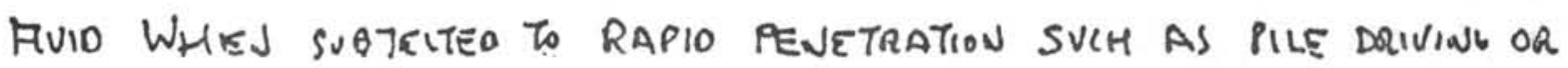
Corint, As procojed by TerzabHI (ref- 1). The penetration resistanle

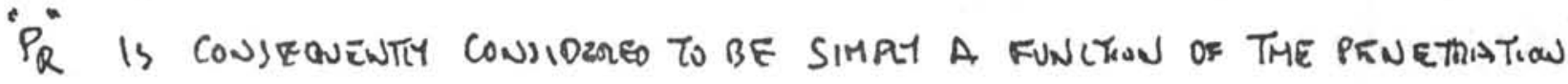
degth ang tre Velocity of penetrationano in this case is adurteo to be A cunjtant For MEOUM STRENGH CLAY AT PR $=53$ (B)/FT - FT/SEC. THIS CONTANT is USED THROVHOUT THE FOlWWIW AWAITSII.? 
PAGE 8 OF 26 MAT 1962 ORH.

INITIAL ACCELERATION OF CORER UPON REIEAJE: (NEW DESIGN)

ASsume: ACrlled PRESUVE, $P_{A}=2000$. PSI

Diametea of piston, $D_{P}=3.50 \mathrm{ln}$ (Given)

3.80

Travel dastanle i $\mathrm{S}=2.0 \mathrm{in}$

WEIHHT OF COREa, $W_{C}=450$ is (GIVEN)

WEIstr of Watea, $W_{W}=77$ is (ES'D)

Vol. of Watien in coace , $V_{w}=1.20 \mathrm{~m}^{3}$

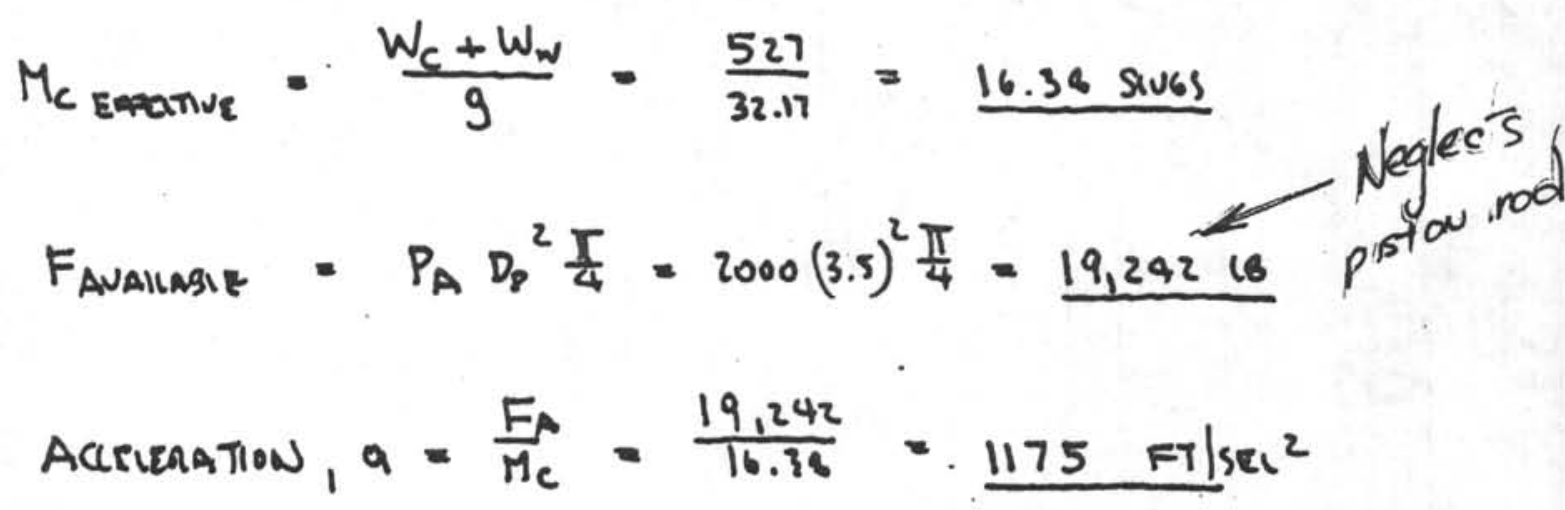

VElocity $\$ 2.0 \omega$ TRANEL, $V_{\text {MaX }}=a t$

Time,$t=\sqrt{\frac{25}{a}}=\sqrt{\frac{2(3)}{12(1175)}}=.021 \mathrm{sEC}$

$V_{\text {MAX }}=1175(.021)=24$ FT/J5C

Fow a 24 filsee vilociry: (Inside core limer)

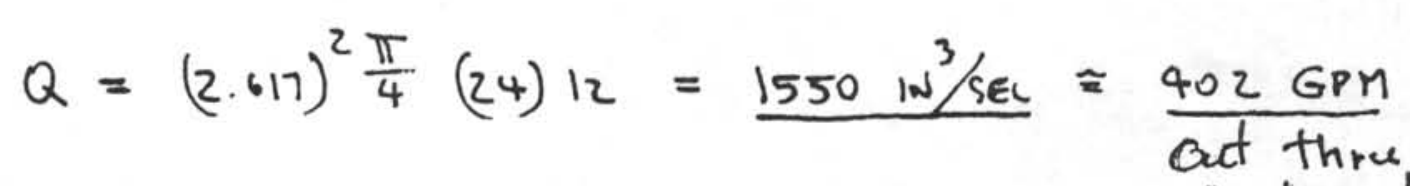
check valve 
PA GE 10 OF 26

MAT 1982

ORT.

PRESsURE DROP DUE TO ORIFICE DISCHARGE: (RE F...4)

$$
\cos )=\left(\frac{1}{c_{v}^{2}}-1\right) \frac{v^{2}}{2 g} \quad \text { Wrong! } \operatorname{loss}=\left(\frac{1}{c_{v}}-1\right)^{2} \frac{v^{2}}{2 g}
$$

LET: VELOCITy GEFFICIEUT, $C_{V}=.90$

B. 244

Dixchase coefacievt, $C=.61$

ORIFICE \#1:

stricter "Fluid Mech."

$\frac{V=Q / A}{\text { not, } V=\frac{Q}{A-C_{d}}}$

$$
\begin{aligned}
& V_{1}=\frac{1550}{(623)^{2} \frac{\pi}{4}(61)}=8282 \mathrm{in} / \mathrm{sec} . \\
& (01)=\left(\frac{1}{(.9)^{2}}-1\right) \frac{8282^{2}}{2(386)}-20,841 \mathrm{NN}=1737 \mathrm{FT} \\
& \Delta P_{1}(1 N \text { PSI })=\frac{1737 \times 69.15}{144} \quad=774 \text { PSI }
\end{aligned}
$$

ORIFICE \#2:

$$
\begin{aligned}
& \bar{v}_{2}=\frac{1550}{\left[2\left(.687^{2}\right) \frac{\pi}{4}+4\left(.438^{2}\right) \frac{\pi}{4}\right] .61}=1891 \mathrm{lw} / \mathrm{sec} \text { (AVRatab) } \\
& \text { loss }=\left(\frac{1}{(.9)^{2}}-1\right) \frac{1891^{2}}{2(386)}=1087 \mathrm{~N}=90.5 \mathrm{FT} \\
& \Delta P_{2}(1 \omega P S I)=\frac{90.5 \times 64.15}{144}=40 \text { PSI }
\end{aligned}
$$

$-79-$ 
PAbE II OE 26 MAY IQBL ORH.

ORIFICE \#3:

$$
\begin{aligned}
& V_{3}=\frac{1550}{\frac{\pi}{4}\left(3.625^{2}-3.50^{2}\right) .61}=3633 \mathrm{N1} / \mathrm{sec} \\
& \operatorname{los}=\left(\frac{1}{.92}-1\right) \frac{3633^{2}}{2(386)}-4,01010-334 F \\
& \Delta_{P_{3}}(10 \rho 5)=\frac{334 \times 64.15}{144}=149 \text { PSI }
\end{aligned}
$$

TOTAL PRESUURE RISE INSIDE CORER AT $t_{1}=.021$ SEL FROM INITIATIOW Afrer 3.0 in traver is:

$$
\Delta_{P_{\text {max }}}=\Delta_{P_{1}}+\Delta_{P_{2}}+\Delta_{P_{3}}=774+40+149=963 \text { PSI }
$$

AT THIS POINT THE AVAILAGIS DRIVE GORLE IS REOULED FROM $F_{\text {Avallarse }}(1)=19,242$ l8 $T_{0}:$

$$
F_{\text {Avalasse (2) }}=19,242-963\left(2.617^{2}\right)^{\frac{\pi}{4}} \approx 14,000 \text { (B) }
$$

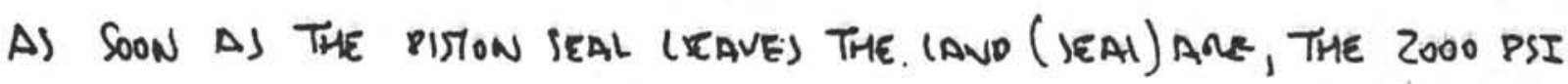

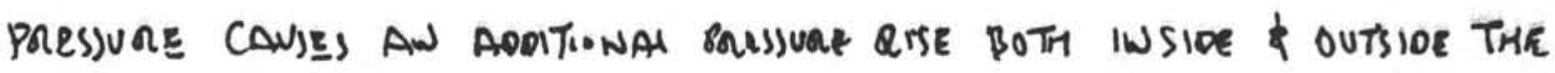
Codea of 2000 PII. AT TMIS time The AVAllagie mive Foeste will

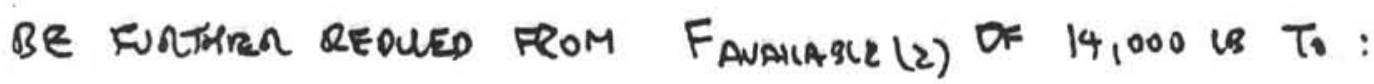

$$
F_{\text {avalasue }(3)}=19,242-(2000+967) 2.617^{2} \frac{\pi}{4}=3,30018
$$

$-80-$ 
PAGE 12 OF 26

MAT 1962

ORT.

ESTIMATED VELOCITY OF PENETRATION VS. STROKE :

(ASSUMINg PRESSURE IS MAINTAINED D 2000 PSI)

$$
\begin{aligned}
& \text { F nAVAl. }=F_{\text {REQ'D }} \\
& \text { FANtI. }=19,242-\left[2000+963 \frac{v^{2}}{24^{2}}\right] 2.617^{2} \frac{\pi}{4} \\
& \text { FrEQ'D }=53 P \mathrm{~V}
\end{aligned}
$$

Thus: $\quad 19,242-\left[2000+963 \frac{V^{2}}{24^{2}}\right]^{1} 2.617^{2} \frac{\pi}{4}=53 \mathrm{PV}$

THIS REDVES To: $\quad-V^{2}-5.89 P V+943.43=0$

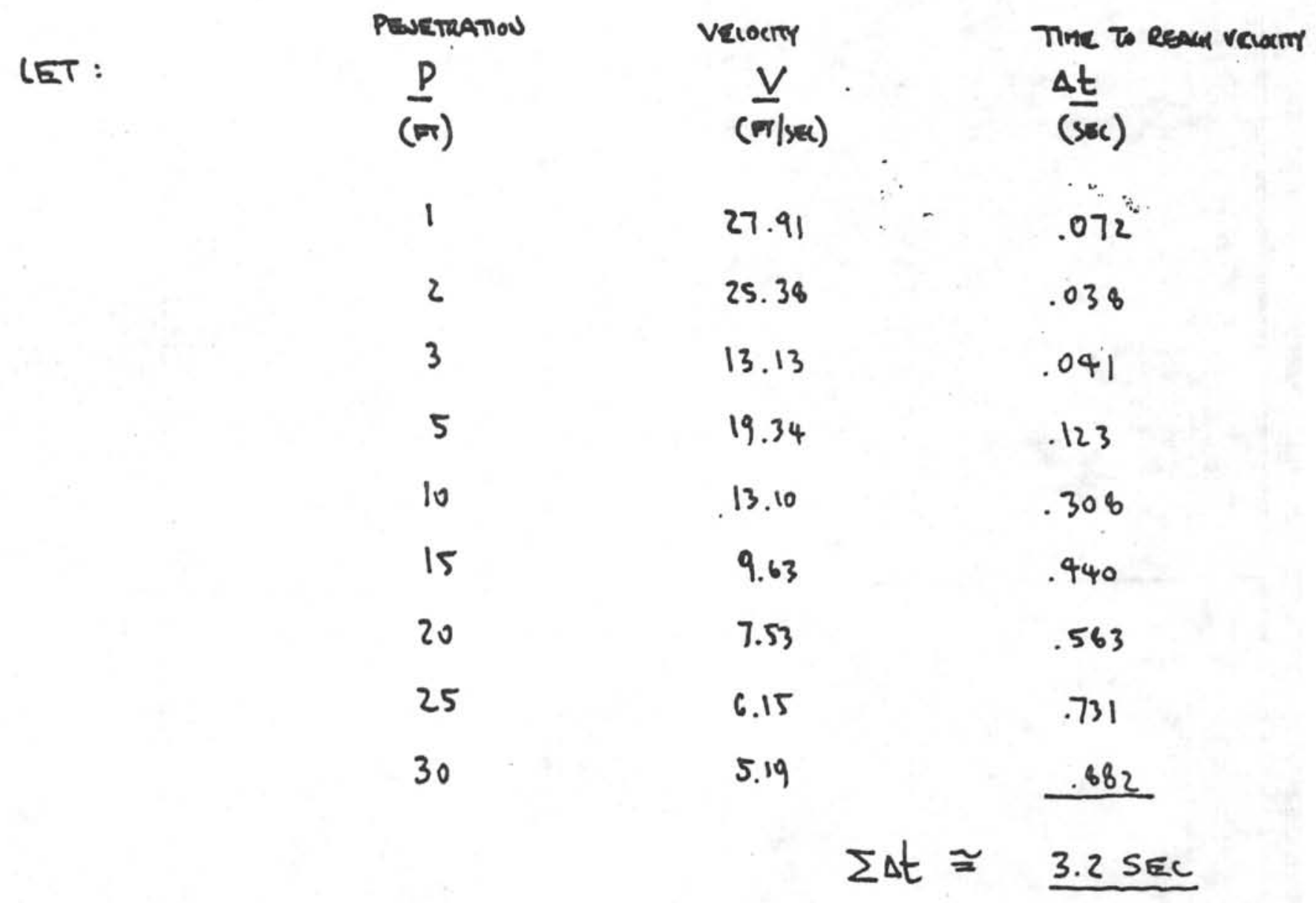

THIS IS PIOTIEO ON THE FOLlOWING PADE:

$$
-81-
$$


FIGURE - 4 .

EST'D. VELOCITY VS. PENETRATION

NEW CORER DESIGN

WITH SEAL IN LOCAL AREA ONLY

Assuming CONJTANT presivar of

2000 PSI IS MAINTAINED OVER

FOU STROKE.

(1500 m DEOTH, MEDIUM CIAY)
PAGE, 13 OF 26 MAY 1982 . OCH. 
STORED ENERGY DUE TO COMPRESSION OF WATER AND EXPANSION OF PIPE IN $1500 \mathrm{~m}$ CONG PIPE STRING:

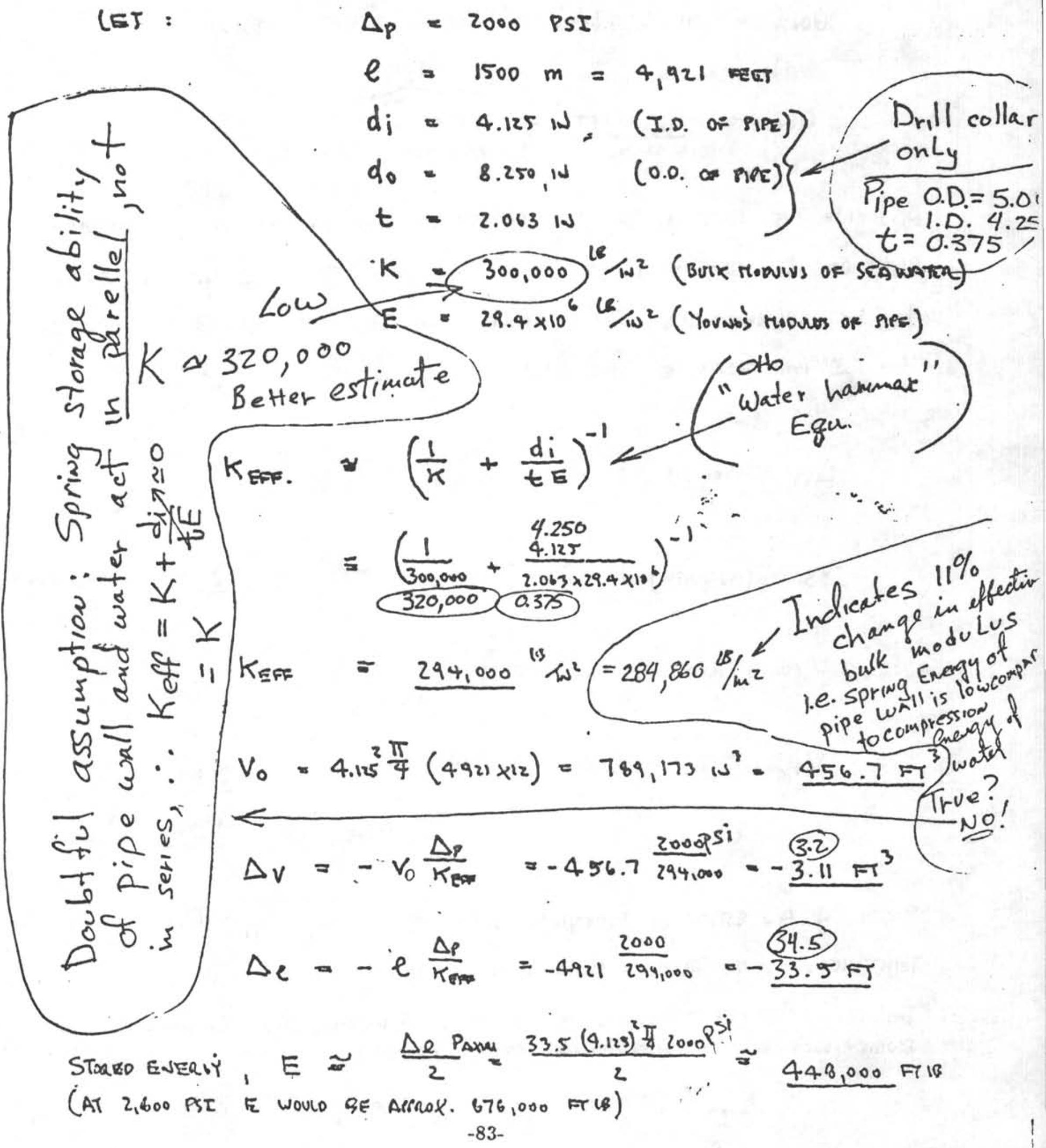


FLOW THROUGH ORIFICE \#3:

(ఏ Z2000 DSI CONTRNT PRESURE, $t_{2}=3.2 \mathrm{SEC}$ )

$$
\begin{aligned}
& \text { QaUT = CA } \sqrt{2 g \frac{\Delta P}{W}}\left(t_{2}\right) \text { (NEGCECTINV VELOCITY OF APPAOACM) } \\
& \text { Q OUT }=.61 \frac{\pi}{4}\left(3.625^{2}-3.5^{2}\right) \sqrt{2(386) \frac{2000}{68.15 / 1728}} \quad(3.20)
\end{aligned}
$$

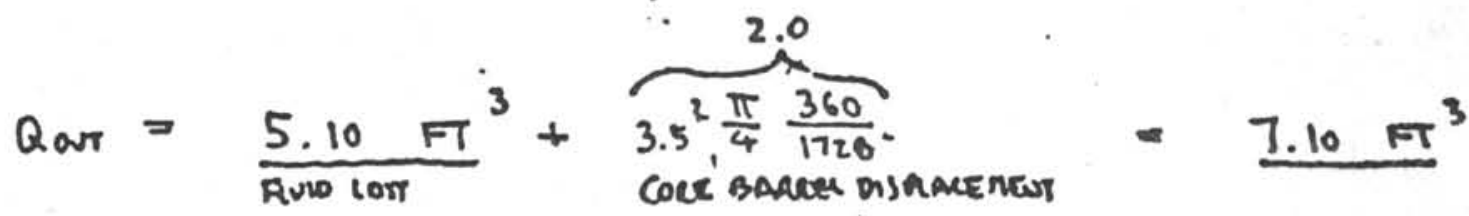

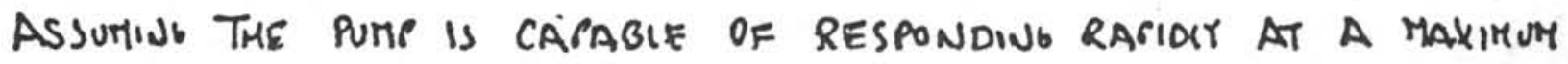
RATE OF $600 \mathrm{GPH}=1.337$ FT3/JES Q 1600 T. 2000 PST EAESJUAE AFTER

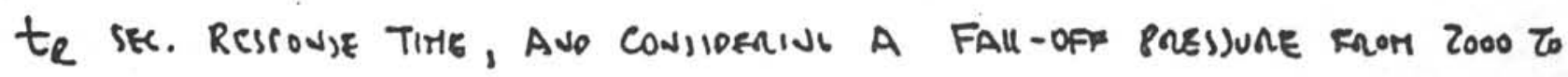
1600 PII is aclectabie, The avallagle volume is over $t_{1}=3.2$ ecoubs:

$$
\begin{aligned}
& \Delta_{V_{1}} \text { D1600 PIT }=-456.7 \frac{1600}{291 \%, 000}=2.80 \mathrm{FT}^{3}
\end{aligned}
$$

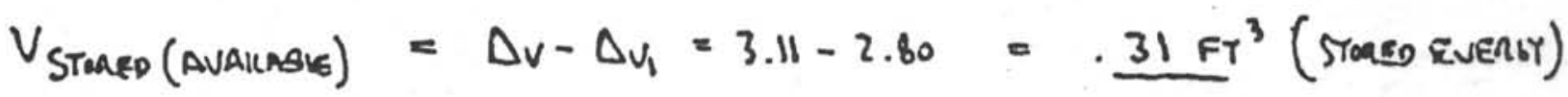

$$
\begin{aligned}
& V(\text { Enon coner })=\frac{\left(2.617^{2} \frac{\pi}{4}\right) 360}{1724} . \quad=1.125^{3} \\
& V_{\text {PUMP }} \quad-\frac{600}{60}\left(\frac{231}{1728}\right)(3.2-1.1)=2.81 \mathrm{kT}^{3} \\
& \sum \text { V VVAIL }=4.24 \mathrm{FT}^{3}
\end{aligned}
$$

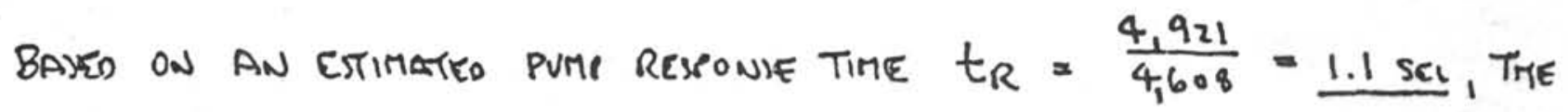

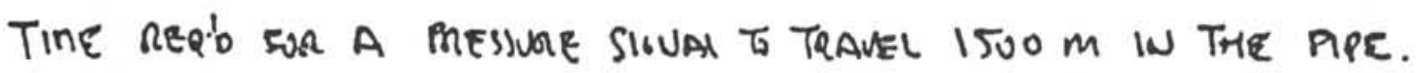

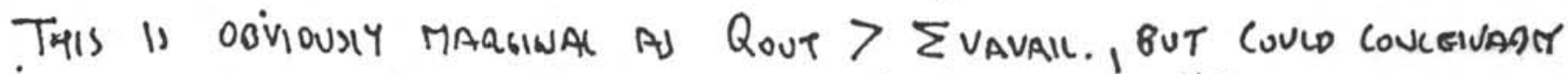
wonk with A some WhaY HIGMER SYJTEM pressure.

$-84-$ 


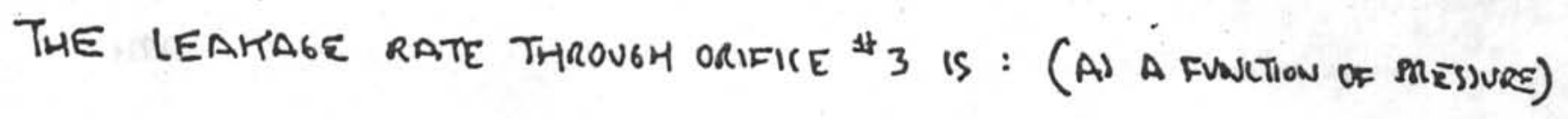

$$
Q_{\text {OUT }}=.036 \sqrt{P} \quad \text { (FI'/SGC) For } P \text { (PSI) }
$$

Also: $Q_{\text {pune }}=1.3377^{\text {FT/ }}$ ser max.

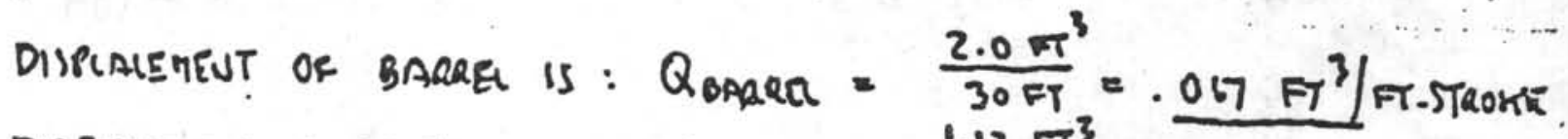

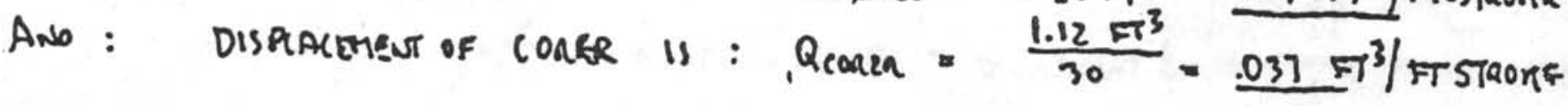

$$
\text { NET DISBLALEMEN OF BARREL - CORR }=.030 \mathrm{FT}^{3} / \text { FT OF STROKE }
$$

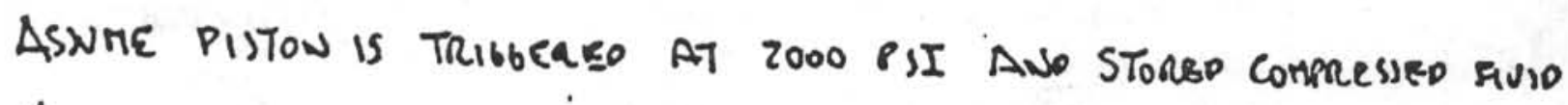
Vourtz is ereaszo so that $V_{A V}=2.0 \mathrm{~F}^{3}$.

Prosnar then falls off to:

$$
P_{2}=\frac{3.11-2.0}{456.7} 294.000 \approx 715 \text { PSI }
$$

The ESTIMATED TIME For THE FAll OFE, FRoM $P_{1}=2000$ 8 SI To $P_{2}=715$ PSI IS THEN:

$$
\begin{aligned}
t \cong\left[\frac{\frac{456.7}{294.000}}{.036}-.030\right] \sqrt{2000}-\sqrt{715} & =.24 \mathrm{SEC} \\
t & =\text { AdJusted } .5 \mathrm{sEC}
\end{aligned}
$$

LET

$$
\begin{aligned}
& \bar{v}=1 \mathrm{FT} / \mathrm{SEC} \quad \mid S=\nabla t=.5 \mathrm{FT} \\
& \dot{t} \equiv\left(\frac{456,7}{\frac{197000}{.076}}-.015\right) \sqrt{2000}-\sqrt{115} \geqslant .50 \mathrm{SEC}(\mathrm{OK}) \cdots
\end{aligned}
$$


PALE 17 OE 26

MAY 1982

ORA.

AT THIS TIME THE STORED ENERGY IS EXHAUSTED!

AFTER I.I SEC. THE PUMK BEGINS TO RESPONO AND HORERUIT THE PRESsURE IS 5 TIL 715 PSI.

is.

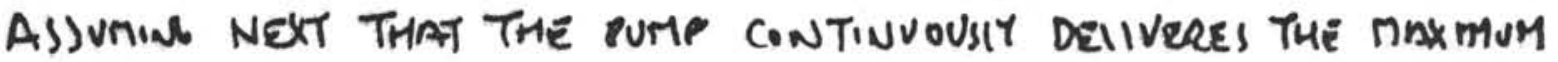

Flow OF 600.68M D 715 PSI THE FORCE BALANcE GE COMES:

$$
F_{\text {AVAILABLE }}=6679-\left[715+963 \frac{v^{2}}{24^{2}}\right] 2.617^{2} \frac{\pi}{4}=F_{\text {READ }}=53 \mathrm{PV}
$$

REakius To: $-V^{2}-5.89 P V+337.4=0$

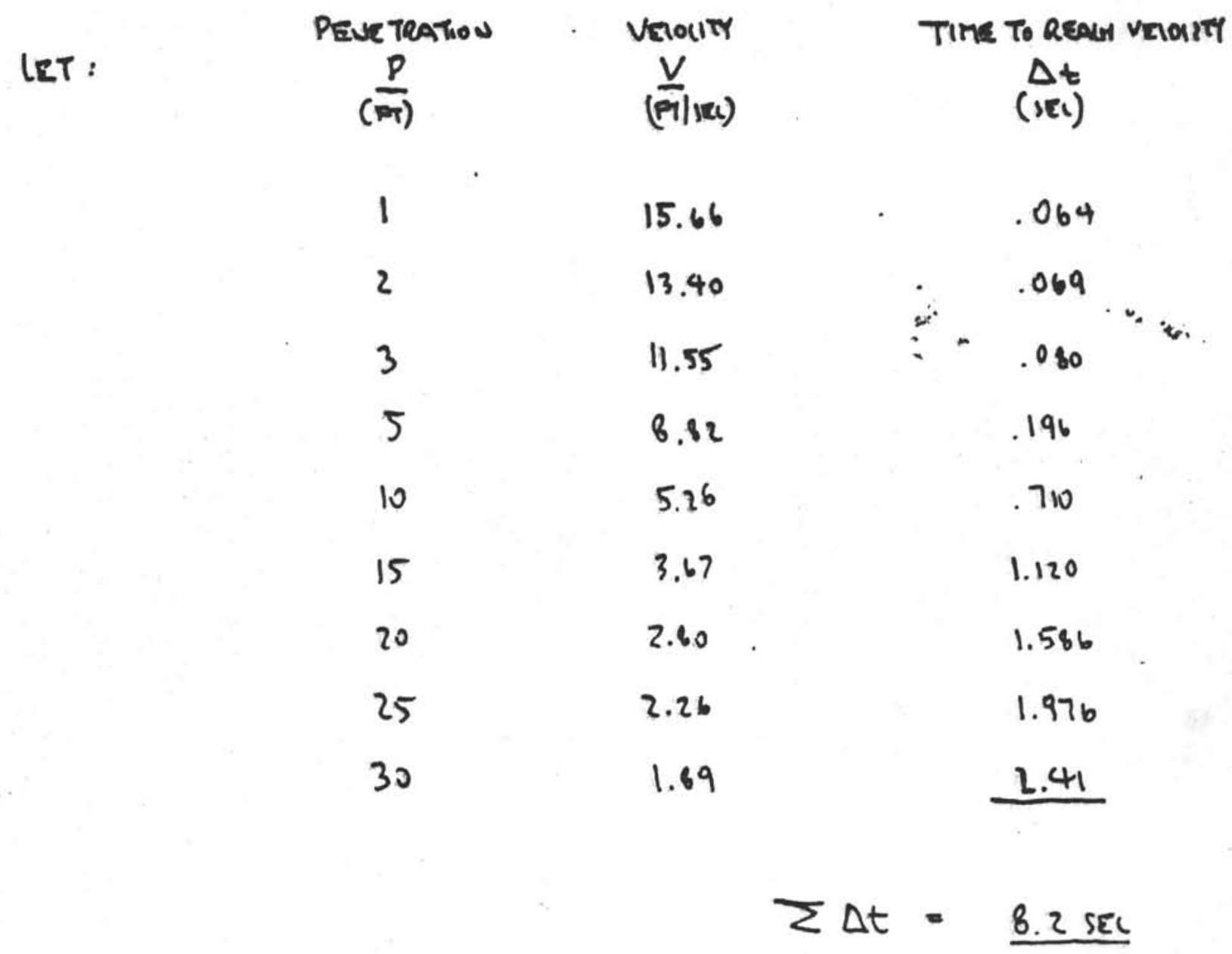

THIS 11 ROTTED ON THE FOIIOWIWG PALE, FIG. -5 -

$-86-$ 
FIGURE -5-

EST'D VELOCITY VS. PENETRATION
PAGE 18 , OF 26 MAY 1982 ORH.

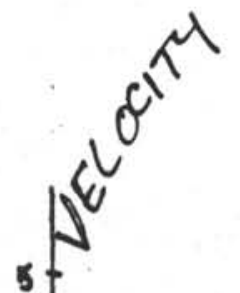

5

29.0
CAICULATED, AS)UMING Zeno Resisfaves

ว

х)

Putre BEGINS TO RESCONO AFTER I/I SELONO $=t_{R}$.
NEW CORER DESIGN

WITH SEAL IJ IOCAM AREAONIY

AsJuTING COWSTANT PRESSURE OF

7I5 PSI CAN BE MAINTANETO

BY PUMP OVER FULL STROKE.

(1500 m DEfTH, MEQIUN CLAY)

15.7

15

\section{7}

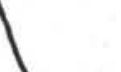

STored EN RrbY

USED, PRCSSURE HAS

DROPEE FROM 2000 PSI

To 715 PSI, DISChaqGed

tr.

$\cdots+1$

$t_{\text {Smoke }}=8.2 \mathrm{seC}+1.1 \mathrm{Sec}$ ONOS $\approx 9.3 \mathrm{sEC}$. To TAL

$\Delta_{P}=715$ PSI CONITANT

VOLUME $=2.0 \mathrm{FT}^{3}$ 
ORA

TABLE OF COMPARISON

(VAC) ${ }^{\text {OLD DELOS }}{ }^{*} \quad \frac{\text { NEW CONCEPT }}{\text { SHOOT OFF }}$

EFFECTIVE PISTON AREA

AVAILABLE FORCE D 2000 PSI

DSPLACEO CORE BARREL VOlUME

$\triangle P$ RE IN BARRy D Z000 PST

$\Delta P$ PRESUME RISE ON TOP OF CORE

EST'D PRES). FAllOFF Q $2000 \mathrm{pIC}$

ETH RUSH FLOW @ HEAD @ZR OO PSI (FT')
5.29

10,600

$\left(N^{3}\right)$

(PSI)

(PSI)

(PSI)

.91
4.24 ( after broken)

8,500

1,936

2,963

2,963

$200+$

$5.1+$

SUMMARY

THE NEW CORER CONCEPT WILL ONLY MARGINAlLY WORK AT $1500 \mathrm{~m}$ DEPTH, AND MEOIUM(CLAY) SOIL IF SEAL ARE ONLY VIED TO SHOOT OF THE TOOL,

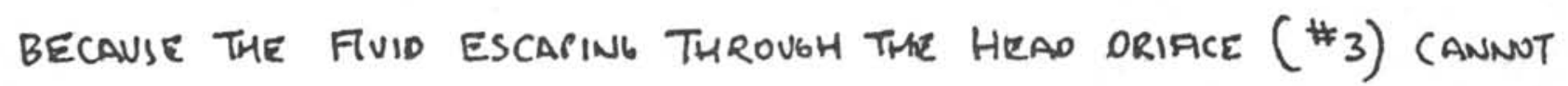
BE RERLENISHED BY THE PUMP FAST ENOUGH. TO AJMer ONE CONTINUOJS $30 \mathrm{FT}$ STROKE. IN ADDITION, THE FOllOWING DISADVANTALES ARE INHERENT WITH THIS CONCET CoMPared to The "BAJE design" :

- Tor of the cons would be subjeited To higH

Presume water interface Which coup cause

partial avidization In this area.

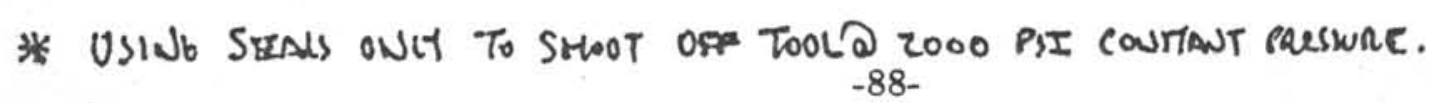


UKH.

IN ADDITION, THE CORE WOUID bE AXIASIY COMPRENIE BY THIS RRESURE UP TO 3000 PSI (DRE MORE)

- the ruid pres)ure actisg on the core during the InITIAI INSEATION WIII MOST (IKEEY FuSH AWAT A PANCT Of This paea so That the useful levith of THe cone samme WIII B.E DECREAJED BY SOTE AMANT.

- the fluid flow escarivi through oqlfice \#3 of $5.1+F^{3}$. WOUD WASH. OUT A SIZEABIE VOIUTE OF Soll in THE INTERFACE AREA, WHICH. MaT OR MAY WOT AfFET THE cose SAMPE.

These disadvantages In meaeut with the "Shout off" prinkirle/

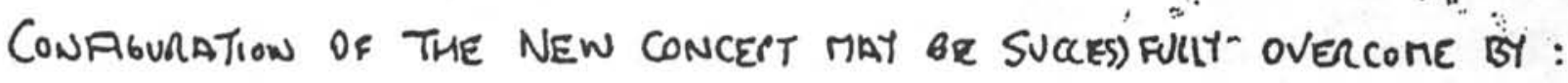

1. USING THE TOP SUB bODY SEALS THRONGHOUT THE STROUTE, WHICH WOULO DECREAIE THE POTENTILL $\Delta P$ RISE IN THE CORE BARREL FROM 23000 PSI TO AROUND BOO PSI WITH CORRESBONOIJG DECREATE IN FIVID OUTFIOW From $5.1+F^{3} T^{3}$ ABOUT $2.6 \mathrm{FT}^{3}$ WHICH WOVIO THEN Easar be MaAe ve by the pume So That PEnETRATION IN ONE SINGLE STROME CAN BR ACOOMOISHEO.

2. enlarbal onifice areas \#, \& \#3 so That The - Combineo pressune dros in threse areas would be reovled

$-89-$ 


$$
\begin{aligned}
& \text { PAEE } 21 \text { OF } 26 \\
& \text { MAY } 1962 \\
& \text { ORH. }
\end{aligned}
$$

To AOUUT 400 PSI WITH FURTHER RENLTIOW IN OUTFIOW THROUGH ORIACE \#3 TO ASOUT $1.9 \mathrm{FT}^{3}$ OVER THE 3.2 selonos IT TAKES To ACHIEVE A $30 \mathrm{FT}$. STROKE.

3. IF THE cone can be subjeited to an axial loado gut must

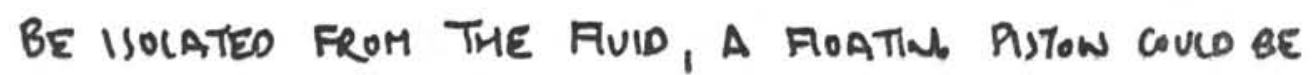
- NTrodved as a sollo barier to slide wifhin the core LINER.

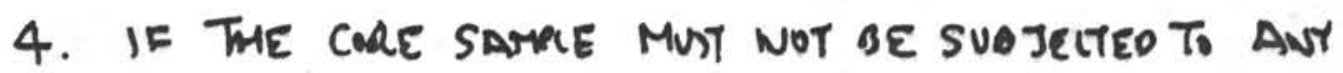

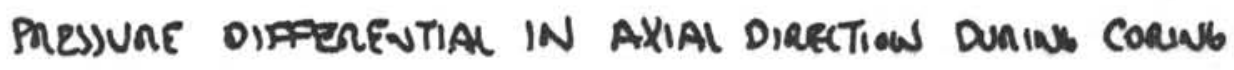
ORERATION, A PISTOW/ROD As) MIGIY MAY BE INCORPORATED IW The desion Whilh wald tenetrate THrongh the coner sub.

A peasible mechanical arranbetent capage of "achievini Ail or The above is SHown on the pollowidg pabe (FI6.6) of THII EsalUative RENORT.

$-90-$ 


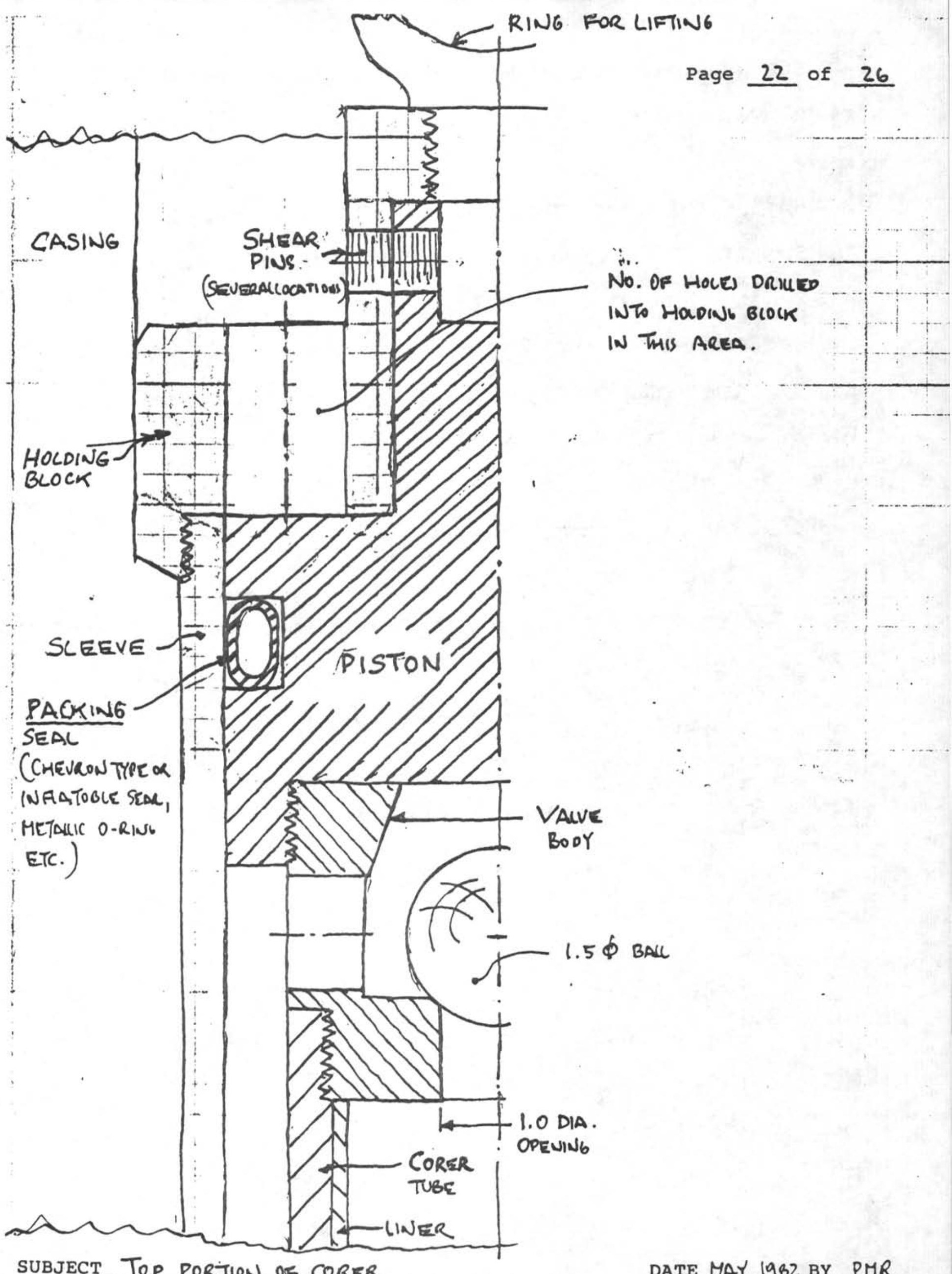


UNH.

THE SCENARIO FOR OPERATION WTH A FULU STROKTE PISTON SEAL ARRANGEHENT WIII BE QUITE OIEFERTAT FROM THE "SHOOT OFF" CONIEPT. $\because$.

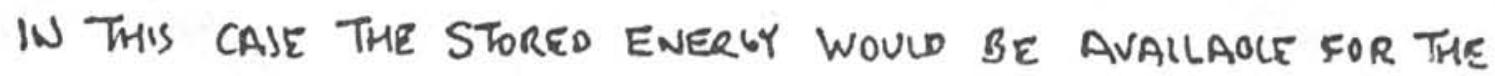
FUll STROKING OF THE CORER SINCE NO FUUD FROM THIS SOURLE WOMD

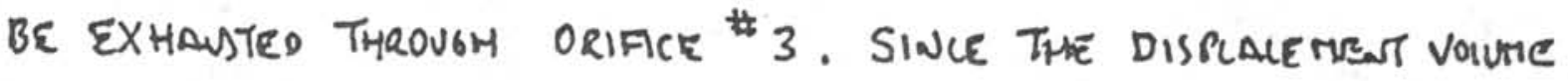
OF THE BARgE IS. $2.0 \mathrm{FT}^{3}$ D $3.5 \mathrm{~N}$ PISTON DIA. ANO 30 PT STROAK ANo THE TOTAS VOIUME OF THE STOREO, PUID IN THE $1500 \mathrm{~m}$ lons STRING is $\Delta_{v}=3.11 \mathrm{FT}^{3}$ The snessune would Deor Fror 2000 PII To:

$$
P_{2}=\frac{3.11-2.0}{456.7} 294,000=715 \text { PSI }
$$

From the stant to The sead of The 30 Er. STrorke. Thed:

$$
F_{\text {AVAII }}=\left(2000-\frac{2000-715}{30}\right) 3.5^{2} \frac{\pi}{4}-400\left(2.67^{2}\right) \frac{\pi}{4} \frac{V^{2}}{24^{2}}=53.8 \mathrm{~V}
$$

Regurlas To: $-V^{2}-14.19 P V+5151.34-110.3 P=0$

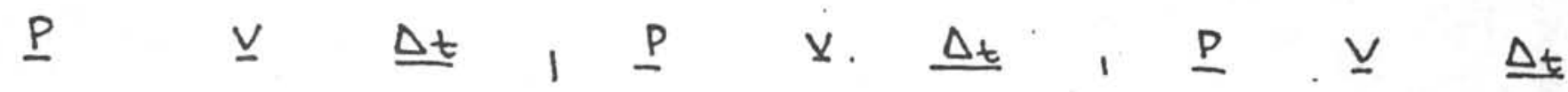

$\begin{array}{lllllllll}.25 & 69.63 & .007 & 5.0 & 41.07 & .023 & 20.0 & 10.02 & .223 \\ .50 & 67.93 & .004 & 7.5 & 31.36 & .069 & 22.5 & 8.15 & .275 \\ 1.0 & 64.26 & .008 & 10.0 & 24.35 & .090 & 25.0 & 6.62 & .339 \\ 2.0 & 57.45 & .016 & 12.5 & 19.19 & .115 & 27.5 & 5.35 & .416 \\ 3.0 & 51.33 & .018 & 15.0 & 15.37 & .145 & 30.0 & 4.29 & .519 \\ 4.0 & 45.69 & .021 & 17.5 . & 12.36 & .181 & \sum \Delta t & & \\ & & & -92 . & & & & & \end{array}$


ORH.

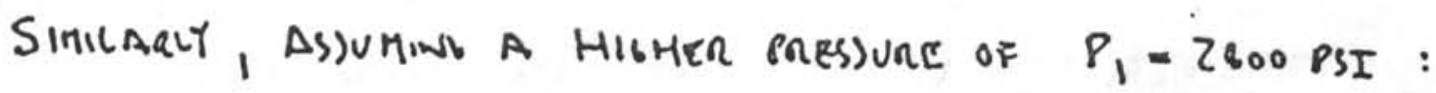

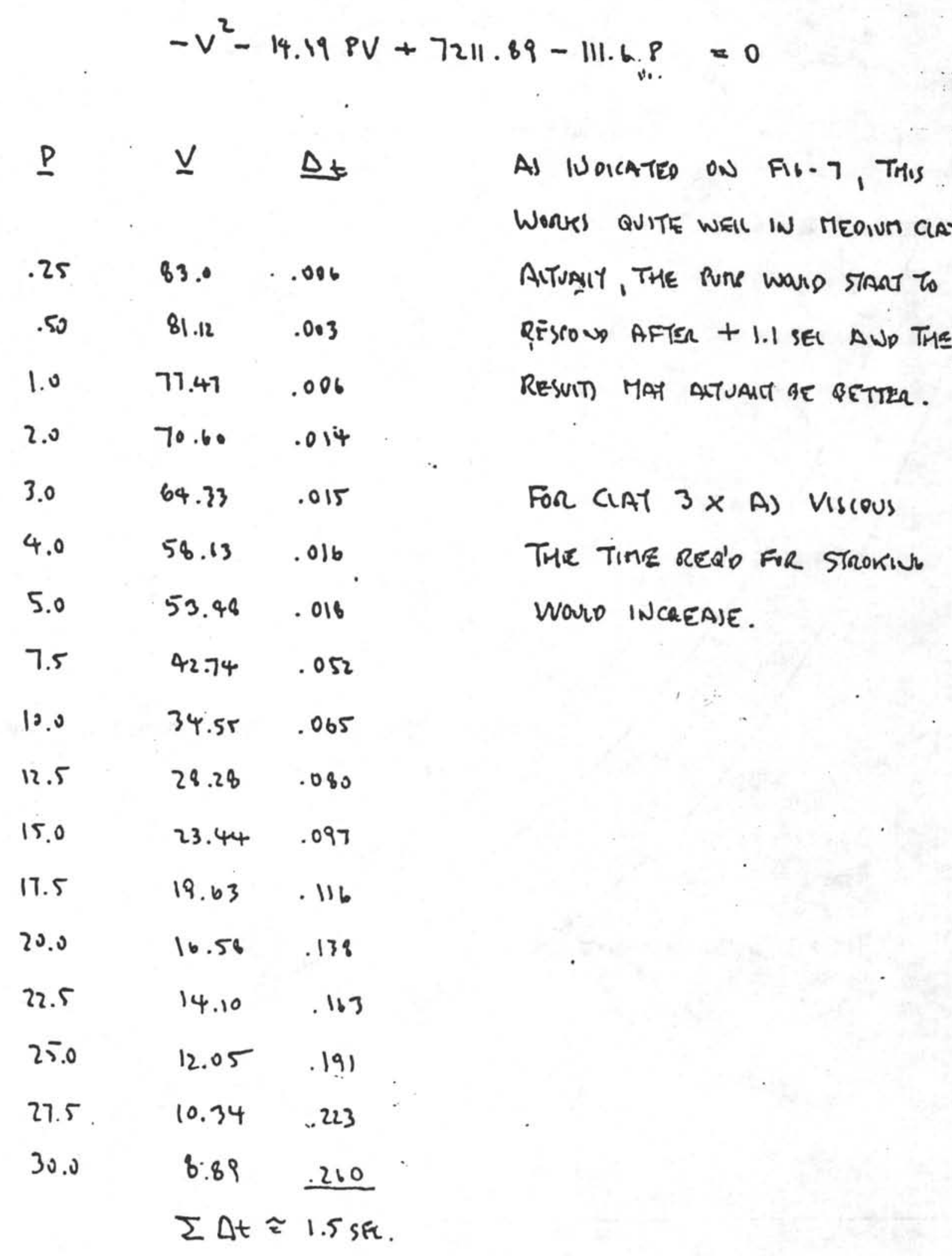

The resuits are rotted on the followin. Pabe, F16.-7$-93-$ 
FIGURE - 7 -

EST'D. VELOCITY VS. PENETRATION

NEW CORER DESIGN

WITH CONTINUOUS SEAL

(1500 m DEPTH, MEOIUH CIAY)
PAGE 25 of 26

MAT 1962 ORT.

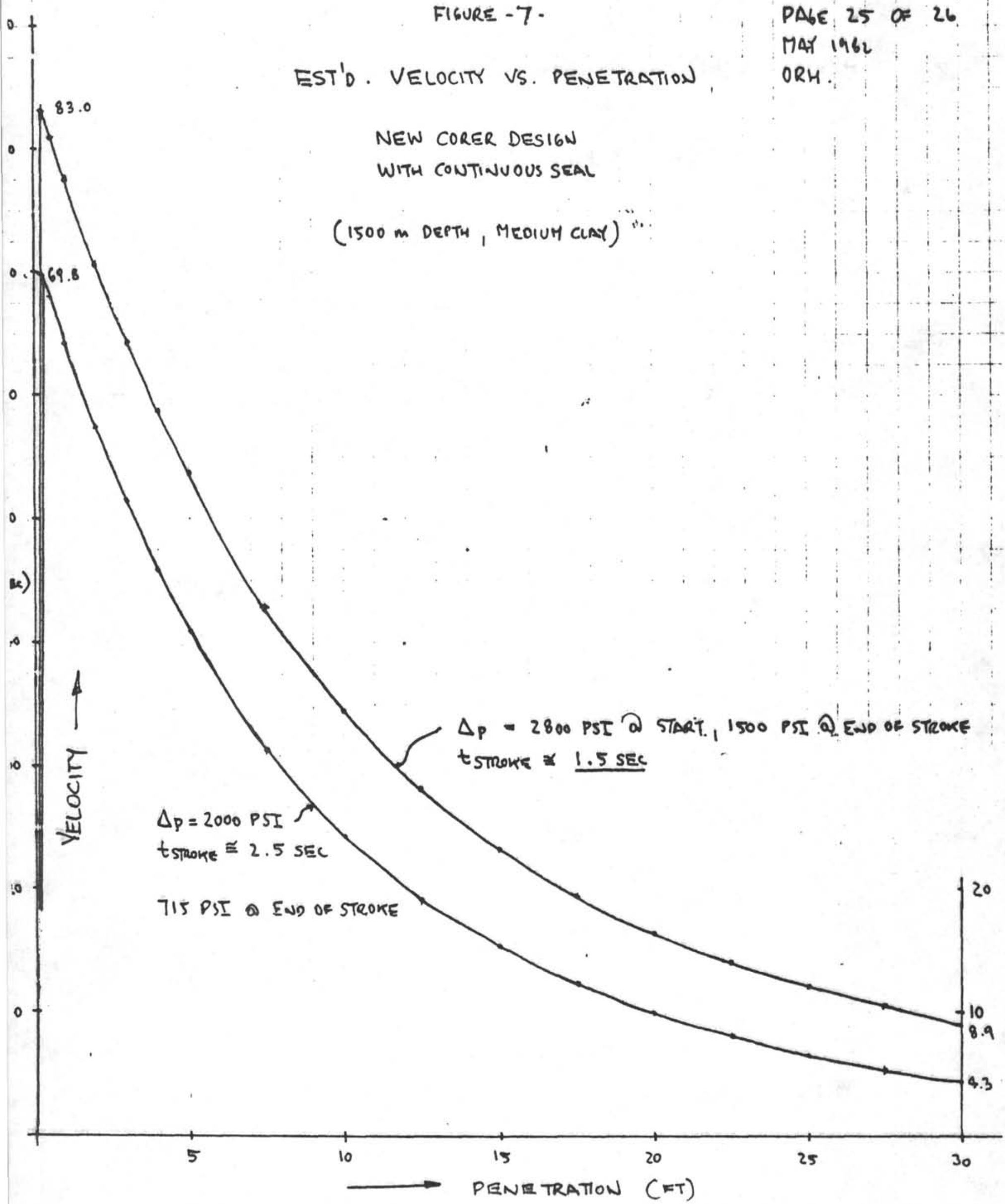

$-94-$ 


$$
\begin{aligned}
& \text { PAGE } 26 \text { OF } 26 \\
& \text { MAY } 1962 \\
& \text { ORT. }
\end{aligned}
$$

CONCLUSION.

The "COntinuous seal" corer concept should Function as well $\propto$ better than the present core in as much as more fore is ismail

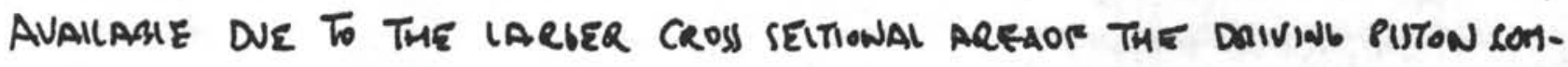
PARED WITH THE EXITING UNIT.

THE "SHOOT OFF" TYPE CORER CONCEPT MAI WORK REAJOWAGH WEI IN

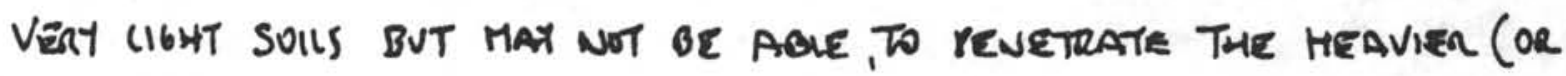

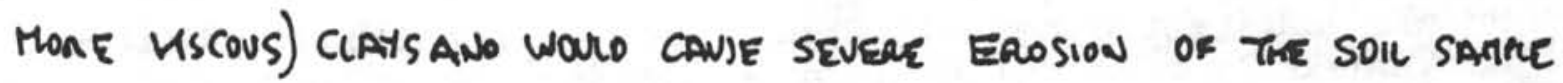
Near the Top of THe corer.

$-95-$ 


\section{JOHN E. HALKYARD \& COMPANY}

Consultants in Engineering and Business Development

Specializing in Mechanical Systems, Hydraulics and Ocean Engineering

May 27, 1982

Mr. Dave Huey

Deep Sea Drilling Project, A-031

University of California

Scripps Institution of Oceanography

La Jolla, California 92037

Dear Dave:

We are submitting herewith our report, "Feasibility Analysis of Vented Core Barrel Conceptual Design" performed as per your Statement of Work dated April 27, 1982. Please note from the report that our analysis is favorable for continuation of work on concept (a), using the Top Sub Body seals throughout the stroke.

Specifically we recommend the tasks outlined in our recommendations which would be carried out in sequence.

Accordingly, we propose that recommendations \#1 through \#4 be performed as separate tasks. We estimate that Task \#1 would be of the same magnitude as the one we have just completed, both in cost and time requirements.

Decisions as to the performance and costs of Tasks \#2 through \#4 could be made upon completion of Task \#1.

We found work on the project to be very interesting and look forward to assisting you in the performance of other specific tasks.

Sincerely yours,

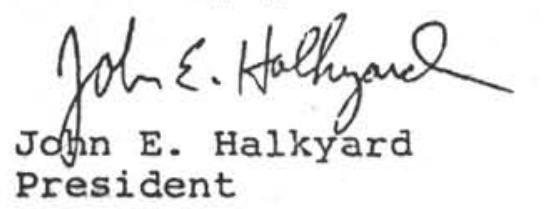

$\mathrm{JEH} / \mathrm{vdw}$

Enclosure 
APPENDIX B

PISTON ROD FAILURE REPORT

$-97-$ 
January 25, 1984

David P. Huey

Deep Sea Drilling Project

Scripps Institute of Oceanography

$U$. of Ca-San Diego,

LaJolla, Ca., 92093

Dear Mr. Huey,

Presented herein is Battelle's report on the project to analyze the failure of a 15-5PH stainless steel piston rod on a core-sampler, and recommend measures to prevent recurrance.

\section{SUMMARY}

The rod failed by simple overstress in pure torsion. Such a failure might recur if galling of the threads forces those assembling the tool to overtorque the rod in order to bottom out the threads. The rod material was as hard and tough as expected, and failed in an entirely ductile manner; 15-5PH is a good choice for this application. Measures to prevent recurrence should include the application of either copper plating or commercial oilfield tubing-connection lubricants during make-up. If electrolytic copper plating is used, the rods should be "baked" at 375-400 F for 4 hours to prevent the possibility of hydrogen embrittlement.

INTRODUCTION

The Deep Sea Drilling Project staff designed an Advanced Piston Corer (APC) for sediment sampling during DSDP's oceanographic studies. This core sampler is withdrawn with three 11-foot long sections of 1.52 inch diameter 15-5 PH stainless steel rod (HIO25 condition) threaded together at 1-1/8-8 Stub Acme threaded connections. During field trials the piston rod failed after three core-samples had been withdrawn, one at 100,000 lbs tensile load, one at 20,000 lbs load, and the last at 40,000 lbs load.

This failure occurred well below the expected minimum tensile strength of the pin, which was calculated as 139,000 pounds. Full-scale laboratory tests of box-and-pin connections failed at an average of 177,800 lbs. The failed rod was sent to Battelle Petroleum Technology Center for analysis. 
David P. Huey

Scripps Institute of Oceanography

January 25, 1984

\section{EXPERIMENTAL PROCEDURE AND RESULTS}

The failure was located near the root of the pin in the intermediate connector. The fracture surface was relatively flat along its outer edge, with a rougher, grey, textured appearance in the center. By contrast, the laboratory full-scale fractures showed a distinct cup-and-cone formation typical of tensile overload failures, with the rough grey appearance covering the entire fracture surface.

Examination of the field fracture under the scanning electron microscope showed that the flat, smooth zone around the outer edge of the fracture consisted of elongated shear dimples, while the rough grey zone in the center showed the more equiaxed dimples indicative of tensile overload.

A section was taken through the failed rod and polished for metallographic examination. The structure was normal for 15-5PH (HI025) stainless steel, consisting entirely of quenched and tempered martensite. The fracture profile was nondescript, with no evidence of stress-corrosion cracking or hydrogen embrittlement. Micro-hardness measurements averaged $427 \mathrm{KHN}_{500 \mathrm{~g}}$ near the fracture surface. This is equivalent to approximately Rockweilg $\mathrm{C} 39$. Significant plastic flow was observed on the threads, indicating that they had been overstressed during make-up.

DISCUSSION

The shiny, flat appearance of the fracture, its orientation, and the shear dimples observed around its outer edge are all indicative of a ductile overload failure in pure torsion. Since the final fracture was by ductile rupture in tension, the rod was apparently stressed past yield in torsion before the tensile loads of core-sampling were applied.

The core sampler is not subjected to torstonal inads in service. Applied loads are purely tensile, and any unexpected additional torsion in service (from, for example, sticking of the rod in its tube) would produce a mixedmode fracture rather than pure torsional overload.

Therefore the only known source of pure torsional stress is the make-up torque.

The specified make-up torque of the rod is $400 \mathrm{ft}$-lbs. This would produce a calculated shear stress of 24,000 psi. Even allowing for a stress concentration factor of 2.6 at the thread, the resulting stress should have been well below the estimated $107 \mathrm{ksi}$ torsional yield strength of the material.

Even relatively hard stainless steels such as 15-5PH (H1025) are prone to galling during machining and assembly. If the threads on the rod had galled 
during make-up before the pin bottomed out in the box, the connection might have been overtorqued in an attempt to free the threads and run the connection together completely.

To prevent galling, the threads must either have a significant hardness difference (greater than ten Rockwell C points) between the contact surfaces, or they must be lubricated with anti-seize compounds. The "Baker-Lok" thread locking compound was thought to provide some lubrication, but it might not be adequate at high contact stresses.

The most common way to achieve a large hardness difference between surfaces without sacrificing strength in the rod body is by plating either the box or the pin (but not both) with a soft material such as copper, silver or tin. This is an effective anti-galling measure. If the plating is electrolytic, the plated zone should be baked at 400 degrees for approximately four (4) hours to drive off hydrogen absorbed by the steel in the plating process.

There are a number of commercial anti-seize compounds used to make up tubing and casing conections in the oil patch. Provided they are zinc-free, any of these compounds should be useful in preventing galling of the rod threads. Anti-seize compounds specifically made for drill pipe connections should not be used, since these can release hydrogen in long-term static applications.

CONCLUSIONS

1) The rod failed by simple overstress in pure torsion.

2) The rod material met the strength and toughness required in the specifications.

3) The only known source of torsional stress occurs during assembly, and operates only if the rod is torqued well beyond the specified $400 \mathrm{ft}$ lbs with the threads either bottomed out or frozen by galling.

4) Galling of the threads is suspected based on damage observed on metallographic examination.

5) Recurrence can be prevented by careful monitoring of applied torque during make-up, and by either plating one set of threads or applying oil-field tubing connection anti-seize compounds to the threads before make-up.

We enjoyed working with DSDP again. If there are any questions on this report, please call or write. Thank you for calling Battelle.

Best regards,

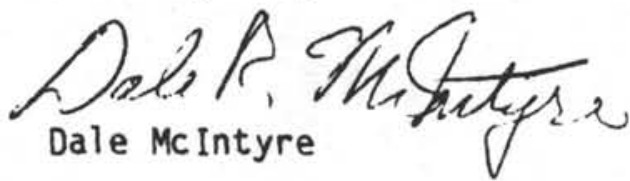

$\mathrm{DRM} / \mathrm{pjm}$ 
APPENDIX C

PISTON CORER PERFORMANCE COMPUTER PROGRAM 
PRJGRAM IPC

..... THIS PFOgRAM PREDICTS THE PEREORMANCE OF THE MDVANCED

FISTCN CORER. WHEN FJRMITIJN CORINJ RESISTANCE IS LERO

IT PREDICTS WATER CJEE PERFOR AAICE. GIVIA A SYEAR

VALUE F.JR A SEDIMENT, PER ORMANZE IS CALCULATED WHICH

WILL REPEZSENT A POSSIRLE EEHAVICZ FCR AN IJEALIZED

SEDIMENT HAVING THAT SHEAR STRENGTH. (THESE VALUES

*... Shoulo be intépreteg heth eajtion.)

THE PROjRAM CALCULATES INSTANTAVEJUS VALUES FDR VELOCITY, ACCELERATIUV, ELAPSED TIME, ORIVIUG FOFEE AGAENST THE

MIIN JEALS, PETARJING FUREES INCLUCING JACK PRESSURE FORCE

OF THE VEVT $I D$ FLUIO, $5 K: N$ FRICTION ORIG $\triangle$ VO BLUFF BUDY

DRAOA AND NET-CRIVING-FORCE ACTING TO ACCELERATE THE-

SCOPING SECTIJN OF THE TCOL.

THEJE-VAFIAZLEJ ARE EVALUATED OVEZ SHJRT INTERVALS OFF -

STROK OUER WHICH ACCELERATION IS ASSUMEC CONSTANT.

VALUES ARE TAJULATEO AT SELECTEJ POINTS ALONG THE STROKE.

SEAL JRAG IS TAKEN AS A CONSTANT SUY (STATIC Z OYVAMIC)

FOR ALL SEALS.

DRIVIUG PRESSURE IS INITIALLY INPUT AT THE ANTICIPATEO

SHOJT-OFF PIESSURE FOR THE NUYOER OF SHEAR PINS UJEJ.

AJ THE TOUL STRDKES, TRIVIN: DRESSURE OECIEASES AT THE

ORIVING FLUID TAKES A PRESSURE JKJP AIPOSS THE DULLING

$N \equiv C K / L A N O I N$ O SHJULOER ENROUTE TO THE YAIN SEALS.

*

-

IMPLICII LOGICIL $(A-Z)$

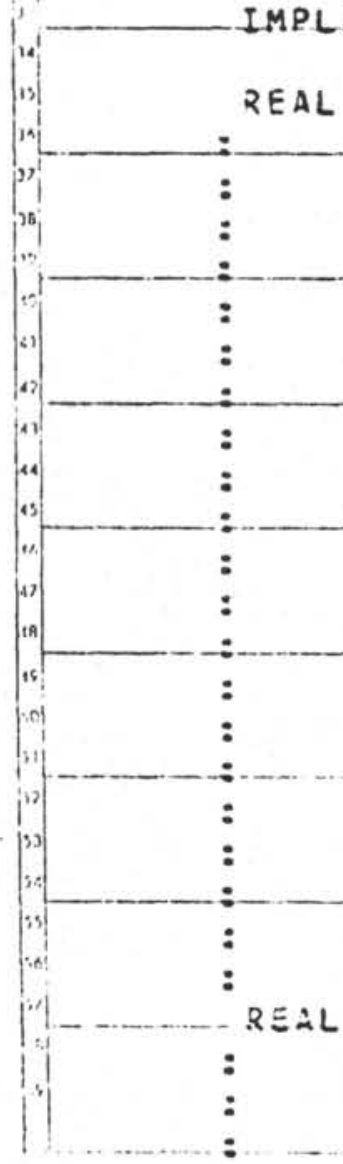

PRESS, ! (P)PRESSURE (PSI)

A.REA_, I (A.LENI ORICICETCTAL AREA (SQ INA)

$\triangle R E+1$, !

LINCR, ! (L INCR) INCKENENTIL STPOKE DISTANCE (FT)

DRAGS, ? (F_SLSEAL DRAG FORCE (LJF)

DRAJSF, ! (F SED) SKIN FRILTION ORAG (LZF)

WEIGHT, ! (W) WEIGHT CF SCJPING COAPONENTS(LOS)

QRAJE = ! (F_ESO) ELUFF JOUY CRAG(LEE)

BACKP, ! $(\bar{r}=)$ EACKFRESSIJRE FORCE OF VENTEJ FLUIO(LBF)

STRUKE, ! (L)LENGTH UF STRJK E (FT)

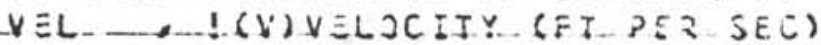

VINEN, ! UPCATEU VEL (FT FER SEC)

ORZVEF, ! (F P)OEIVE F JRCE C:V MAEV SESLS (LJF)

$N E I . F$, I N NET ACCSLERITINJ CORCE (LZF)

ACCEL, !(A)ACCELERATZOY (FT PEQ SECCND SDUARED)

TIME, !ELAPSEJ TINE OF STROKE (SEE)

COUNT, !CCNTRCL VARIAULE FOR FRENTINS

REYNO, !REY IOLOS NU:HEER

SHLEPT, !PCENT IN STRJKE NHERE SNUEJER FNGAOES (FT)

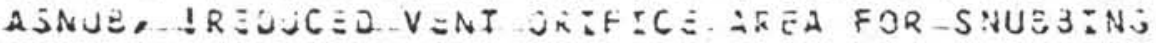

SUMK, ISUA JF LOSS COEFFIEIENTS

DELP IFRESSURE JROP ACR JSJ -ANCINZ JHJULOER

REAL ....AJ,... IFLOA 2REA PAJT LAVCENG JHOULOER (SOALA.)

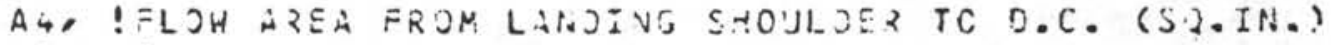

N1, !NUMSER JF ALWAYS-JP EN EYPASS TOLEJ

N2. INUMOER OF PLUGABL EYEASS HOLES 

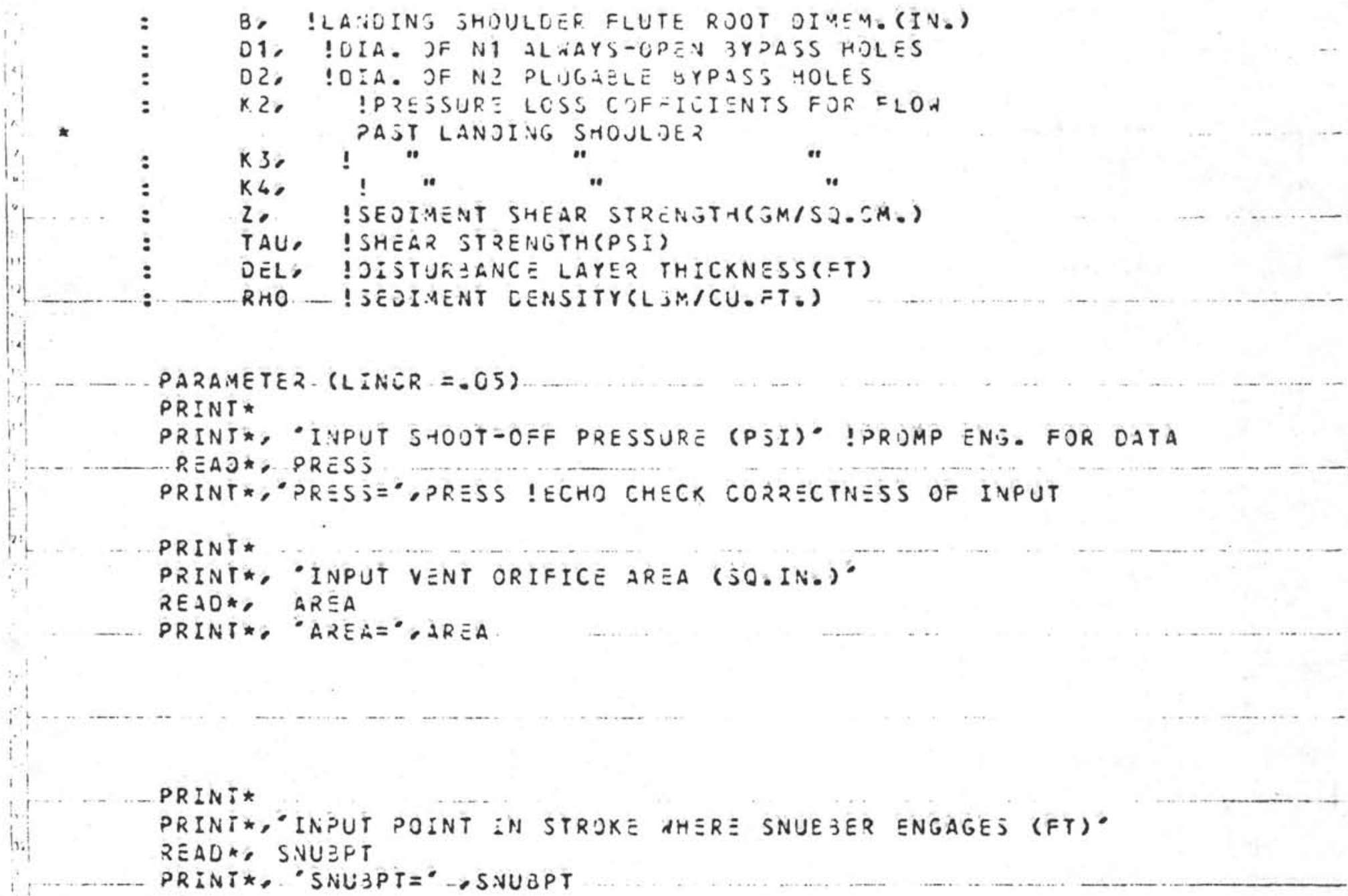

PRINT*

PRINT*, INPUT REDUCED VEVT CRIFICE AREA =OR SNUBZING

: $\left(S .2 .2 N^{\circ}\right)^{\circ}$

READF, ASNJE

PRINT*, -ASNJU $=\bullet, A S N U j$

$\star 23456737$

PRINT*

PRINTA, ZNPUT_3-FLUTE OIMENSION (1.3J TO 1.83)

READ*B 8

PRINT*, $j=\bullet, 3$

PRINT*, IINJUI-NI, NUYYER-OF_ALNAYS-CPE.V EYPASS-HOLES

REAS*, $N 1$

PRINI*, ${ }^{N} 1=\because, \quad V 1$

PRINT*

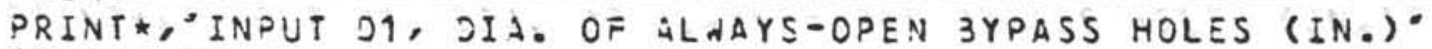

READ*, O1

ORINT*, OU1=-.01

PRINT*

PRINT*, INPUT N2, NUMBER OF PLUGABLE EYPASS HOLES LEFT OPEN

REAQ*:VIL

PRINT*, $0^{\circ} 2={ }^{\circ}, \mathrm{N}$ ?

PRINT*

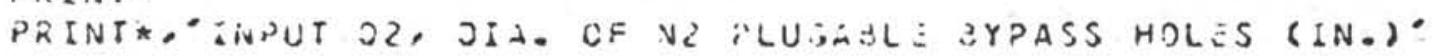


REAO,$C 2$

PRINT*, $J Z^{\circ}=, C ?$

PRINT*

PRINT*, INPUT SEJIMEVT SHEAR STRENGTH (GMISQ.CM.)

: - IF WATER COREOINPUT ZERO .

$R E A O N=Z$

PRINT*, $Z={ }^{\bullet}, Z$

.....INITILILATION....

OATA ORA.GSF, JRAG3B ZACKP,-STROKE,VEL,CUUNT, TIME,OELPI -

:

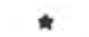
....CÁlulatí CONŚ́tants...

* $\quad A 4=5.503-3 * 3+1.3700 * 0 * * 2$ =OR FLUTED L.S. WITH HOLES

$A Z=0.7854 *(\sqrt{1}) 01 * * 2+N 2 * 32 * 2)$

$-K 2=-j .55 *(1-\dot{4} 317.21) *((7.21 / 45) * 2)$

$K 3=(7.21 / A 3-1) *(10.22 / A 3-1) * 1.7$

* K K4 $=((A 3 / A .4-1) *(2.5 * 13 / 44-1)+((1-43 / 5.73) *+2)) *$

$K_{4}=((1-23 / 6.5 ;) * 2) *((9.39 / 43) * * 2)$

$A R E A 1=A R E A$

TAU $=.01422 .3 \cdots-Z-1$ SHEAR ..STFENGTH (PSI) ...

DEL $=.1 / 12$ ! IISTURSANC LAYER TH:CKNESS (FT)

RHO $=121$ ISEOIMENT CENSITY (LEM/CU.CT.)

DRAGJ =-3JO ! TOTAL-APPROX. SEAL CZAG CONSTANT (LBF).

WEIGHT $=4 \overline{\text { I }}$ !WT. CF SCOPING COAPJNENTS (LEA)

..PRINT HEACER .

PRINT*

PRINT*

PRINT*

PRINT*

PRINT*,-PRESSURE $=0$-ERESS,- (PSI):

PRINT*, "VENT AREA $=^{\circ}, A R E A,^{\circ}\left(S S^{\circ} I \mathrm{H}_{0}\right)^{\circ}, 0^{\circ}$ SNUBEED VENT

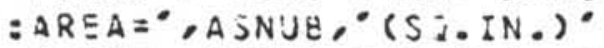

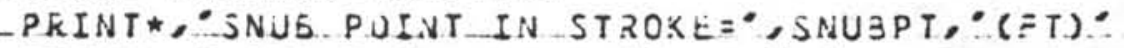

PRINT*, $W E I G H T={ }^{\circ}, W E I G H T,,^{\circ}(L Q E)^{\circ}, 0^{\circ}$ SHEAR STRENGTH $=\bullet, Z$,

: (OM/S2.CM.)"

PRINI*, SSEAL IRAJ $=0$, JRAGS, $0(L E . E)=$

PRINT*, : $11={ }^{\circ}, N 1, \circ A L W A Y S-O P \leq N$ EYFASS HCLES AT $01=0,01$

PRINT*, $N 2={ }^{\circ}, N 2,0^{\circ} P L U G A E L E$ BYPASS HOLES AT $J 2={ }^{\circ}, 02$

P.RINI*

PRINT $(4 C T 6, A, T 14, A, T E S, A, T 3 B, A, T 4 B, A, T S O, A, T O E, A$,

:T75, 4, T(S, $2 / 1)$ )

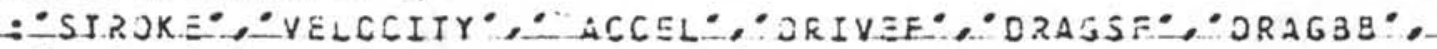

$:^{\circ B A C K P *, " N E T}=0^{\circ}$, BAPSEO TIME*,

$:^{\circ}(\ddot{r} T)^{\circ}, 0^{\circ}(T T / J E Z)^{\circ}, 0^{\circ}(F T / S / S)^{\bullet},,^{\circ}(L B F)^{\bullet}, 0^{\circ}(L B F)^{\bullet},{ }^{\circ}(L E F)^{\circ}$

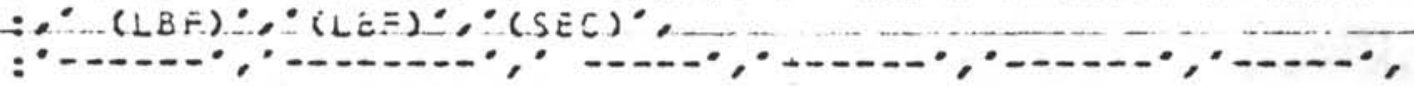

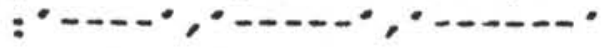

$\star 234567$

PPINT *

JO NHILE (STROKE .LE. 3O.2S) 


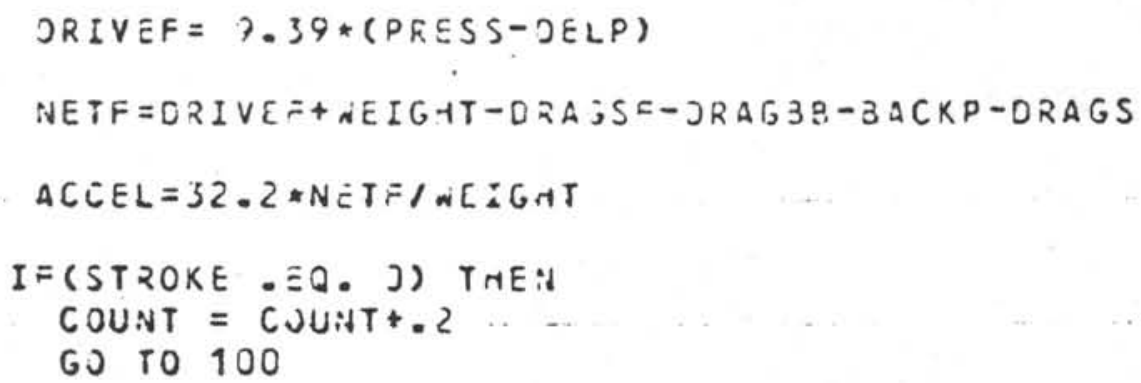

$\star 2345678$

$-I I M E=I I M \equiv+(V: N E d-Y E L) / A C C \equiv L$

$V E L=V N E W$

SU $4 K=29.7 C+0.03 E * S T K O K E+K 2+K 3+K 4$

DELP $=(3 U Y X * V E L * * Z) / 1+4.4 j$

IF ( DELP . OT. JEESS) THE:

JELP $=$ PRESS

ENJIF 
IF (STRUKE OGE. SNLIPT) THEN

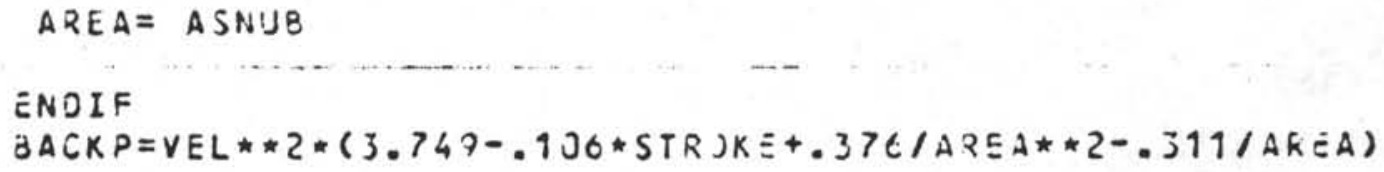

ELSE

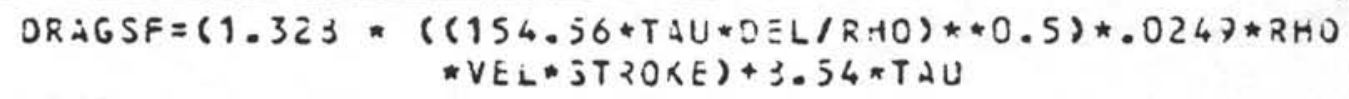


1:REM ... A.P.C.

Performance.

Program

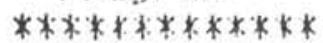

10:REM ...LI $=$ I $\mathrm{ncr}$

emental Stroke.

Distance (Ft. )

$15: L I=.05$

20: REM ...A=Uent Orifice Totol Area (Sq. In.)

25: $A=2.06$

39:REM ...W We igh $t$ of Scoping $C$ omponents (LbS .)

35: $w=490$

48:REM ...SN=Snub pt, Point in $S$ zroke Where $5 n$ ubber Engages ( $\mathrm{Ft}$. )

45: $S N=28.75$

50:REM ...A2 =Redu ced Uent Orifi ce Area for $\mathrm{Sn}$ ubbirig (Sa. In. )

$55: A 2=.11$

60: REM ...NI =No. O f Always -open Bypass Holes

6.5: $\mathrm{Nl}=2$

70: REI $\ldots$ DI=Dia. of $\mathrm{Al}$ ways - npen

Bypass Holes

(In.)

75: $01=.4375$

80: REM ...D2:=Dia. of Pluggale By pass Holes (In .)

$85: D 2=.4375$

90:REM ...DEL $=D$ is turbance Layer

Thickness (Ft .)

95:DEL $=.1 / 12$

100: REM ...RHO $=$ Sed iment Density (LFm/Cu.Ft.)

105: $\mathrm{RHO}=120$

110: REM ... SE $=$ Tot a I Approx. Seal Drus Constant ( $L B f$ )

115: $\mathrm{SF}=\mathrm{BOH}$

200: INPUT "SHIOOT-O FF PRESSURE (W SI ) $=" ; P$.
210: INPUT "fHOf PLU GGABLE HOLFSO PEN = ";N\%

220: INPUT "Sedimen tSheur.Str ( $1 \mathrm{~s} / \mathrm{Sq}$ $(m)=: ; 7$

236: $A 3=P 1 / 4 *(N) * 0$ $1 \wedge 2+N 2 * 02 \times 2)$

$250: K 2=.55 *(1-A 3 /)$ $.21) *(<) .21 / \cap 3$ )$\wedge 2)$

$260: k \cdot 3=() .21 / A 3-1)$ $*(10.82 / \cap 3-1) *$ 1.7

$270: K 4=(C 1-A 3 / 6.55$ )$\sim 2) *((9.39 / A 3$ )$\cap 2)$

$280: A 1=A$

2.90: TAU:=.014223*2.

$300: \mathrm{SF}=0: \mathrm{BG}=0: \mathrm{FB}:=0$ $: L=0: U=0: T=0: 0$ $P=0$

310:REM ...PRINT H EADER

320: LF 3: LPRINT "P ="; USING “"\#\#\# \#";P;"PSI";" N2 ="; USING "\#\# "; N2

330: LPRINT " $Z="$ ;USING "\#\#.\#\#م "; Z

340:LPRINT "-...-- - - -

500: IF L>30.25THEN 950

510: $F P=9.39 *(P-D P)$ : NETF $=F P+W-S F-$ $B B-F B-S E: A C C=3$ 2. $2 * N E T F / W$

520: IF $L>1$. OAND L< 27THEN 800

530: IF $L>=27$ THEN 5 60

540: IF INT (5*L) $(5\rangle$ ( $5 * L$ ) THEN 8 THO

550: COTO 700

508: IF $L\langle>I N T$ (L) THEN 8AD

700:LPRINT "L="; USING "\#\#\#.\#"; L;". T="; USING "\#\#I.\#\#"; $T$

705:LFRINT " $\quad U="$ ;USING "\#\#引. \#" ;U

710:LPRJNT" ACC =";USING "H\#\#\# \#.\#"; ACC
720:LPRINT " FP:= "; USING "\#\#\#\#\# \#. \#";FP

730:LPRINT " FB= ";USING "\#\#\#\#\# \#. \#";FB

740:LPRINT " NETF $="$; USING “\#\#\#\# \#\#. \#";NETF:LF 1

750: IF DP $>P T H E N$ \& 00

755: LPRINT "DP PP. . ....":LF 1

$890: L=L+L . I$

8QS: WAIT O:FRINT" $L="$; USING "\#\#\# \#\#";L

810: U2 =SQR (UN2+2* ACC $* L 1): T=T+(U$ 2-U) $/ A C C: U=U 2$ : $K S U M=29 . J+.088$ $* L+K 2+K 3+K 4$

820: $D P=(K S U M * \cup \cap 2)$, 144. 45: IF DPSP THFN 825

822: $D P=P$

825: IF LUSNTHEN 84 $\theta$

830: $A=A 2$

$840: \mathrm{FB}=\mathrm{Un} 2 *(3) 49-$. $.106 \mathrm{NL}+.376 / \mathrm{AN}$ $2-.311 / A): R \Gamma=1$ .495EC*U: IF TA U $>$ OTHEN 860

850: $S F=(U \cap 2 *(12.50$ $+.318 * \mathrm{~L})) /(C$ LOG $\left.\left(R F_{-}\right)\right) \wedge 2.58$ )$: B B=.005913 \times 4$ 2: GOTO 500

$860: \mathrm{SF}=\langle 1.328 *<<15$ 4. 56*TAU*OEL/R HO) $\cap .5) * .0249 *$ RHO*U*L ) +8.54* 950: FND

"APC Performance" BASIC Routine for PC-2 Computer 
APPENDIX D

DESIGN CALCULATIONS 
TENSION (PULLOUT) LIMIT: BEEFED

Limiting factors: 1. Quick Release Strength

2. Inner Barrel This. (those

that are loaded during pullout.)

3. Piston Rod \& connection's

(1) Quick Relent e

Existing VLHPC Quick Releases fail now at 100,000 16. tension or Failure begins as a bearing load (surface) failure.

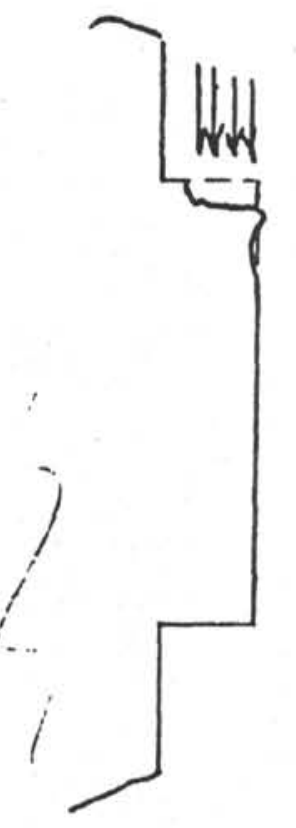

This failure mode is direct h proportional to contact area between the lugs an $Q$ the Cap Sub Windows.

$\therefore$ An increase in Lug/ Window - contact area should bring about a corresponding. (proportional) i -crease is teusil load capacity. (With no $\therefore$ change in watesial.) 

Present Q.R. Lug/Window
Contact Area! $\left\{\begin{array}{l}\text { OP 4339-3 } \\ \text { OP } 4338-5\end{array}\right.$

$\frac{4 N}{60}$

2

$2 x$

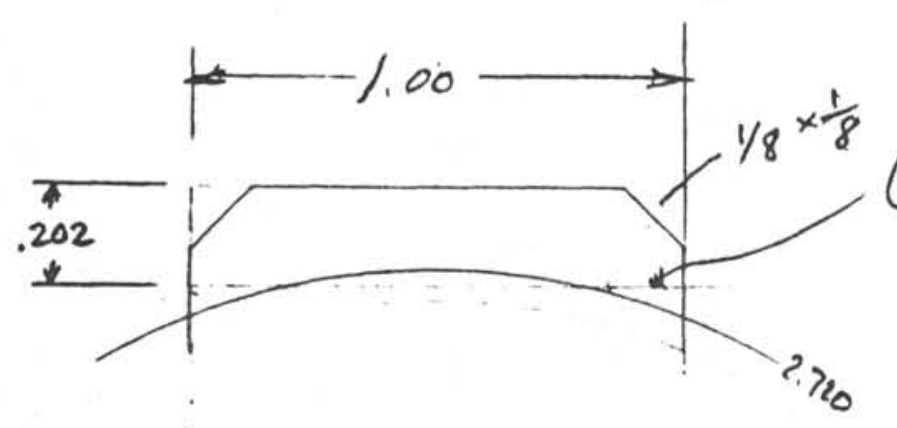

Contact $.202(1)-(.125)^{2}$
Contr
Ts\% $=0.186 \mathrm{in}^{2}$

/per Lug

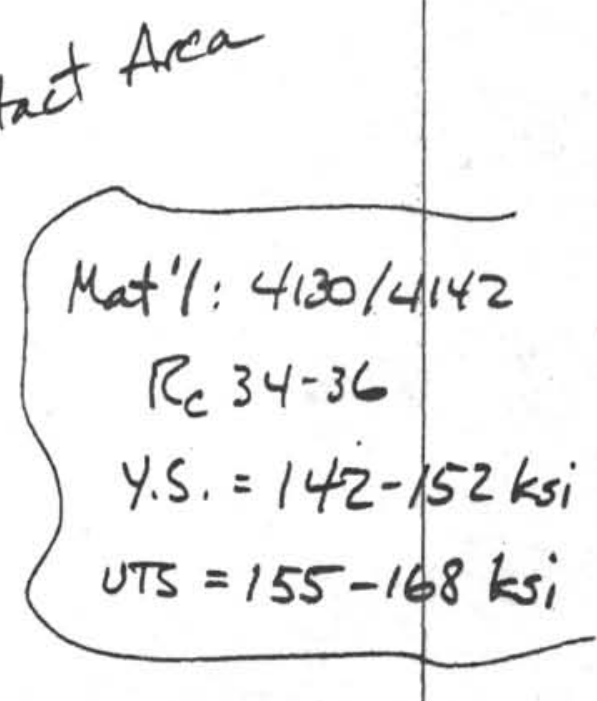

Total Contact Area $=0.372 \mathrm{in}^{2}$ (2) Lugs

For 4.S. (compression) $=150 \mathrm{ksi}$

Bearing stress failure of the Lugs should begin at 150,000 si $\left(.372 \mathrm{~m}^{2}\right)=55,800 \mathrm{lb}$. overpull Ultimate failure man not occur until $168,000(1372)=62,500 \mathrm{lb}$.

* This fits in with experiences of Q.R. failures. Total load at failure would be harder to determine because of wedging action required to separate parts after (during) lug failure.

$-114-$ 


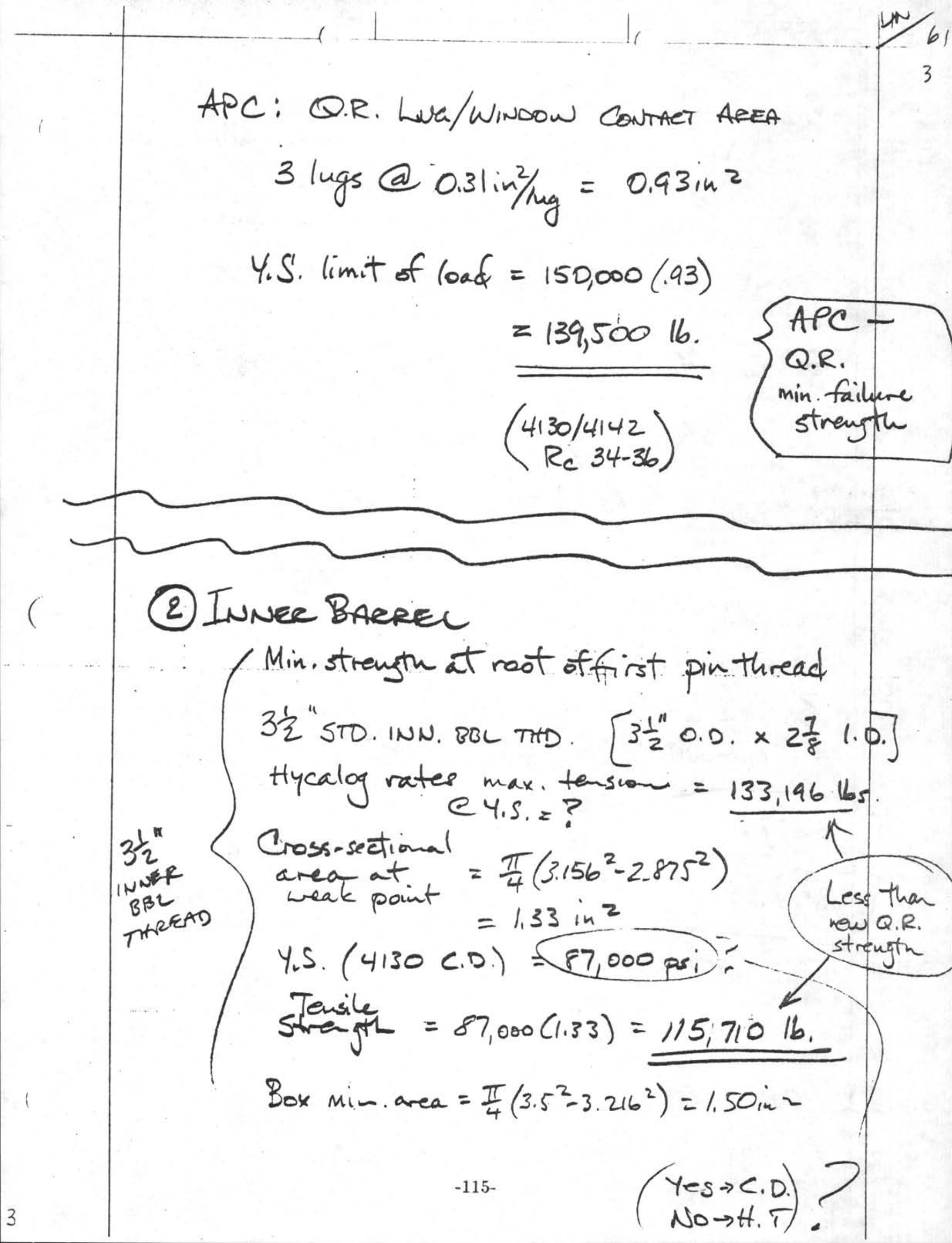




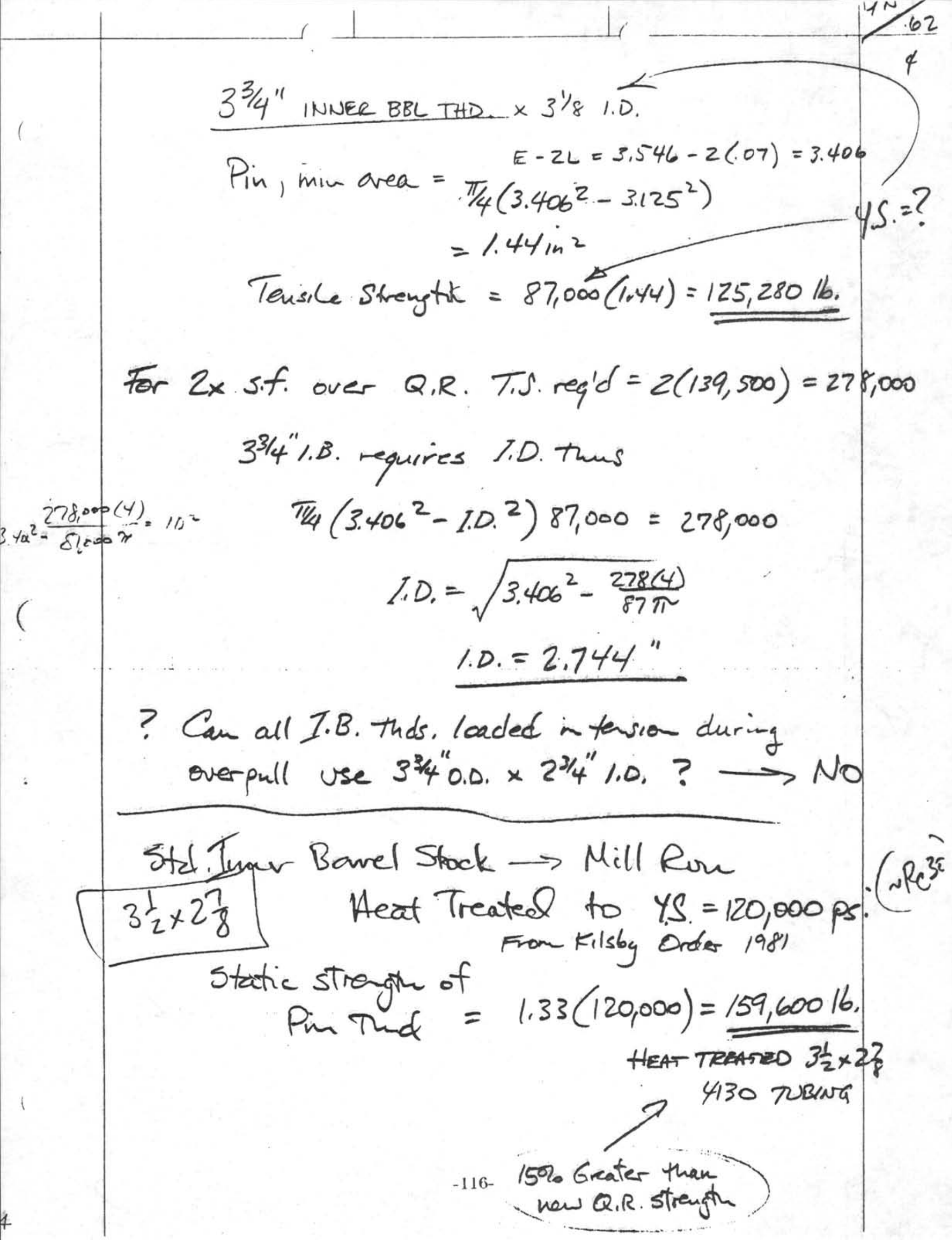


Hre

(3) Piston Rod (غे Connfections) Stranetet

5

Pistoin HD. Shater Pin

$.375 D\left(A . C H 1150\right.$, YS $=125,000$ psi $\left(M_{\text {in }}\right)$ Loaded area (drouble shear) $=2 \frac{\pi}{4}(.375)^{2}=0.22$ in 2 streugth $=125,000(.22)=27,50016$. Do not cary pultat
loal on Pistan Hd. Use rod upset

PISTON ROD w/THREADED MIO-CONNECTION $1 \frac{1}{2}$ "O.D. RoO w/ $1 \frac{1}{8} "-7$ une Male Tensile Area $=0.748 \mathrm{in}^{2}$ Mat'l. : Nitronic 32 oribo Y.S. $=65,000$ psi (annealed) Mase. Pullant load $=48,620 \mathrm{~B}$.

Rod w/o tHreaded CONNEctal BODY

$$
1 \frac{1}{2} " \text { O.D. Area }=1.767 \mathrm{im} 2
$$

Mat'1. Nitrouic 32 or 60 Y.S. $=65,000$ psi (annealed)

$$
\text { Max. Pull }=114,855 \mathrm{~kb} \text {. }
$$

Rod Connection of $1 \frac{1}{2}-6$ UNC TAOS.

$$
\begin{aligned}
& A_{t}=1.405 \quad \text { eys }=65,000 \\
& \text { eys<100k } \quad M_{\text {ak }} \text {. Rull }=91,32516 .
\end{aligned}
$$


Failure Scenarios - Durina Ourrpulus

WDRST: ROD EAILURE

Loss of everything below rod

Mis.: Q.R. Fance

Loss of entive scoping ass'y

below Q,R. female

Best: Ininer barren Tho. Fallure

hoss of scoping ass'j bclaw 160,00016 tailed connection iे jinkng of remainter of failed connecting (pin)

To get Rod strengin to 150,000 it (min).) Assumen $1 \frac{3}{8}-8$ stub Acme The at Piston Ros louver vipset to $1 \frac{7}{8}$ "dia.

$$
\text { Min Coos-Area }=1.193 \mathrm{in}^{2} \text { (Female) }
$$

At Streagh $=150,00016$

$$
\text { Min. Y.S. req'd }=\frac{150,00016}{1.193 \mathrm{in}}=126,000 \text { psi }
$$

Mat. 1? 17-4 PH? 4315s??

Elgiloy? MP35N 
Assume Kod must be joined by Thd. Comn.

7

Use Matl $=15-5 \mathrm{PH}$ (H1025) - K $10 \mathrm{HA}$ Length (mas Y.S. $=165,000$ pai $\quad$ CVN $=35$ A-16s.j Sections

Worst Case: $1 \frac{1}{2}$ "Rod Dia. -8 pitch Stud Acme Thd.

Try $1 \frac{11}{8}-8$ Min. Himar Dia. of Seraw" $\$$ Max. Maj. Dia. of Nut

$$
\begin{aligned}
& D=1.125 \\
& p=.125
\end{aligned}
$$

\$5 1.030

\#71.145

$k=1.050$

\#6 1.013 Dia

$A_{1}=0.845$ in $^{2}$

$\$ 8 \quad 1.162$

$S=$

$A_{2}=0.758$

Try 1 "-8

$s=1-1$

$D=1.000$

$\$ 71.020$

$p=.125$

\#5 . 905

$\$ 81.037$

$k=.925$

$\$ 6.888$

$A_{1}=0.655 .019$ in $^{2} \quad A_{2}=0.968$

5 ?

$S=$,

Compare 18"-8 Machinery's Hdbk.

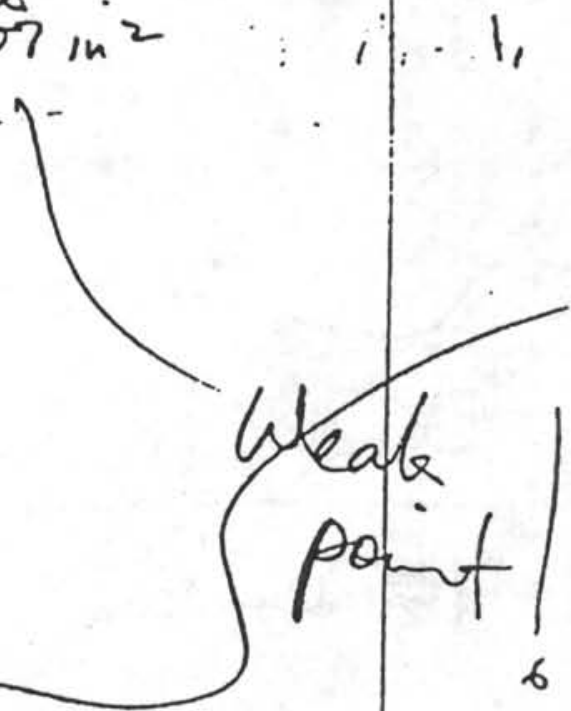

$$
\text { Stress Area } \quad \begin{aligned}
E & =1.088 \\
3 & =1,079
\end{aligned}
$$$$
\# 4=1.062
$$

$+9 E=1.088$ \#10 1/205

$\# 8 \quad 1.162$

$$
\begin{array}{cl}
A_{1} \\
(\text { Male })
\end{array} \quad \pi\left(\frac{E_{s}+K_{s}}{4}\right)^{2} \quad \begin{aligned}
& \# 4=1.062 \\
& \# t=1.013
\end{aligned}
$$

$$
\begin{aligned}
& =\pi\left(\frac{1.062+1.013}{4}\right)^{2} \\
& =0.845^{\circ} \mathrm{in}^{2} \text { Male }
\end{aligned}
$$

\#12 K+.05p $=0-.6 p+.0$$$
=D-. s p p
$$

$H_{12} \quad 1.056$

Stress Area $=\frac{\pi}{4}(0.0)^{2}-\pi\left(\frac{\# 8+\# 10}{4}\right)^{2}$

(Fenale)

$$
\therefore=\frac{\pi}{4}(1.5)^{2}-\pi\left(\frac{1162+1.105}{4}\right)^{2}=0.758 \text { Ferale }
$$




$$
\begin{aligned}
& 1 /-8
\end{aligned}
$$

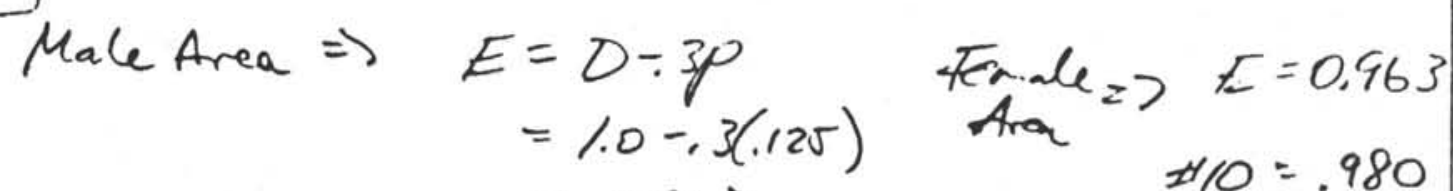

$$
\begin{aligned}
& =0.963 \\
& \pm 10=.980 \\
& \# 3=0.955 \\
& \# 4=0.938 \\
& \text { Mole Area }=\pi\left(\frac{.938+.888}{4}\right)^{2} \text { Fare }=\frac{\pi}{1}(1.5)^{2}-\pi\left(\frac{1.077+.88}{4}\right)^{2} \\
& =10.655 \\
& =0.968
\end{aligned}
$$

Worst Case Weak Pt.

$1 \frac{1}{2}$ "Dia.Rod Connected by $1 \frac{1}{8} "-8$ Stub Acme This.

Min. Tensile Stress

For $S=150,000$ Area occurs at female $=0.758 \mathrm{in} 2$

$$
\text { Y.S. Regild }=\frac{150,000}{.758}=198,000 \text { psi }
$$

with 15-5 PH, y.S. $=165,000$ psi Min. Strength $=125,000 \mathrm{ps}$

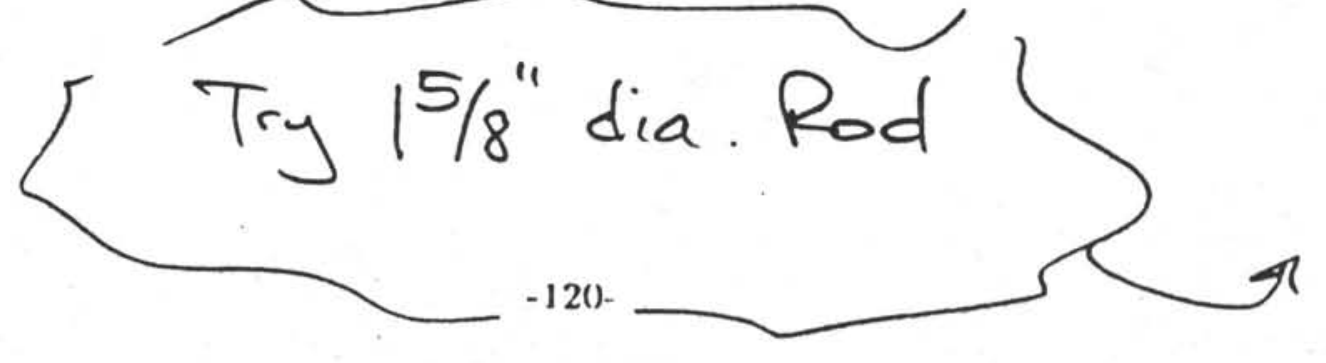


Strength of Connections $w / 1 \frac{5}{8} " \mathrm{Dia}$. Rod?

Try $1 \frac{1}{4}^{\prime \prime}-8$ stub Acme or 13/4" Bia.

$$
D=1.250, p=0.125, E=1.213, k=1.175
$$

\#3 1.204

\#7 1.270

$\$ 4 \quad 1.187$

\#5 1.155

$\# \quad 1.287$
$\$ 9 \quad 1.213$

$\# 6 \quad 1.138$

$\# 10 \quad 1.230$

Male Stress Area $=\pi\left(\frac{1.187+1.138}{4}\right)^{2}=1.061$ in $^{2}$

Female Stress Area $=\frac{\pi}{4}(1.625)^{2}-\pi\left(\frac{1.287+1.230}{4}\right)^{2}$

$15 / 8$ "Rod.

$$
=0.830 \mathrm{in}^{2}
$$

Female Stress Aver

$$
18 / 4^{\prime \prime} \operatorname{Rod}=1.16 / \mathrm{in}^{2}
$$

Try $1 \frac{1}{8} "-8$ stub Acme $D=1.125, p=125, E=1.088, k=1.050$

\#3 1,080 \#7 1.145 Male Stress Area $=\pi\left(\frac{1.063+1.013}{4}\right)^{2}$

\#4 $1.063 \pm 81.162$

$\# 51.030 \# 91,088$

$=0.846$ in $^{2}$

$\# 1.013 \# 1.105$

Female Stress Area $=\frac{\pi}{4}(0.0 .)^{2}-\pi\left(\frac{1162+1.10}{4}\right.$;

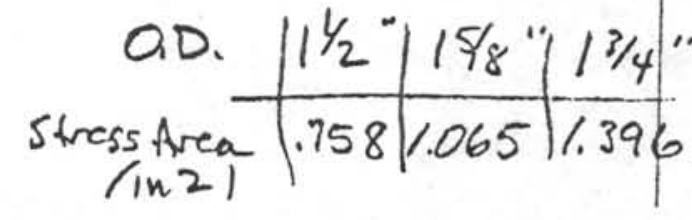

$-121-$ 
APC: Piston Roo Connection Strentetty

- Calculations done after:

1. Unexpectedly low level tensile failure of pin The ad at Site 606 A

2. Observation of machine shop techniques to produce threaded specimens.

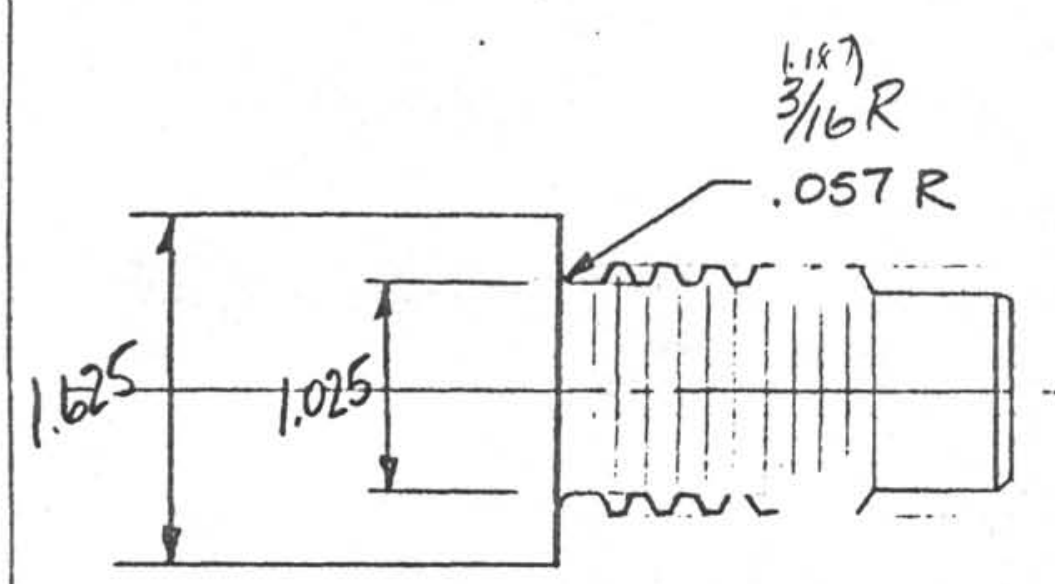

$1 \frac{1}{8}-8$ STUB ACME PIN CONNECTION

Matt. : 15-5 PH Lond. : H1025

$$
\text { Y.S. }=165,000 \text { Psi (or mare) }
$$

Static Tensile strength

Rod: $S=\frac{\pi}{4}(1.625)^{2}(165,000)=342 \mathrm{k}$ lbs.

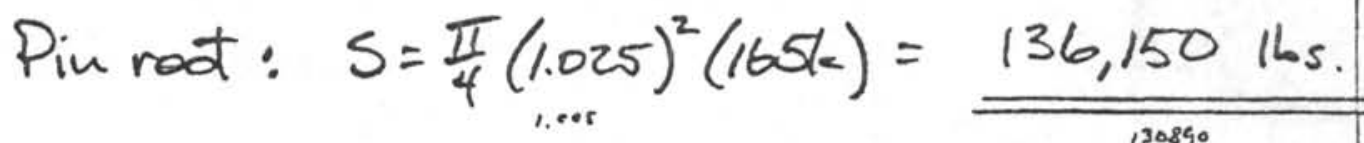

Stress concentration

Ref: Peterson "Stress Conc, Factors"

$$
\begin{aligned}
& D=1.625 \\
& d=1.025 \text {...65 } \\
& r=.057 \\
& .187
\end{aligned}
$$

Fig. $72,9 g .96$

$$
D / d=1.58 \quad r / d=\frac{.187}{1.057}=.056
$$

1.62 Sforplicable only $K_{t}=2.22$ for cyclic or loading. Q? Does shade or fluctuating load
occur during pull

$\frac{(w / \text { StrCouc.) Net } S=61,890 \mathrm{lb} 24,040161}{-123}$ 
Pre-Load

Ret: Shingler Pg. 303 ?

$$
k_{6}=\frac{A E}{l}
$$

$$
A=\frac{\pi}{4}(1.125)^{2}=0.994 \mathrm{mi}^{2}
$$$$
E=28.5 \times 10^{6} \mathrm{psi}^{\circ}
$$

$l=0.150$ (root below last thread)

$$
k_{b}=\frac{.994 \mathrm{in}^{2}\left(28.5 \times 10^{6} \mathrm{~kb} / \mathrm{m}^{2}\right)}{0.15}=7.9 \times 10^{8} \frac{\mathrm{lb} \mathrm{f}}{\mathrm{in}}
$$

$k_{m} \equiv$ compression stifles of shoulders of pin and box at pre-load

$$
\begin{aligned}
& \text { Compression area }=\frac{\pi}{4}\left(1.625^{2}-1.01^{2}\right) \\
& A_{m}=1.273 \mathrm{in}^{2} \\
& k_{m}=\frac{A E}{l} \\
& \text { Use } \ell=.150+.3^{*}=.45 \mathrm{in} \\
& k_{m}=\frac{1.273 \mathrm{in}^{2}\left(28.5 \times 10^{6} \frac{16}{1 \mathrm{n}^{2}}\right)}{.45 \mathrm{in}}=8 \times 10^{7} \frac{16 \mathrm{f}}{\mathrm{in}} \\
& F_{i}=\frac{T}{0.2 d}=\frac{500 \mathrm{At}-16_{f}}{0.2(1.025 \mathrm{in})}\left(12 \frac{1 \mathrm{u}}{4}\right)=29,268 \mathrm{lb} f
\end{aligned}
$$

$-124-$ 
C

$$
\begin{aligned}
P & =100,00016 t \\
F_{b} & =\frac{k_{b} p}{k_{b}+k_{m}}+F_{i} \\
& =\frac{1.9 \times 10^{8} \frac{16}{\mathrm{in}}(100,00016 \mathrm{f})}{\left(1.9 \times 10^{8 / \mathrm{kg}}\right)+\left(8 \times 10^{\left.7 \frac{16}{\mathrm{in}}\right)}+29,268\right.} \\
& =70,370+29,268
\end{aligned}
$$$$
=99,63816 \mathrm{f}
$$

80 


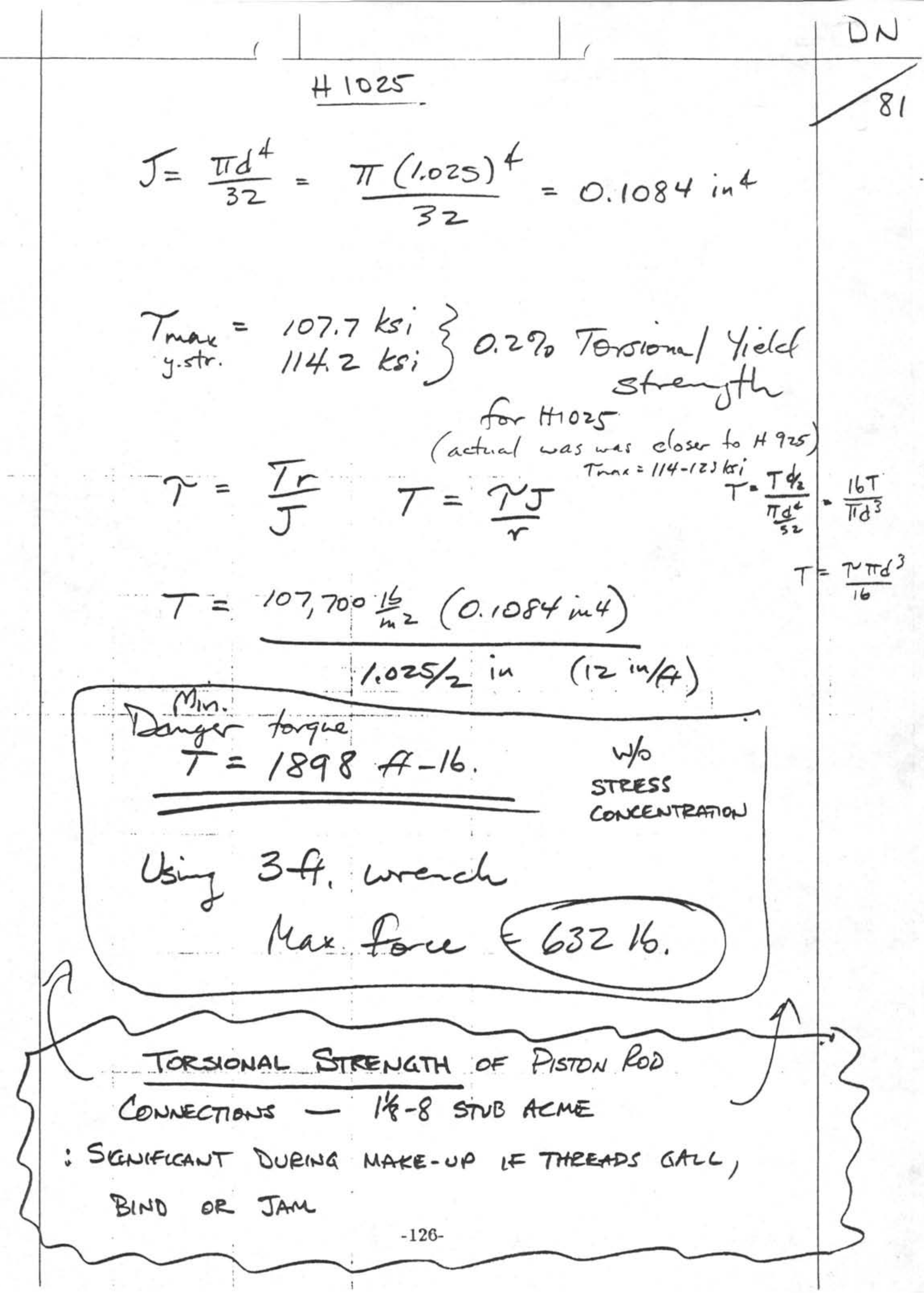




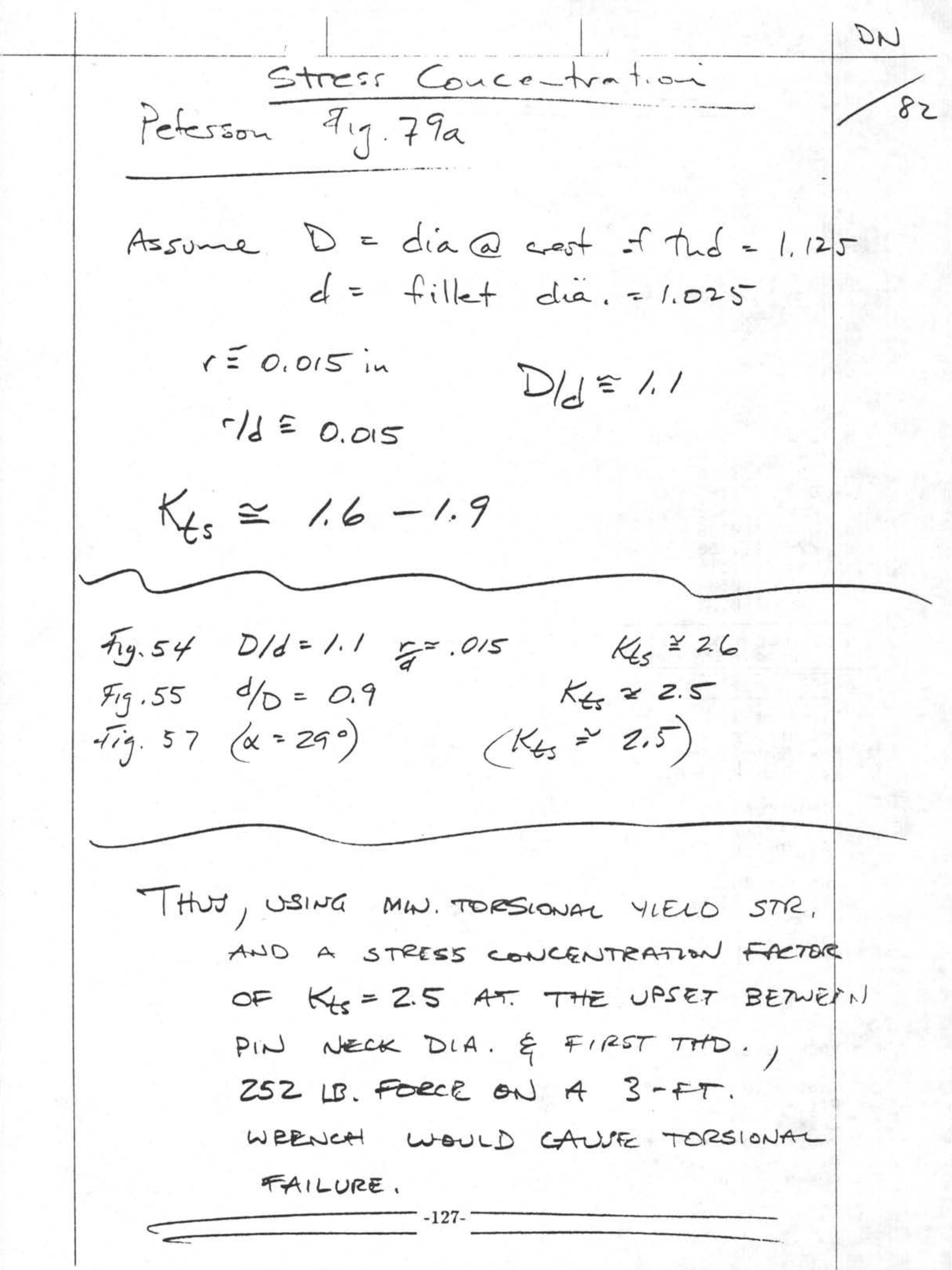




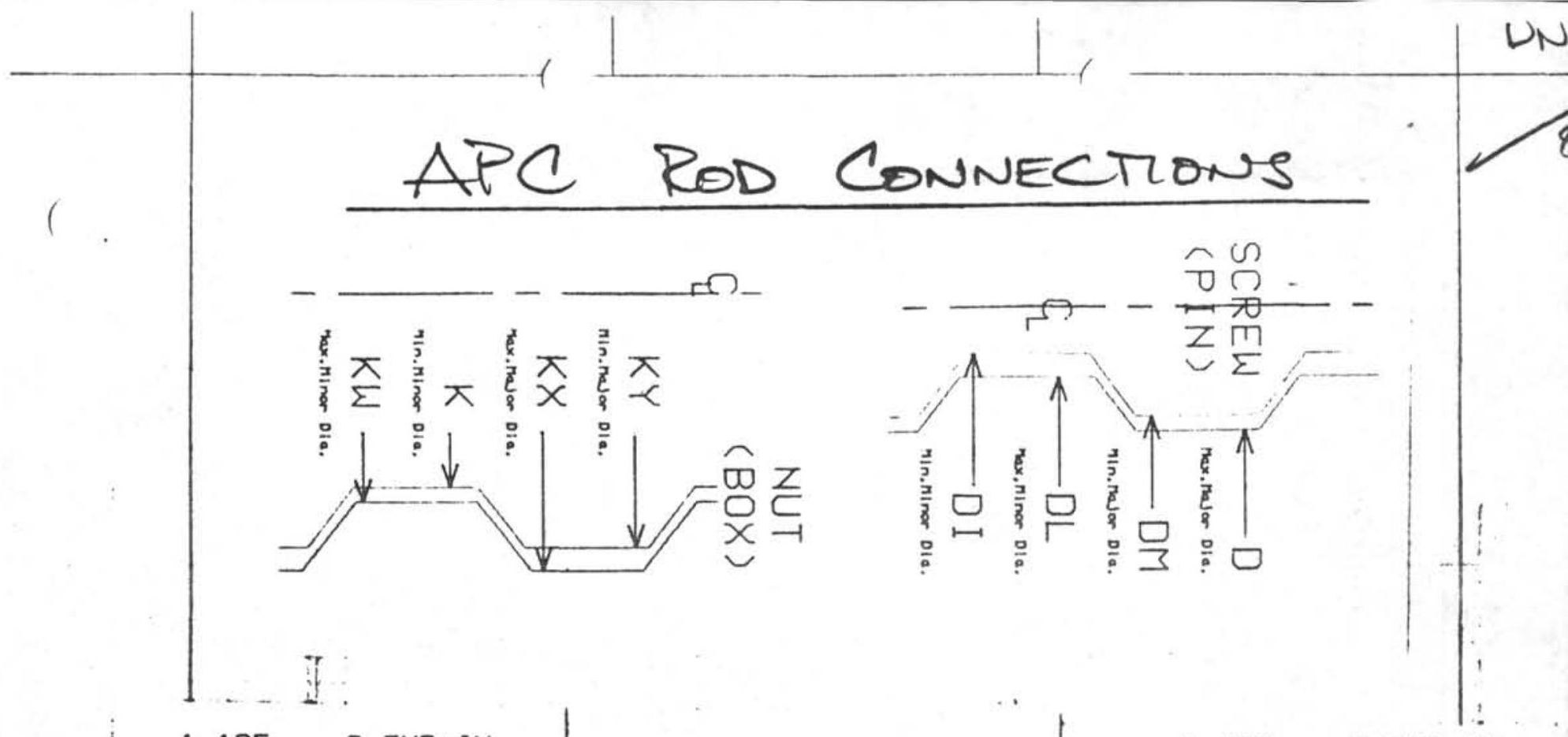

$1.125-8 \mathrm{THD} / \mathrm{IN}$

$-\cdots$

$D=1.1250 \mathrm{IN}$.

$D M=1.1187$

$\mathrm{DL}=1.0300$

$D I=1.0130$

$K Y=1.1450$

$K X=1.1619$

$K=1.0500$

$\mathrm{KW}=1.0562$

INTERMEDIATE ROD CONNEETIONS

\section{STRESSED AREAS}

Pin Tensile Area d

(at Thd.) $=0.845$

Box Tensile Area

(at Thd.) $=1.065$

MIINIMUM AREAS

(Approx.)

At Root of Pin $\begin{aligned} & \text { of } \\ = & 0.793\end{aligned}$

At Box Thd.Relief
$=1.004$ i. $1.6^{0}$

(Box 0.0. $=1.625)$

Thd. Shear Area Per

Inch of Engagement

$=1.6989$ SQ. IN.

MACHINING DIMEN. S

Thd. $\mathrm{Ht} .=0.0375$

Pitch Dia $=1.0875$

Crest $=\quad 0.0528$

$\operatorname{Root}$ (Nut) $=0.0476$

Wire Dia. $=0.0645$

OverwireDi $a=1.168$

$\begin{aligned} 1.250 & -8 \mathrm{THD} / \mathrm{IN} \\ \mathrm{D}= & 1.2500 \mathrm{IN} . \\ \mathrm{DM}= & 1.2437 \\ \mathrm{DL}= & 1.1550 \\ \mathrm{DI}= & 1.1376 \\ \mathrm{KY} & =1.2700 \\ \mathrm{KX} & =1.2873 \\ \mathrm{~K} & =1.1750 \\ \mathrm{KW} & =1.1812\end{aligned}$

MOD.II TOP ROD CONNECTION

STRESSED AREAS

Pin Tensile Area

(at Thd.) $=1.060$

Box Tensile Area

(at Thd.) $=1.897$

MINIMUM AREAS (Approx.)

At Root of Pin $=1.002$

At Box Thd.Relief

(Box 0.0 $=2.0290)$

Thd. Shear Area Per

Inch of Engagement

$=1.0909$ SQ. IN. l. 8938

MACHINING DIMEN.S

Thd. Ht. $=0.0375$

Pitch Dia $=1.2125$

Crest $=$

0.0528

$\operatorname{Root}($ Nut $)=0.0476$

Wire Dia. $=0.0645$

OverWireDi $a=1.293$

-128 -
$1.375-8 \mathrm{THD} / \mathrm{IN}$

$D=1.3750 \mathrm{IN}$.

$D M=1.3687$

$\mathrm{DL}=1.2800$

$D I=1.2623$

$K Y=1.3950$

$K X=1.412 \theta$

$K=1.3000$

$\mathrm{KW}=1.3062$

BOTIOM CONNECTION AT SNUBBER

STRESSED AREAS

Pin Tensile Area

(at Thd.) $=1.299$

Box Tensile Area

(at Thd.) $=1.637$

MINIMUM AREAS

(Approx.)

At Root of Pin $=1.235$

At Box Thd.Relief $=1.563$

(Box 0.D. $=2.000)$

Thd. Shear Area Per

Inch of Engagement

$=$ 1. 2.0877

MACHINING DIMEN. $s$

Thd. Ht. $=0.0375$

Pitch Dia= 1.3375

Crest $=$

0. 0528

$\operatorname{Root}$ (Nut) $=0.0476$

Wire Dia. $=0.0645$

OverwireDia $=1.418$ 
Connection Strengths of Rod Sectors

Top of upper SEction - $1 \frac{3}{8}-8$ STUB

ACME

$$
\begin{aligned}
& \frac{15-5 P H \text { ROO CONN. TO }}{(\text { MmE) }} \frac{4340, R_{C} 32}{\text { (FEMALE) }} \\
& 45=165 k s i \\
& \text { UTS }=145 \mathrm{ksi} \\
& \text { UTs }=170 \mathrm{ksi}
\end{aligned}
$$

From Mach.

Halle. pg. 1150 Shear area

? $v$ this?

$$
\text { of rod the., } A_{s}=\pi n L e K_{n_{\text {max }}}\left[\frac{1}{2_{n}}+.57735\left(E_{\text {sim }}-K_{n}\right.\right.
$$

Shear area

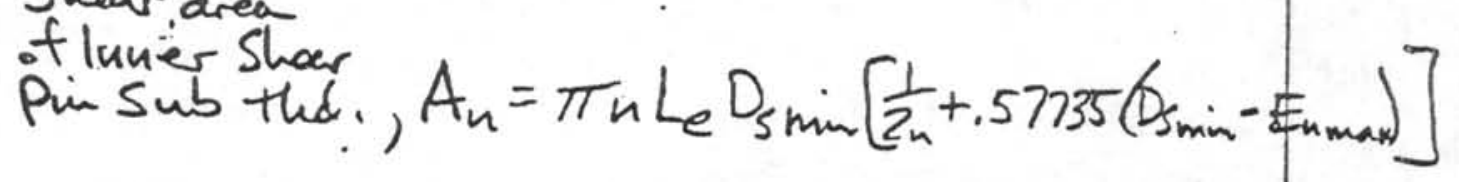

$$
n=8 \quad L_{e}=\underset{\text { unkmoum }}{(T B D)}
$$

$$
\begin{aligned}
& \text { \# } E_{\text {spin }} \Rightarrow E=1.3375 \quad \# 3=1.3281 \quad E_{S_{\text {min }}}=1.31 .04 \\
& \text { \#12 } K_{u \text { max }} \Rightarrow K=1.300 \quad \# 12=1,3063=K_{u_{\text {max }}}
\end{aligned}
$$

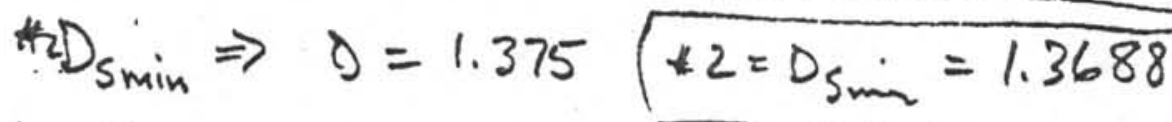

$$
\text { Ho } E_{\text {un ax }} \Rightarrow E=1.3375 t_{\text {to }} E_{\text {max }_{\text {max }}}=1.3552
$$

$$
\begin{aligned}
& A_{5}=\pi(8) \operatorname{Le}(1.3063)\left[\frac{1}{16}+.57735(1.3104-1.3063)\right] \\
& A_{5}=2.130 \mathrm{Le} \\
& A_{n}=\pi(8) L e(1.3688)\left[\frac{1}{16}+.57735(1.3688-1.3552)\right] \\
& A_{n}=2.420 \mathrm{Le}
\end{aligned}
$$




$$
J=\frac{A_{s}(170 \mathrm{ks} \%)}{A_{n}(145 \mathrm{ksi})}=\frac{2.130 \mathrm{Le}(170)}{2.420 \mathrm{Le}(145)}=1.032
$$

Reg'd Length of Engagement to prewent stripping of luternal Thd (in shear pinsub)

$$
\begin{aligned}
& Q=J L_{e} \\
& L_{c}=\frac{2 A_{t}}{\pi K_{n \max }\left[\frac{1}{2}+.57735 n\left(E_{\text {suin }}-K_{\text {mmax }}\right)\right]}
\end{aligned}
$$

$$
\text { At (tersil Area) }=\pi\left(\frac{\$ 4+* 6}{4}\right)^{2}
$$

$\# 6 \Rightarrow=1.300-.02=1.28 \quad \# 6=1.262$

$$
A_{t}=\pi\left(\frac{1.3104+1.262}{4}\right)^{2}=1.300 \mathrm{in}^{2}
$$

$$
L_{e}=\frac{2(1.3)}{\pi(1.3063)[.5+.57735(8)(1.3104-1.3063)]}
$$

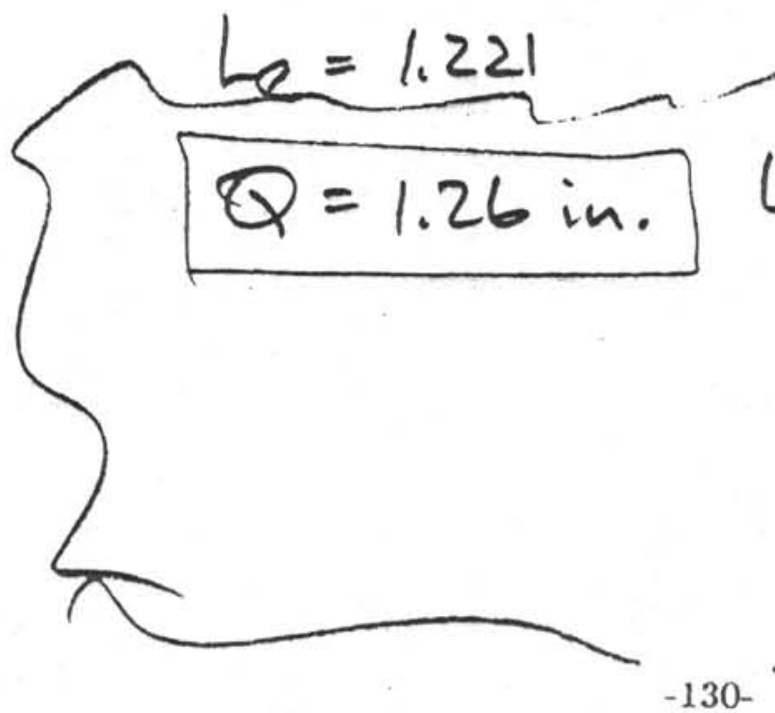

REQD.

LENRTH OF ENGAGEMENT a Piston Rod in shear pin sub 
SHEAR PINS

Pressure Working

Area

$$
\begin{aligned}
& =\frac{\pi}{4}\left(3.8^{2}-1.625^{2}\right) \\
A & =9.267 \mathrm{in}^{2}
\end{aligned}
$$

Max. load at 3000 psi

$$
L=3000(9.267)=27,80216 \mathrm{f}
$$

Using 17-4 PH shear Pins,

(1) Condition $H 900$ Soublerhear.

$-1 / 69$ 


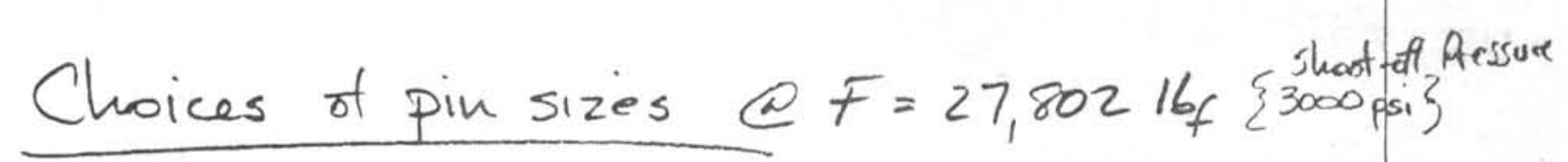




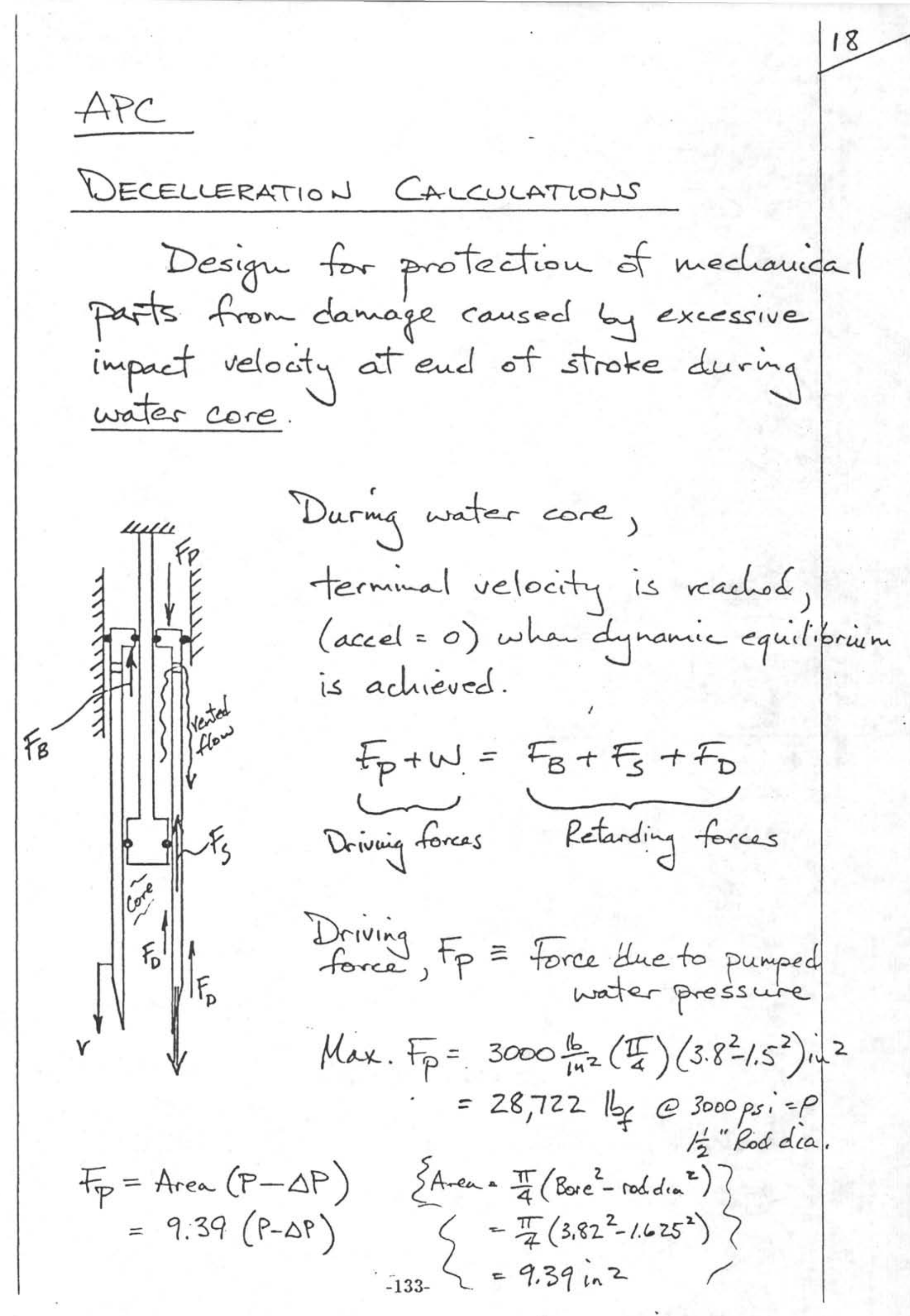


$K_{1}$ : Sudden contraction

41

Assume break motto annular flow acts as a sudden contraction from $A_{0}$ to $A_{1}$ ( (flu si\%)

(from Crave th $40, \mathrm{pg}, A \cdot 26$ )

$$
\begin{array}{cc}
\left\{V_{0}\right\} K_{1}=\frac{0.5\left(1-\beta^{2}\right) \sqrt{\sin \theta / 2}}{\beta^{4}} \quad \begin{array}{l}
\text { Let } \\
\theta=1800 \\
\beta^{2}=\frac{A_{1}}{A_{0}}
\end{array} \\
A_{0}=\frac{\pi}{4}(4.125)^{2}=13.36 \mathrm{in}^{2} \\
A_{1}=\frac{\pi}{4}\left(4.125^{2}-2.82^{2}\right)=9.56 \mathrm{in}^{2} 7.21 \mathrm{in}^{2} \\
\beta^{2}=A_{1} / A_{0}=\frac{0.5760}{0.540} \\
K_{1}=\frac{0.5(1-.746)(1)}{(.716)^{2}}=0.2770 .789 \\
.546
\end{array}
$$

Add 15\% to account for fact that annular flow with large surface area rather Than concentric pipes occurs here.

$$
\left.K_{1}=1.05(\dot{i} 779)=\frac{0.29}{0.829} \text { \{acting on } V_{0}\right\}
$$

$K_{2}, K_{3}, K_{4}$ : Dependent on geometry of flow paths thru handing showier - varies with open hole sizes, pluggable hole sizes and number of holes left open.

-135- 
$K_{5}$ : Annular flow

(from Raymond Paper)

$K_{5}=0.48 \frac{L(H)}{D(m)}$ for straight pipe

$D=4 R_{H} \quad R_{H}=$ Ingdranlic radius

(from Crane\#tio) $R_{H}$ for annular openings can be taken as approx. $1 / 2$ passage width Therefore take $R_{4}$ at $A_{5}$ to be

$$
\begin{aligned}
& \frac{1}{2}\left(\frac{3.82-2^{2} 62}{2}\right)=0.330 \\
& D=4 R_{H}=1.32 .0 \\
& D .30
\end{aligned}
$$

than $K_{5}=0.48 \frac{7}{(12)(118)}=0.212$.

$K_{6}$ : Sudden enlargement $A_{5}$ to $A_{7}$

$$
\begin{aligned}
& K_{5}=\frac{\left(1-\beta^{2}\right)^{2}}{\beta^{4}} \\
& \beta^{2}=\frac{A_{5}}{A_{7}} \\
& A_{5}=\pi / 4\left(3.82^{2}-2.52^{2}\right)=\begin{array}{l}
6.55 \\
5.95
\end{array} \\
& A_{7}=\frac{\pi}{4}\left(3.82^{2}-1.55^{2}\right)=\frac{9.571 \mathrm{~m}^{2}}{9.39} \\
& \beta^{2}=\frac{5.95}{9.57}=\frac{.621}{.698}
\end{aligned}
$$

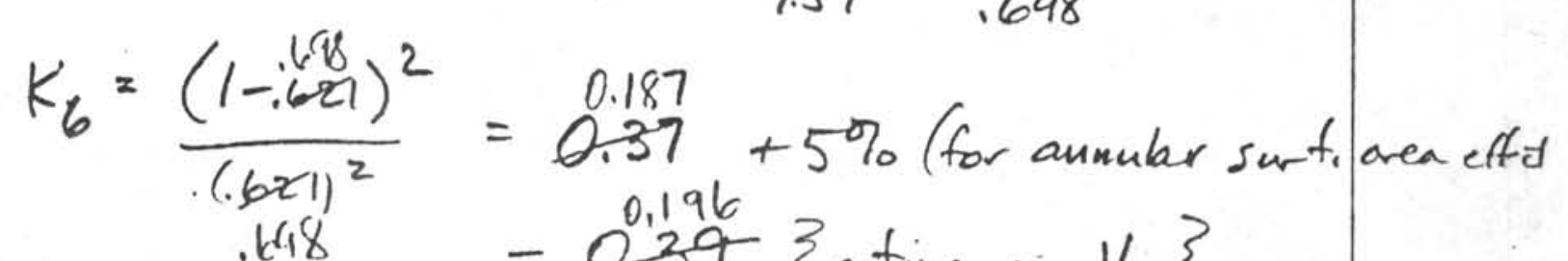

$$
\begin{aligned}
& \left..148=0.0 .1969 \text { acting on } V_{7}\right\}
\end{aligned}
$$


$K_{p}$ : Annular straight pipe flow

45

$$
\begin{aligned}
& K_{7}=f(l) \\
& =0.48 \frac{l}{D_{1}},{ }^{A} \text { in } \\
& D=4 R_{H}=4 \text { cross ora } \\
& =\frac{\left.(4)\left(3.2^{2}-1.5^{2}\right)^{2}\right)}{\pi(3.8+1.5 .625} \\
& K_{7}=\frac{0.48}{\frac{2.33}{5.445}} \ell(\mathrm{ft}) \\
& =2.3 \mathrm{in} \text {. } \\
& K_{4}=0.209 l(t t) \quad\left\{\text { on } V_{7}\right\}
\end{aligned}
$$

$K_{0}=0.48 \frac{L}{D(m)} \quad$ Use $2000 \mathrm{~A} .=L$ as average effected length of pipe where How from "storage" must pass Velocity is variable from

$$
V=0 \text { to } V_{0} \text {, Ave }=\frac{V_{g}}{2}
$$

$$
\begin{aligned}
& \left.K_{0}=0.48 \frac{2000}{4.125}=232 \text { \{acting on } \frac{V_{0}}{2}\right\} \\
& \Delta_{p}=\frac{K_{0 p} V^{2}}{2 g c}=\frac{f}{2 g a} K_{0} \frac{V_{0}^{2}}{4} \rightarrow \frac{K_{0}}{4}\left\{\text { action } V_{0}\right\} \\
& \left\{V_{0}\right\} K_{0}=58
\end{aligned}
$$

$-137-$ 
$\Delta P$ across stationary portions of The tool as moving section scopes

$$
\begin{aligned}
& \Delta P=\sum K_{i} \frac{\rho Q_{c}^{2}}{z_{a} A_{i}{ }^{2}} \\
& Q_{c} \equiv \text { flow from } \\
& \text { compressed "storage" } \\
& K_{1}=0.229 \text { conf. to } V_{0}=Q_{c} / A_{0} \\
& K_{2} ; K_{3}, K_{4} \text { - Calculated separately } \\
& K_{5}=0.2 / 40.212 \text { conf. to } V_{S}=Q_{c} / A_{5} \\
& K_{6}=0.39 \quad 0.196 \\
& \begin{aligned}
K_{7} & =0.21 \mathrm{l}(\mathrm{A} .) \\
& .088
\end{aligned}
\end{aligned}
$$

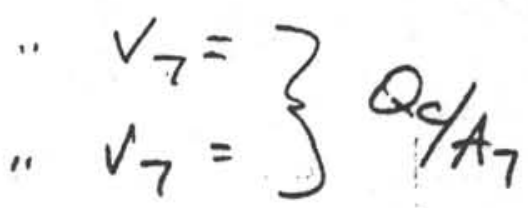

$$
\begin{aligned}
& K_{0} \cong 58
\end{aligned}
$$

To simplify, adjust all $K$ 's to act as coefficients to $V_{7}$

$$
\begin{aligned}
& K_{i}^{\prime}=K_{i}\left(\frac{A_{7}}{A_{i}}\right)^{2} \quad\left\{\text { all acting on } V_{7}=Q_{c} / A_{7}\right\} \\
& K_{1}^{\prime}=.829\left(\frac{9.39}{13.36}\right)^{2}=0.41 \\
& K_{5}^{\prime}=.212\left(\frac{9.39}{6.55}\right)^{2}=0.44 \\
& K_{6}^{\prime}=.196 \\
& K_{7}^{\prime}=0.088 \mathrm{l} \\
& K_{0}^{\prime}=58\left(\frac{9.39}{13,36}\right)^{2}=28,65 \\
& \left\{\begin{array}{c}
\sum K=29.7+0.088 l+K_{2}+K_{3}+K_{4} \\
\text { acting on } v_{7}
\end{array}\right.
\end{aligned}
$$




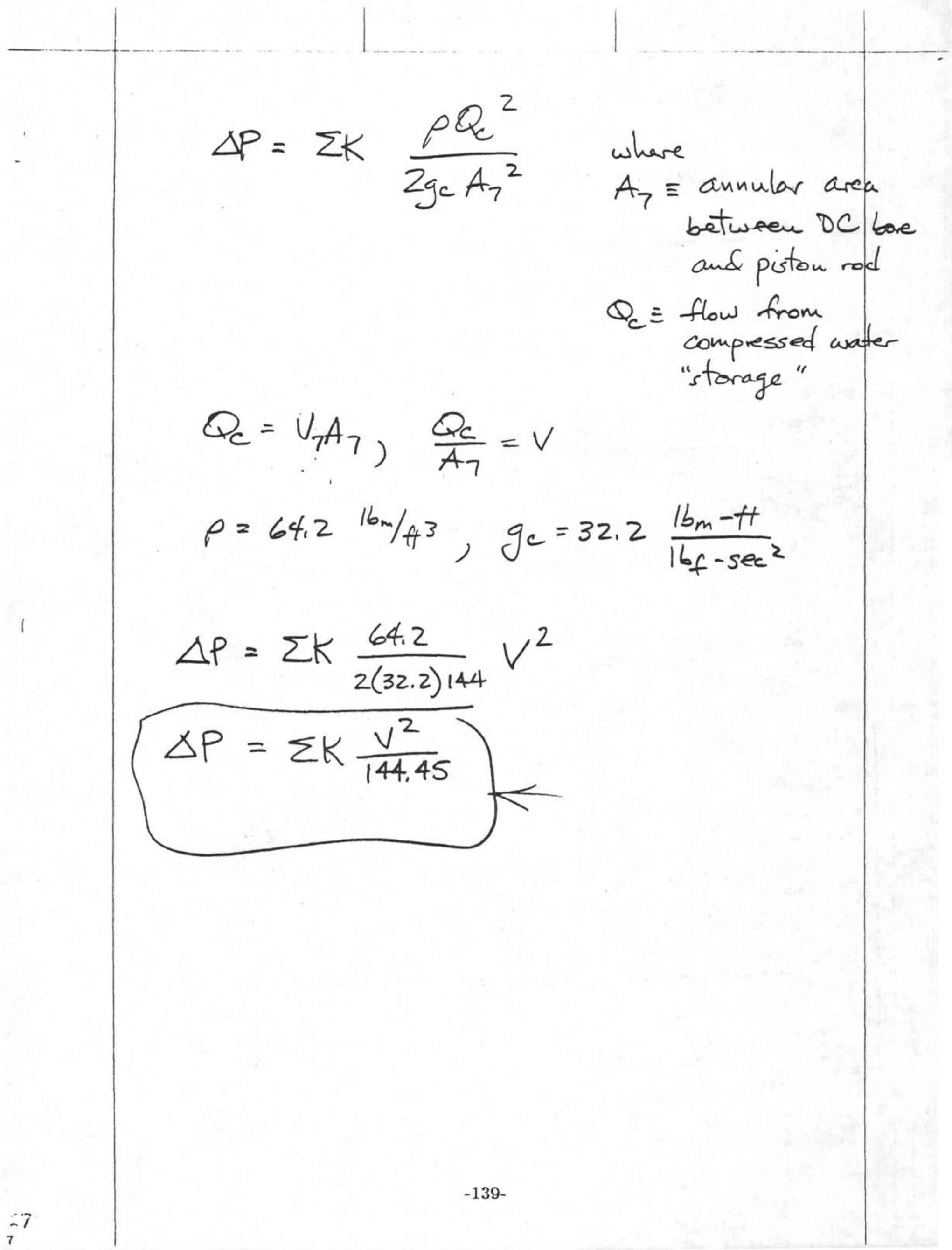


Weights,

Core bbl sections $=332 \mathrm{ll}$.

QR, seal sub, shear

$$
\approx \frac{\pi}{4}\left(3.25^{2}-1.5^{2}\right) 48(.283)=8816 \text {. }
$$

Catchers, shoe, lower liner seal sub, spader sub

$$
\approx \frac{\pi}{4}\left(3.5^{2}-2.5^{2}\right) 40(.283)=\frac{53}{473}
$$

Use

$$
W=475 \mathrm{k} .
$$

Retarding

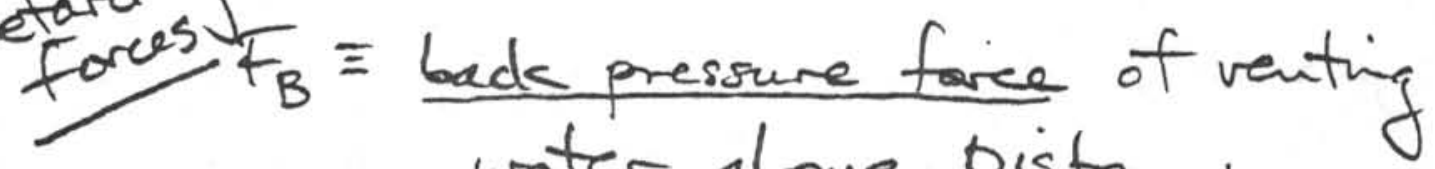
water above piston; a function velocity, $V$

$F_{S} \equiv$ farce caused by seal drag of cylinder seal, rod seal \& piston head seal; a function of velocity, $v$

$F_{D}=$ force caused by water drag resistance of carer into water; a function of velocity, $V$.

Iterative solution req'd.

e.g.j) Try term. based on $30 \mathrm{f}$. stroke in $1.5 \mathrm{sec}$.

$$
\text { Vire } \cong V_{\text {term }}=\frac{30 \mathrm{~A}}{1.5 \mathrm{sec}}=20 \mathrm{f} / \mathrm{sec}
$$

$-140-$ 
$F_{B}$ Simple Vent Model:

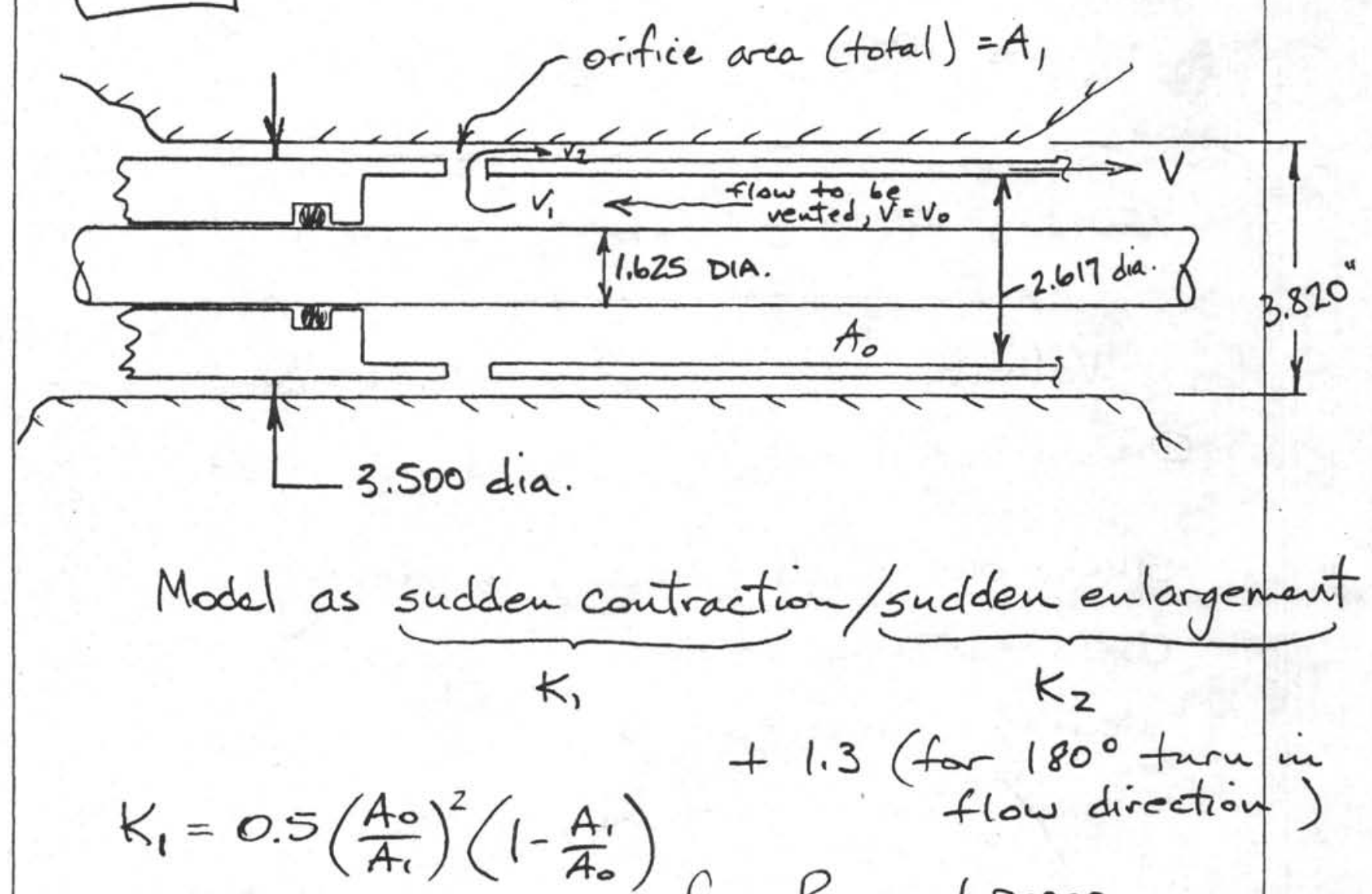
flow direction )

from Raymond paper

$$
\begin{aligned}
A_{0}=\frac{\pi}{4}\left(2.617^{2}-1.625^{2}\right) \cdot 3.31 \mathrm{in}^{2} \\
K_{1}=0.5\left(\frac{3.31}{A_{1}}\right)^{2}\left(1-\frac{A_{1}}{3.31}\right) \\
=\frac{5.46}{A_{1}{ }^{2}}-\frac{1.65}{A_{1}}\left\{0 u V_{0}=V\right\}+1.3 \\
K_{\frac{2}{2}}\left(1-\frac{A_{1}}{A_{2}}\right)^{2}=\left(1-\frac{A_{1}}{1.84}\right)^{2}=\left(1-\frac{2 A_{1}}{1.84}+\frac{A_{1}{ }^{2}}{3.386}\right) \\
\left\{V_{1}\right\} K_{2}=1-\frac{A_{1}}{.92}+\frac{A_{1}{ }^{2}}{3.386}, \text { Adjust to } V_{0} \text {, multiply by }\left(\frac{A_{0}}{A_{1}}\right)^{2} \\
K_{2}=\left(1-\frac{A}{.92}+\frac{A^{2}}{3.386}\right)\left(\frac{3.31}{A_{1}}\right)^{2}
\end{aligned}
$$


Adjusted to $V_{0}=V$

$$
\begin{aligned}
& K_{2}=\left(1-\frac{A}{.92}+\frac{A^{2}}{3.386}\right) \frac{10.96}{A^{2}} \\
& K_{2}=\frac{10.96}{A^{2}}-\frac{11.91}{A}+3.237
\end{aligned}
$$

VENTED FLOW OUT ANNULUS TO BIT THROAT

Velocity, $V_{2}$, in annulus between corer OD. $\varepsilon_{1}$ drill collar I.D. is not equal to $\frac{Q}{A_{2}}$ since one wall (corer) is moving. Use relative velocity $V_{2}^{\prime}=1.96 \mathrm{~V}$ between vented flow and corer.

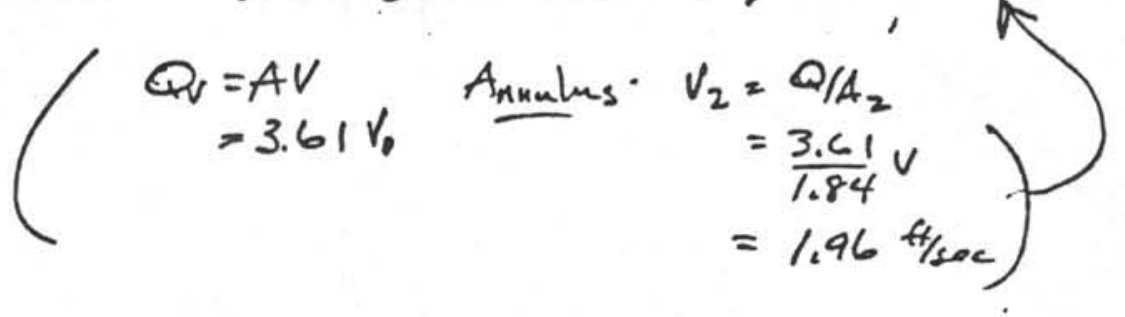

$$
\begin{aligned}
& \operatorname{Re}_{D_{h}}=\frac{\rho V D_{h}}{\mu g_{C}}=\frac{64.2(100)(3.82-3.5)}{4 \times 10^{-5}(32.2) 12}=1.33 \times 10^{5} \\
& E=150 \times 10^{-6} \mathrm{At} \\
& D_{h}=.0267 \mathrm{ft} \\
& K_{\text {ann }}=\frac{f L}{D_{h}}=\frac{0.032}{0.0267}(31-l) \\
& =(37.15-1.2 \ell) 3.84 \\
& k_{\text {ain }}=142.6-4.608 \ell \\
& K^{\prime} \propto\left(\frac{V_{2}}{V}\right)^{2} K=(1.96)^{2} K \\
& =3.84 \mathrm{~K}
\end{aligned}
$$




$\left.\begin{array}{rl}F_{B} & =\Delta P\left(A_{0}\right)=\frac{3.31 \sum K \rho^{2}}{2 g c(144)} \\ & =\frac{3.31(64.2)}{2(32.2) 144} \sum K V^{2} \\ & =\frac{v^{2}}{43.64}\left(163.6-4.608 l+\frac{16.42}{A^{2}}-\frac{13.56}{A}\right) \\ F_{B} & =v^{2}\left(3.749-0.106 l+\frac{376}{A^{2}}-\frac{.311}{A}\right)\end{array}\right\}$


Fo

31

Seal drag is significant for all three seals. Piston Head seal is pressurized (by everincreasing $F_{B}$ )

Take S.W.A.G. total $\bar{F}$ (dynamic) as $60+145+100=305$ e 2000 psi

Say $F_{s}=300$ ll at any pressure

(Static or dynamic)

* This estimate is close enif since the magnitude is only 5-10\%. of the other significant variables involved.

$-145-$ 


$$
\begin{aligned}
B \text { luff dray } & =\frac{0.2 \rho v^{2} A}{2 g c} \\
& =\frac{0.2(64.2) \frac{\pi}{4}\left(3.5^{2}-2.6^{2}\right) v^{2}}{2(32.2) 144} \\
& =\frac{v^{2}}{168}
\end{aligned}
$$

25
15

$-147-$ 
Coring Resistance Relationships

52

Assume that the only know property of the cored sediments is shear strength, $T$. The coring resistance relationship must be a function of varying $\tau$ plus variables having to do with the corer but independent of the cored material.

Assume that the corer penetrates the sediment material in such a way that disturbance of the insitu material is limited to a "fluidized" disturbance day er of thickness $\delta$ on both the inside and ont side of the corer.

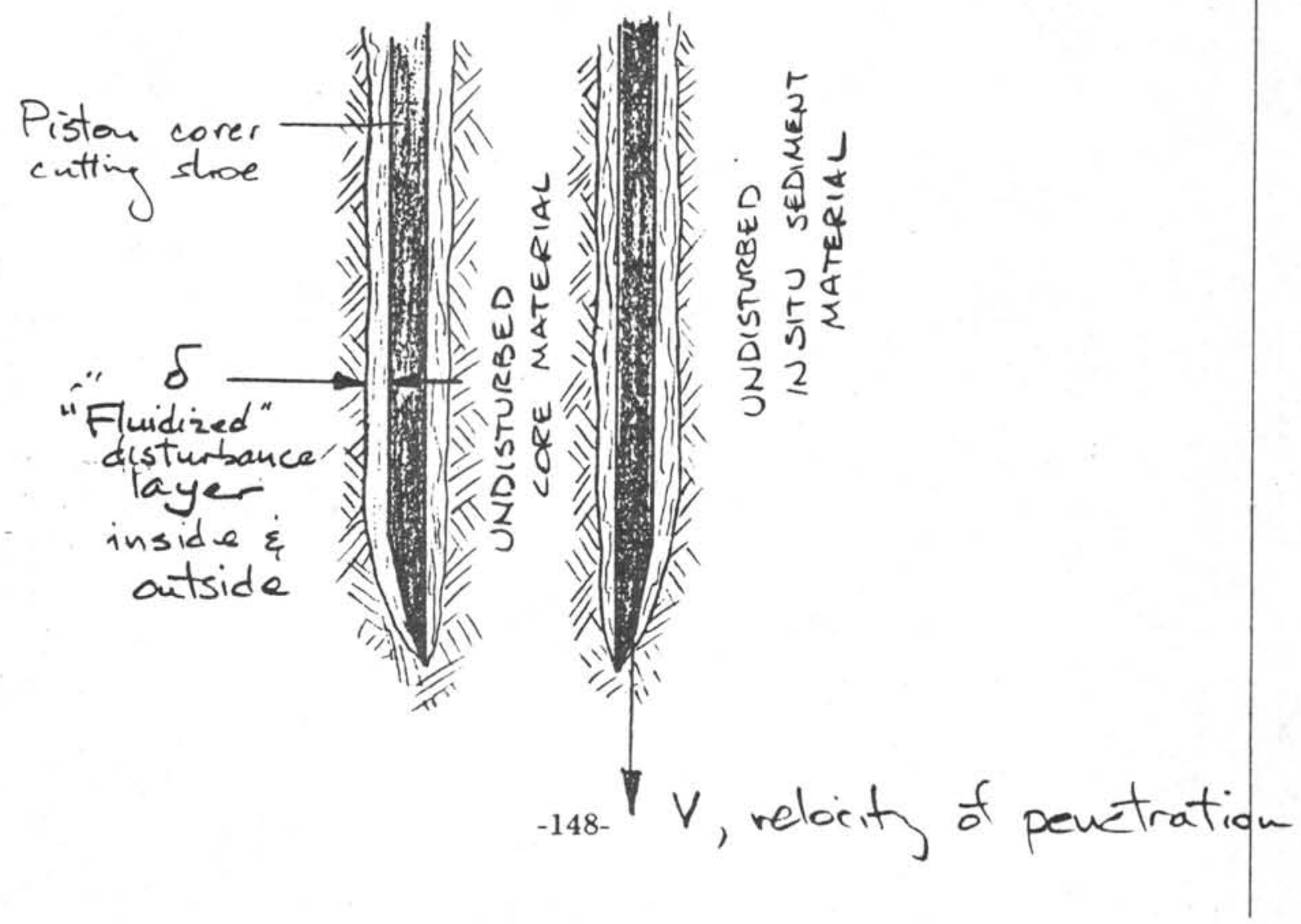


Further assume that conditions within. the disturbance layer simulate laminar flow of a highly viscous flick. (Reynolds number can later bc calculated to check if famminar flow conditions are likely to exist.)

Then fridionistance to punctuation of the corer into the sediment can be approximated by using the skin friction equation,

$$
\begin{aligned}
& \text { Drag }=C_{d f} \frac{\rho V^{2} A}{2 g c} \quad \begin{array}{c}
\text { where } \\
\text { ifensity of }
\end{array} \\
& \text { "fluidized" material } \\
& \text { within the } \\
& \text { c. disturbance layers } \\
& V=\text { velocity of pendratio. } \\
& A=\text { affected surface } \\
& \text { area }
\end{aligned}
$$

$C_{D f}$, Frietwin drag coefficient can be determined by using the Blasius Equ. for laminar boundary layer flow ore a flat plate. In this case, the inside or autrils

$$
C_{\text {Of }}=\frac{1.328}{\sqrt{R_{e}}}
$$

surfaces on the

corer are treated as a flat plate of length

$-149-$ $\ell_{\dot{s}} \cdot \operatorname{cor} d t u=\pi d$ 
where $R_{e}=\frac{V R}{A x}=\frac{\rho V l_{\text {total }}}{g c \mu}$

$$
\begin{aligned}
\mu & =a b s \cdot \text { viscosity } \\
& =\text { Jet }
\end{aligned}
$$

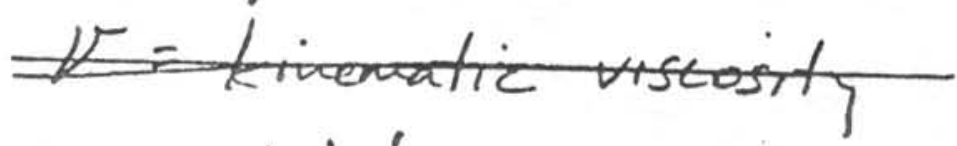

$\ell_{\text {total }}$ length of corer.

54 $P,-$ Freud density in the disturbance lays shard may vary between sediments from 143 to $183 \mathrm{lb} / \mathrm{ft}^{3}$

(Ref: DSDP Tech. Report \#9)

or $124 \mathrm{lb} / \mathrm{ft}^{3}$ (Ref: Nugent, HPC Anal. Report)

Since this parameter is used to the $1 / 2$-power in the later derivation, no great error is introduced by assuming it constant. Choose mean density, $\rho=120 \mathrm{lb} / \mathrm{ft}^{3}$ for any value of sediment shear strength, $T$. in, absolute viscosity of the sediment must be derived as a function of $\lambda$, which is give. 
From the definition of $\mu$

55

$$
\mu=\tau \frac{d y^{\prime}}{d v}
$$

This defines a Newtonian third which the "fluidized sedinat" in the corer disturbance layer probably is not. However, lacking move accurate information. purswer-this as a rough approximation $\frac{d y}{d V}$ is The inverse $y=$ be velocity gradient in th- boundaticy layer. To find a value certain assumptions are required.

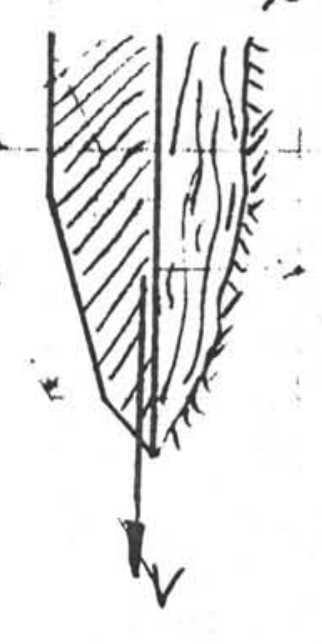

$d y_{\text {max }}=\delta=$ (by assumption) $1 / 10 "$ Then $\frac{d y}{d y}=\frac{a_{1}}{d x}$ (constant slope) $\frac{\text { Therefore } \mu^{\prime}=\frac{\tau(0.1)^{\prime \prime}}{V}=\frac{\tau \delta}{V}}{-151-}\left\{\begin{array}{c}\text { Defined viscosity } \\ \text { for his relatioustly } \\ \text { outs, } \mu^{\prime}\end{array}\right.$ 
"typical

56

Arbitrarily select a viscosity" to represent "liquified" sediment

$$
\begin{aligned}
& \mu^{\prime}=1 \times 10^{-3} \frac{1_{f f}-\sec }{t} \leftarrow 100 \text { low, } \\
& =.001 \\
& \text { SAl } 10 \text { OwL } \mathrm{C}^{32^{\circ} \mathrm{F}} \\
& \mu>10^{2}
\end{aligned}
$$

The other source of penetration resistance comes from the actual displacement resistance of the sediment to make way for the rolumine occupied by the corer wall.
This is a function of the frontal area and tie compressive strength of the sediment.

Use a compressive strength related to shear strength of $S_{c}=2 \pi$.

The frontal area to be "Compressed aside",

$$
\begin{aligned}
A_{f} & =\frac{\pi}{4}\left(0 . D^{2}-\text { core dian } a^{2}\right) \\
& =\frac{\pi}{4}\left(3.5^{2}-2.61^{2}\right)=4.27 \mathrm{in}^{2}
\end{aligned}
$$

"Displacement resistance" is then

$$
S_{c} A_{f}=S_{c}\left(4.27 \mathrm{in}^{2}\right)=4.27 S_{c}
$$

$-152-$ 
Therefore

$$
D_{\text {rag }}=C_{D_{f}} \frac{\rho V^{2} A}{2 g_{c}}+4.27 \delta_{C}
$$

where.

$A=$ surface area in contact with sediment

$$
\begin{aligned}
& =l[\pi(0.0 .)+\pi(1.0 .)] \\
& =\pi l[0.0 .+1.0 .]
\end{aligned}
$$

$$
\begin{aligned}
& D_{r a g}=\frac{1.328}{\sqrt{\operatorname{Re}}} \frac{\rho V^{2} \pi l(0.0 .+1.0)}{2 g c}+4.27(2.7) \\
& =\frac{1.328 \sqrt{\mu^{\prime} g_{c}}}{\sqrt{\rho v e_{\text {teal }}}} \frac{\rho V^{2} \pi l(0.0+1.0)}{2 g c}+8.54 \tau \\
& =\frac{1.328 \sqrt{e_{c} d \mathrm{dV}}}{\sqrt{\rho^{V \ell_{\text {total }}}}} \frac{\rho V^{2} \pi l(0.0+1.0)}{2 g c}+8.54 \tau
\end{aligned}
$$

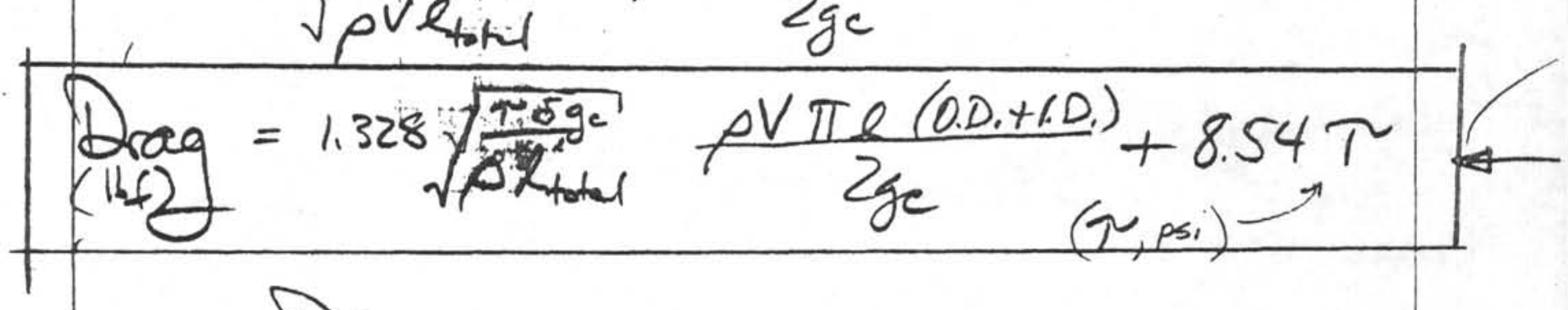

DraG due to SEDIMENT PEnETRation RESISTANCE, $f(\tau, l, V)$

$-153-$ 
APPENDIX E

EXCERPTS FROM CRUISE OPERATION MANAGER'S REPORTS LEGS 94-96 
APPENDIX E

EXCERPTS FROM CRUISE OPERATION MANAGER'S REPORTS LEGS 94-96 
The Advanced Piston Corer (APC) was successfully tested on Leg 94. It recovered 37 cores on two holes. The core quality was comparable to that of the VLHPC. All of the special features functioned as designed. The one readily evident feature was the ease of handling afforded by its short (38') length, and its mechanical simplicity. Unfortunately, part of one of the two units was lost down hole apparently due to excessive pull-out forces. Shortly thereafter the lower BHA, including the Seal Bore Drill Collar, was also lost so that no more APC coring could be attempted on this Leg.

\section{ASSEMBLY}

Both APC tools were assembled during the 8.1 day transit to site 606 . The assembly procedure outlined in the manual was very clear and there were no insurmountable problems. The tool with the anti-spiral groove was the first to be assembled. The rod connections were Baker-locked together. However, when the tool was scoped together it did not close fully, so that the shear pin holes through the Outer and Inner Shear Pin Subs did not align. It was found that the Anti-Spiral Key OP4770 was wedging at the top of the groove in the rod. Both Keys were shortened to the dimensions shown in Fig. 1 to solve the problem.

The second APC was assembled without incident. The lower, scoping section of the second barrel was mated to the upper section of the first tool, and an extra liner lock hole was marked and drilled through the Vent Sub OP4758, so that both scoping sections aligned with the same upper section.

\section{INITIAL TEST - SITE 606}

A partial BHA was hung off below the rig floor. It consisted of a bit, bit sub, bit sub spacer, seal core drill collar, landing/saver sub, $3^{\prime}$ spacer, top sub, head sub, Monel drill collar, and two stands of $81 / 4^{\prime \prime}$ drill collars. The APC with the anti-spiral groove was installed and run down with the BHA. $V$-packing was used for both the inner and outer seals. One shear pin was used and one flow control screw was left out. Unknown at the time, the APC was inadvertently installed so that the $4 " 0$. D. Top Sub was landed on the Seal Bore Collar instead of on the Landing Saver Sub. The Drilco boreback in the top of the collar allowed enough space for the pin of the Landing Saver Sub to make up fully without contacting the APC Top Sub.

The circulation head was installed onto the BHA, and the system was pressurized. It appeared that the pin sheared at $700 \mathrm{psi}$, for when the pump was stopped the pressure bled off. Of course it was impossible to retrieve the tool, for the Top Sub was trapped in a space between two 3.8" I.D. sections. The BHA was tripped, and the installation error was discovered; it was also discovered that the pin had not sheared. 
The shear pin was changed, and the APC was run back down with the BHA. This time the pin definitely sheared at 1000psi; the event was heard and felt through the pipe. After retrieval the APC would not scope fully closed. It was later found that a shear pin stub from the wall of the Outer Shear Pin Sub had fallen in and was trapped between the jam nut and the inner ledge of that sub. The seals were fine, and the Anti-Spiral Key caused no friction problems. But, as evidenced in this test and in actual coring, the outer seals allow some flow-by.

\section{SITE 606. WATER DEPTH $=3022$ METERS}

Eighteen APC cores were taken in spongey, adhesive nanno ooze grading from soft to firm. Of the 165.8 meters cored, 154.1 meters were recovered for a $92.9 \%$ total recovery. The core quality was excellent. The average time per core was 1.5 hours; this included handling the Kuster orientation tool. The first 12 cores were taken with the grooved piston rod; the last 6 were taken with the grooveless piston rod. V-pack seals were used for both the inner and outer seals.

Following the APC Operational Guidline Chart, two hard (17-4PH) shear pins were used, and no speed control set screws were removed for the first few cores. By core 12 all of the speed control screws were removed, and two pins were still being used. During this time there was no clear indication of shoot-off on any of the cores. The drill string was typically pressurized to 1500-2000 psi to shoot the core.

Beginning on core 13, three shear pins were used (two hard and one soft), with all of the speed control screws removed. Immediately thereafter the shoot-off pressure became very distinct, with a 400-500 psi bleed-off at 2700-2950 psi. This suggests that full stroke may not have been achieved when only two pins were used, though the cores were always nearly full.

The one recurring problem was that the stubs from the sheared pins usually fell out of the wall and onto the internal ledge of the Outer Shear Pin Sub OP4715, to prevent the tool from reclosing fully. These stubs were routinely fished out with a small magnet attached to a length of stiff wire, but more often than not, one stub would find the groove in the rod and fall deeper into the tool and lodge in the inner seals which required almost total disassembly to remove. In addition, during the first ten or so runs through the pipe, much rust also accumulated on the ledge. The shear pin problem was almost completely solved by the following technique: Both ends of the pins were flared with a hammer. Then they were cut in half and inserted through each end of the shear pin holes. The wall-stubs were now held in place, but a few times the center stubs fell out and had to be fished.

The outer V-packing seals normally lasted for 10 runs. The inner seals were replaced only when damaged by shear pin stubs. 


\section{SITE 606A}

Nineteen APC cores of excellent quality were taken at this site. The groveless piston rod was again used without incident until near the bottom of the hole. An overpull of 100,000 lbs was needed to retrieve core 18 . Previously no overpulls higher than 20,000 lbs. were necessary. Less than 20,000 lbs. overpul1 was needed to retrieve core 19. The piston rod parted at 40,000 lbs. overpull while attempting to retrieve core 20 . The break occurred at the base of the pin connection on the Center Piston Rod OP4762 (see attached photos). The Lower Piston Rod, Piston, and the entire scoping section were lost down-hole.

Several hours later, while washing into Hole 607B, the BHA broke off at the mandrel pin connection of the lowest bumper sub. With it went the Seal Bore Drill Collar, the Landing/Saver Sub, and the Bit Sub Spacer. It appears to be only a coincidence that it was lost so soon after the APC failure, but the impact loads and/or the 100,000 lbs. overpull may have been contributing factors. The bumper sub was last magnafluxed at the end of Leg 93.

\section{CONCLUSION}

The shorter tool length, ease of handling, and mechanical simplicity make the APC a superior tool to the VLHPC. Obviously either the piston rod will have to be strengthened or the overpull limit will have to be lowered to prevent the failure that occurred on this leg. The inner ledge of the Outer Shear Pin Sub traps pipe corrosion debris and shear pin stubs, but it is not a major problem. A polypak outer seal was tried once, and it was destroyed after one run. The V-packs worked very well, though they have to be changed more often than the static outer seals of the VLHPC. The antispiral groove on the one piston rod functioned perfectly; no friction problems were observed either during activation or resetting of the tool. The Break-away Piston Head was not used.

The core liners fractured quite often during APC coring. They were usually not badly damaged - a football shaped crack or partial collapse near the top or the bottom, sometimes a split extending the length of the liner. This is a common problem with the VLHPC also, and is probably due to a break in the atmospheric pressure seal between the o-rings outside the liner. Several times an unbroken o-ring from the Lower Liner Seal Sub was found several meters up inside the core, suggesting that the 1 iner may compress to expose the lower o-rings due to thermal and mechanical contraction during coring. 
SPECIAL TOOLS -- CORING SYSTEMS -- LEG 95

Aduanced Piston Corer (APC)

The APC, the latest generation of the hydraulic piston corer, was used on Leg 95 after successful prototype trials on Leg 94 . Results of its usage on this voyage were generally favorable. A few design deficiencies and operating encumberances were noted but the tool could be considered operational. It was used at Site 612 to take seven cores before the sediment becane too firm for piston coring.

One of the features, the anti-spiral grooved rod, was abandoned when the a) ignment of the groove between the rod sections could not be maintained. An ungrooved rod is available to be used for Leg 96 and the grooved assembly remains a viable backup if used without the key which tracks in the groove.

The Seal Bore Orill Collar and Landing/Saver Sub, both of which have honed bores 3.80 inches in diameter, were stored in the casing rack filled with fresh water and sealed by gasketed thread protectors to minimize deterioration of the honed working surfaces.

At the end of Site 612 the APC was picked up and go-deviled to the bit at 25 strokes/min. without the wireline attached to test if this could be done without pre-shearing the shear pins. If successful the APC could be operated without the wireline in the pipe thus making piston coring compatible with the Heave Compensator during bad weather aperations where core disturbance is always a problem. The APC had two 17-4 shear pins installed and all four pluggable speed control holes were plugged. The tool was retrieved with the shear pins sheared. All evidence pointed to the pins being sheared at the moment of impact at the landing shoulder. The landing impact was thus calculated to have been greater than $39.59^{\prime}$ s.

\section{Breakaway Piston Head}

The new Breakaway Head for the piston coring systems was tested quite successfully at Site 612 with the APC. It is adaptable to either the APC or ULHPC with minor hardware exchanges. The breakaway portion of the head, designed to come off when suction is applied to the top of the core, performed exactly as intended and was found "brokenaway" on top of the core inside the liner after each piston core run.

The assembly was designed to use only Polypak seals which were not satisfactory. A redesign to V-packing seals will be done before future use. Further testing will determine if flow-in disturbance after partial strakes is effectively eliminated by this new device but early indications after Leg 95 testing are positive. Use of the Breakaway Piston Head causes no distinct rig floor problems as long as several head portions are available for redressing. with the single upper assembly attached to the Piston Rod. 
INTERNATIONAL PHASE OF OCEAN DRILLING

DEEP SEA DRILLING PROJECT

OPERATIONS RESUMF.

LEG 96
APC H:N.

$\begin{array}{lll}\text { 614 } & 616 & \text { L17A } \\ 614 A & 616 A & \\ 615 & 616 E \\ 615 A & 617\end{array}$

The 96 th and final scientific expedition of the Deep Sea Drilling Project concluded $151 / 2$ years of continuous worldwide geological coring operations by the drillship GLOMAR CHALLENGER. For the final voyage, the vessel returned "home" to the Gulf of Mexico. The primary focus of study was the sedimentary and biostratigraphic nature of the Mississippi Fan, the huge accumulation of sediment extending across the Gulf from the outlet of the Mississippi River.

Twenty holes were cored at eleven sites on the Mississippi Fan and in the Orca and Pigmy intraslope basins. The scientific goals of the cruise were achieved despite powerful currents that taxed the vessel's positioning system to the limit and unstable hole conditions that frequently threatened to stick the drill string and halt cperations. A successful logging program was carried out that produced successful well logs from seven holes.

The voyage commenced on Scptember 26, 1983 at Port Everglades, Florida and terminated on November 8, 1983 at Mobile Alabama. Total length of the leg was 43.1 days, of which 32.3 days were spent on site, 3.5 days in port and 7.3 days in transit. Mechanical breakdown accounted for only 0.5 hour.

\section{Ft. Lauderdale Port Call}

Leg 96 had its official beginning at 0654 hours, September 26, 1983 with the first mooring line at Berth Two of Port Everglades in Fort Lauderdale, Florida. Shortly after arrival, it was necessary to shift to Berth 0oe. This was accomplished by 1000 hours, and port call activities then commenced in earnest.

Principal work items included the top overhaul of No. 9 engine, repair of No. 1 gyro compass, U.S. Coast Guard inspection of GLOMAR CHALLENGER, crew change, offloading of cores, on-loading of 1000 sacks of barite and miscellaneous freight and an open house for local visitors. With all scheduled work completed, the vessel departed her berth at 1808 hours, September 29.

Ft. Lauderdale to Site 614

Excellent speed was achieved on the transit to the initial operating area. A nearshore countercurrent of the Gulf Stream combined with a following wind and calm seas to produce a speed 
of over 11 knots as CHALLENGER rounded the Florida Peninsula and turned west past the Florida Keys. A few hours after leaving the countercurrent, the vessel encountered another current which carried her toward the operating area at speeds increasing to about 13 knots. This unexpectedly strong current hampered maneuvering for the relatively complex preliminary profiling survey. After a $4-1 / 2$ hour survey, a positioning beacon was launched at 1332 hours, October 1, marking arrival at Site 614. The drill site was located about 120 miles west-northwest of the Dry Tortugas Islands and about 150 miles north-northwest of Cuba.

Hole 614 - Lower Mississippi Fan

The approach profile was extended about 15 minutes beyond the beacon drop point before the vessel was turned and the towed seismic gear was retrieved. As the vessel began to approach the beacon to take station, the beacon's acoustic signal weakened abruptly and developed pulse characteristics that were rejected by the positioning system. Using LORAN C navigation, the ship struggled back to the drop coordinates against the strong current and an alternate frequency beacon was dropped at 1510 hours.

Satisfactory positioning was finally achieved at 1645 hours, and the pipe trip began. The current pushed the bottom hole assembly (BHA) so strongly against the moonpool bracing that it was necessary to let the vessel drift momentarily to facilitate setting the upper guide horn into position. The drill string continued to be forced strongly against the pipe restraint and to vibrate violently for the duration of the pipe trip.

The precision depth recorder (PDR) reading placed the seafloor between 3310 and $3320 \mathrm{~m}$ below the rig floor. The core bit was positioned at $3314 \mathrm{~m}$ for the first attempt with the advanced hydraulic piston corer (APC). The corer stroked to $3323.5 \mathrm{~m}$ and was recovered nearly filled with core $(9.33 \mathrm{~m})$. One joint of pipe was set back and another core was "shot" from $9.5 \mathrm{~m}$ higher to ascertain that no sediment had been missed. It was necessary to interrupt this operation for one hour when the current and wind pushed the vessel about 60 meters off station. The corer was recovered with no trace of sediment, and the water depth was established at $3314.1 \mathrm{~m}_{r}$ Two additional mud cores of good quality were taken to $27 \mathrm{~m}$ BSF (below seafloor), where soft, loose sand was encountered. Penetration and recovery were reduced to nil, and the same interval was cored three times before a twometer sand core was recovered. As the corer was being lowered for the next attempt, a sudden drop in sandline weight indicated that the coring assembly had been lost. On recovery of the sandline, it was found that the wireline swivel had come apart, leaving the APC, the sinker bar assembly and the lower portion of tine swivel in the pipe. The dimensions of the swivel prohibited recovery from the pipe by wireline fishing. A round trip was therefore necessary to continue operations. In the meantime, however, the dressed corer had settled into position in the outer 
core barrel. The bit was lowered to the bottom of the hole and the pipe was pressured to actuate the corer before the drill string was recovered.

The corer was recovered from the BHA at the drill floor at 1700 hours, October 2, containing about eight meters of loose sand.

Hole 614A

With the round trip complete, Hole $614 \mathrm{~A}$ was spudded at 2341 hours, October 2. The bit was "washed" down to $37 \mathrm{~m} \mathrm{BSF}$, the total penetration of Hole 614. Another ten meters of loose sand was cored before mud and clay strata were again encountered. APC coring continued through the day in sediments consisting of alternating sand and mud beds, with sand predominating. Core recovery was unexpectedly high, though penetration of the corer, as expected, was limited. This was held to as little as two meters in the cleaner and coarser sands. At about $115 \mathrm{~m}$ BSF, the clay became much stiffer and became a factor in both reduced penetration and increased overpull on retrieval. At $131 \mathrm{~m}$ BSF, the APC was retired in favor of the extended core barrel (XCB). Two XCB cores were attempted with only a few centimeters recovered each time. At this point, the scientific objectives were considered to be accomplished and coring operations were terminated at a total drill string depth of $3464.4 \mathrm{~m}$. The drill string was recovered and the vessel was under way at 0140 hours, October 4 .

Site 614 to Site 615

The next intended drill site lay only about eleven miles to the northeast of Site 614. Because of extensive preliminary profiling, only the $3.5 \mathrm{kHz}$ echosounder was used to supplement LORAN C navigation for final site location. At 0459 hours, a $13.5 \mathrm{kHz}$ acoustic beacon was dropped at the desired location. The approach profile was extended 2.5 miles beyond the drop point before the ship turned to return to the beacon. During this time the beacon's signal was monitored as it fell to the seafloor. The pulse width was noted to be too short for acceptance by the dynamic positioning system (DPS) and the signal rapidly dropped to a low level. More PDR profiling was then done to locate a proper drilling location and a $16 \mathrm{kHz}$ beacon was launched at 0547 hours. As the vessel waited to take station while the second beacon fell through the water column, the original $(13.5 \mathrm{kHz})$ unit began to transmit a strong usable pulse which obliterated the now very weak $16 \mathrm{kHz}$ signal. Optimistically acknowledging that flexibility is a virtue and that one of two is not bad, the GMI staff switched the DPS back to $13.5 \mathrm{kHz}$ and took station on the nearby original beacon.

The pipe trip began at 0700 hours. At 0750 hours, the $13.5 \mathrm{kHz}$ signal degenerated to a completely unusable level. The $16 \mathrm{kHz}$ 
beacon was now acquired at a distance of $760 \mathrm{~m}$ and the DPS was shifted back to that frequency. It soon became apparent that the $16 \mathrm{kHz}$ pulse was too weak to be heard through the thruster noise and rrequent loss of acoustics occurred. With beacons transmitting unusable signals on both operating frequencies, it was necessary to abandon the location and to find an alternate drill site out of acoustic range of the two beacons. The BHA was recovered and CHALLENGER got under way profiling at 0900 hours.

A target area was selected about $1.3 \mathrm{~km}$ north of the beacons. The towed seismic gear was streamed as less geophysical information was available for the new location. A new $13.5 \mathrm{kHz}$ beacon was launched at 1037 hours, and an additional 1-1/4 hour of surveying was done before the gear was retrieved and final station was taken. The pipe trip commenced at 1245 hours.

Hole 615 - Lower Mississippi Fan

With the PDR depth at 3279 meters, the core bit was positioned at 3275 meters to ensure recovery of the sediment/water interface in the first 9.5 meter APC core. The core barrel was recovered with only traces of sediment in the core catcher, indicating that the very soft material had been washed out during retrieval. A second core was "shot" from two meters deeper and 2.6 meters of core was recovered, establishing water depth at $3283.9 \mathrm{~m}$.

Continuous APC cores found sand beginning at only 19 meters BSF, but good penetration and recovery were realized to about $105 \mathrm{~m}$ BSF through alternating sand and mud strata. Performance then dropped sharply, with the APC apparently unable to make significant penetration. At $143 \mathrm{~m} \mathrm{BSF}$, the XCB system was deployed. Recovery remained low, but representative cores, averaging about two meters, were obtained to about $210 \mathrm{~m} \mathrm{BSF}$. Below this depth only traces of sand and clay were generally recovered. Desperation attempts with the APC were met with full barrels of flow-in sand or very short cores of hard clay. At about $495 \mathrm{~m} \mathrm{BSF}$, an abrupt lithology change to carbonate ooze resulted in a return to excellent core recovery with the XCB.

Hole conditions had, remained good, considering that the penetrated section consisted of over $60 \%$ uncemented sand. Up to five meters of hole fill had been noted between cores, but periodic mud flushes had been fairly effective in cleaning the hole. As the bit (which was not equipped with a float valve) approached 500 meters BSF, back pressure could no longer be controlled and shut in pipe pressures to $400 \mathrm{psi}$ were noted. It was necessary to slug the pipe with weighted mud before core barrels could be dropped against the back flow. Core barrel No. 52 became stuck at the bit and two wireline trips were required to retrieve it. With most of the scientific objectives of the site achieved, coring operations were terminated at $523.2 \mathrm{~m}$ BSF for the safety of the drill string. 
The lack of core recovery had lent increased importance to the logging program for the delineation of lithologic units. The apparent poor hole conditions made prospects of getting to bottom for open-hole logs look slim. Preparations were therefore made to run a through-pipe formation density/compensated neutron/gamma ray (FDC/CNP/GR) IOB. The hole was flushed with mud to counteract the back pressure. One stand of pipe was then set back to allow for cumulative hole fill. By the time the logging sheaves had been rigged and the sonde started down the pipe, shut in back pressure had increased from zero to $260 \mathrm{psi}$ and the drill string had become stuck. It was necessary to abort the logging attempt to attempt to free the drill pipe. About 35 minutes of "working" the pipe was required to free it and the through-pipe logging concept was abandoned.

The hole was then filled with 300 barrels of barite weighted mud and the bit was pulled to 3330 meters. The dual induction/longspaced sonic/gamma ray (DIT/LSS/GR) tool was then assembled. About $2-1 / 4$ hours were spent in tracing an intermittent electrical leak to a connection in the cabling between the winch and recording cabs. The long logging sonde stopped abruptly only a few meters after its lower end had passed through the bit and would go no further. The tool was manipulated with little progress for about one half hour but, just before efforts were abandoned, it broke through into open hole. To the surprise of everyone, the hole was then found to be absolutely clear as the sonde descended to only 17 meters off total depth. A log of excellent quality was then recorded for the length of the hole. The upper portion of the logging sonde had already started into the pipe when the lower portion became firmly stuck at the same spot that had given trouble on the down trip. After over two hours of effort, the tool was finally freed by moving the core bit up and down over the logging tool.

When the first sonde had been recovered, two joints of pipe were added to place the bit below the interval of tight hole. The FDC/CNL/GR tool was then deployed, but the run was aborted when a special spectral gamma ray module malfunctioned. It was replaced by a standard gamma ray cartridge and adapter. This second logging tool also encountered obstructions in the first 20 meters of open hole. It broke into smooth going after much effort, and another good $\log$ was recorded from the same depth as the first run.

With logging operations completed, the sheaves were rigged down and the bit was pulled clear of the seafloor in preparation for respudding.

Hole 615A

Hole 615A was spudded at 1317 hours, October 9, in 3285.9 meters of water after the vessel had been offset 19 meters to the northeast. The hole was drilled to collect cores for 
geotechnical studies at a later date. Since sand was of little interest for this purpose, coring efforts were concentrated on the more clay-rich intervals. Recovery performance of the APC and XCB systems was consistent with that of the first hole as $615 \mathrm{~A}$ was drilled and spot cored to a total depth of 3494.4 meters. The drill string was recovered, and GLOMAR CHALLENGER departed for the next drill site at 2035 hours, October 10 .

Hole 616 - Flank of Middle Mississippi Fan

The new drill site was located about 190 miles southeast of the tip of the Mississippi River delta. The transit was made in 11$1 / 4$ hours, and a beacon was let go at 0745 hours, October 11. After an additional 1-1/2 hours of profiling, the vessel returned to take station on the beacon (which was functioning perfectly).

Following the pipe trip, two unsuccessful attempts were made to capture the sediment/water interface with the APC. Both core barrels were recovered without core and with the breakaway piston head resting at the bottom of the liner. The first barrel stroked to $3000.5 \mathrm{~m}$ and bore traces of sediment on the core catcher. The second extended to $2997.5 \mathrm{~m}$ and was recovered without a trace. For the third attempt, a fixed piston head was installed, and the bit was positioned at $2995.5 \mathrm{~m}$. The 9.5 meter corer recovered 6.1 meters of core, and water depth was established at 2998.9 m (compared with 2993 m ?DR depth).

Good results were obtained with the APC through clay and silt to about $75 \mathrm{~m} \mathrm{BSF}$, where recovery dropped to about $50 \%$. The APC was replaced by the XCB system at $104 \mathrm{~m}$ BSF, but four consecutive cores produced a total of only $1.36 \mathrm{~m}$. Three APC cores then achieved about one half stroke before a withdrawal overpull of 95,000 pounds again prompted a switch to XCB coring. Three consecutive XCB cores yielded $4.9 \mathrm{~m}$ of sand and clay core. With recovery low, the XCB was retrieved on each second pipe joint to $296 \mathrm{~m} \mathrm{BSF}$. Continuous XCB cores then gave increasingly good recovery to $371 \mathrm{~m}$ in very stiff clay. The XCB was then dropped for the final planned core, and a 40 barrel mud flush was pumped into the pipe to condition the hole for logging.

As the connection was being made for the final core, the drill string abruptly became stuck. This was completely unexpected, as no hole problems had been encountered up to that time. Two hours of working the pipe failed to budge it, and it became evident that the BHA was permanently emplaced. Lack of bumper sub action indicated that the stuck point was more than $50 \mathrm{~m}$ above the bit. Because of low core recovery through the lower two thirds of the section, well logs had again become increasingly important for the fulfillment of the site's scientific objectives. The stuck pipe now precluded open-hole logging, but a through-pipe gamma ray $\log$ could still be run to delineate the sand/clay boundaries. The logging sheaves were rigged, and a FDC/CNP/GR $10 \mathrm{~g}$ was recorded. Surprisingly there was only about four meters of fill 
and nine meters of open hole was logped below the bit. The natural gamma ray curve was quite readable and was even more useful than had been anticipated.

The severing apparatus was then assembled and run down the pipe. The prima-cord charge successfully parted the string in the lowermost joint of 5-1/2 inch drill pipe. When the logging cable was retrieved, it was found that the line had parted just above the cable head, resulting in the loss of the casing collar locator and the shooting sinker bar assembly.

The drill pipe was then recovered, with the severed joint arriving on deck at 0930 hours, October 14.

Hole $616 \mathrm{~A}$

The second borehole was added to the drilling program to obtain an oriented core in a shallow zone of steeply dipping beds and to recore the interval of low recovery at 114-142 $\mathrm{m} \mathrm{BSF}$ in Hole 616 .

Assembling and spacing out the replacement BHA added about four hours to the "down" trip time and Hole 616A was spudded at 1917 hours. The hole was drilled without coring to $34.6 \mathrm{~m} \mathrm{BSF}$, where the oriented core was desired.

The special non-spiraling APC assembly and the prototype gyro orientation tool were then deployed. The coring assembly was retrieved after an apparently normal actuation. Disappointment prevailed when the core barrel was found to contain only $39 \mathrm{~cm}$ of sediment. The sticky clay had held the core catchers open, allowing the core to fall out during retrieval. The misadventure was compounded when it was found that no orientation data had been recorded. The wiring of the Byro tool had been damaged during final assembly. It was further discovered that a pressure case 0-ring seal had failed. The pressure case had flooded and the gyro was damaged beyond repair.

The hole was then drilled to $94 \mathrm{~m} \mathrm{BSF}$, where the pipe began torquing. A bentonite mud flush freed the pipe after a delay of one half hour. Continuous coring began at $103.5 \mathrm{~m}$, but operations were again interrupted after two cores when the APC became stuck in the drill pipe as it was lowered for core No. 4H. Two additional wireline trips were made in attempts to dislodge the corer, but each time the overshot pin sheared and no progress was made. The APC was finally knocked to the bottom by pumping a standard inner barrel down the pipe at high speed. Core No. $4 \mathrm{H}$ was "shot" and retrieved routinely, and no evidence was found as to the cause of the sticking. The following core attempt produced an incomplete stroke indication and no core was recovered. As this was to be the final core of the hole, no further attempt was made and coring operations were terminated to maintain the operating schedule. The core bit was then pulled clear of the seafloor for respudding. 
The final hole at Site 616 was a planned 200 meter penetration dedicated to geotechnical purposes. Continuous APC cores were taken to about $95 \mathrm{~m} \mathrm{BSF}$, where complete stroke of the corer was no longer achieved. Coring then continued in the APC mode with uncored intervals drilled of to maintain the operating pace of one pipe connection per core. At $165 \mathrm{~m} \mathrm{BSF}$, the withdrawal overpull following core No. $19 \mathrm{H}$, reached 90,000 pounds. Coring force was reduced somewhat for the remaining four cores by using $2-1 / 2$ shear pins instead of the maximum three. Overpull then remained within operating limits to the total depth of $204.3 \mathrm{~m} \mathrm{BSF}(3203.1$ m pipe depth).

Excessive torque was required to rotate the drill string on three occasions during the coring of Hole 616B. In each case, operations were interrupted to flush the hole with bentonite mud and the hole trouble disappeared.

After a routine pipe trip, the vessel got under way for Site 617 at 1445 hours, October 16 .

Site 616 to Site 617

The middle fan operating area lay about 105 miles to the westsouthwest of Site 616. The approach course was altered slightly to bring the vessel to a turning point just to the northeast of the operating area. A southwesterly profile then crossed the closely spaced proposed Sites $M F-7 A, M F-6 A$, and $M F-5$ in order. $A$ reciprocal line was run back across the latter two sites. Another turn was made and beacons were dropped for Sites MF-6A and $M F-5$ (617). The transit and survey were made in $15-1 / 2$ hours. The seismic gear was then retrieved and the vessel was positioned on offsets $575 \mathrm{~m}$ south and $720 \mathrm{~m}$ west of the second beacon.

Hole 617 - Middle Mississippi Fan

At 1334 hours, October 17, the 9.5 meter APC was shot from the PDR depth of 2477 meters. The eight meters of sediment recovered established water depth at $2478.5 \mathrm{~m}$.

Before the second core could be attempted, shifting winds from heavy rain squalls combined with a strong local current to carry the vessel about 120 meters off station. Weather conditions stabilized and positioning became sufficiently steady to resume coring after a delay of $1-1 / 2$ hours.

APC coring then proceeded smoothly through clay and silty mud to a depth of $191.2 \mathrm{~m} \mathrm{BSF}$, where the scientific objectives were considered accomplished. The power sub was left in the string to lay out doubles, and the bit was pulled clear of the seafloor at 
1227 hours, October 19 to end Hole 617 operations.

Hole $617 \mathrm{~A}$

The unexpected absence of sand in Hole 617 led to reconsideration of plans to drill an additional hole at Site MF-7A for geotechnical studies. The known favorable conditions prompted the decision to relocate the middle fan geotechnical hole to Site 617 . The vessel was therefore offset 30 meters to the southwest to avoid the Hole 617 disturbed area, and Hole $617 \mathrm{~A}$ was spudded at 1303 hours.

Continuous APC cores were taken to $74 \mathrm{~m} \mathrm{BSF}$ without significant problems. Two core attempts at this depth met with no recovery or apparent penetration. The corer was being lowered for a core attempt one joint $(9.5 \mathrm{~m})$ deeper, when operations were interrupted by weather.

The wind, which had been almost exactly opposing the strong current, shifted about 30 degrees to the vessel's port quarter and increased in velocity. The ship's thrusters were unable to maintain heading against the resultant turning moment and the vessel broached. It was then quickly carried about 360 meters off station by the current before action could be taken to arrest the excursion.

The rig was brought back over the hole after a $3 / 4$ hour delay, and the APC was run down the pipe. With the BHA not yet fully supported by the hole, damage to the BHA can be expected from a large positioning excursion. Suspicions were confirmed when the APC stopped at the approximate location of the bumper subs, indicating a bent sub. This, of course, meant that no more coring could be done in Hole $617 \mathrm{~A}$ and that a pipe trip was necessary.

The APC was retrieved and the drill string was recovered. It was found that the mandrel of the upper bumper sub was, indeed, slightly bent. As the next stand of drill collars was brought through the rig floor, it was discovered that the lowermost drill collar and the entire outer core barrel assembly had been lost when bending forces had caused the rotary shouldered connection to fail.

During the pipe trip, it had been determined that positioning could not be maintained within operating limits under the existing current and weather conditions. The only alternative was therefore to move to the Orca and Pigmy Basin operating areas to the west and to hope for improved conditions upon the vessel's return to the middle fan.

Hole 618 - Orca Basin

The 148-mile transit was made in 16 hours. Site 619 was located 
APPENDIX F

CURRENT DRA WINGS

$-171-$ 
E. PARTS LIST

ADVANCED PISTON CORER - MOD. II

\begin{tabular}{|c|c|c|}
\hline $\mathrm{P} / \mathrm{N}$ & DESCRIPTION & NO. REQ'D. \\
\hline OP4800 & Advanced Piston Corer Assy. - Mod. II & - \\
\hline OP4704 & Pulling Neck Lock Nut & 1 \\
\hline OP4710 & Speed Control Set Screw, 5/8-11 UNC: $\times 5 / 8 \mathrm{SS}$ & $0-4$ \\
\hline OP4712 & Support Washer & 1 \\
\hline OP 4713 & Stop Washer & 1 \\
\hline OP4721 & Shear Pin, $1 / 4$ dia $\times 3-7 / 32,17-4 \mathrm{PH}$ & $1-3$ \\
\hline OP4725 & Shear Pin. $1 / 4$ dia $\times 3-1 / 8$, Mild Steel & $1-3$ \\
\hline OP 4728 & Outer Seal Male Adaptor & 1 \\
\hline OP4729 & ()uter Seal V-Spacer & 2 \\
\hline OP4730 & Outer Scal Female Adaptor & 1 \\
\hline OP4752 & Quick Release Nut & 1 \\
\hline OP4753 & Quick Release Dog & 2 \\
\hline OP4756 & Vent Snubber & 1 \\
\hline OP 4766 & Piston Rod Snubber & 1 \\
\hline OP4769 & Piston Rod Extension (Std. Hd.) & 1 \\
\hline OP 4801 & Pulling Neck & 1 \\
\hline OP4803 & Split Bushing & 1 \\
\hline OP 4805 & Landing Shoulder Sub & 1 \\
\hline OP4807 & Outer Shear Pin Sub & 1 \\
\hline OP4809 & Inner Shear Pin Sub & 1 \\
\hline OP4811 & Shear Pin Sleeve & 1 \\
\hline OP4813 & Split Swivel Sub & 1 \\
\hline OP4815 & Inner Seal Sub & 1 \\
\hline OP4817 & Upper Piston Rod & 1 \\
\hline OP4818 & Center Piston Rod & 1 \\
\hline OP4819 & Lower Piston Rod & 1 \\
\hline OP4821 & Outer Seal Sub & 1 \\
\hline OP 4823 & Anti-Spiral Key & 1 \\
\hline OP4825 & Male Quick Release & 1 \\
\hline OP4827 & Female Quick Release & 1 \\
\hline OP4829 & Vent Sub & 1 \\
\hline OP4834 & Hang Off Tool & -- \\
\hline OP4836 & Shear Pin Tool & - \\
\hline OP 3210 & Inner Core Barrel, $3-1 / 2 \times 2.87 \times 14^{\prime} 9-1 / 2^{\prime \prime}$ & 2 \\
\hline OP3231 & Inner Barrel Sub, 12-1/8" & 1 \\
\hline OP3400 & Core Liner, Butyrate, $2.817 \times 32$ ' -6 " & 1 \\
\hline OP4345 & Piston Seal Retainer & 1 \\
\hline OP4360 & Liner Seal Sub & 2 \\
\hline
\end{tabular}


NO. REQ'D.

\begin{tabular}{ll}
\hline OP4361 & Core Liner Retaincr Screw \\
OP4362 & Slim Nose Catcher Sul) (Alt.) \\
OP4376 & Catcher Sub \\
OP4377 & Heat Flow Core Catcher - Body (Alt.) \\
OP4378 & Heat Flow Core Catcher - Cone (Alt.) \\
OP4381 & Piston Head Body \\
OP4382 & Plastic Tuhe Support. \\
OP4383 & Lock Pin. Piston Head \\
OP4390 & Male V-packing Adaptor (Piston Hd.) \\
OP4391 & Feinale V-packing Adaptor (Piston Hd.) \\
OP4392 & V-Spacer (Piston Hd.)
\end{tabular}

Fasteners \& Seals

OD2232 O-ring \#2-232, Buna-N, 70D. 4

OD2331 O-ring \#2-331, Buna-N, 70D. 1

OD3150 Polypak, Molythane, \#37501625-625B 2

OD4200 V-packing, Molythane, \#31202000VP 3

OD4300 V-packing, Molythane, \#37503000VP 3

OD6555 Set Screw, Socket, 1/2-13 UNC x 1/2, Stainless 4

OD7111 Roll Pin, $1 / 8 \times 5 / 8$, Stainless 1

OD7140 Roll Pin, $3 / 16 \times 1-3 / 8$, Stainless 4

OD7142 Roll Pin, 3/16 x 1-3/4, Stainless · 1

OD7180 Snap Ring, \#5100-62 1

OD7231 Hex Nut, Stainless, 3/4-10 UNC 1

Core Catcher Alternatives

OR7010 Core Catcher, Complete, Dog Type "10" 1-2

OR7020 Core Catcher, Complete, Dog Type "8" 1-2

OR7100 Core Catcher, Complete, Flapper Type 1

\section{Outer Barrel Components}

OL1021 Landing/Saver Sub 1

OĹ1029 Long Bit Sub 1

OL1044 Seal Bore Outer Core Barrel 1 


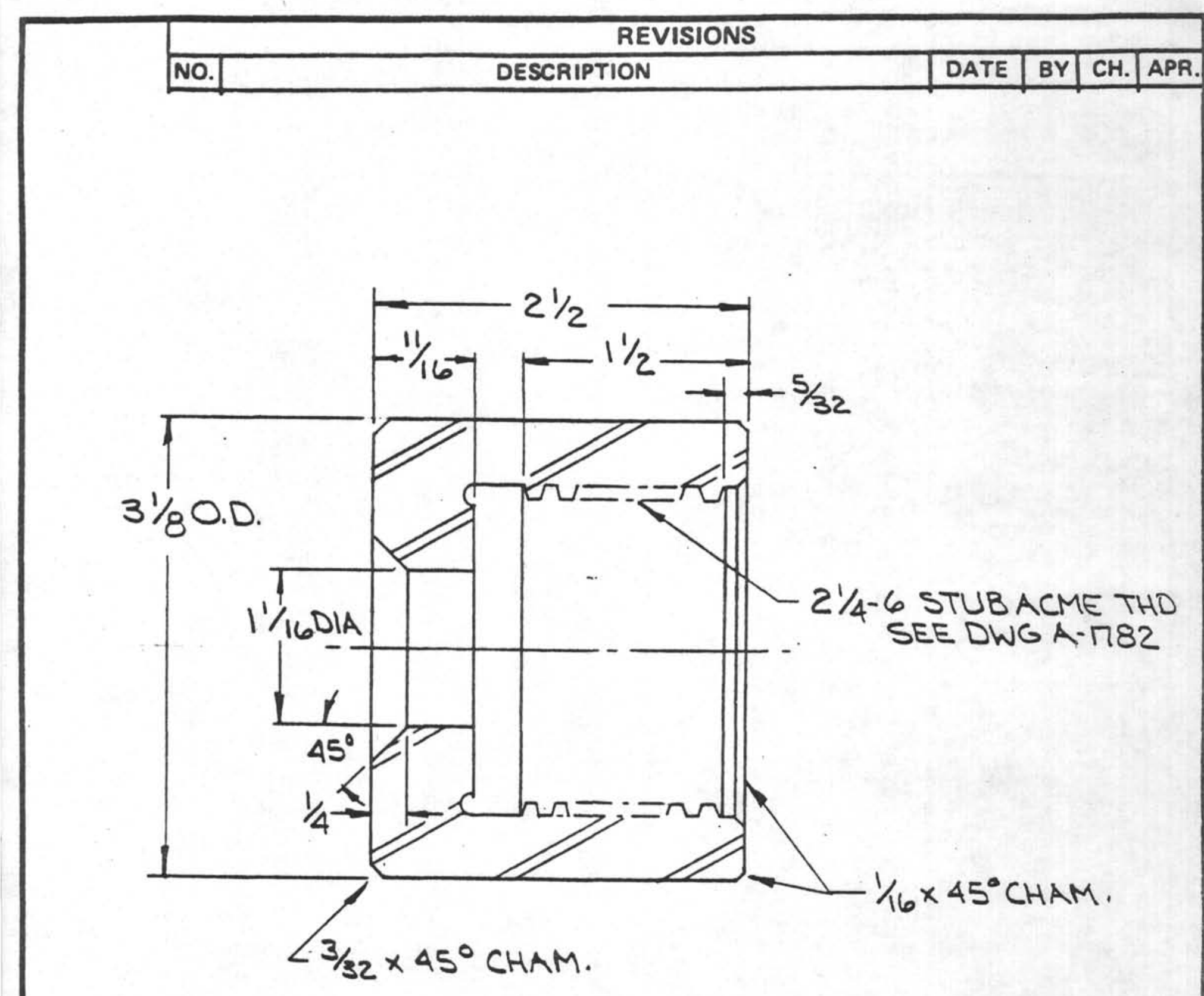

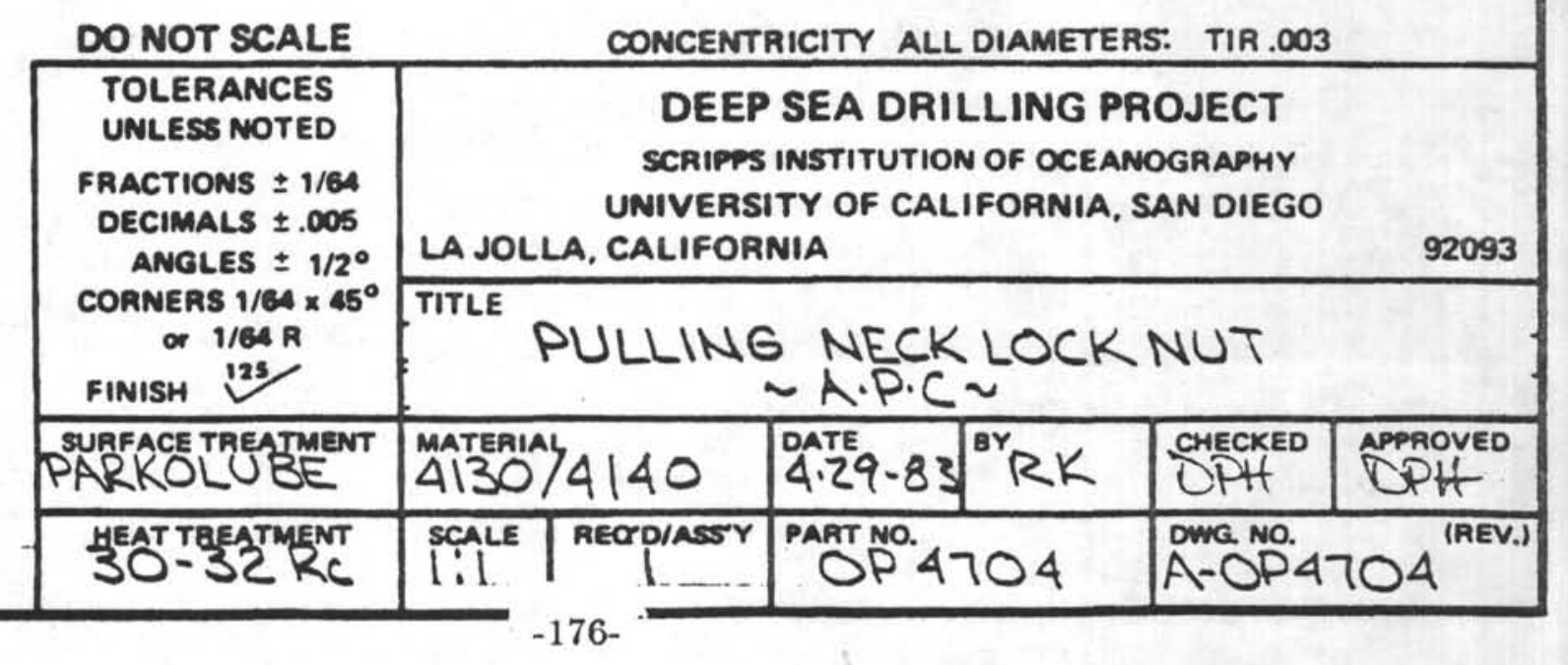




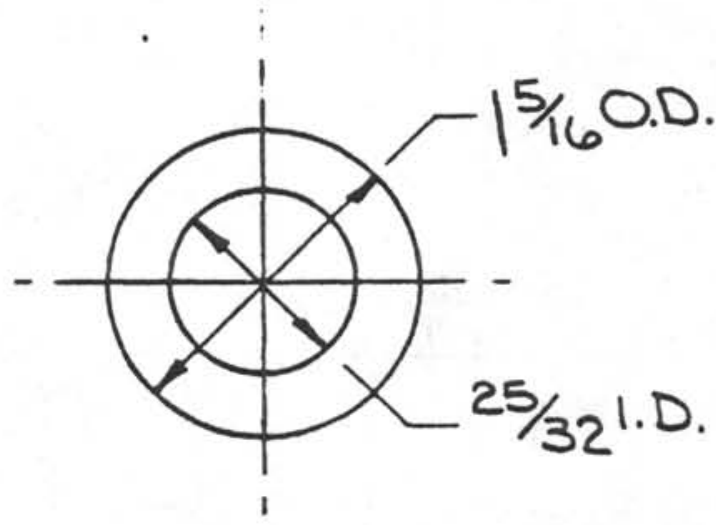

$3 / 16$

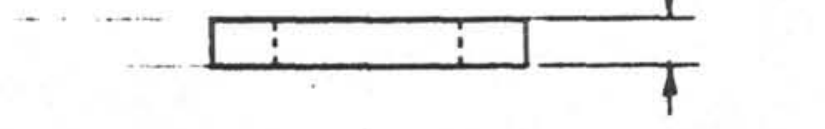

DO NOT SCALE TOLERANCES UNLESS NOTED

FRACTIONS $\pm 1 / 64$

DECIMALS \pm .005

ANGLES $\pm 1 / 2^{\circ}$ CORNERS $1 / 64 \times 45^{\circ}$

or 1/6A R

FINISH 12s
CONCENTRICITY ALL DIAMETERS: TIR.003

DEEP SEA DRILLING PROJECT

SCRIPPS INSTITUTION OF OCEANOGRAPHY UNIVERSITY OF CALIFORNIA, SAN DIEGO

LA JOLLA, CALIFORNIA

SUPPORT WASHER $\sim$ A.P.C. TITLE

SUAFACE TREATMENT PARKOLUBE 4.29.83 ${ }^{\text {AY }} \mathrm{RK}$ \begin{tabular}{l|l|l}
\hline SCALE & RECOOIASSYY & PAAT NO.
\end{tabular} OP 4712 CHECKED APPROVED $\mathrm{DH}$ 


\begin{tabular}{|l|l|l|l|l|l|}
\hline NO. & DESCRIPTION & DATE & BY & CH. & APR. \\
\hline
\end{tabular}
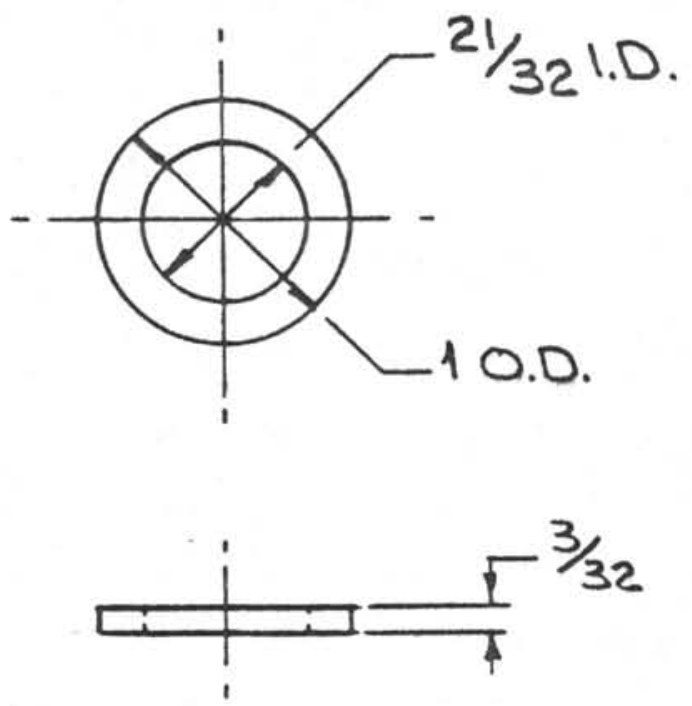

DO NOT SCALE TOLERANCES UNLESS NOTED

FRACTIONS $\pm 1 / 64$ DECIMALS \pm .005 ANGLES $\pm 1 / 2^{\circ}$ CORNERS $1 / 64 \times 45^{\circ}$ of 1/64R FINISH 125 SURFACE TAEATMENT PARKOLUBE HEAT TAEATMENT $28-32 R_{C}$
CONCENTRICITY ALL DIAMETERS: TIR.003

\section{DEEP SEA DRILLING PROJECT} SCRIPPS INSTITUTION OF OCEANOGRAPHY UNIVERSITY OF CALIFORNIA, SAN DIEGO LA JOLLA, CALIFORNIA 92093 STOP WASHER $\sim A . P . C$. -

MATERIAL $4130 / 4140$ 4.29.83 RK \begin{tabular}{l|l|l|l}
\hline SCALE & REODD/ASSY & PAAT NO. & OWG. NO \\
\hline
\end{tabular} li: 1 OP4713 


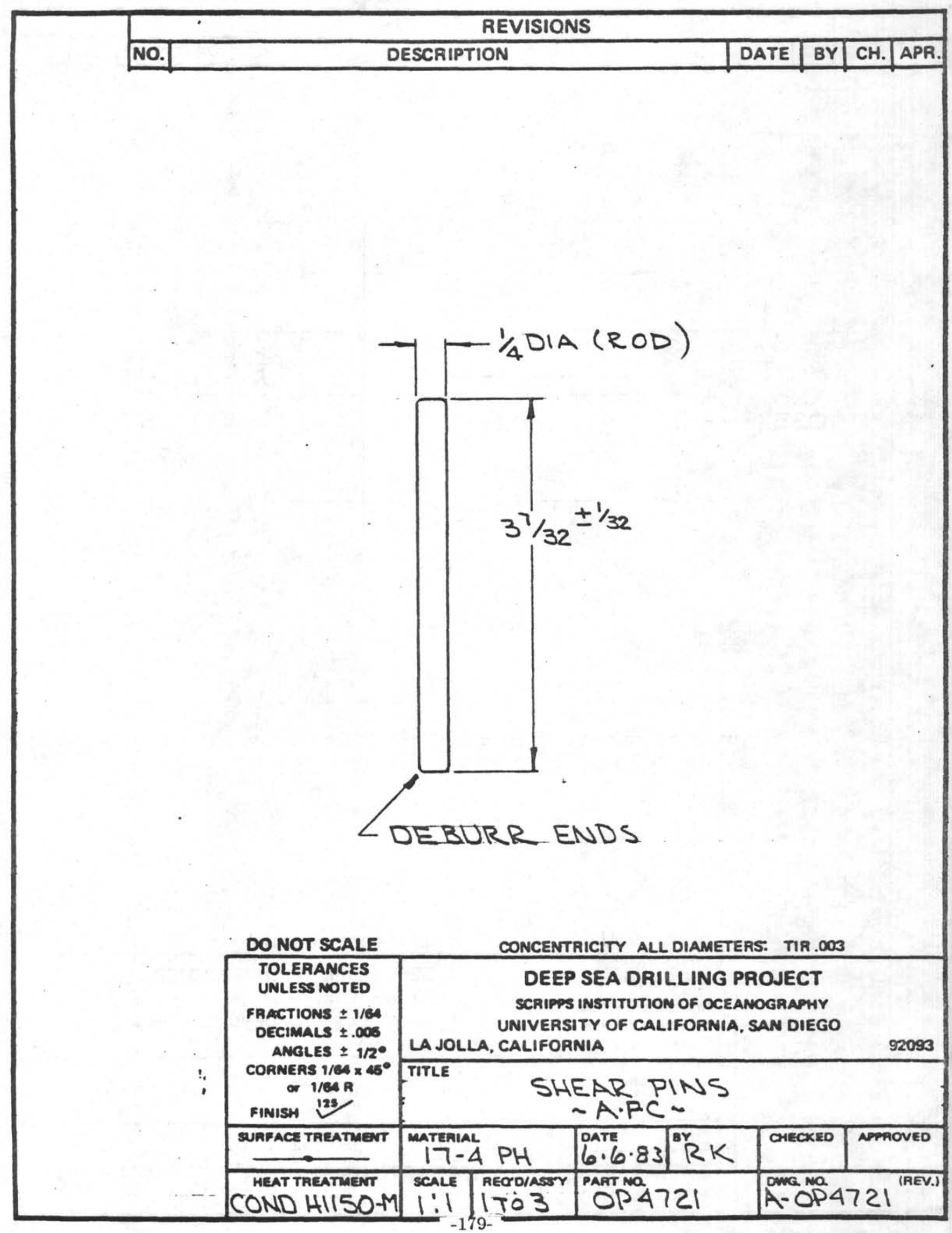




\begin{tabular}{|l|l|l|l|l|l|}
\hline NO. & DESCRIPTION & DATE & BY & CH. & APR. \\
\hline
\end{tabular}

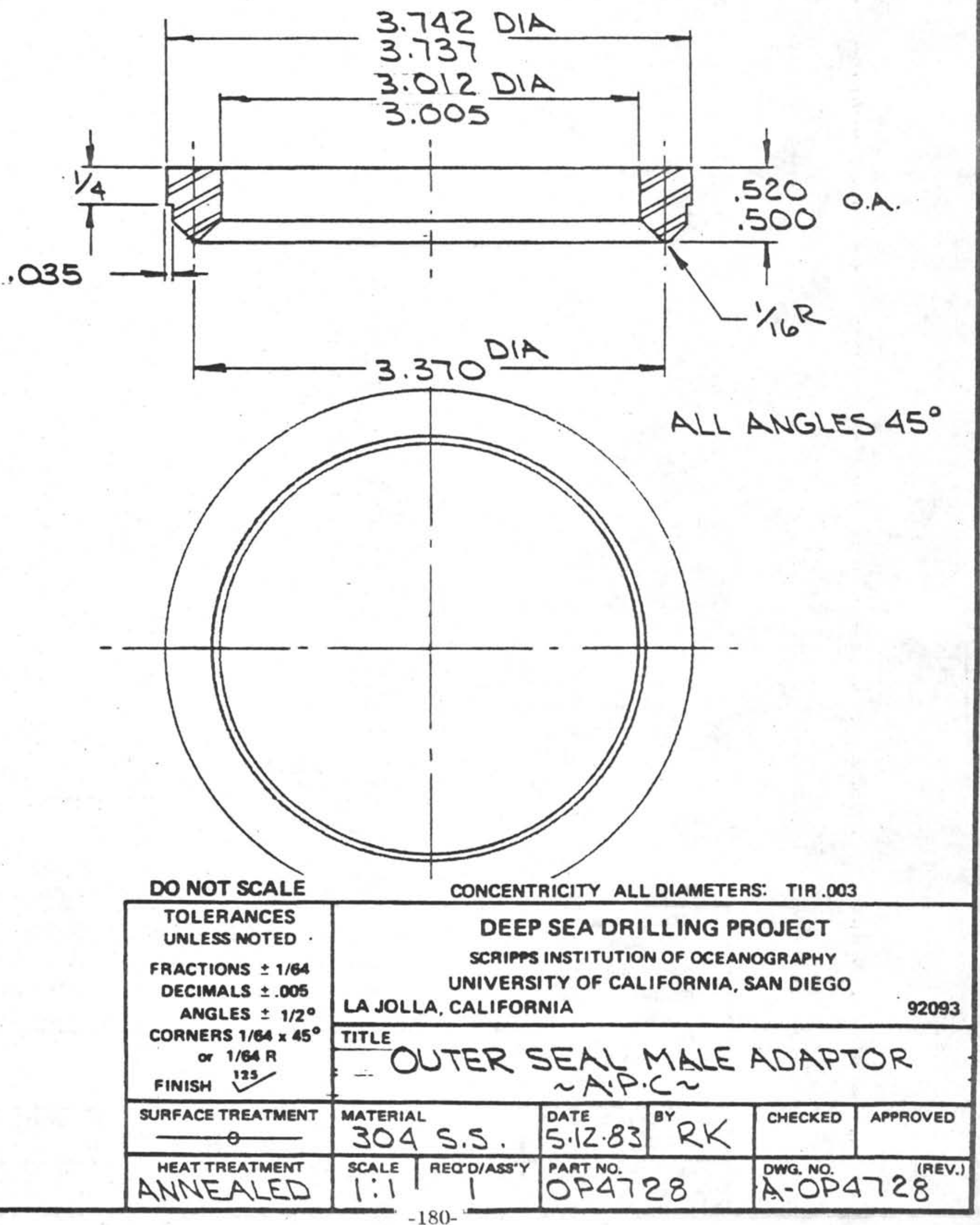




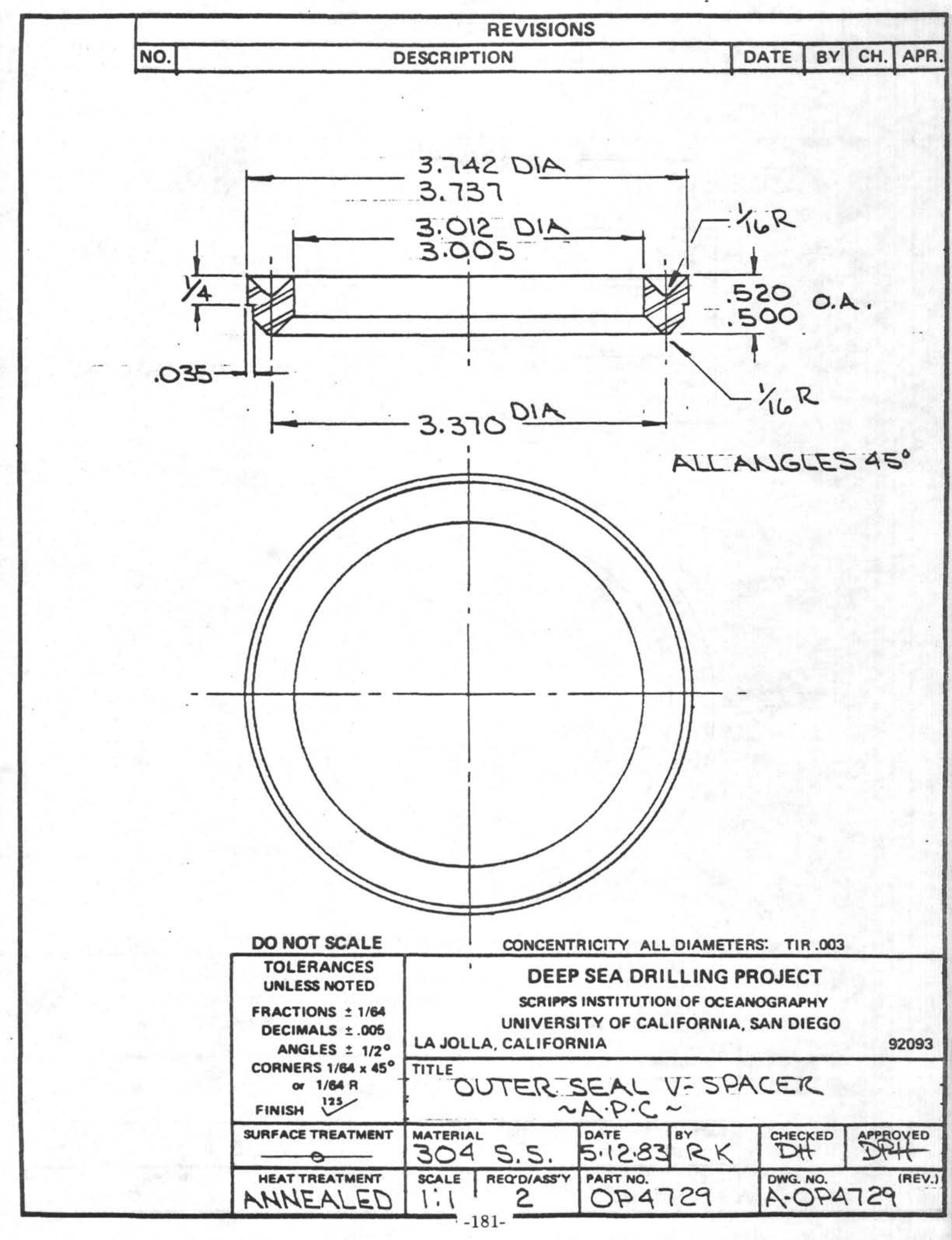




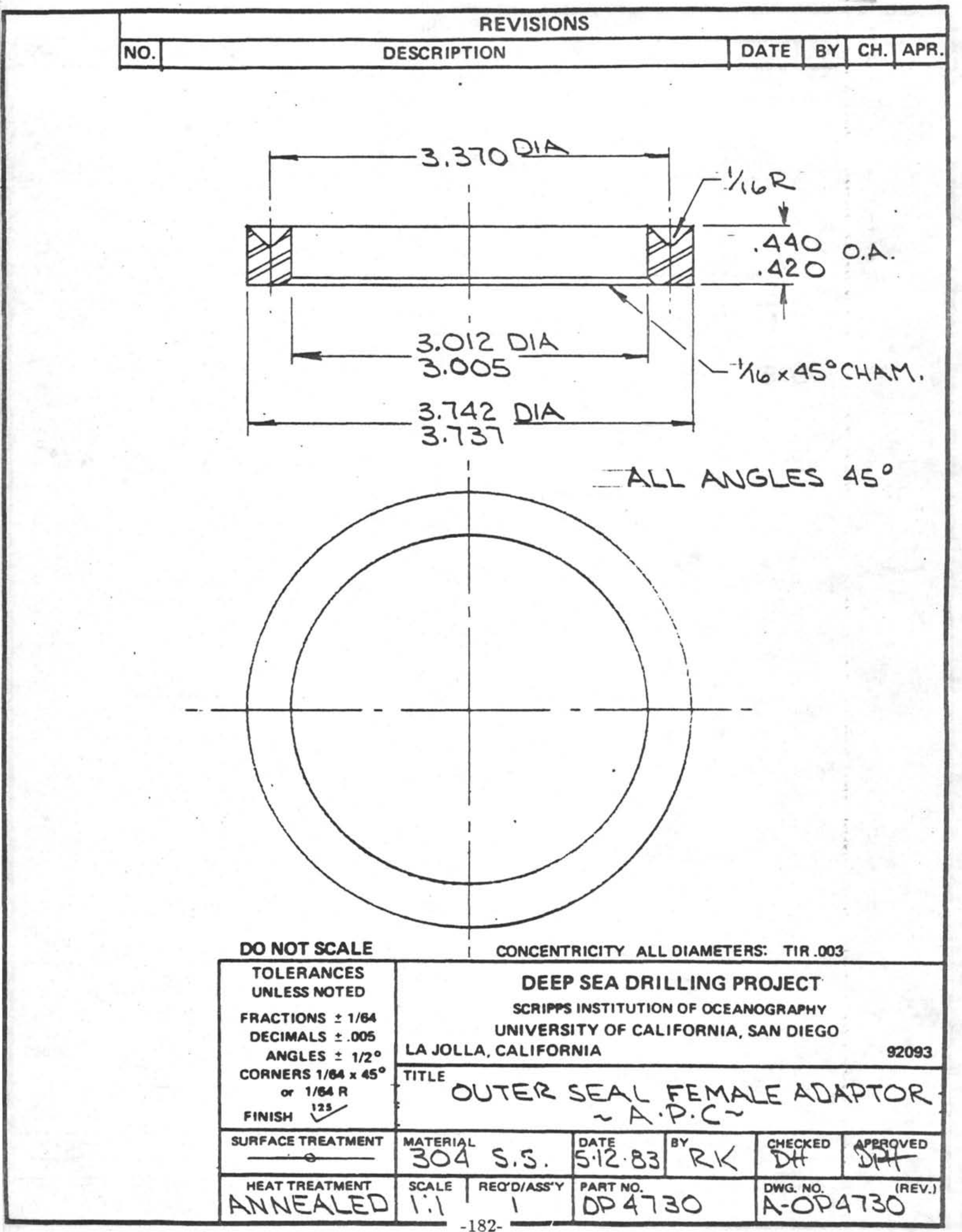




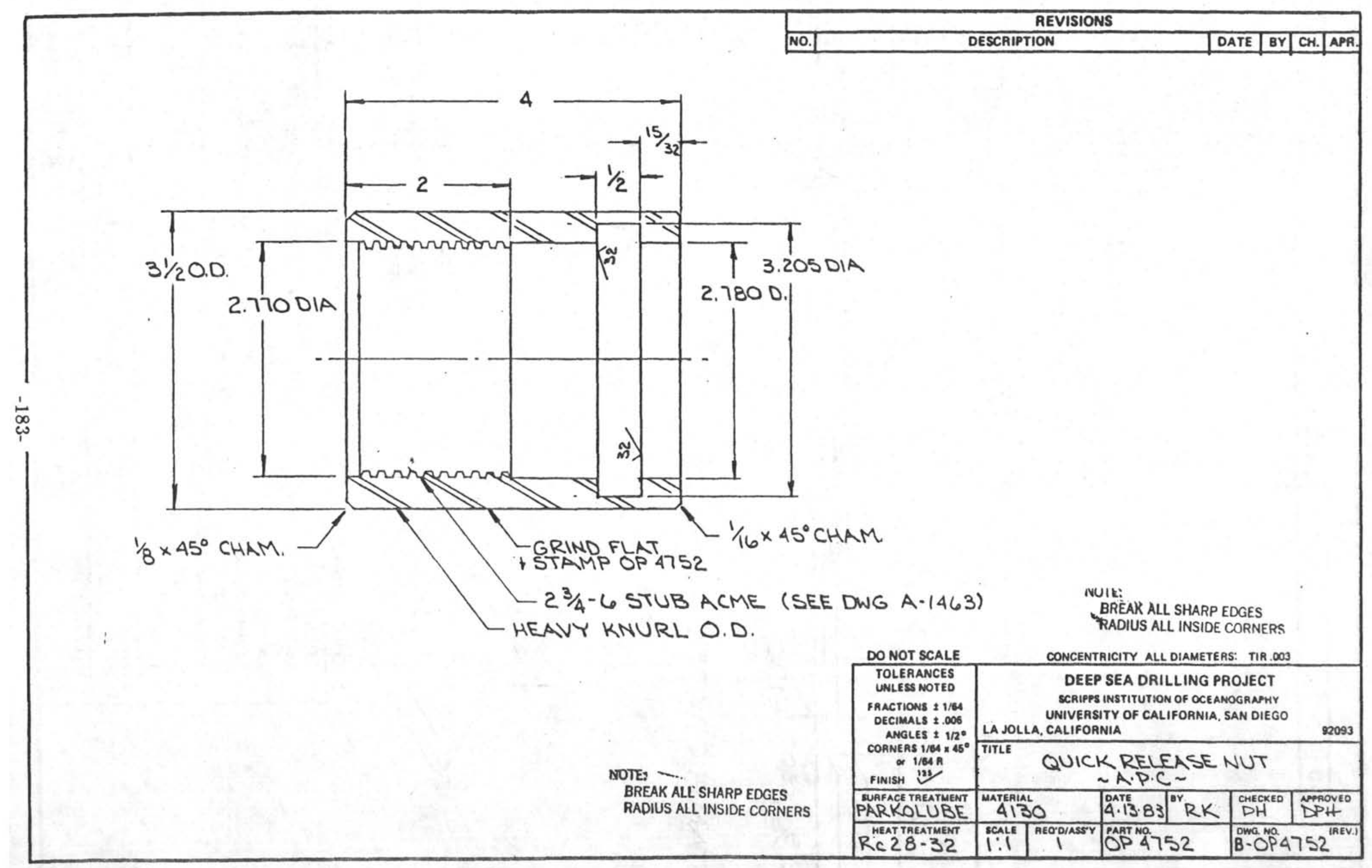




\begin{tabular}{|l|l|l|l|l|l|}
\hline NO. & DESCRIPTION & DATE & BY & CH. & APR. \\
\hline
\end{tabular}

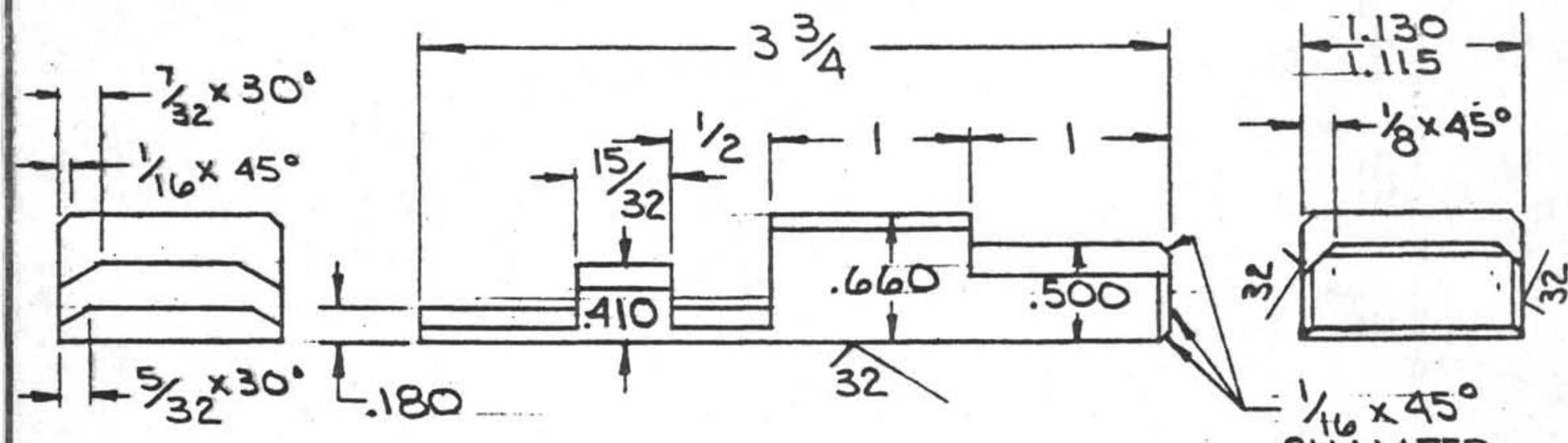

STAMP: OP 4753

CHAMFER

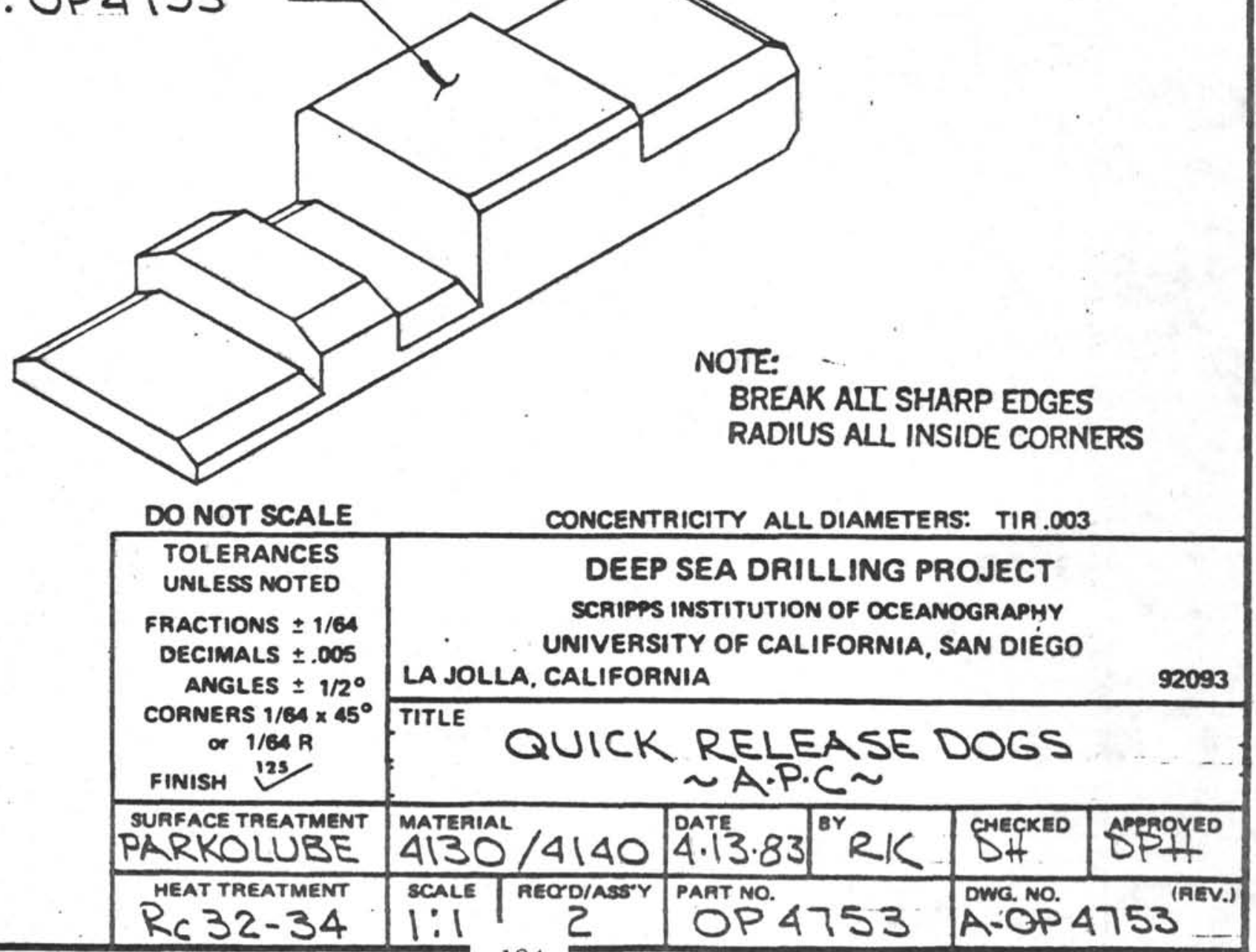




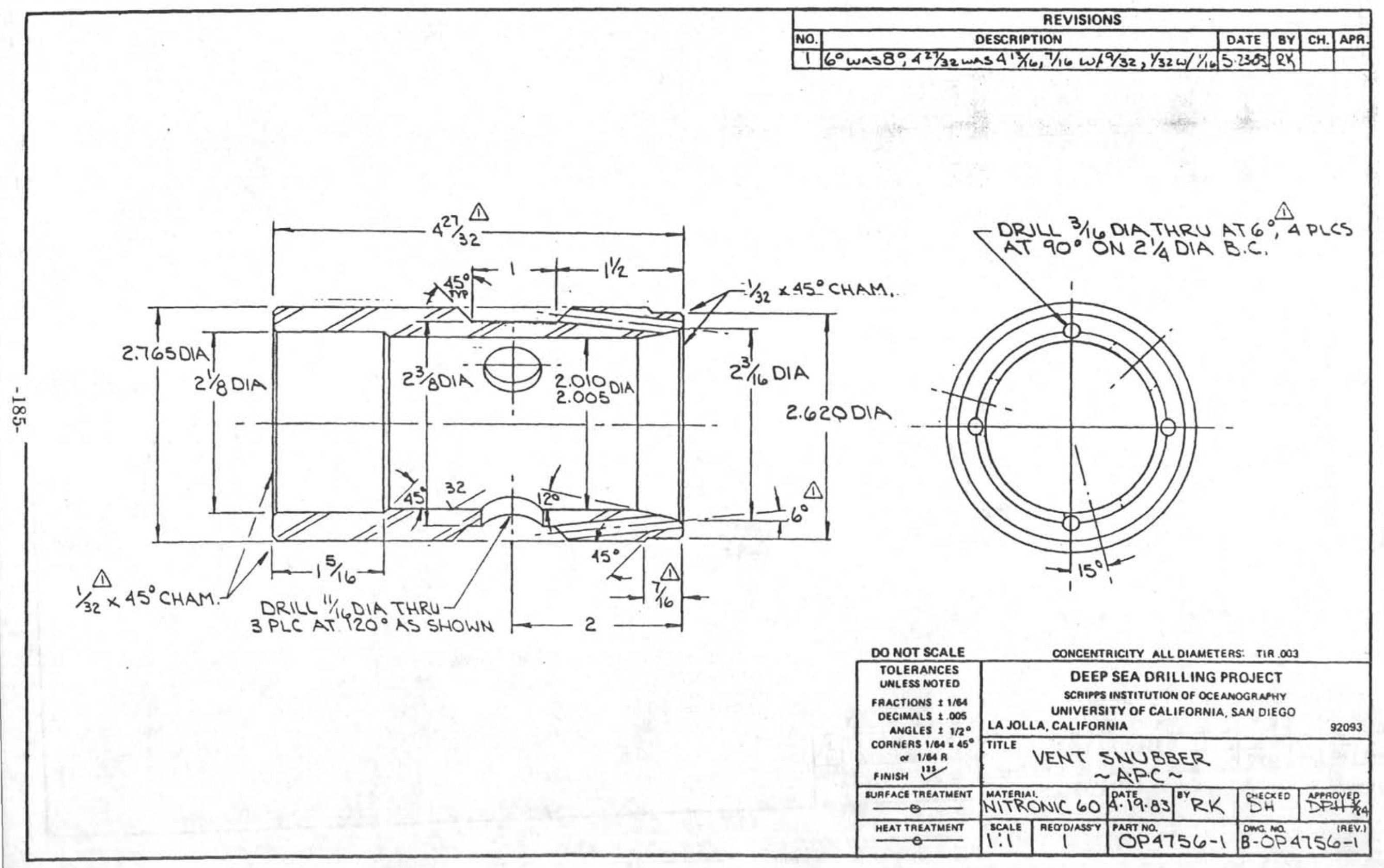




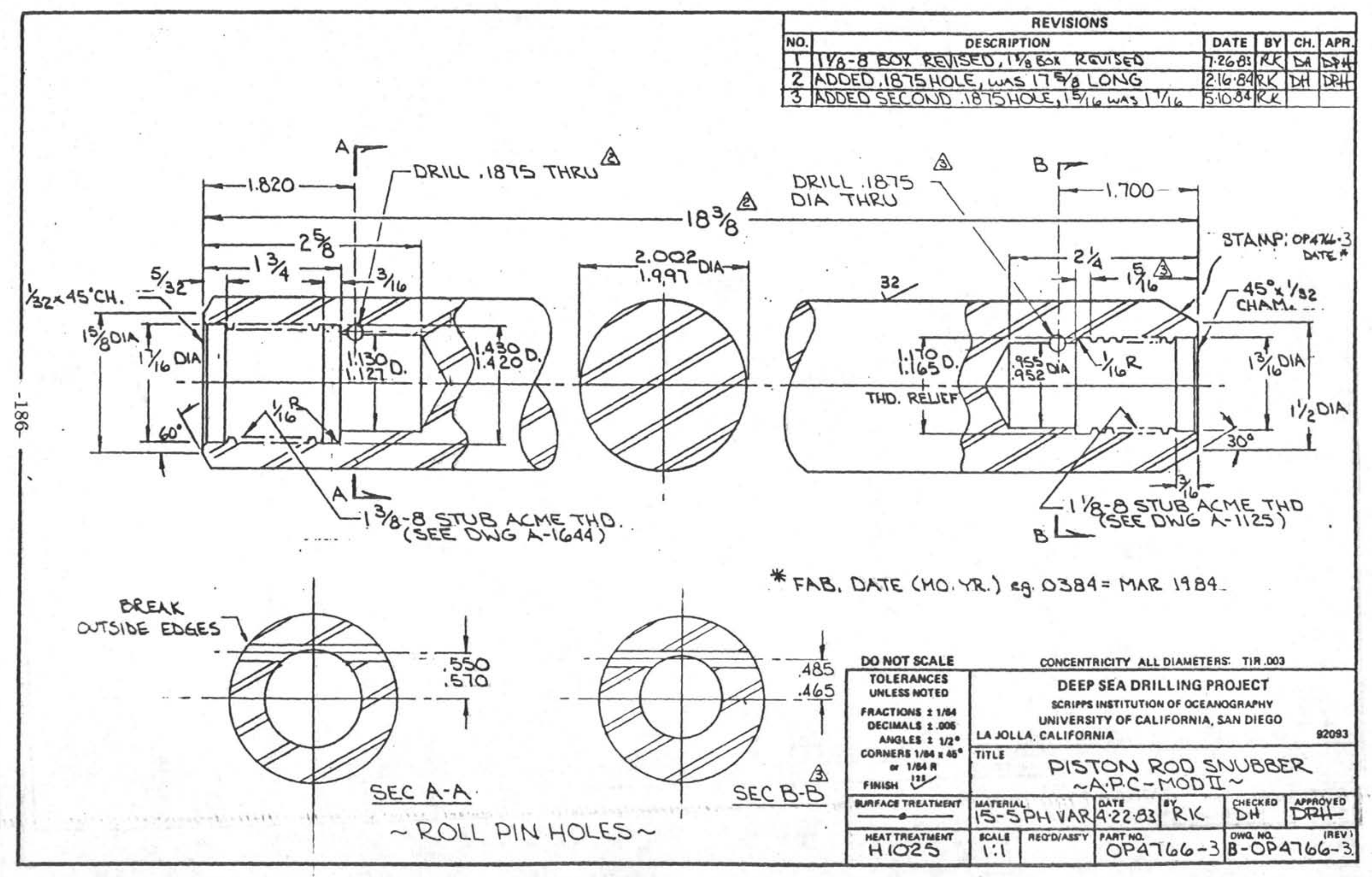


REVISIONS

\begin{tabular}{|c|c|c|c|c|c|}
\hline NO & DESCAIPTION & DATE & $\mathrm{BY}$ & $\overline{\mathrm{CH}}$ & $A P$ \\
\hline 1 & I1/8-8 PIN REVISED & 7.2580 & RE & $D$ & OPH \\
\hline 2 & ADDED NOTCH & $5 \cdot 10.89$ & $R \mathrm{~K}$ & & \\
\hline
\end{tabular}

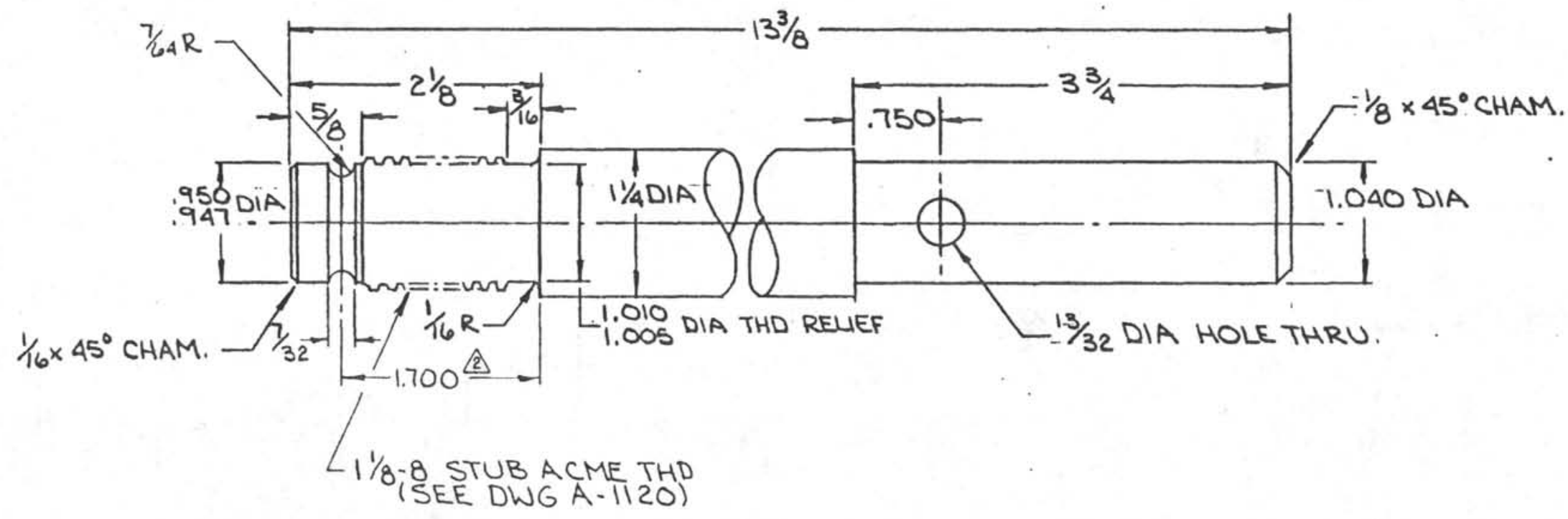

\begin{tabular}{|c|c|c|c|c|}
\hline \multirow{4}{*}{ 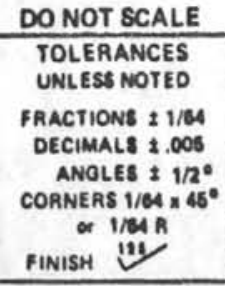 } & \multicolumn{4}{|c|}{ CENTRICITY ALL DIAMETERS: TIR.003 } \\
\hline & \multirow{2}{*}{\multicolumn{3}{|c|}{$\begin{array}{c}\text { DEEP SEA DRILLLING PROJECT } \\
\text { SCRIPS INSTITUTION OF OCEANOGRAPHY } \\
\text { UNIVERSITY OF CALIFORNIA, SAN DIEGO } \\
\text { LA JOLLA, CALIFORNIA }\end{array}$}} & \\
\hline & & & & 02093 \\
\hline & \multicolumn{4}{|c|}{$\begin{array}{l}\text { IIILE } \\
\text { PISTON ROD EXTENSION N NAPC } \\
\text { FOR VLHPC PISTON HEAD }\end{array}$} \\
\hline $\begin{array}{l}\text { SUAFACE TAEATMENT } \\
\text { PARKOLUBE }\end{array}$ & $\begin{array}{l}\text { MATEAILL } \\
4 / 30\end{array}$ & \begin{tabular}{|l|l|} 
parte & ar \\
4.21 .83 & $R K$ \\
\end{tabular} & CHECKED & SPPAOVED \\
\hline $\begin{array}{l}\text { MET TAEATMENT } \\
\text { RE } 30-32\end{array}$ & 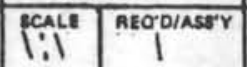 & PARTOPO $476^{\circ}$ & $B-C$ & $169-2$ \\
\hline
\end{tabular}




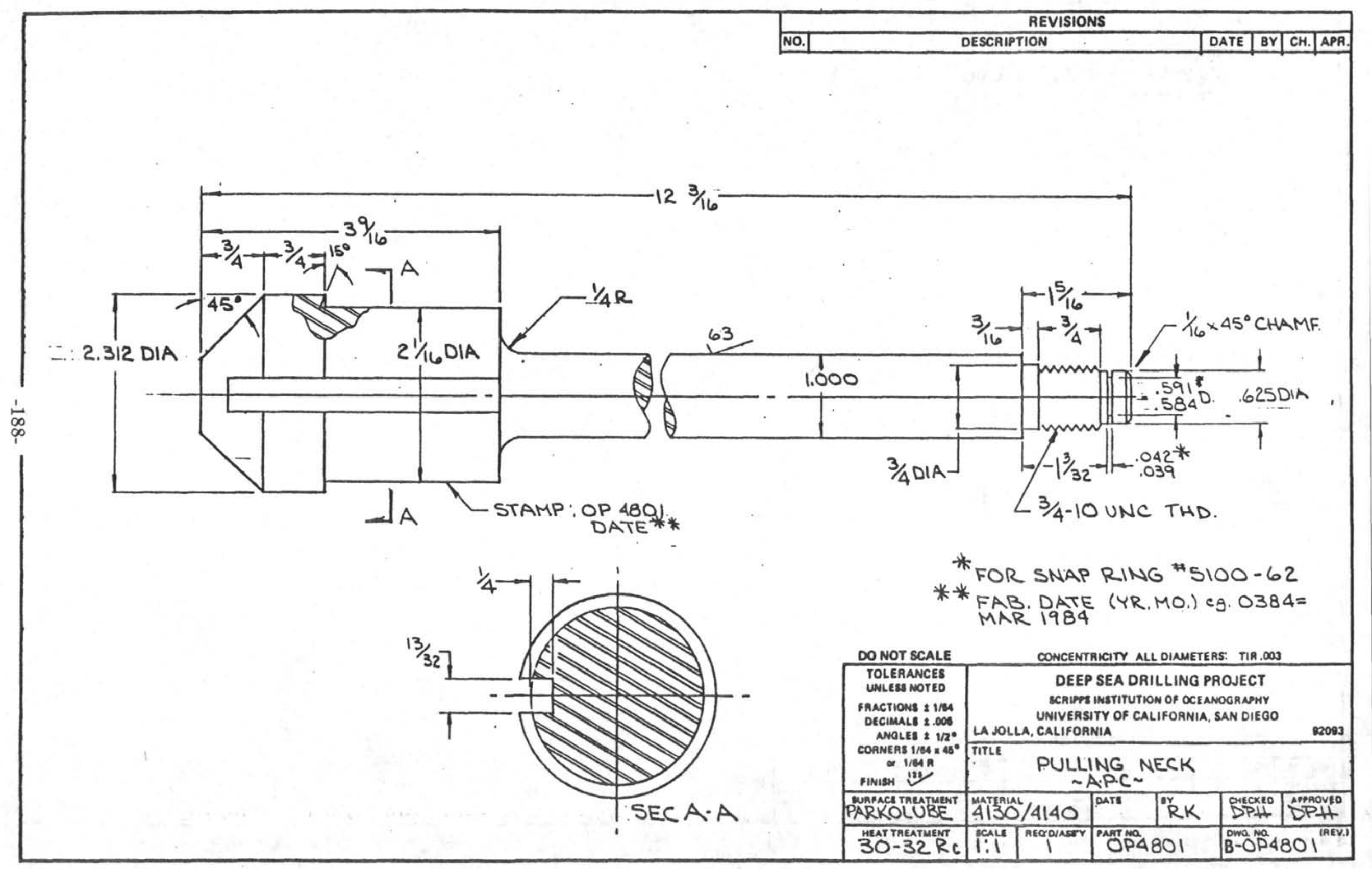




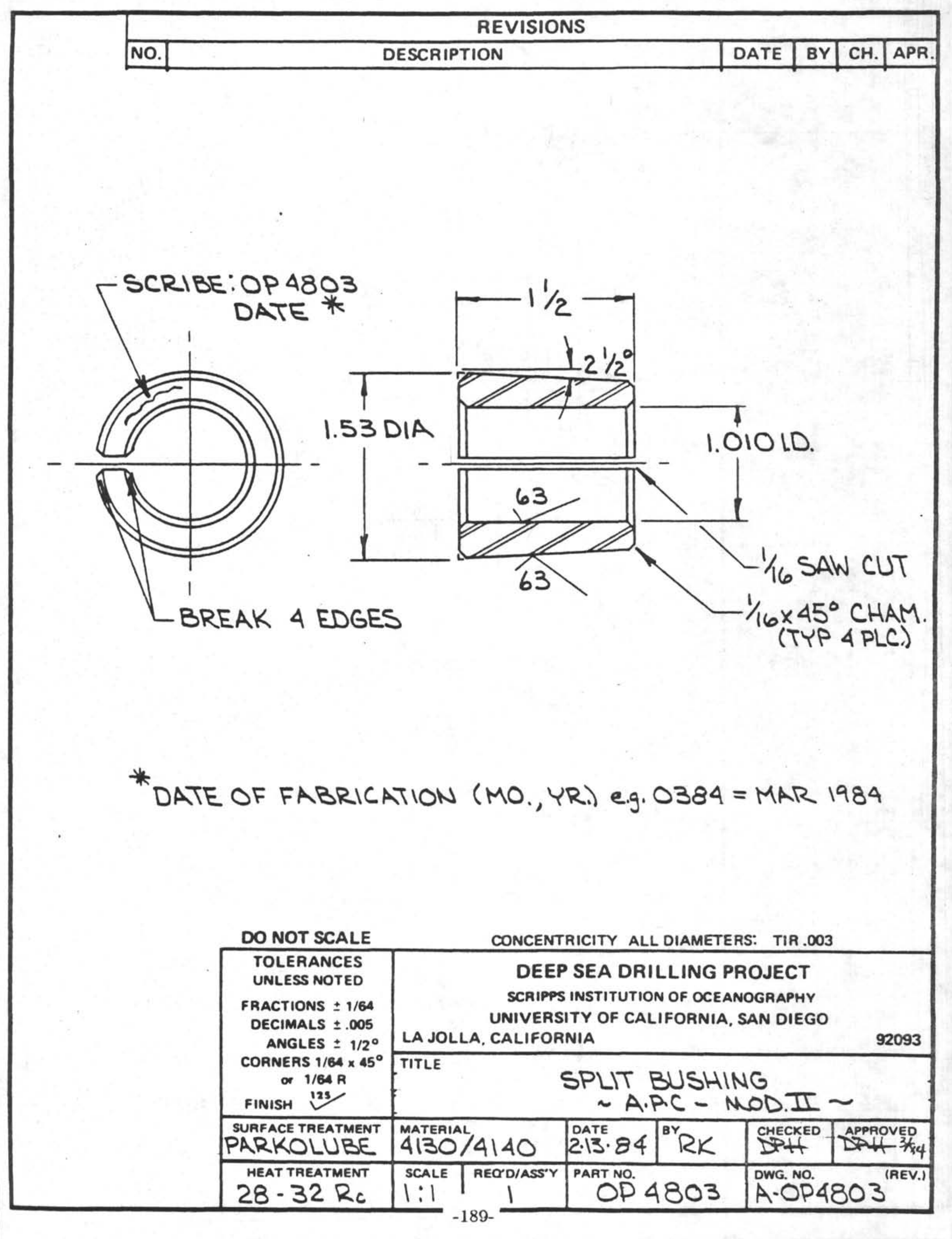




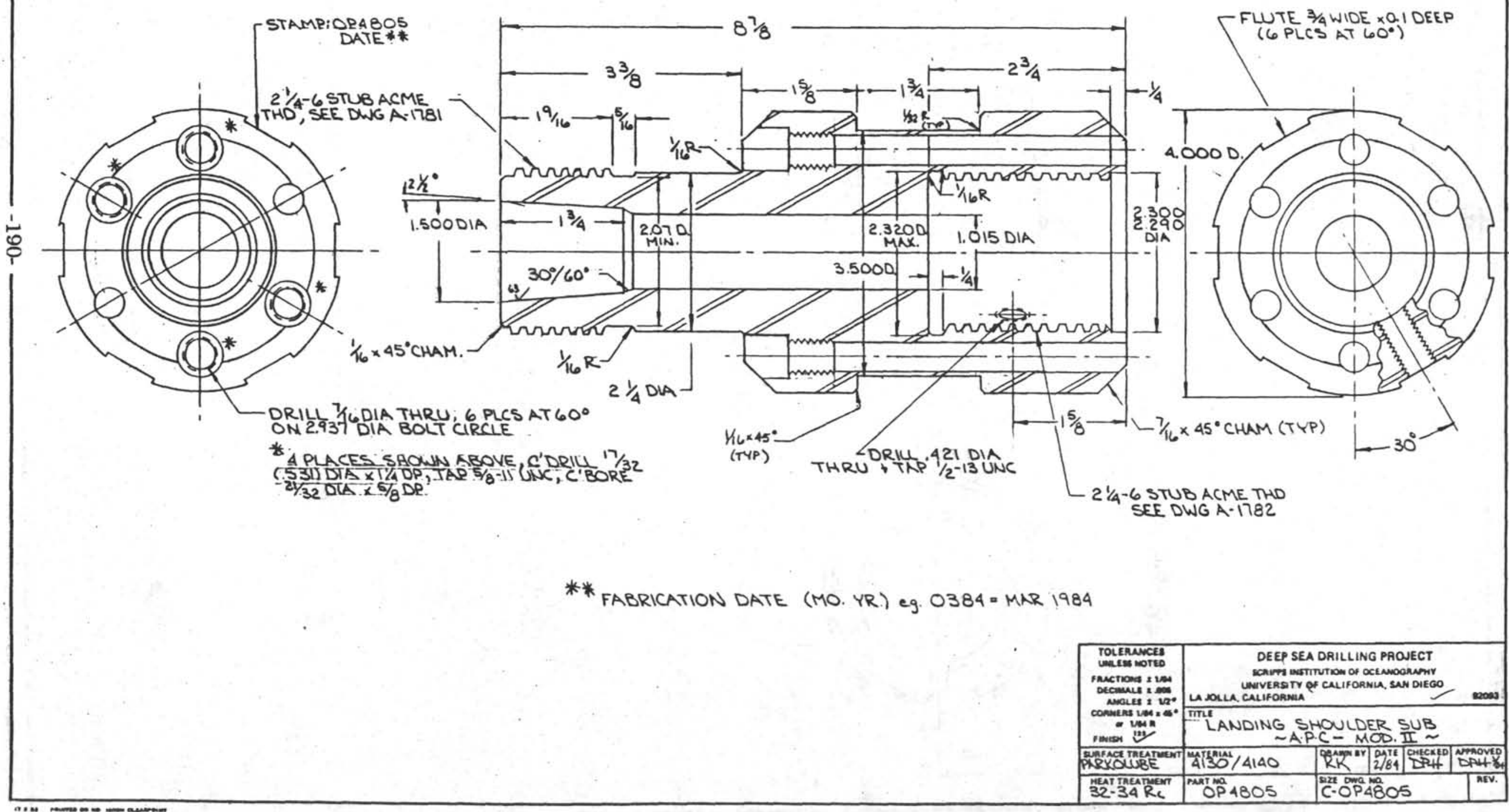




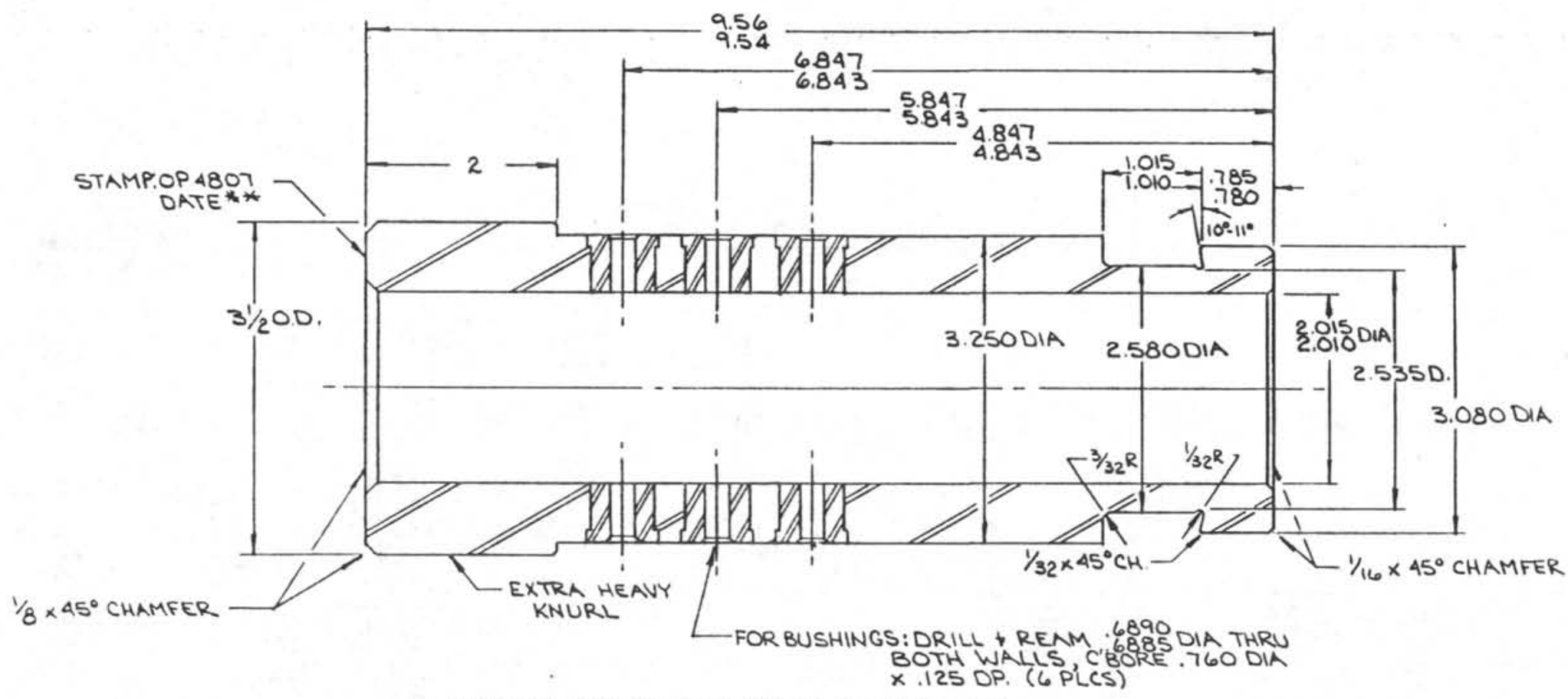

* heat treat before installing bushings

* * Fabrication date (mo.yr.) eg. $0384=$ mur. 1984

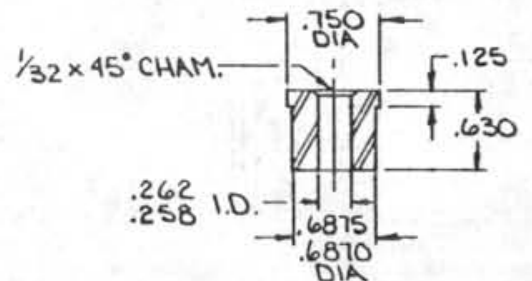

OUTER SHEAR PIN BUSHING ( 6 REQ'D)

MAT'L: CARPENTER STENTOR-OIL HARD (AISI TYPEO2)

OR CARPENTER "SOLAR" TOOL STEEL OR EQUIV.

INSTALL WITH LOCTITE 271 AND GRIND FLUSH INSIDE

+ OUTSIDE.

\begin{tabular}{|c|c|c|c|}
\hline \multirow{2}{*}{ 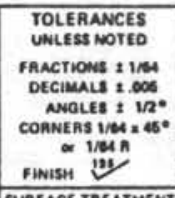 } & \multicolumn{2}{|c|}{ 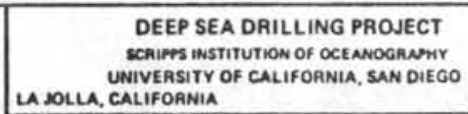 } & \\
\hline & $\begin{array}{r}\text { चiTLE } \text { OUTER } \\
\sim A P C\end{array}$ & $\begin{array}{l}\text { HEAR PIN SUB } \\
\text { MOD II } \sim\end{array}$ & \\
\hline $\begin{array}{l}\text { SUAFACE TMEATMENT } \\
\text { PAR KOLUBE }\end{array}$ & $\begin{array}{r}\text { MATERIAL } \\
4130\end{array}$ & $\begin{array}{l}\text { DoRWN BY DATE CHEC } \\
\text { R.1684 }\end{array}$ & Wrao \\
\hline 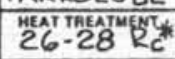 & $\begin{array}{l}\text { PARTNO } \\
\text { OP } 4807\end{array}$ & 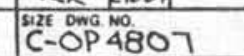 & \\
\hline
\end{tabular}




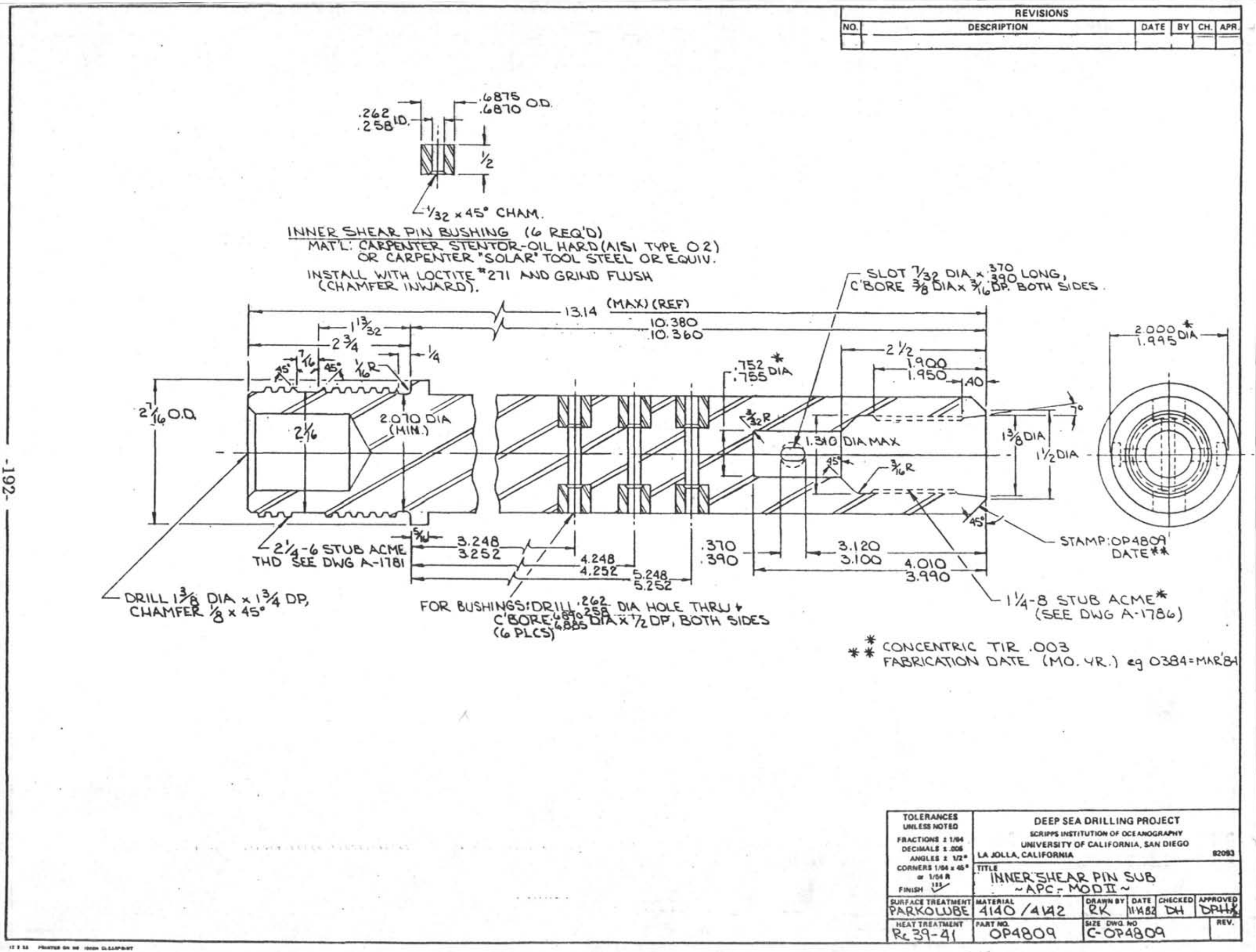




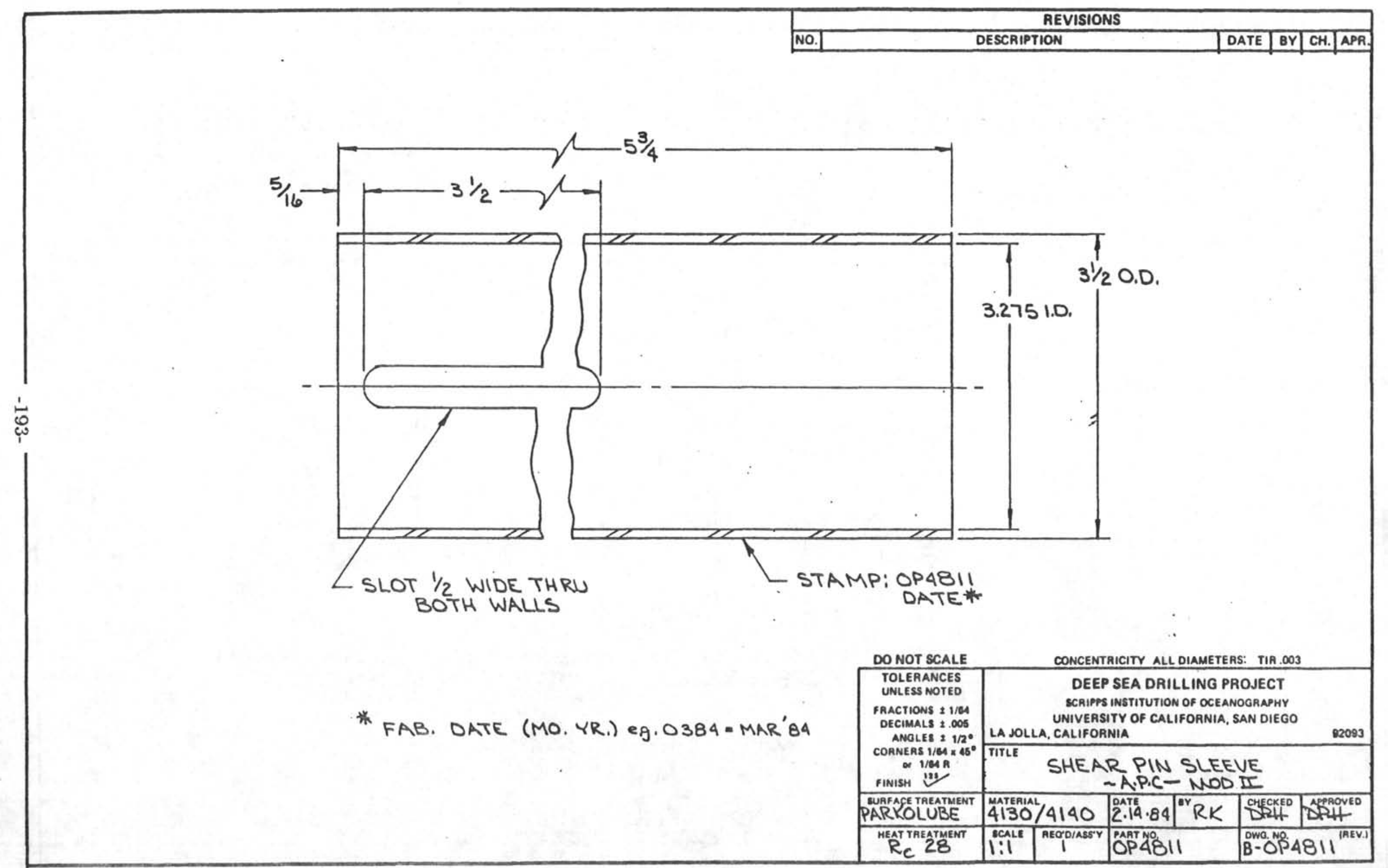




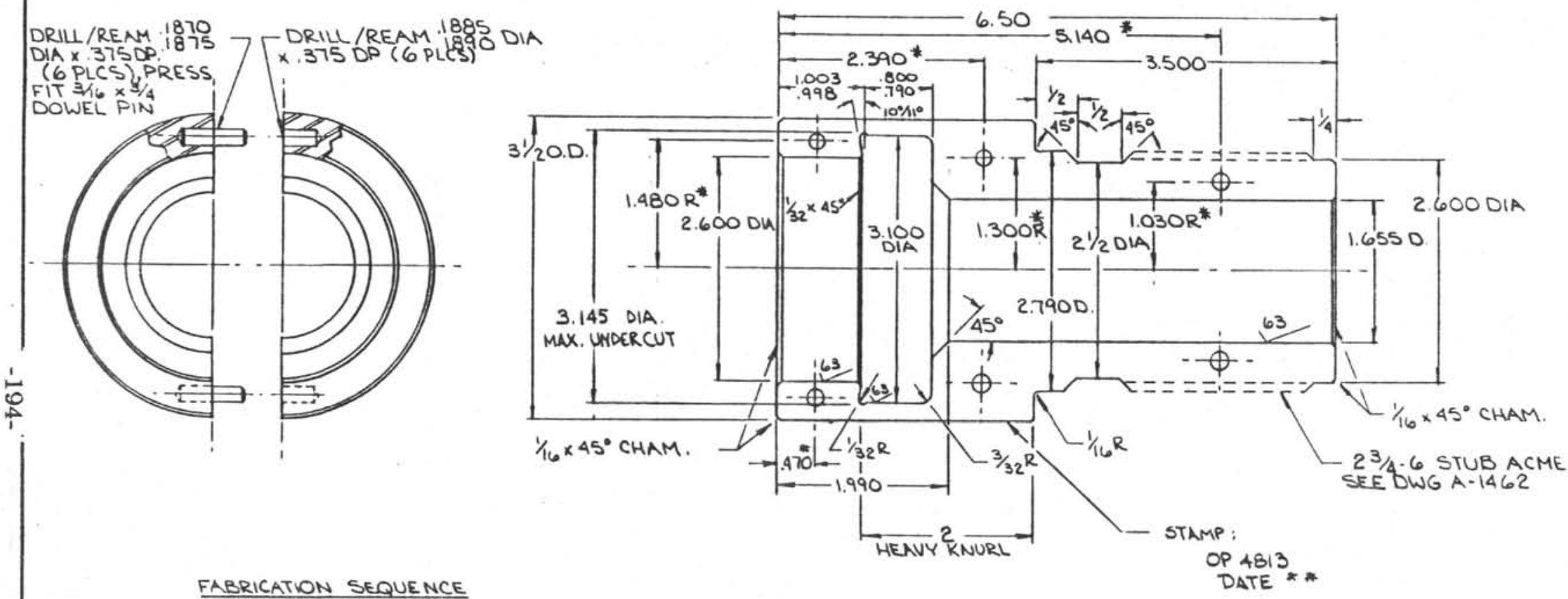

\footnotetext{
ROVGH MAGHINE 33/40.0. $\times 13 / 81.0$.

2. STRESS REUEVE

2. STRESS REUEVE

4. MILL MATING SUREACES FLAT , SQUMRE

5. DRUL/RENM DOWEL HOLES NO INSTAUL DOWELS

6. ASSEMBLE AND TACK WELD HALVES

7. FINISH MACHINE

8. SPLIT HNLVES AND REMOVE WELLS

9. DEBURE NL THREADSAT SPLIT SURFACE

10. HENT TRENT.
}

* basic dimension, (TYP 2 plcs)

* fabrication date (mo. yr.) eg. 0384 = MnR 84

\begin{tabular}{|c|c|c|c|}
\hline \multirow{2}{*}{ 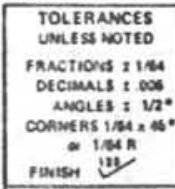 } & \multicolumn{2}{|c|}{ 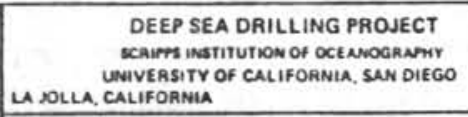 } & \multirow[t]{2}{*}{20203} \\
\hline & SPLI & MIVEI SUB & \\
\hline 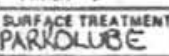 & matgint 30 & 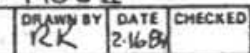 & Wenoved \\
\hline $\begin{array}{l}\text { MET ThEATWET } \\
28-32 R_{c}\end{array}$ & OPAT 4813 & 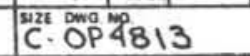 & nev. \\
\hline
\end{tabular}




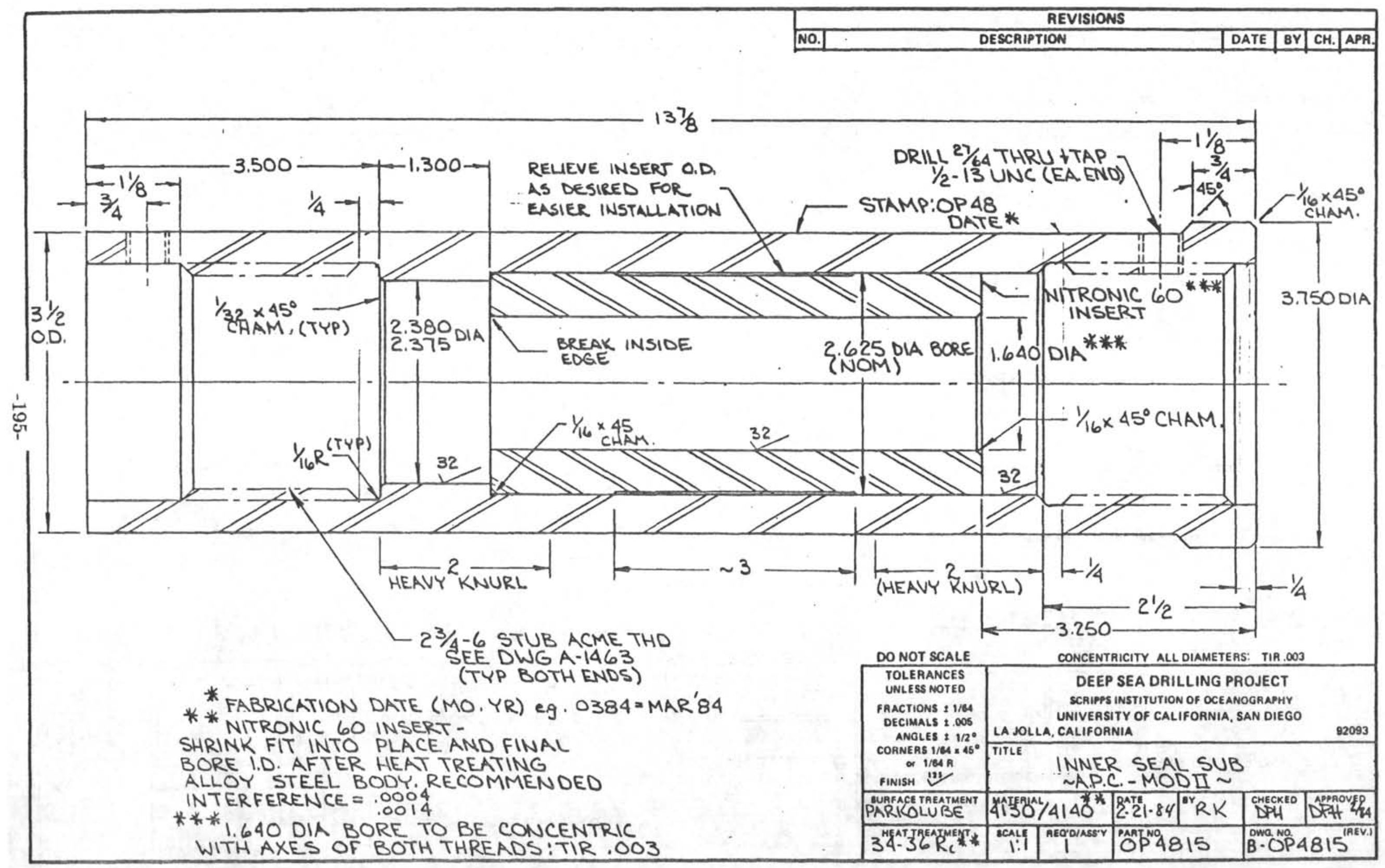




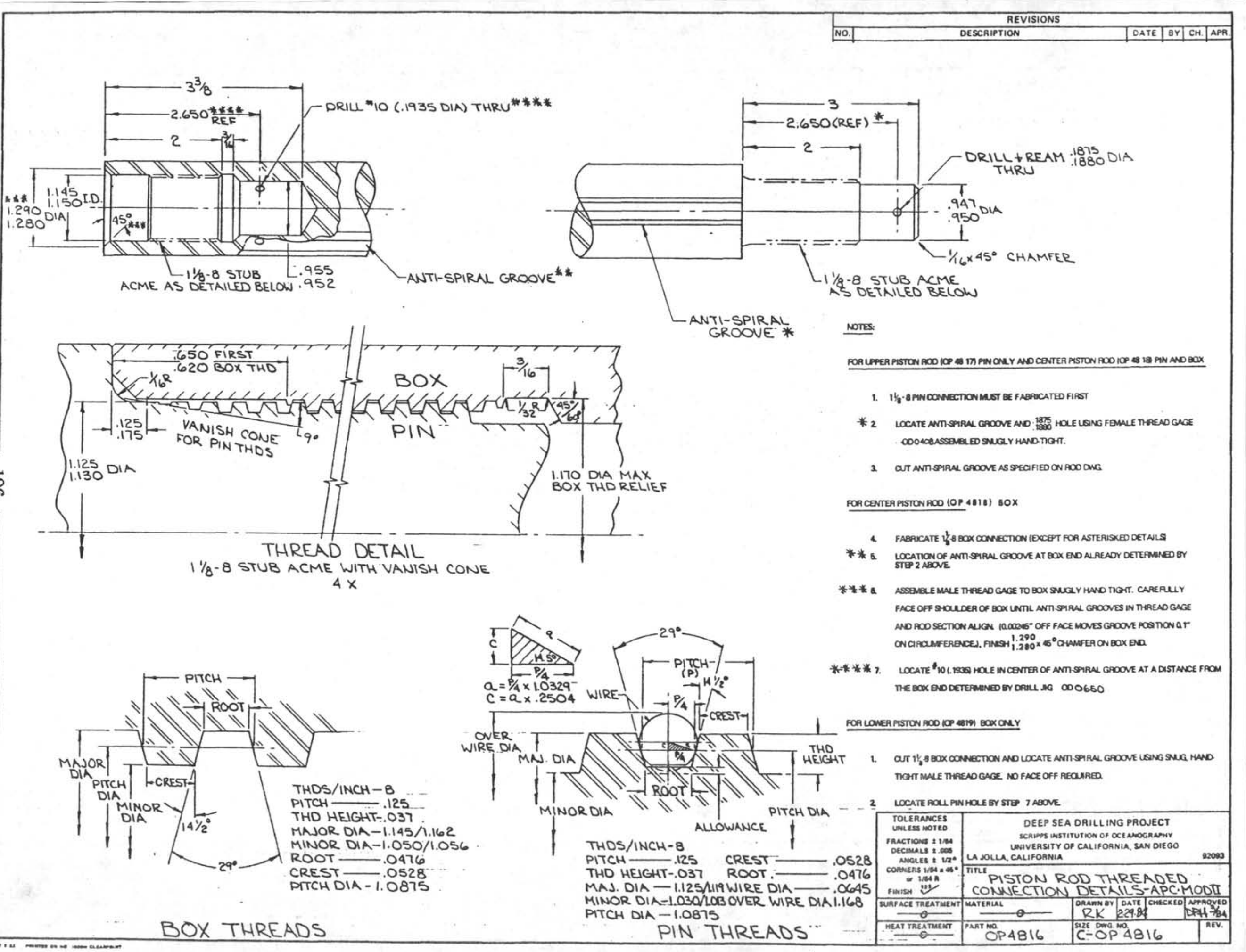




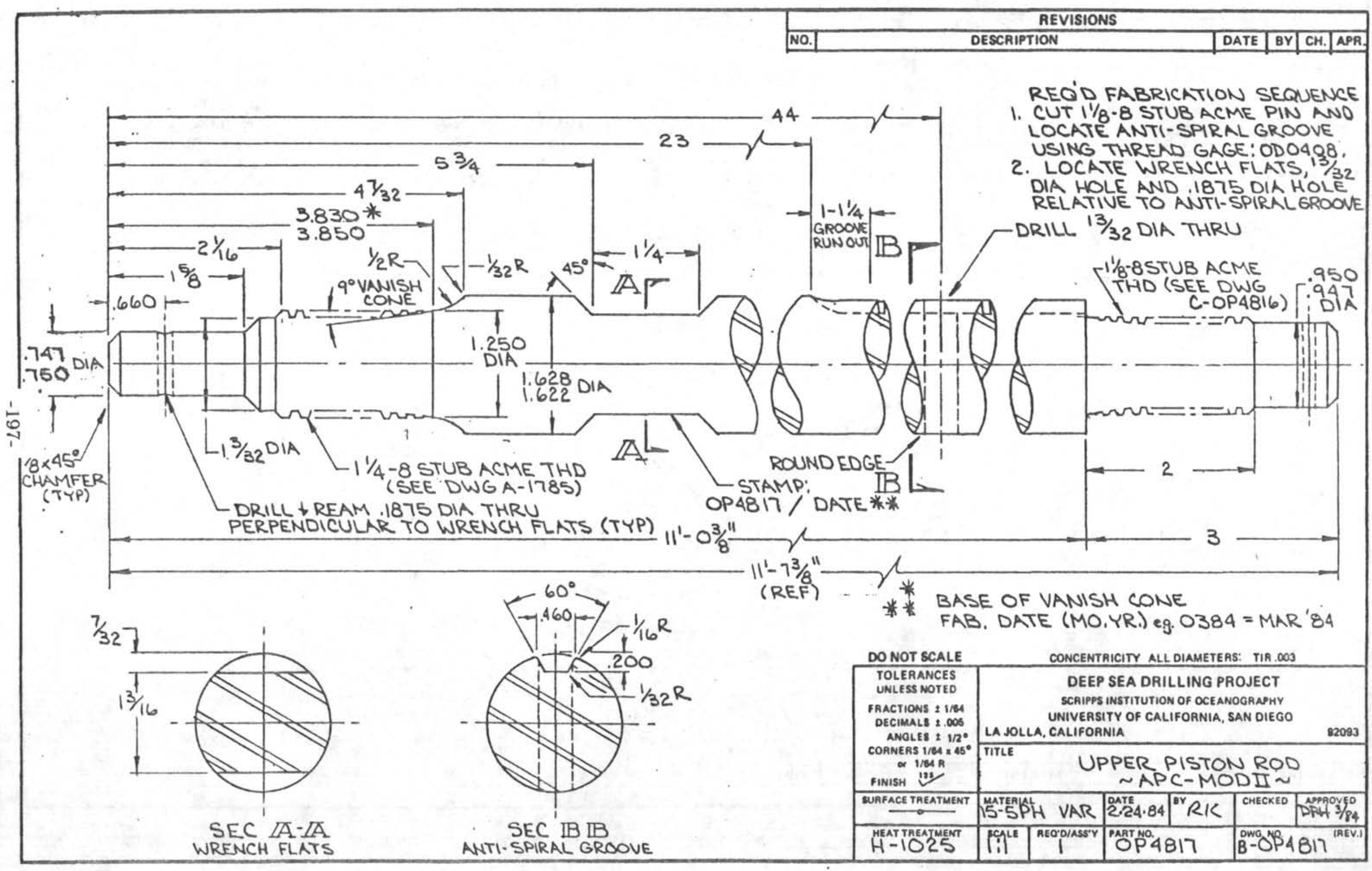




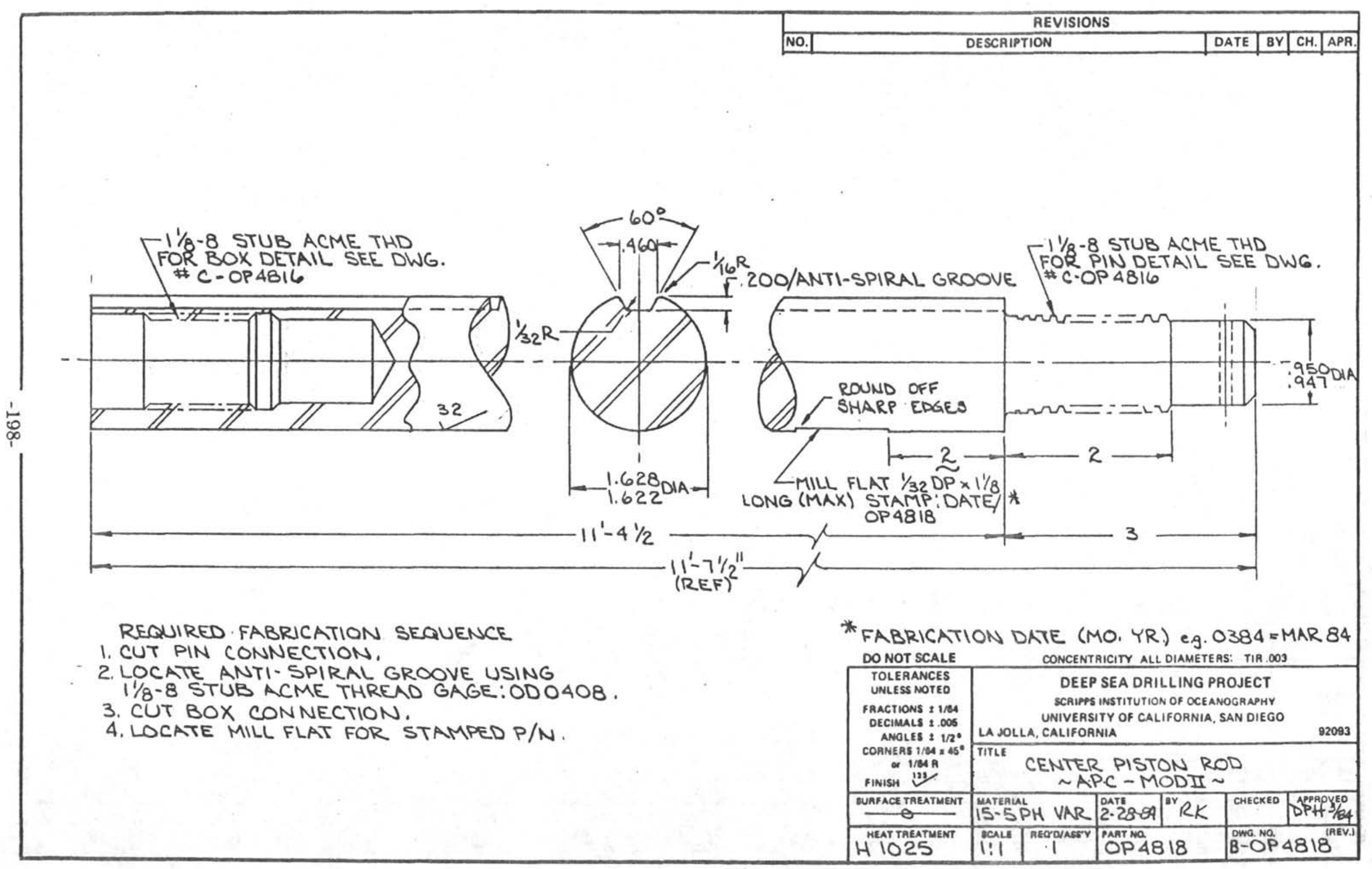




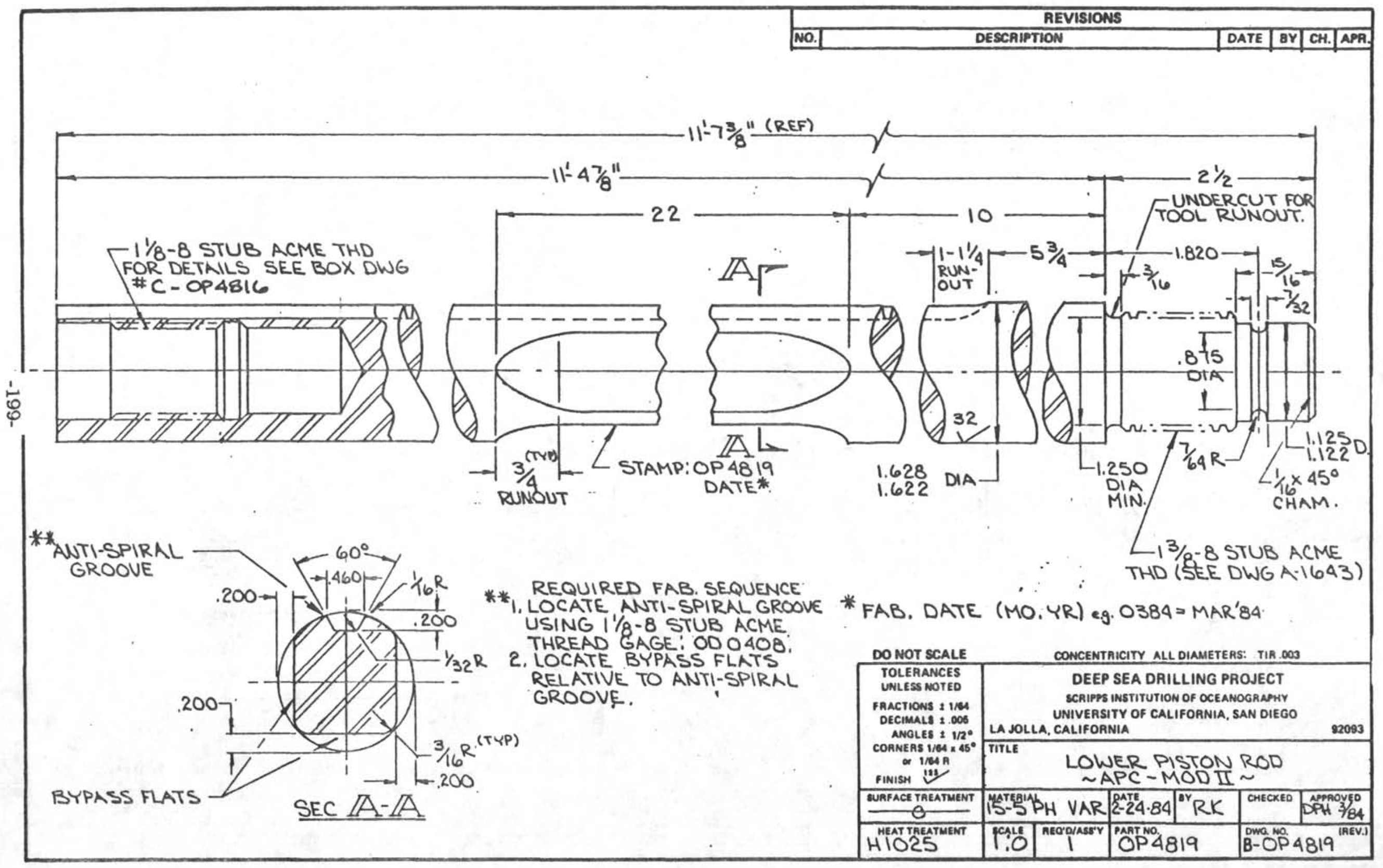




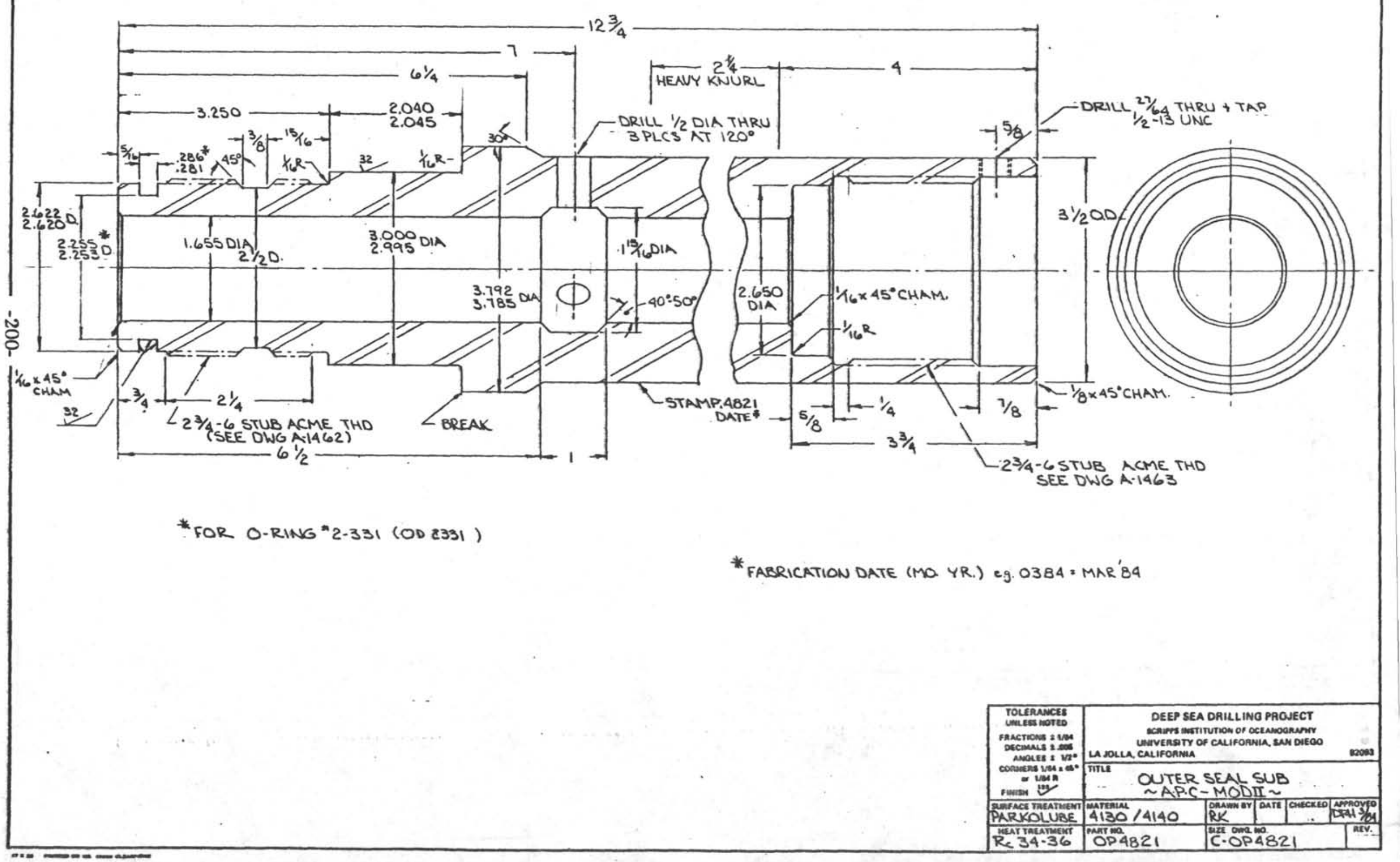




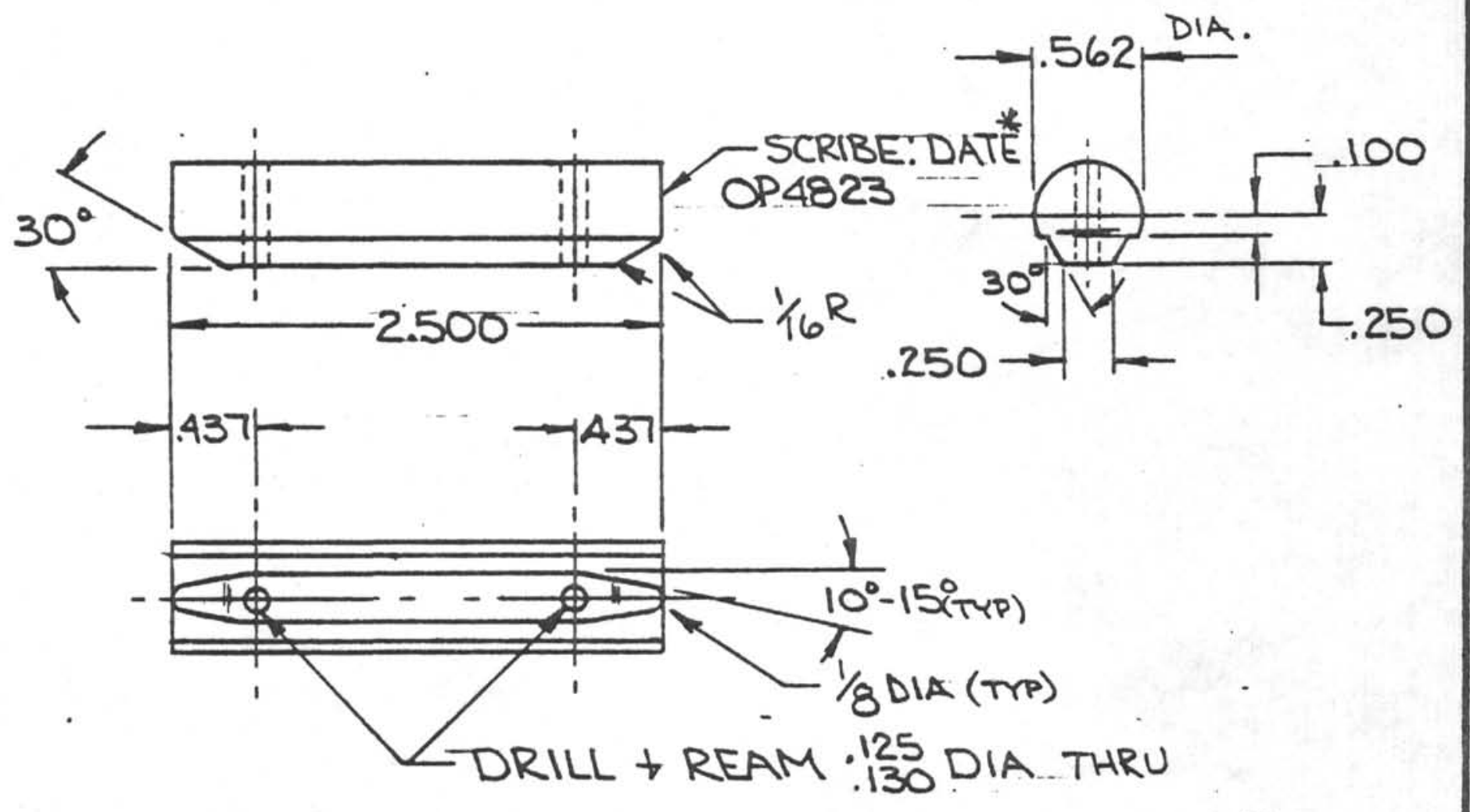

* Fab. oate (MO. yr) eg. 0384 = Mar'84 -

DO NOT SCALE

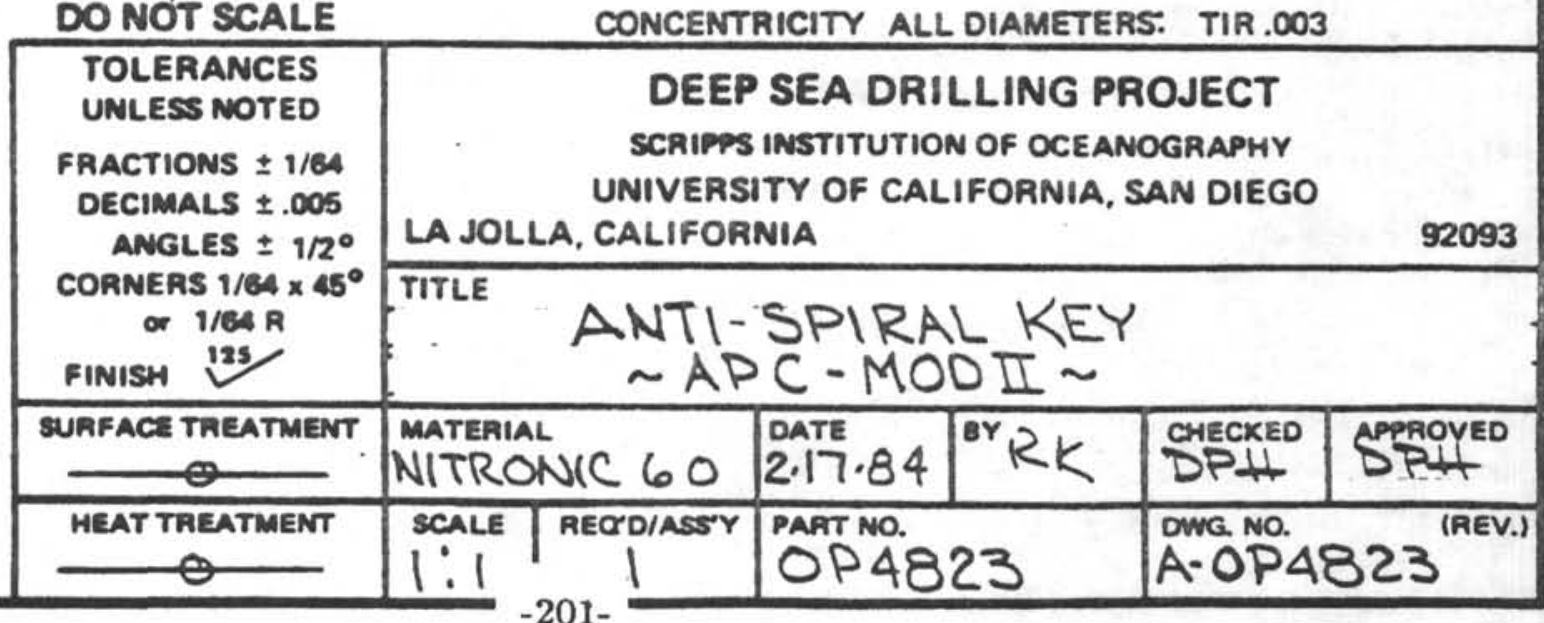




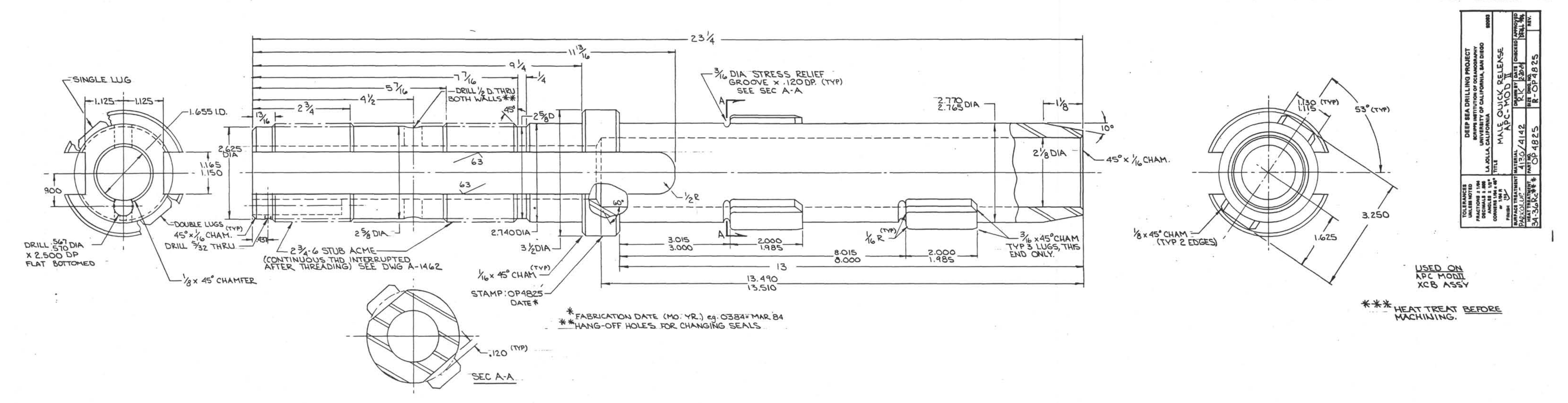




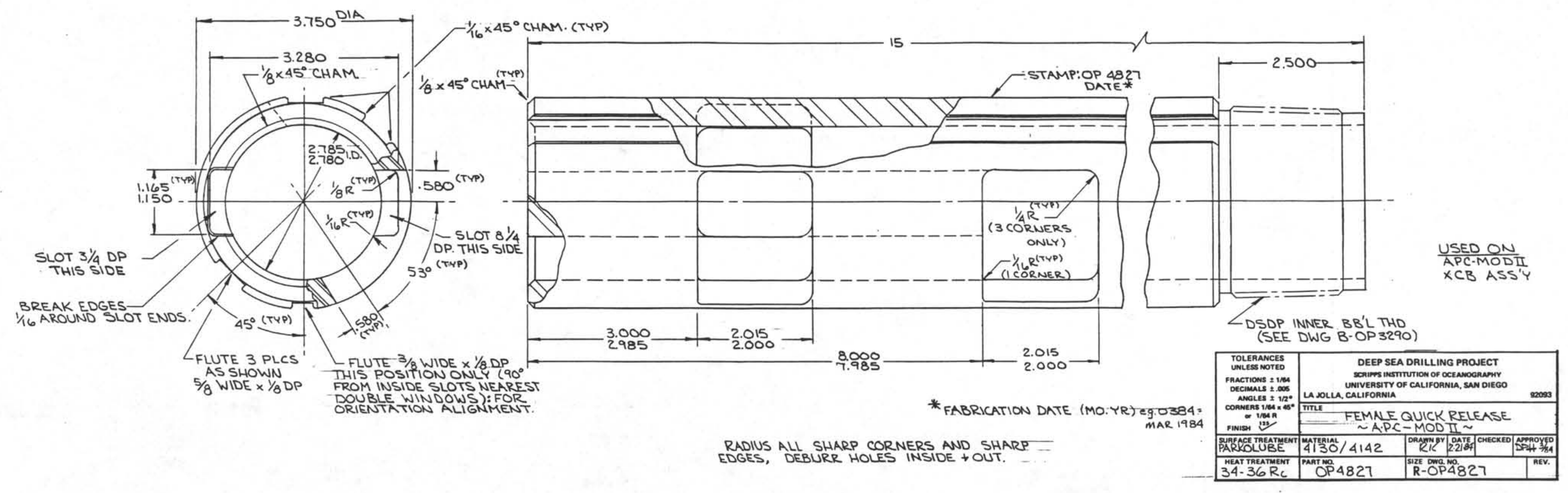




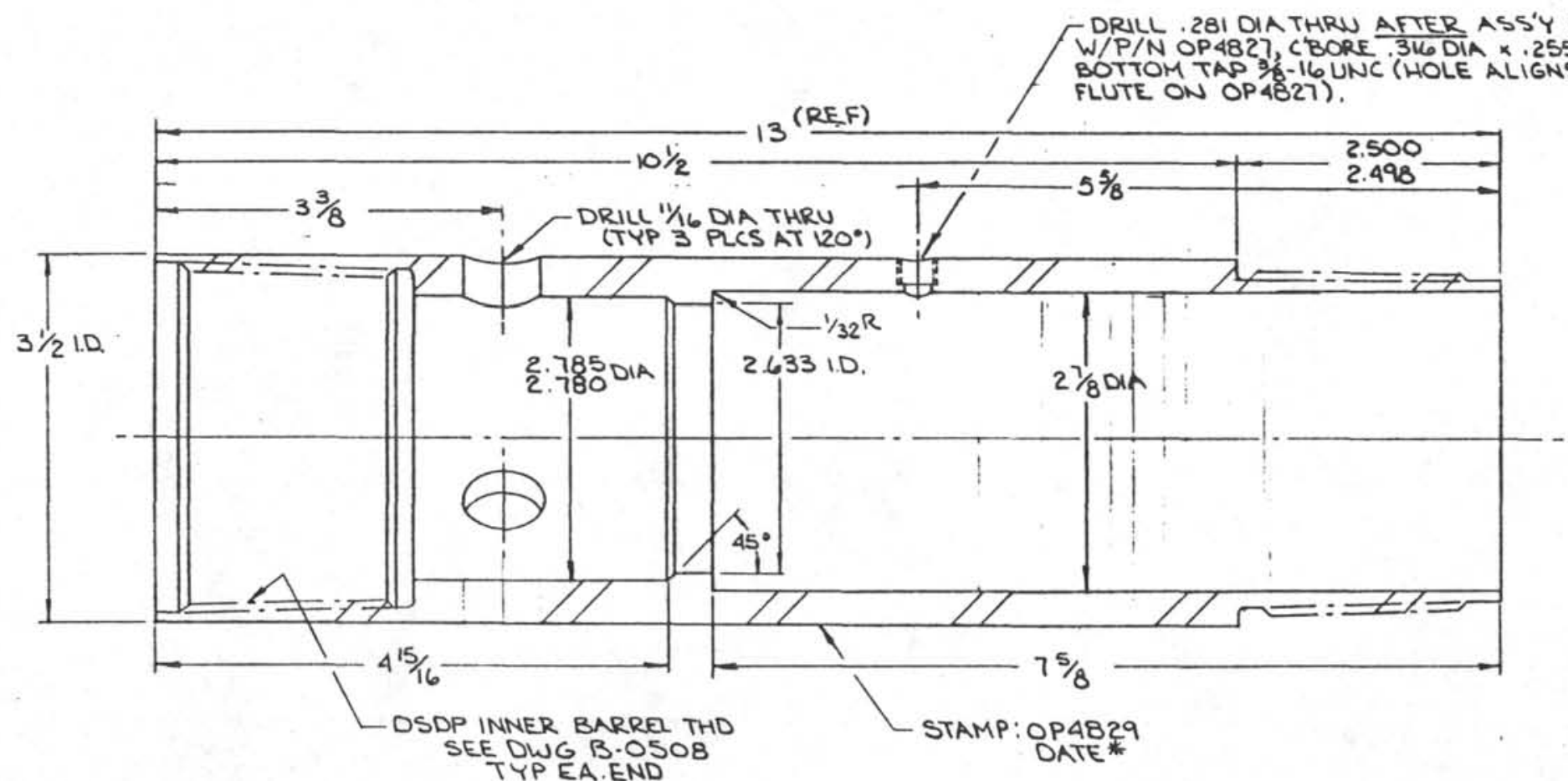

* fabrication date (mo.yr) eg. 0384 = mar 84

\begin{tabular}{|c|c|c|c|}
\hline 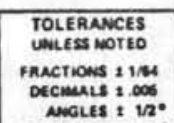 & 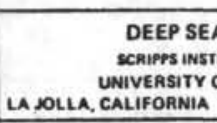 & $\begin{array}{l}\text { A DAILLING PROJECT } \\
\text { IUUTOOOOF OCENOGRNAY } \\
\text { OF CALLFOANIA, SAN DIEGO } \\
\end{array}$ & 20053 \\
\hline 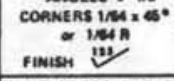 & $\begin{array}{l}\text { VEN } \\
\sim A P C \\
\sim\end{array}$ & $\begin{array}{l}\text { TSUB } \\
\text {-MODL }\end{array}$ & \\
\hline PARACEDREASTHENT & $4130 \% / 4140$ & 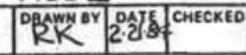 & 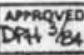 \\
\hline 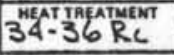 & OP 4829 & size owa No 29 & \\
\hline
\end{tabular}




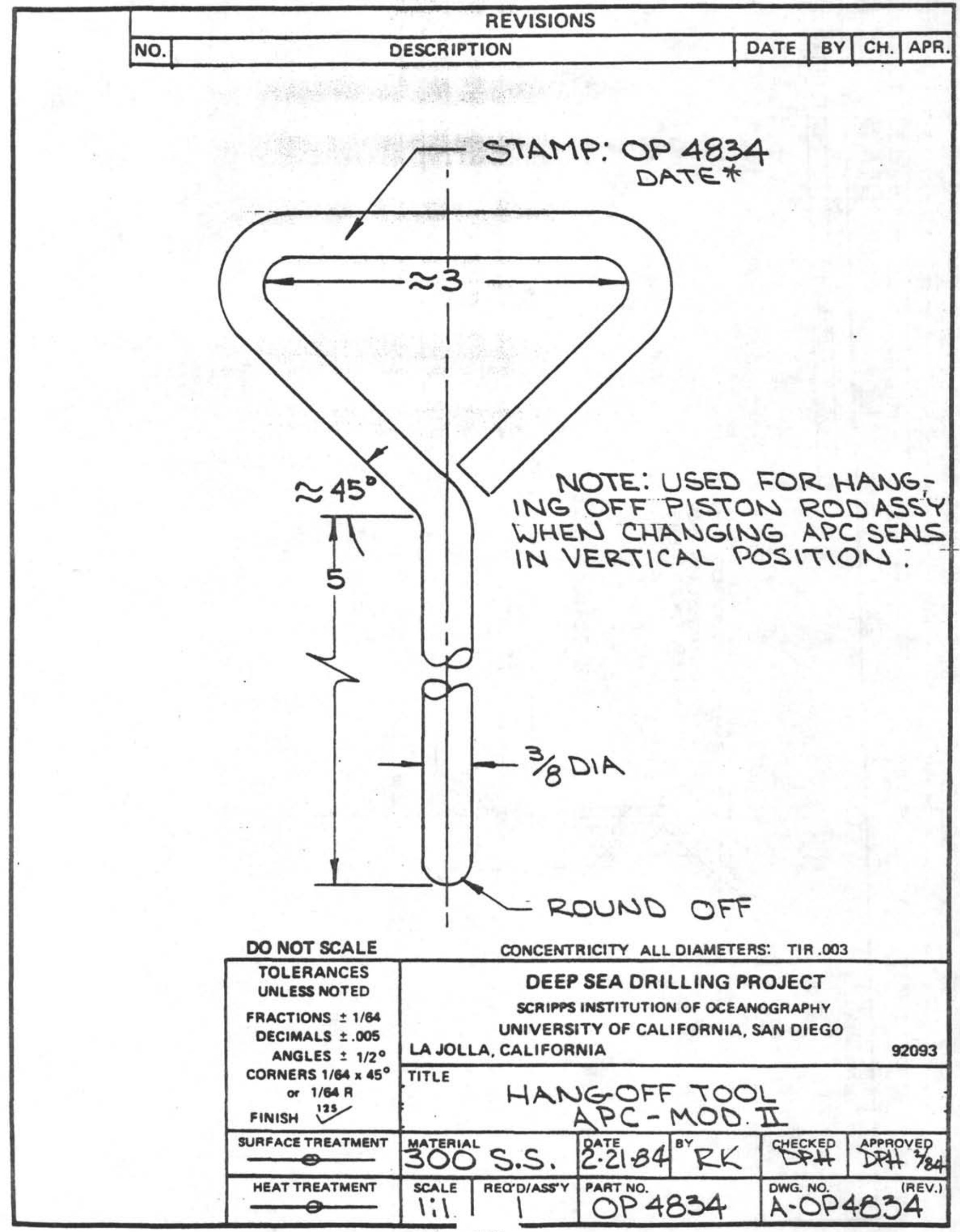




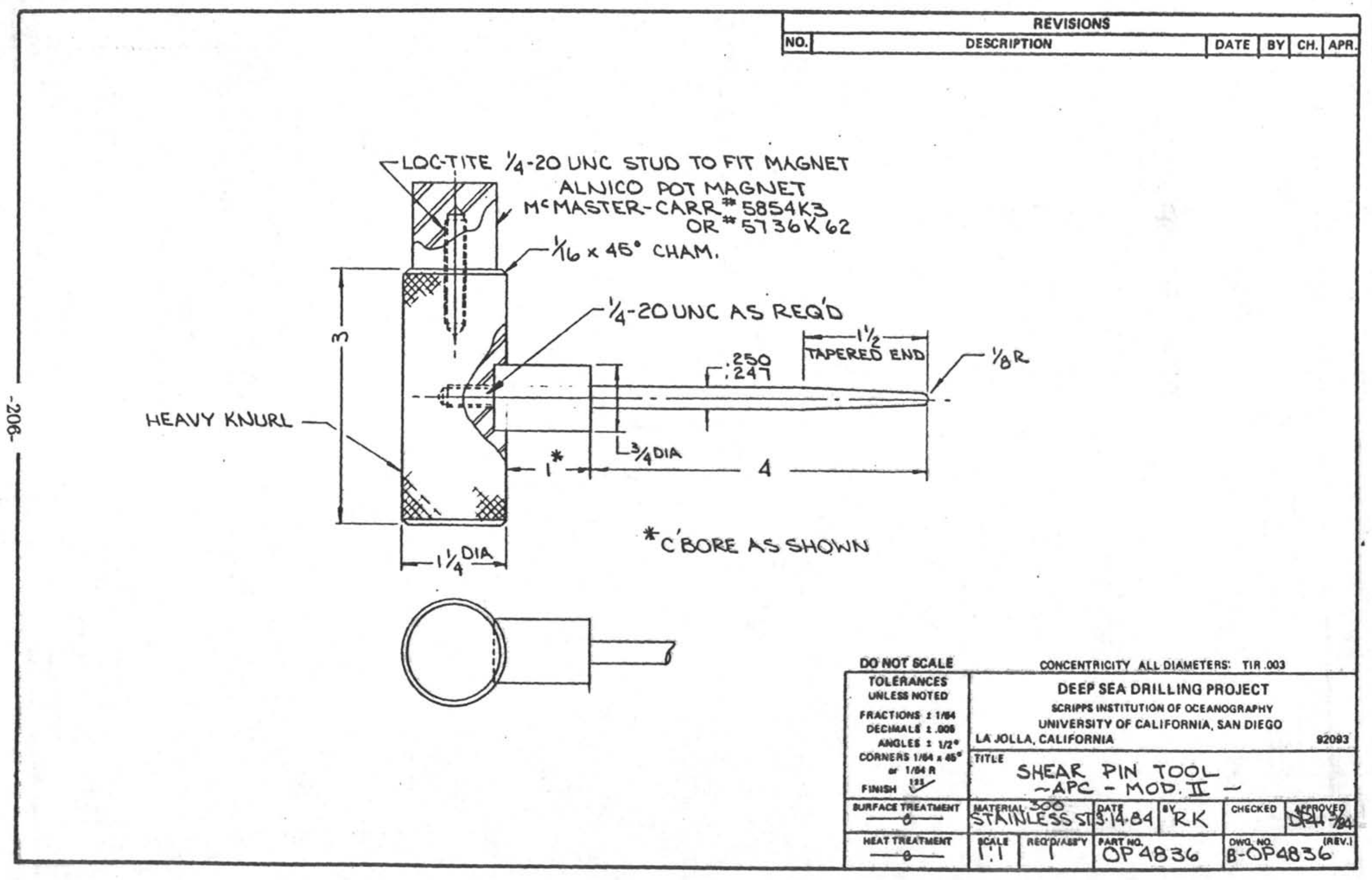




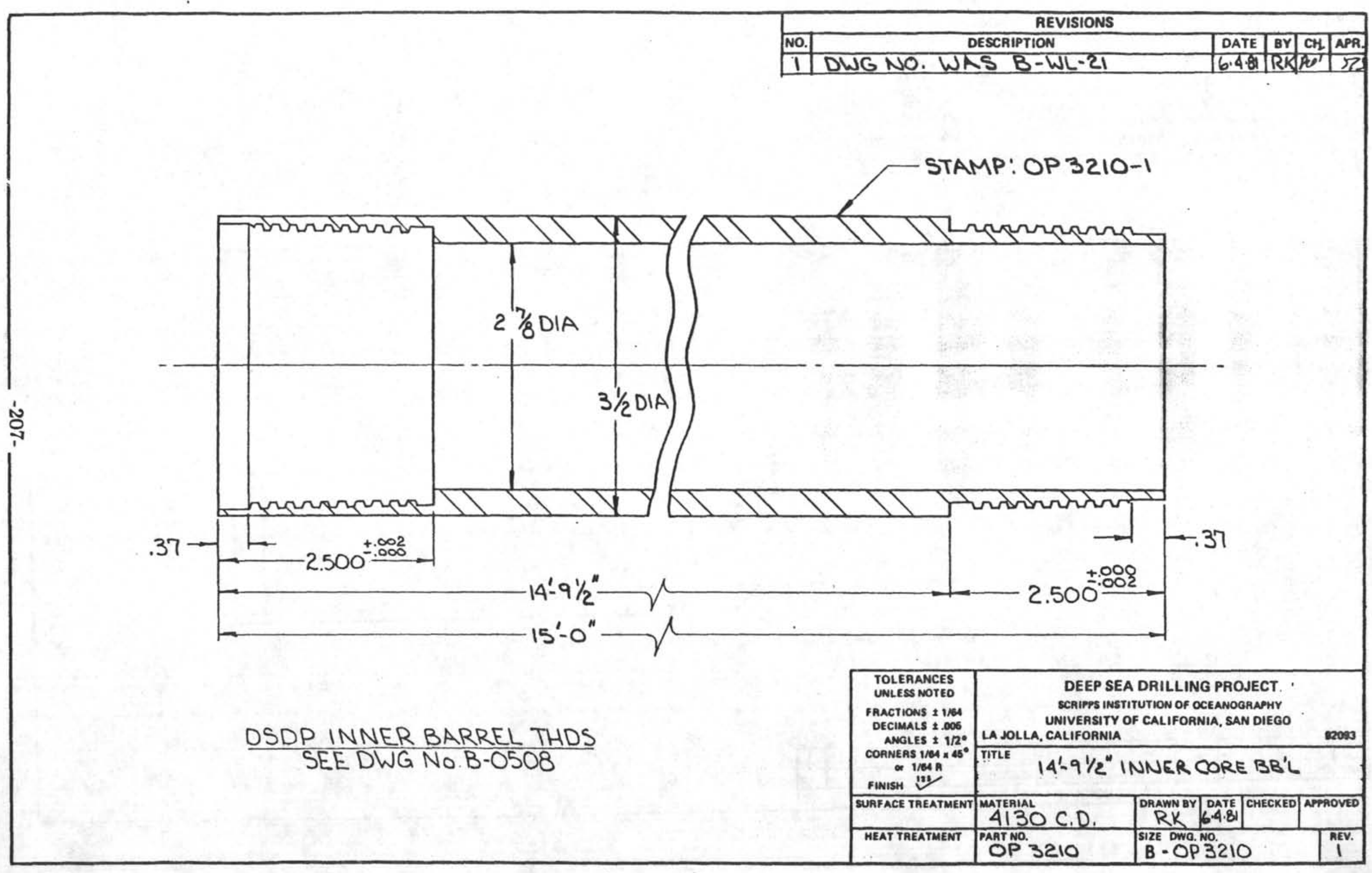




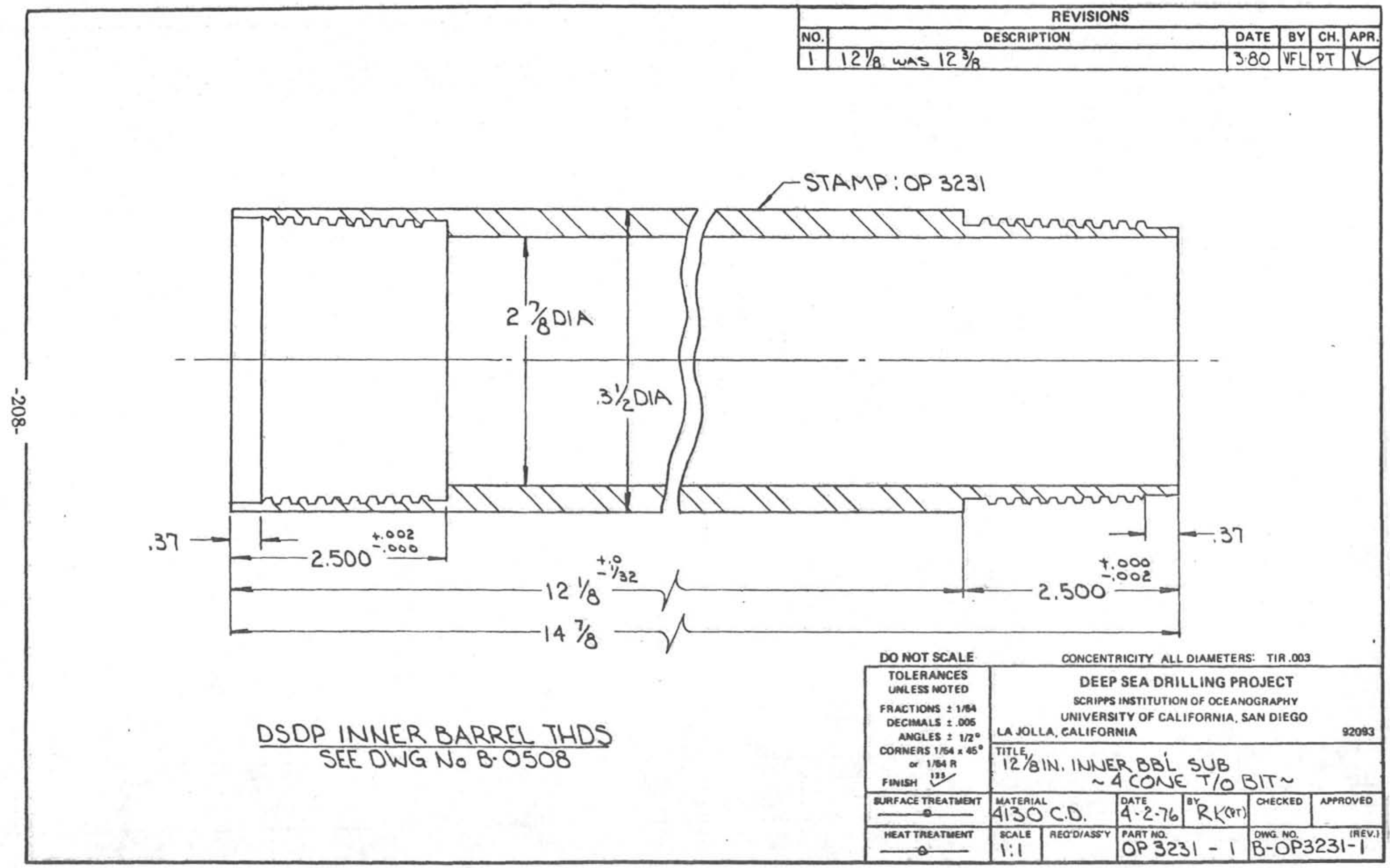




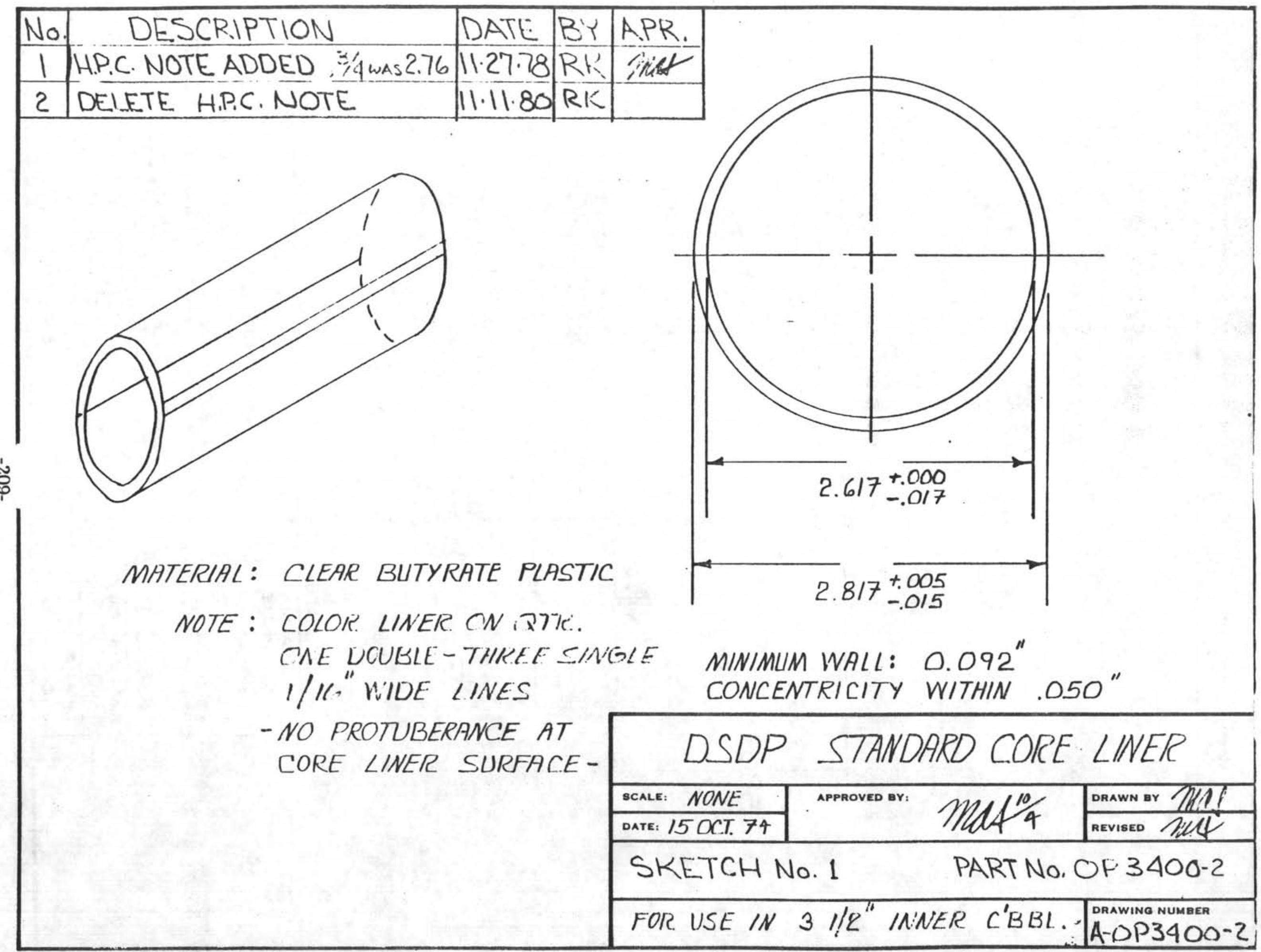




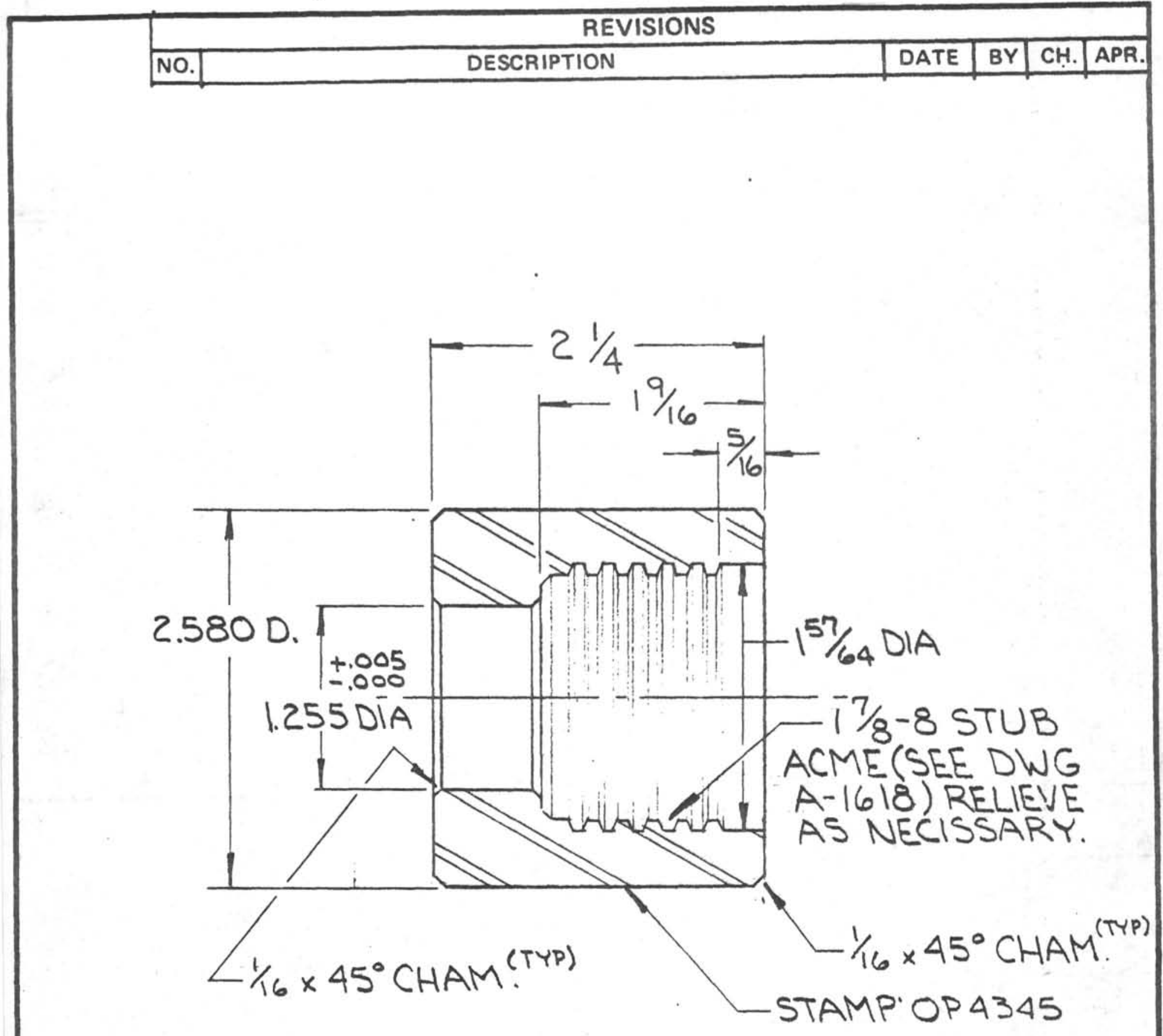

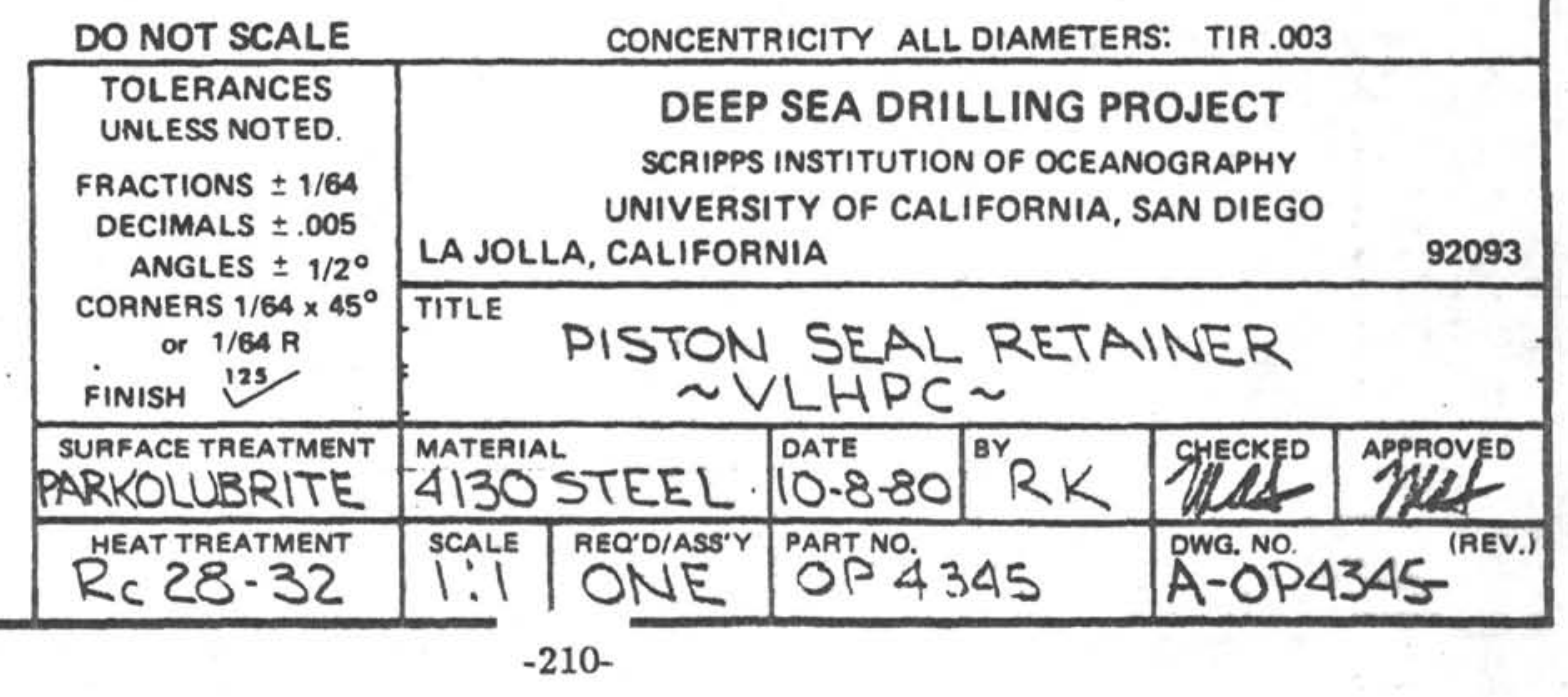




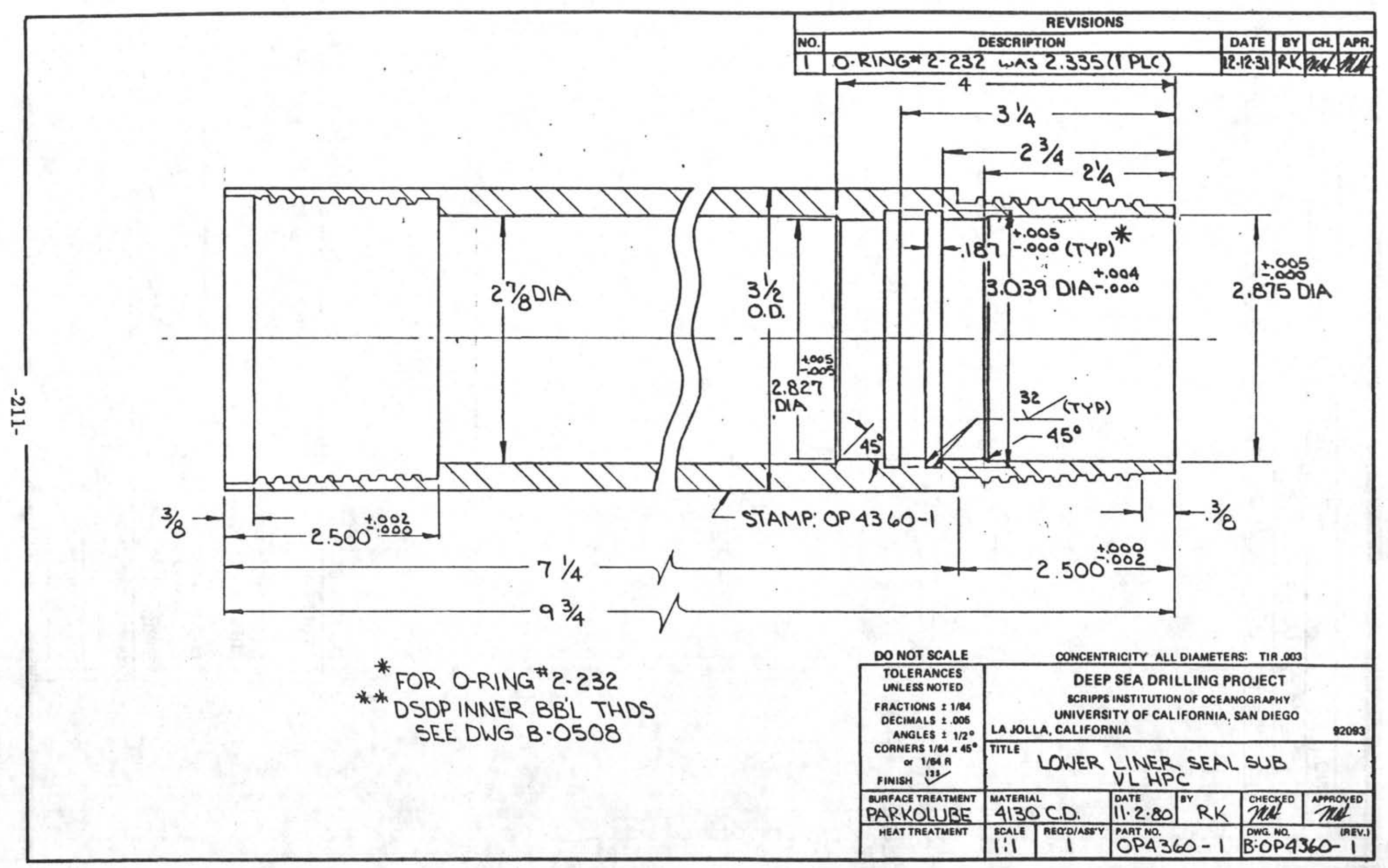




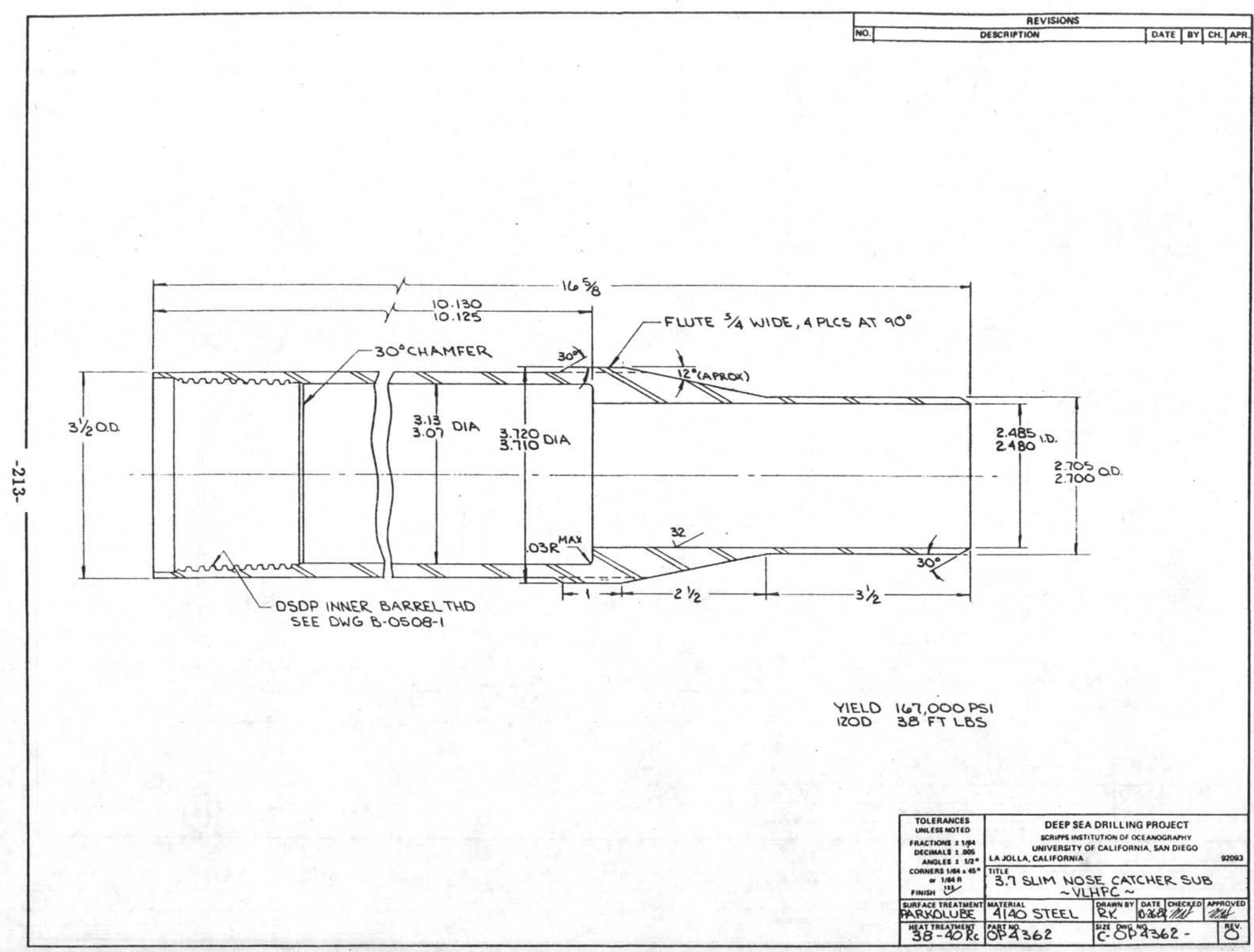




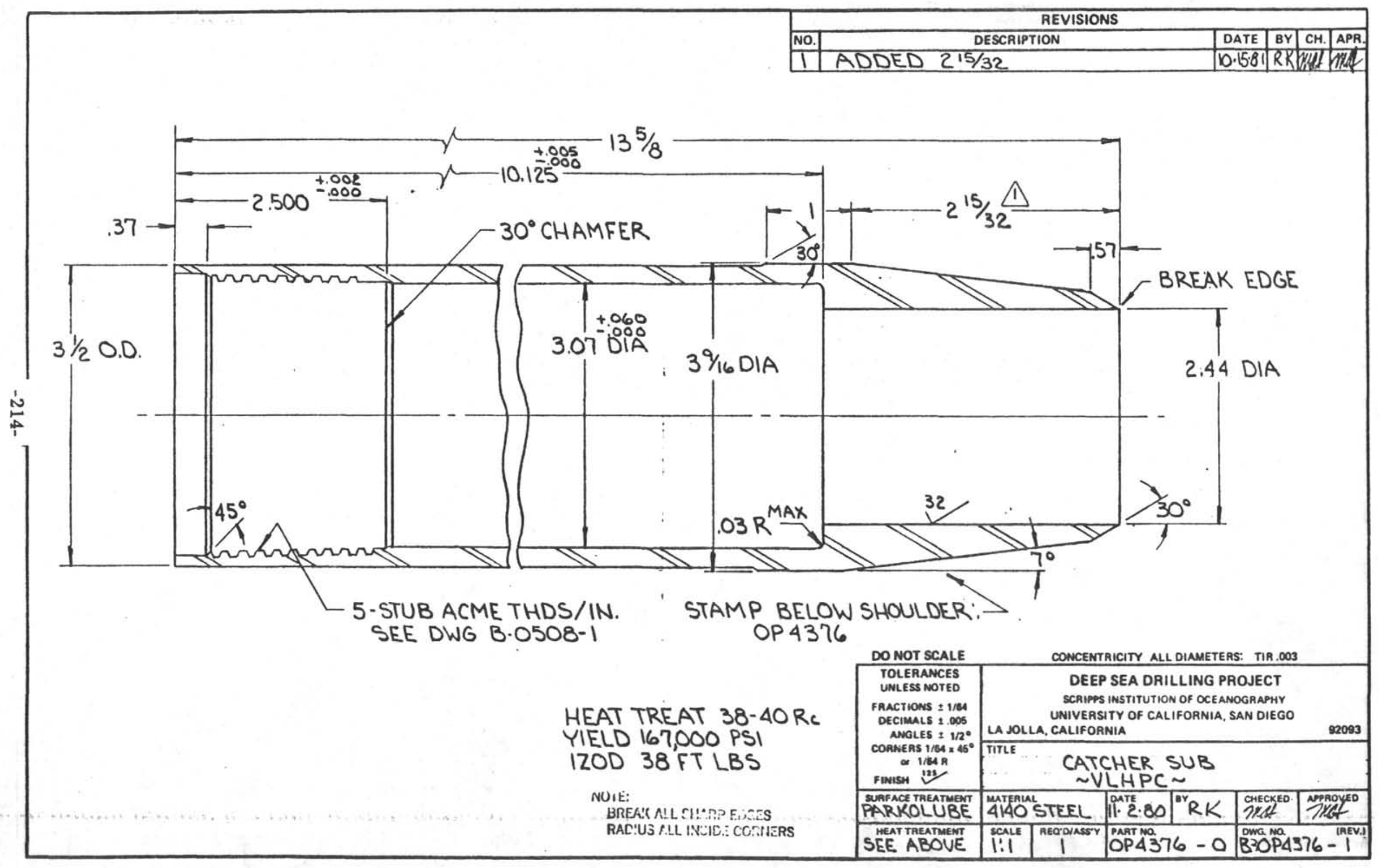




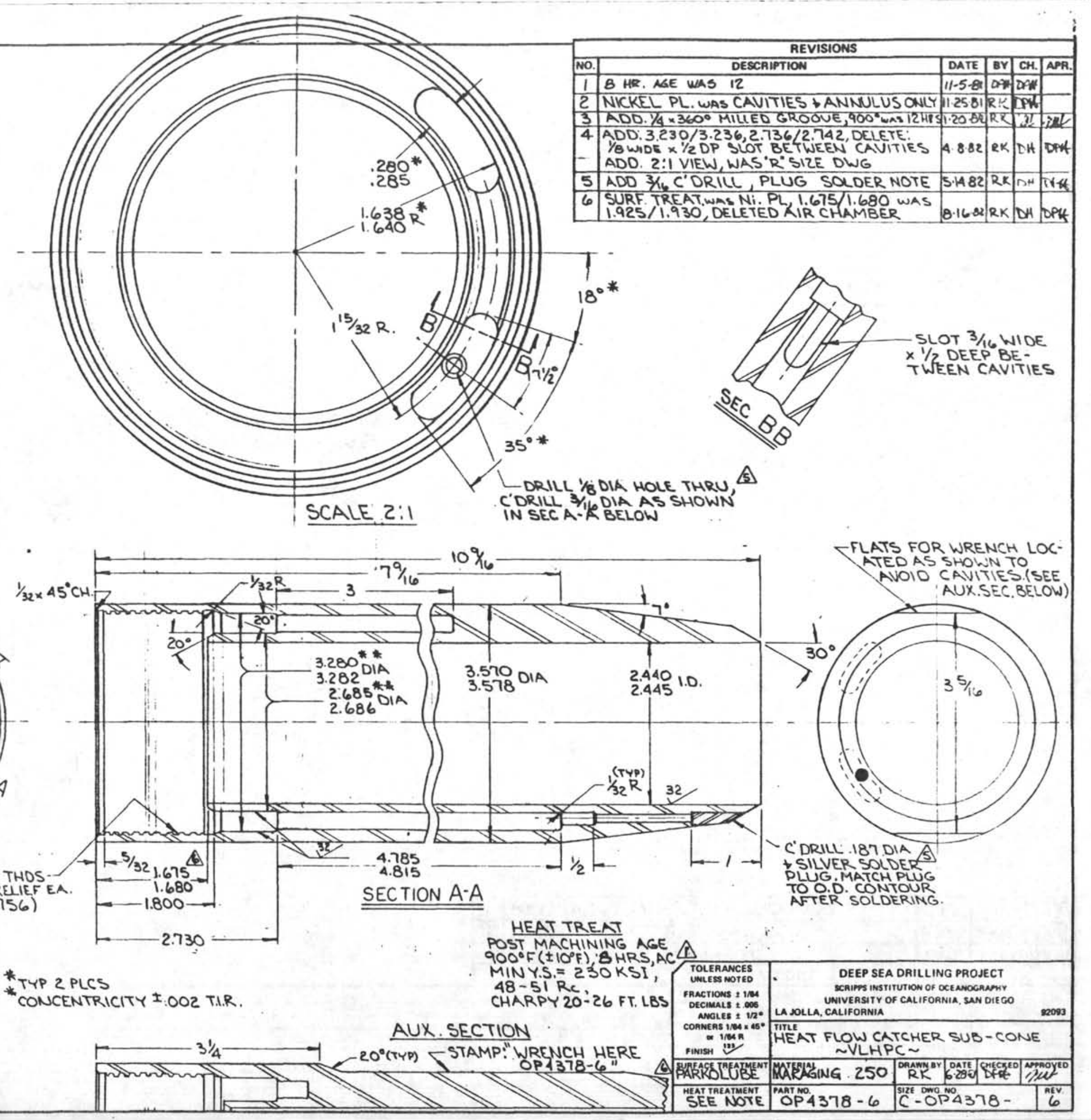




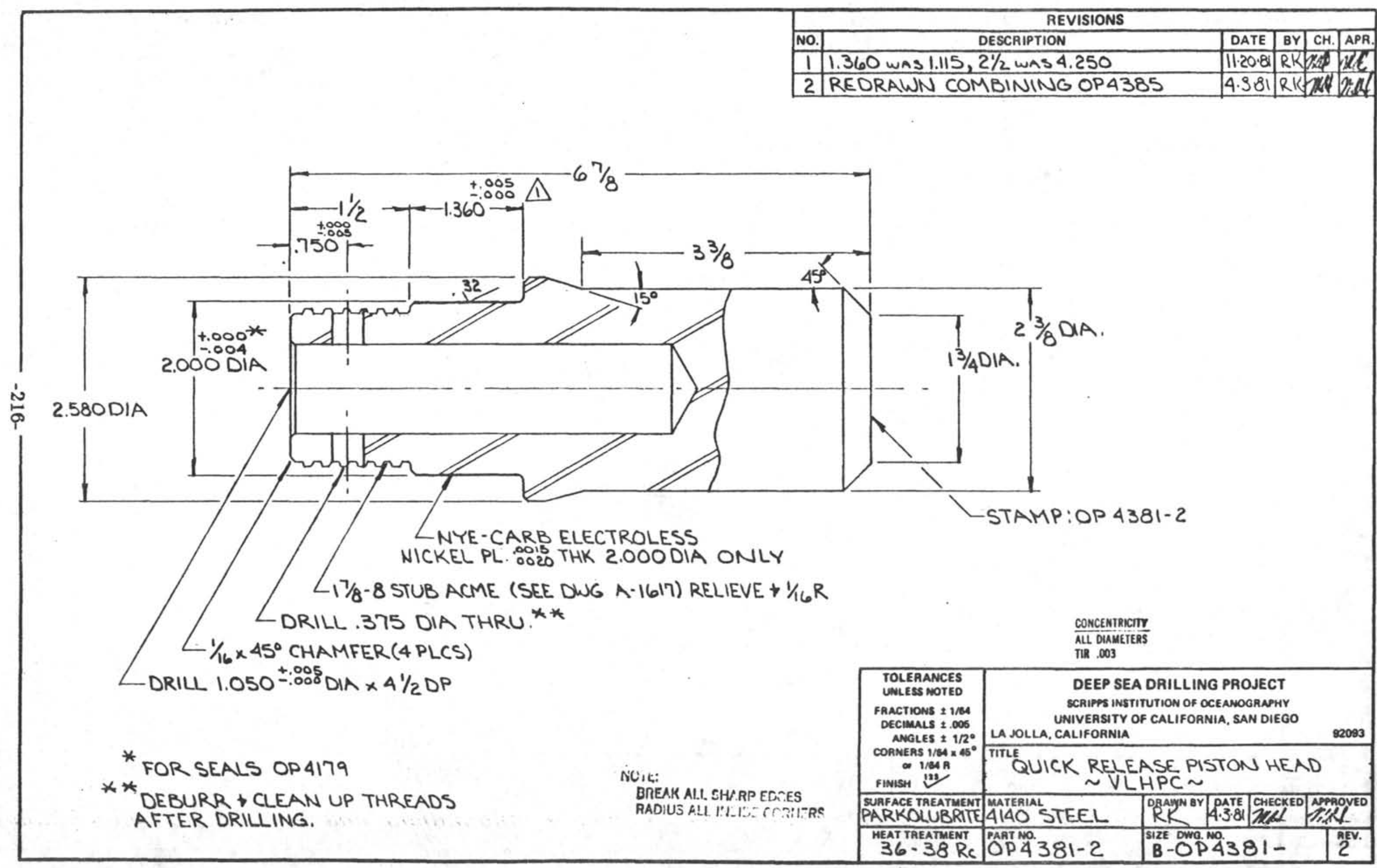




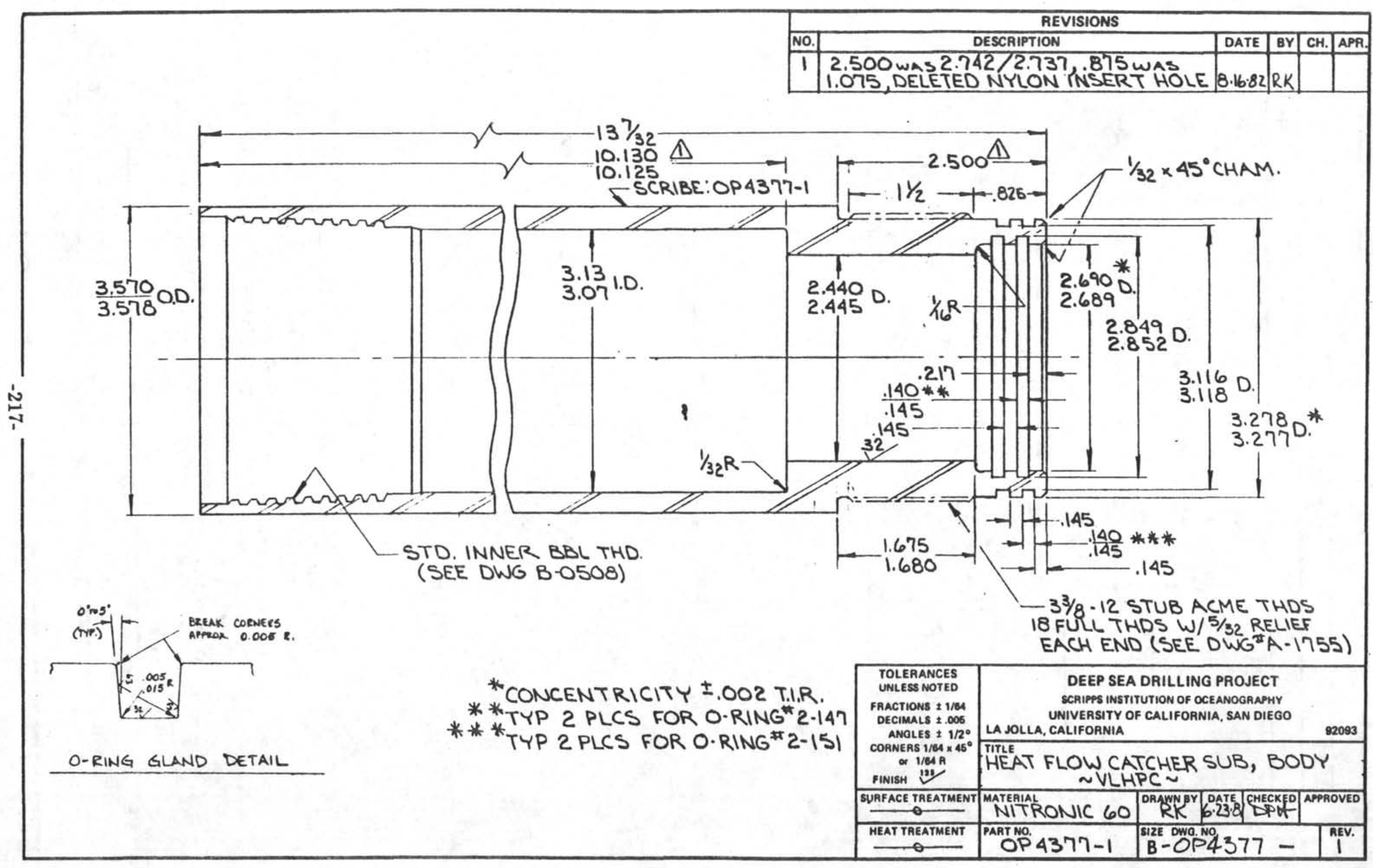




\begin{tabular}{|c|c|c|c|c|c|}
\hline NO. & DESCRIPTION & DATE & BY & $\mathrm{CH}$. & APR. \\
\hline 1. & WAS 2 & 4.1681 & RK & Dest & 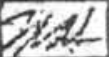 \\
\hline
\end{tabular}

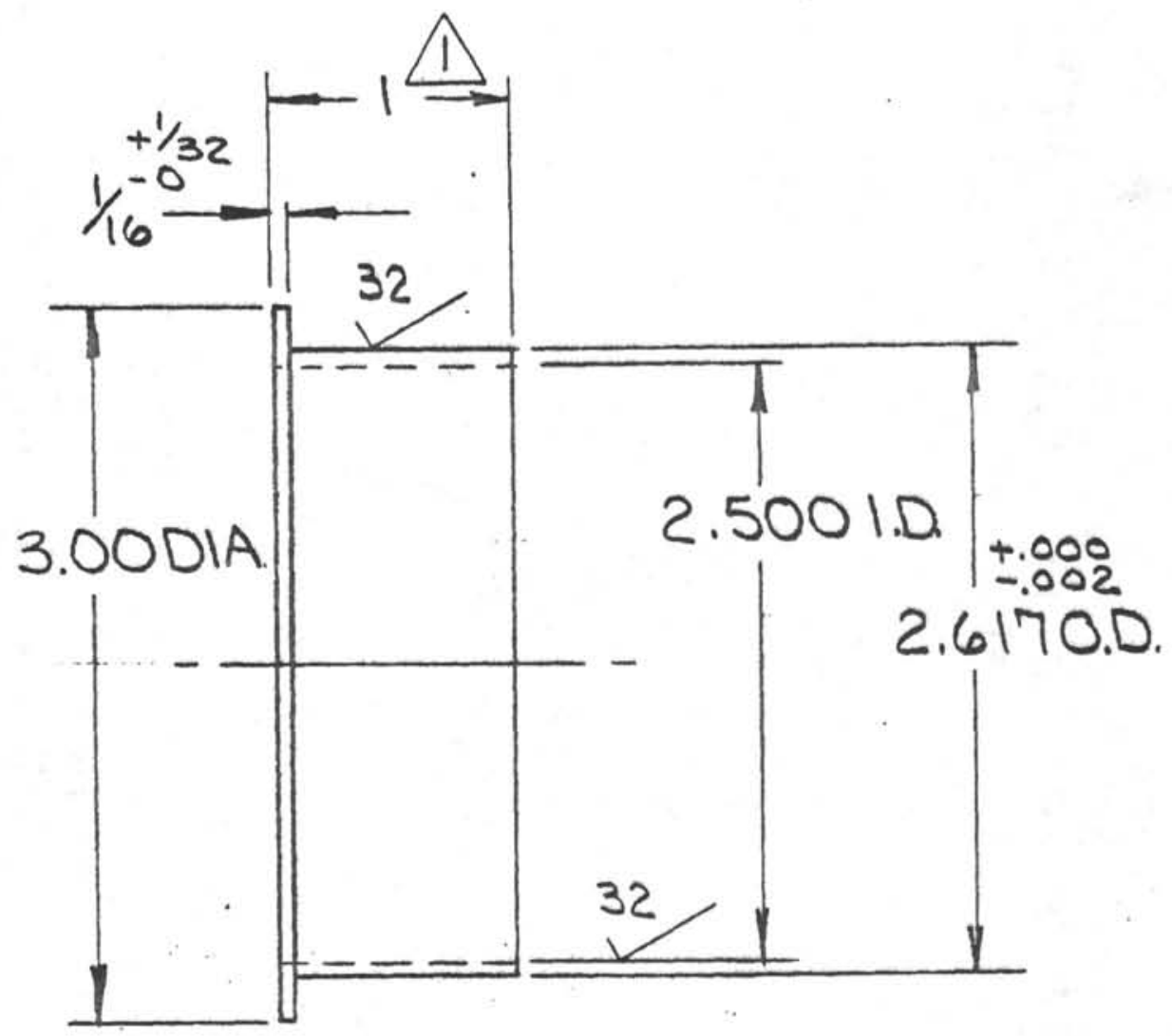

MAT'L:

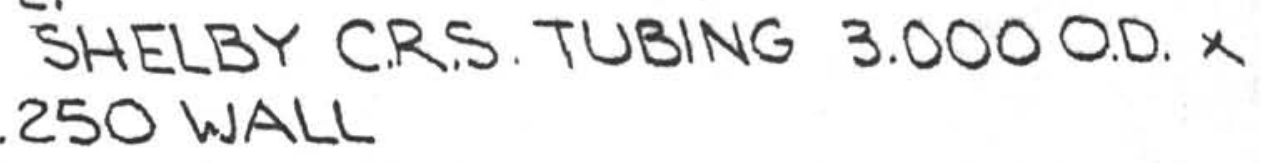

DO NOT SCALE CONCENTRICITY ALL DIAMETERS: TIR.003

\begin{tabular}{|c|c|c|c|c|c|}
\hline \multirow{2}{*}{$\begin{array}{l}\text { TOLERANCES } \\
\text { UNLESS NOTED } \\
\text { FRACTIONS } \pm 1 / 64 \\
\text { DECIMALS } \pm .005 \\
\text { ANGLES } \pm 1 / 2^{\circ} \\
\text { CORNERS } 1 / 64 \times 45^{\circ} \\
\text { or } 1 / 64 R \\
\text { FINISH } 125 \\
\end{array}$} & \multicolumn{4}{|c|}{$\begin{array}{l}\text { DEEP SEA DRILLING PROJECT } \\
\text { SCRIPPS INSTITUTION OF OCEANOGRAPHY } \\
\text { UNIVERSITY OF CALIFORNIA, SAN DIEG O } \\
\text { A JOLLA, CALIFORNIA }\end{array}$} & \multirow[t]{2}{*}{92093} \\
\hline & \multicolumn{4}{|c|}{ TITLE PLASTIC TUBE SUPPORT } & \\
\hline SURFACE TREATMENT & $\begin{array}{l}\text { MATERIAL } \\
\text { SEE ABOVE }\end{array}$ & DATE 21.80 & ${ }^{B Y} R K$ & $\begin{array}{l}\text { CHECKED } \\
\text { ZNAS }\end{array}$ & Apgroved \\
\hline HEAT TREATMENT & \begin{tabular}{l|l} 
SCALE & REO'D/ASS'Y \\
$1: 1$ & 1 \\
\end{tabular} & PAAT NO. & $2-1$ & DWG. NO & $2-1^{\text {(AEV.) }}$ \\
\hline
\end{tabular}




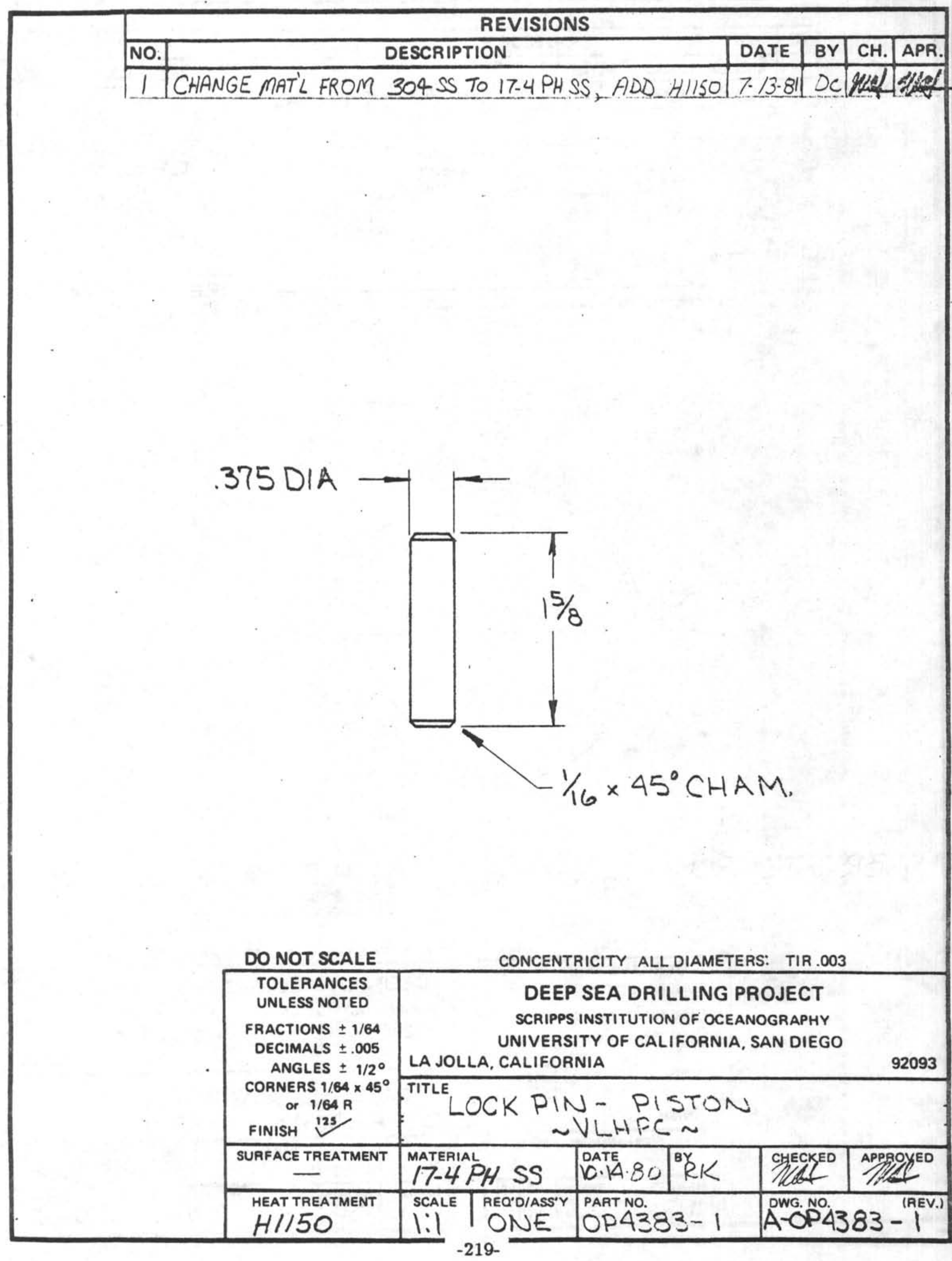




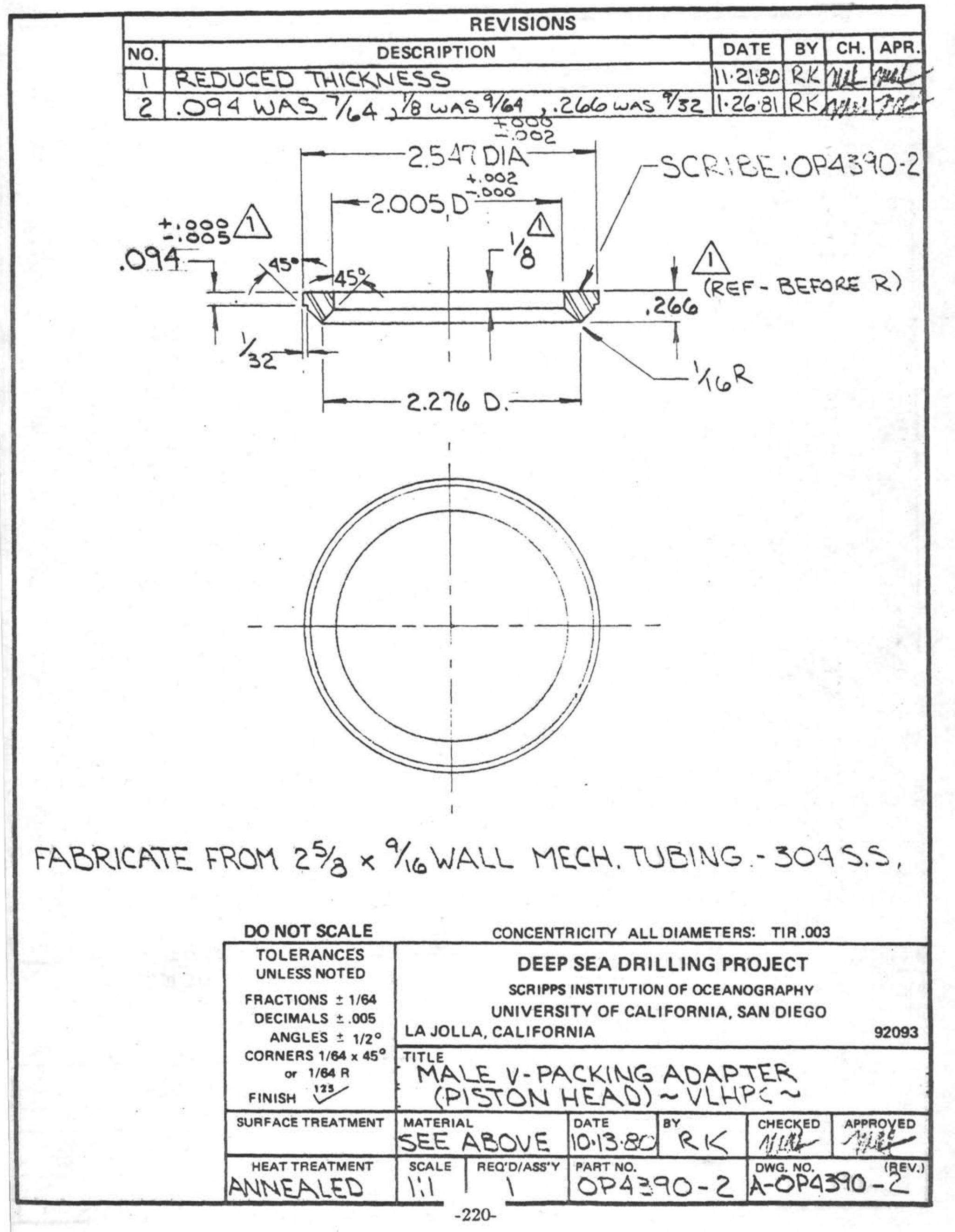




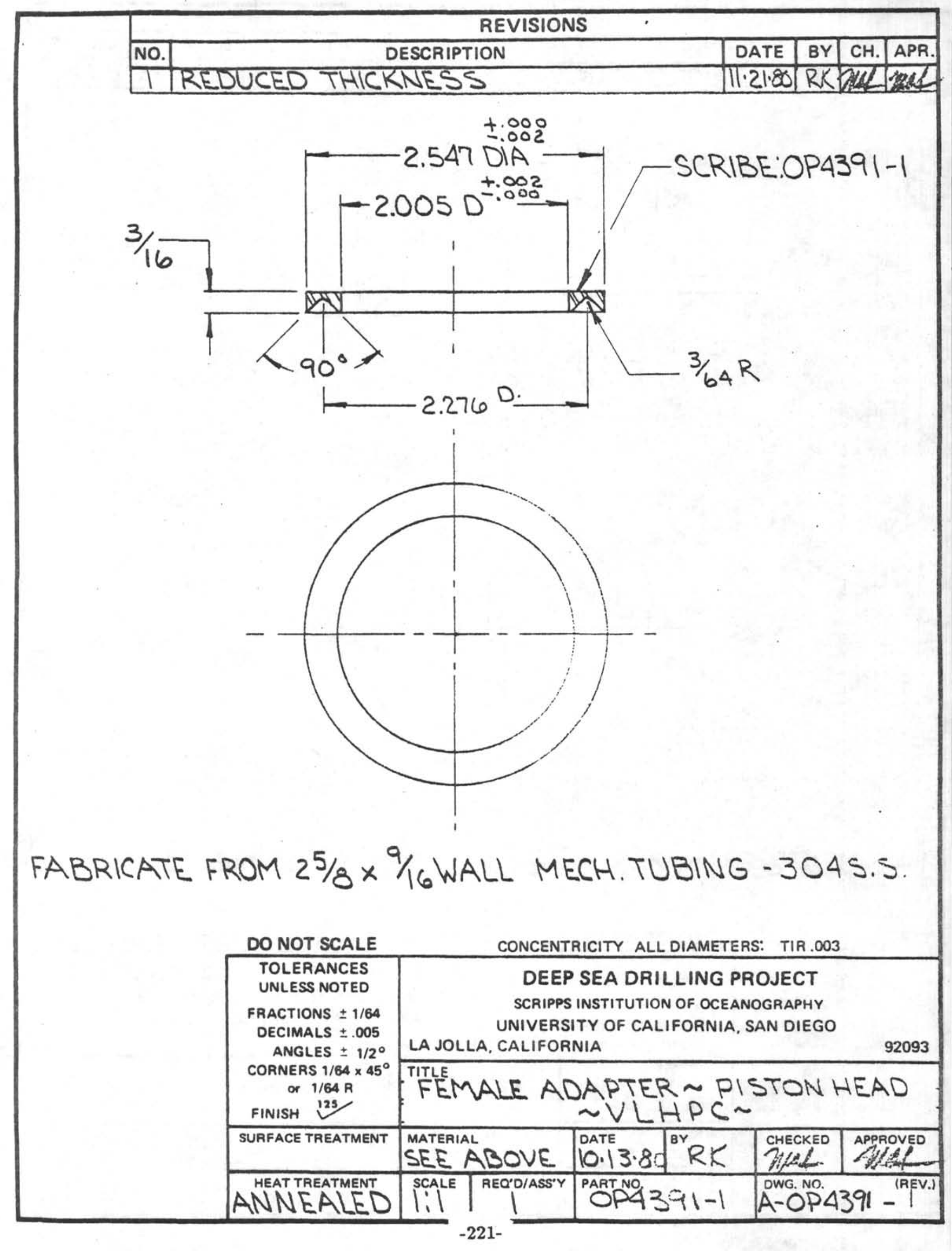




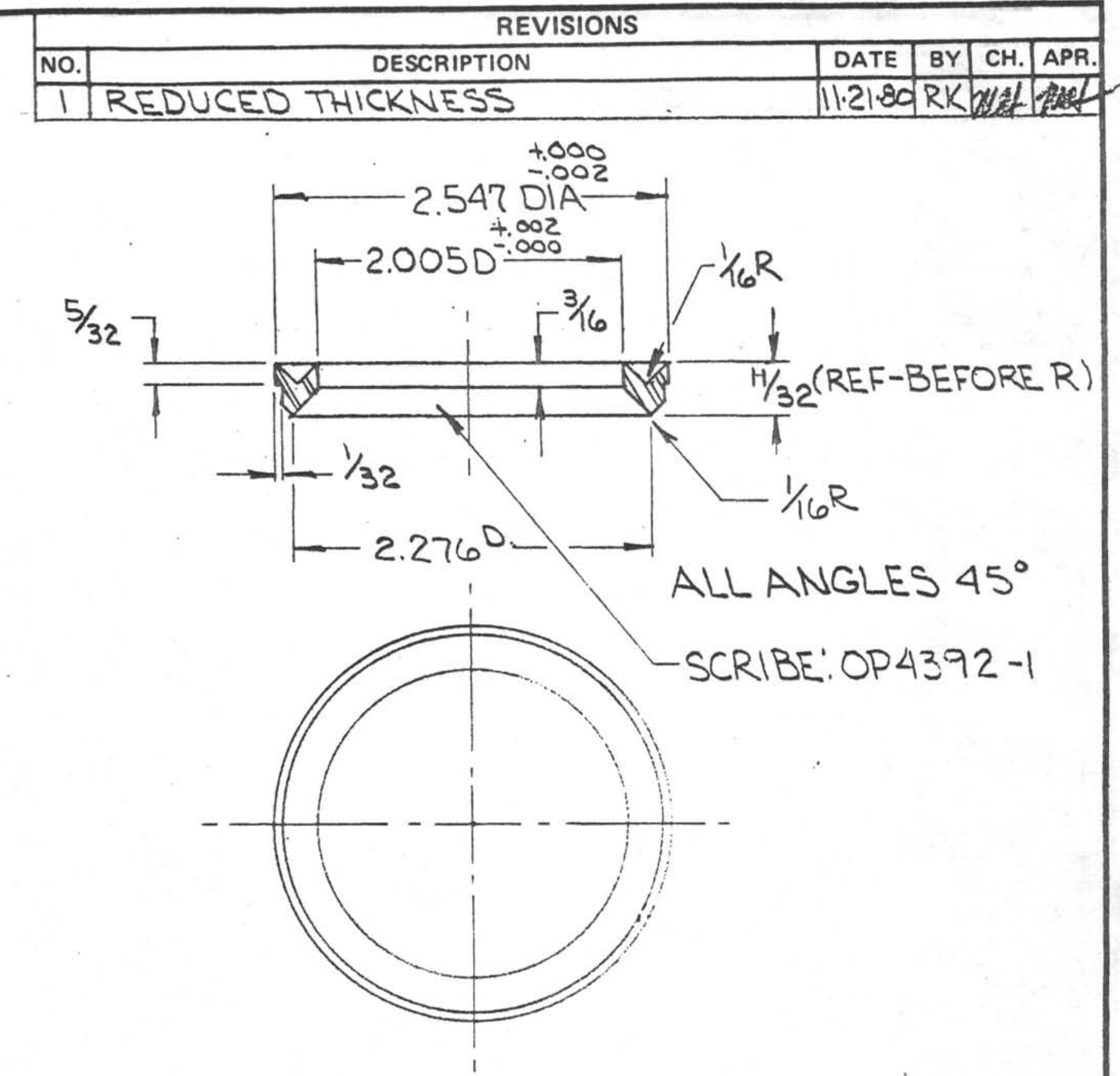

FABRICATE FROM $25 / 8 \times 9 / 16$ WALL MECH TUBING - 3045.5.

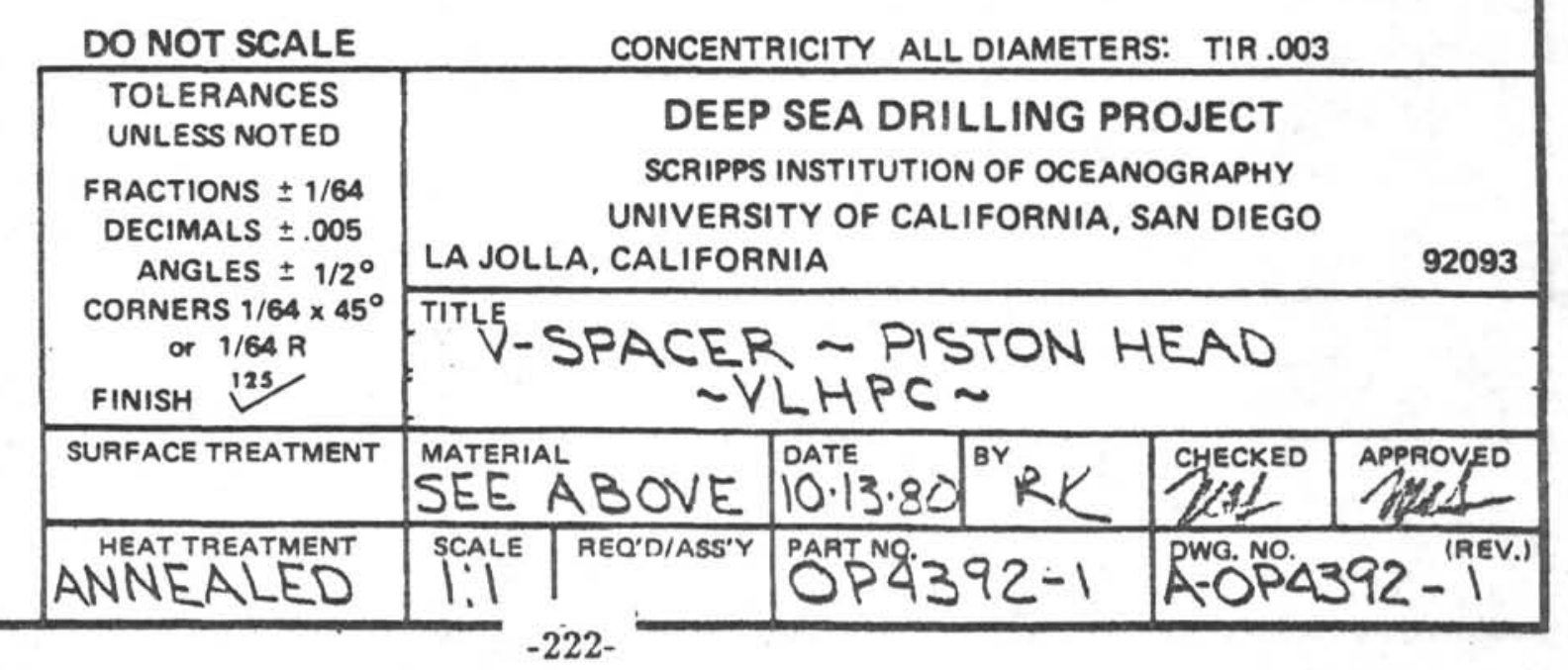




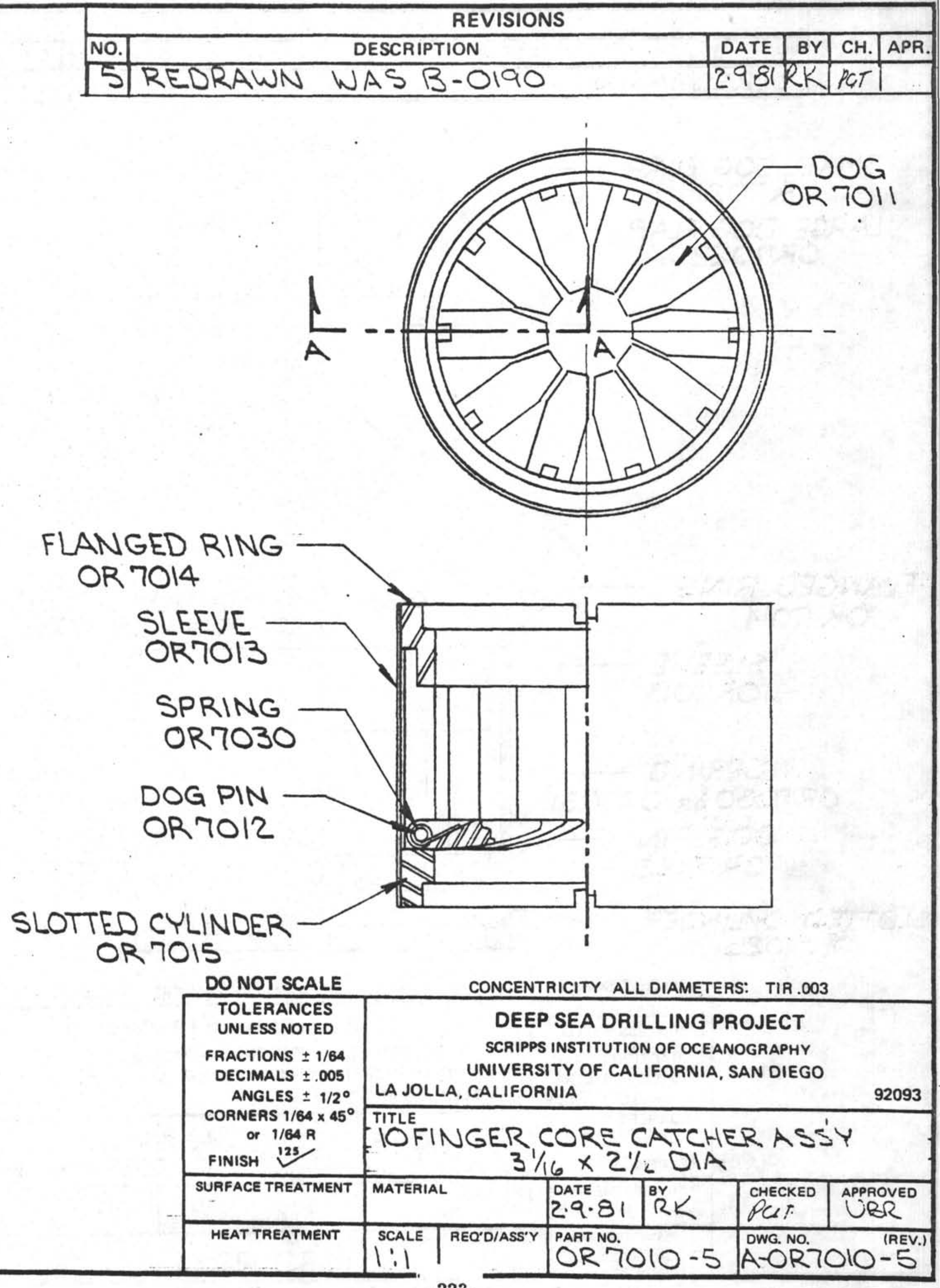




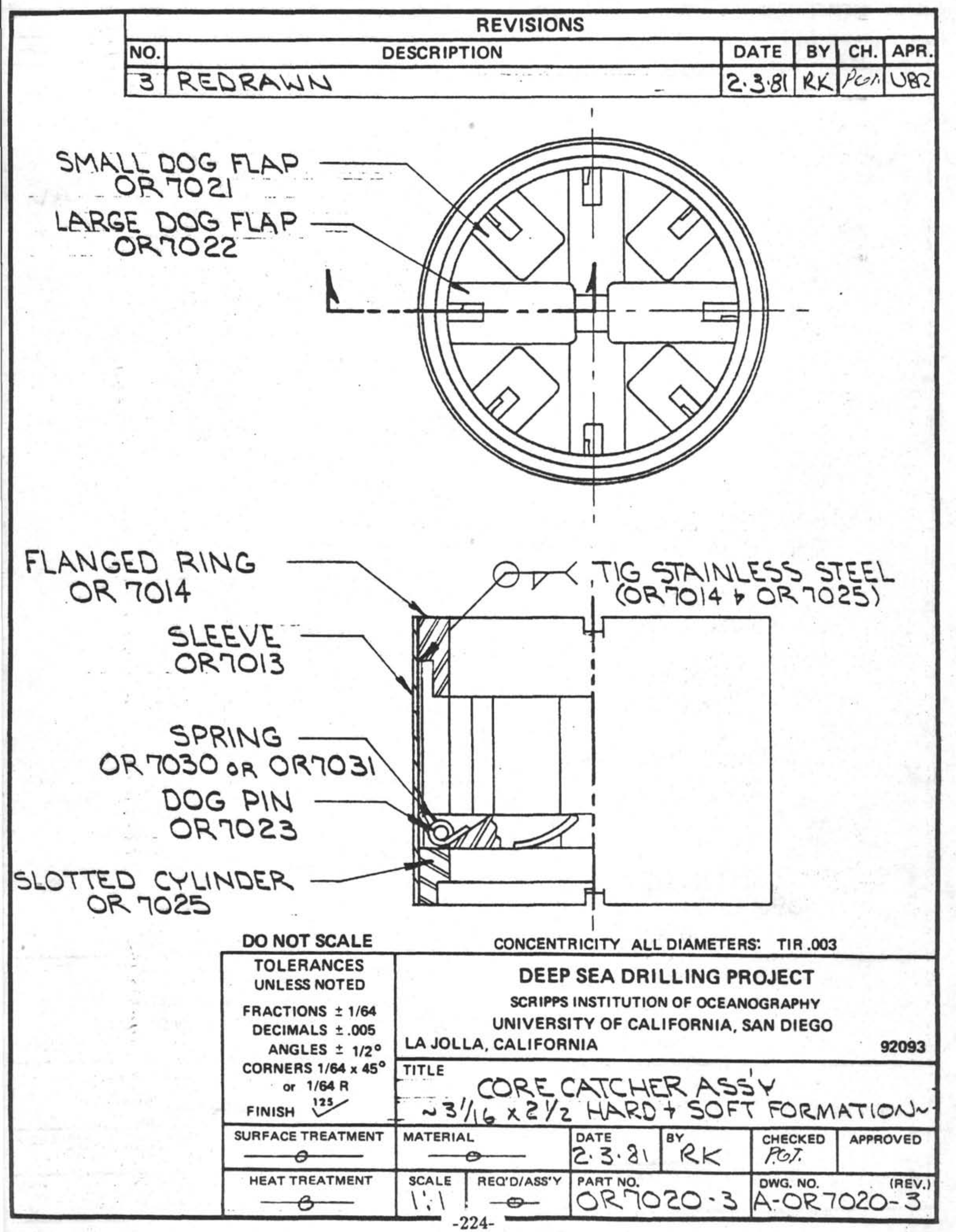




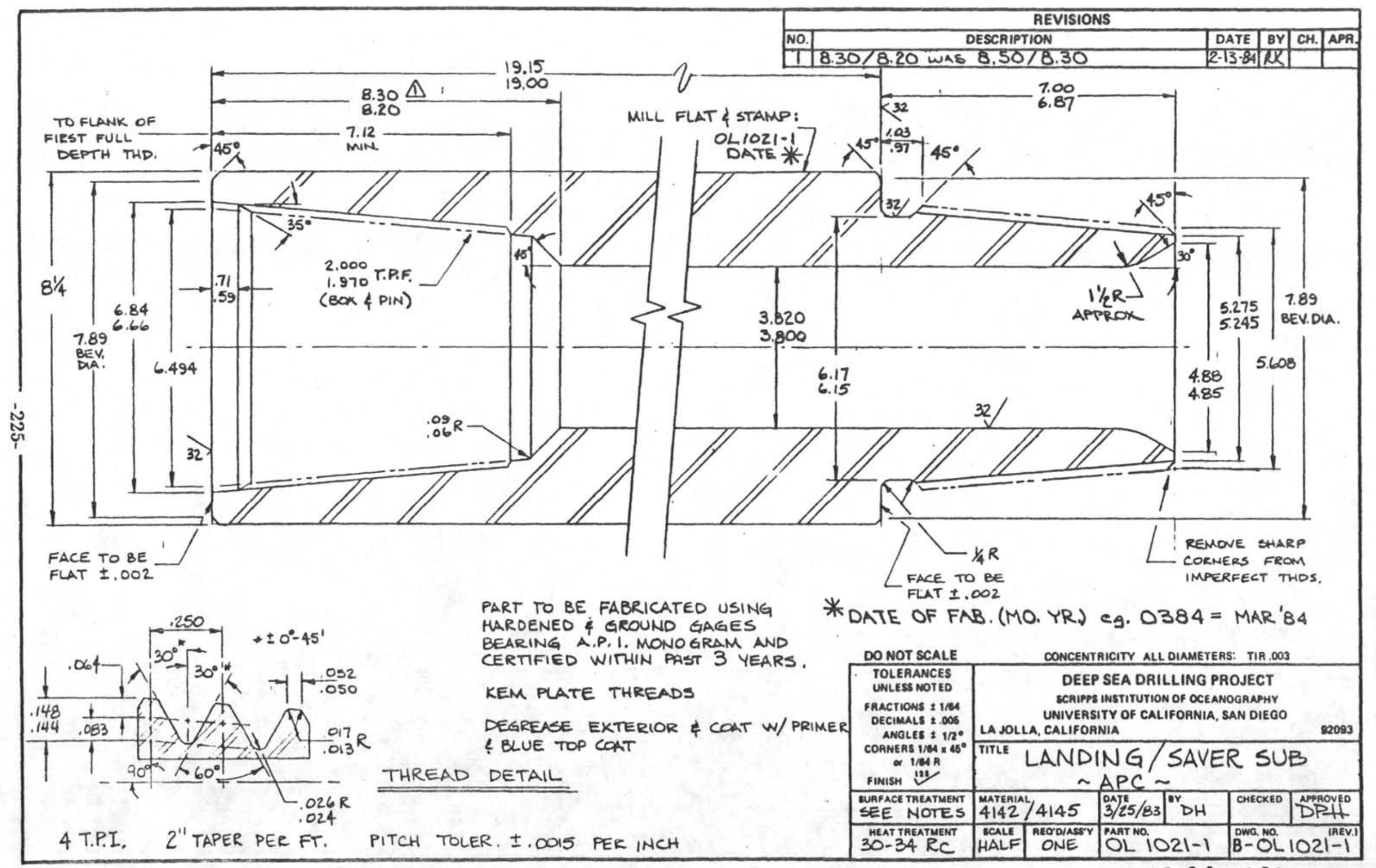

WAS OG 0620 


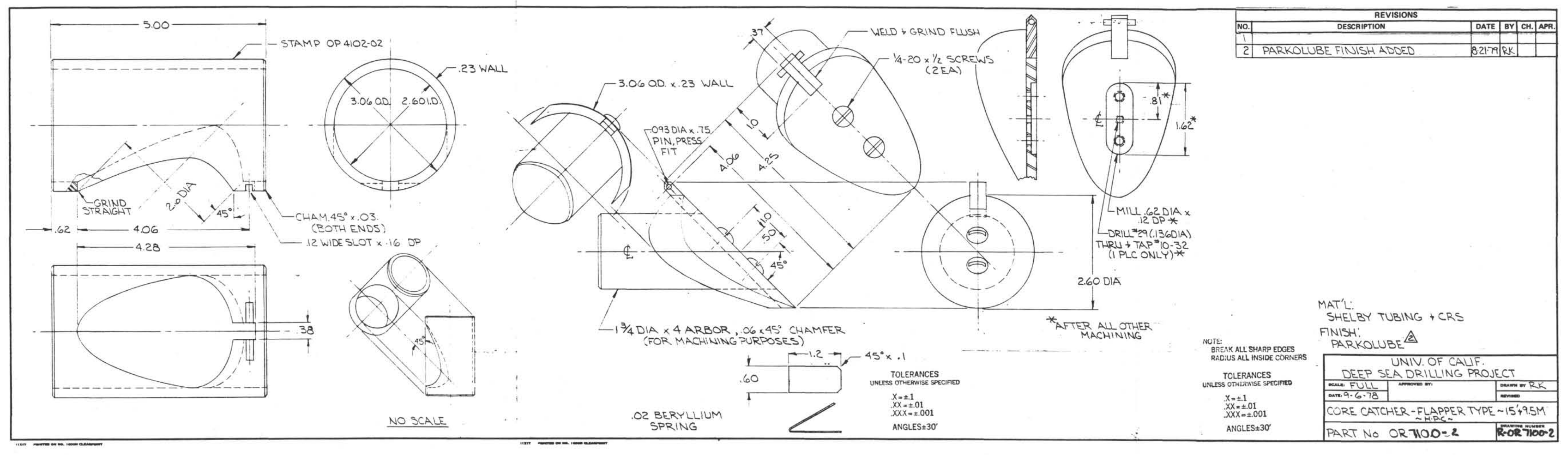




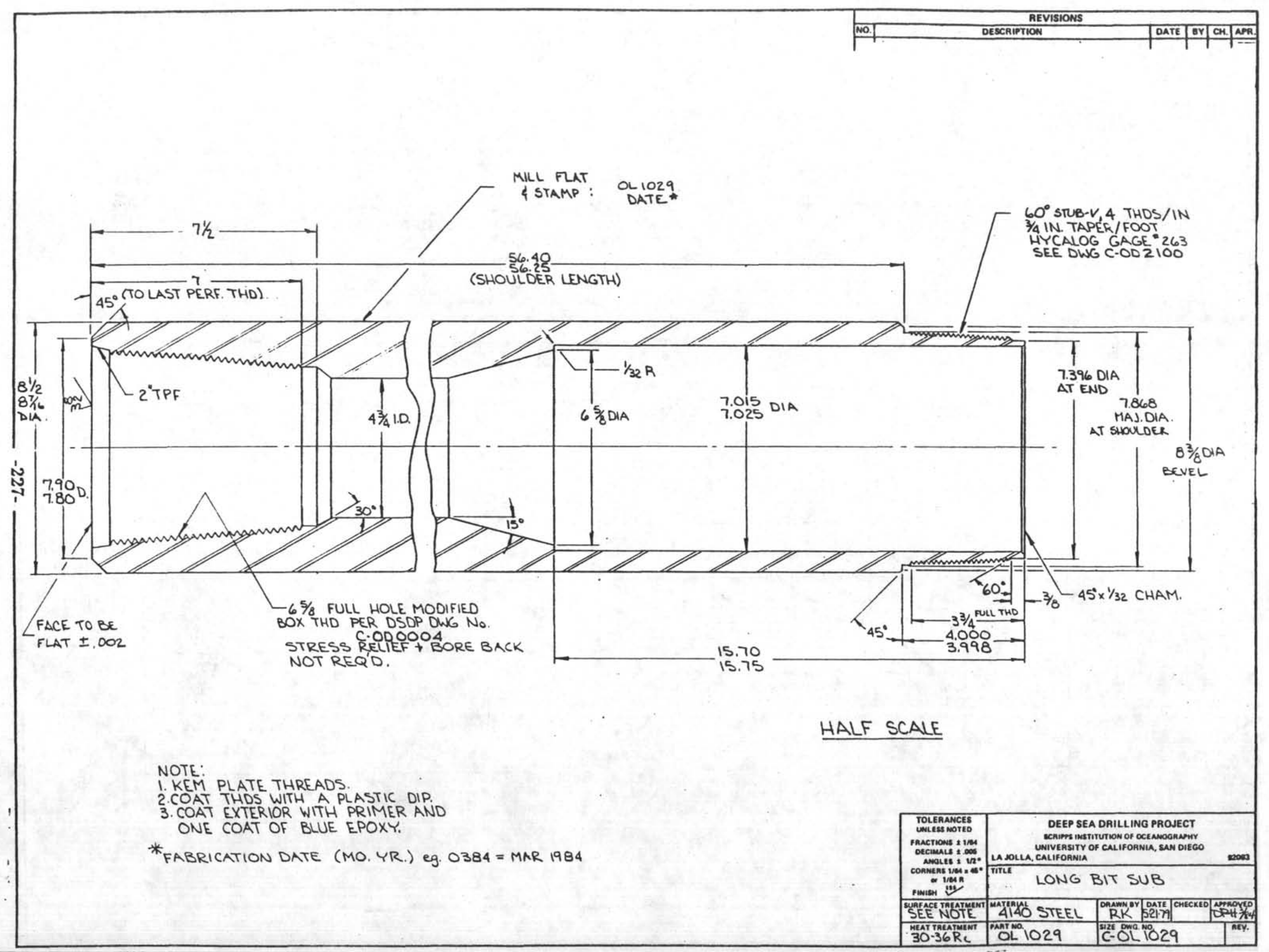




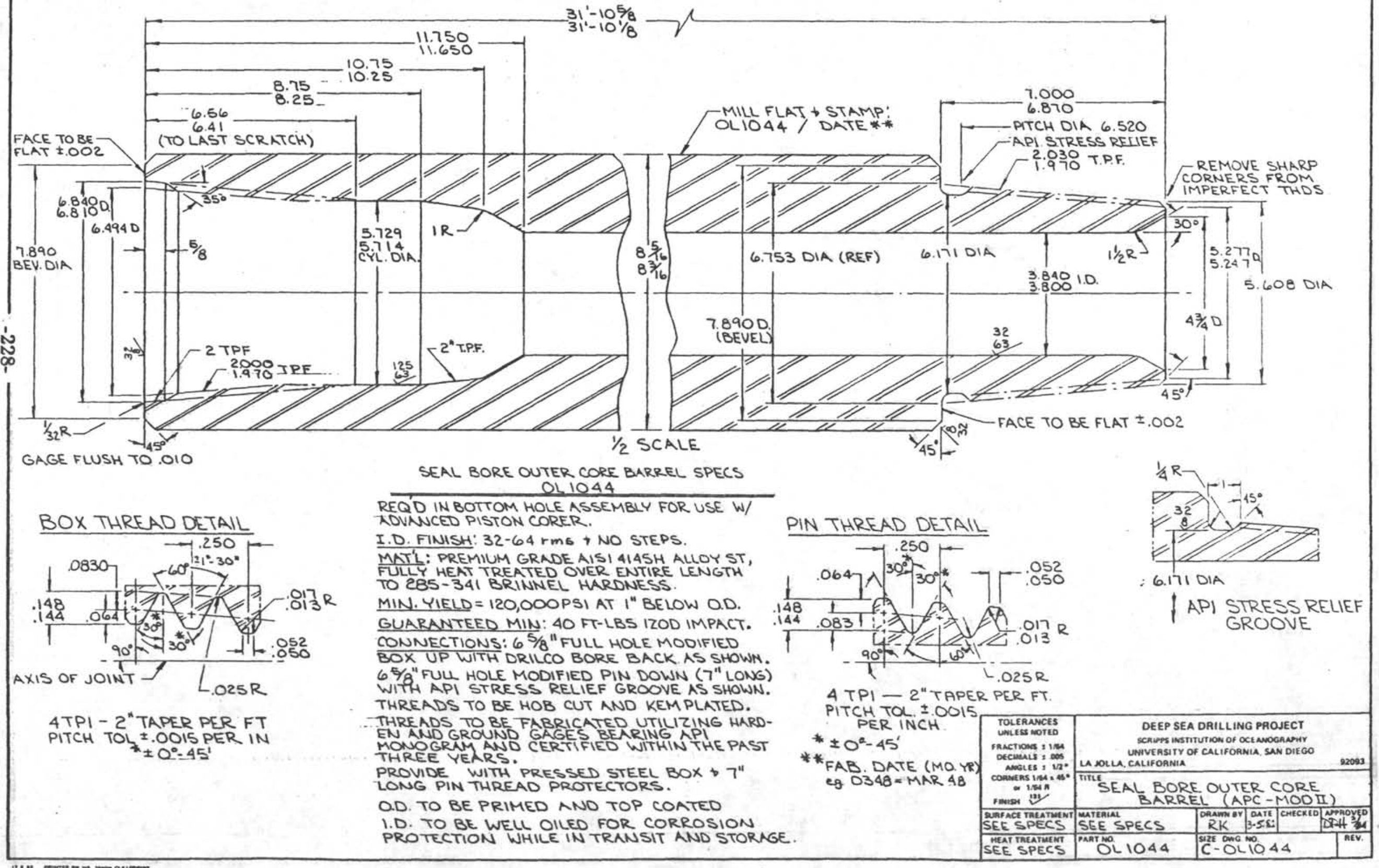


APPENDIX G

OLD DRAWINGS

$-229-$ 


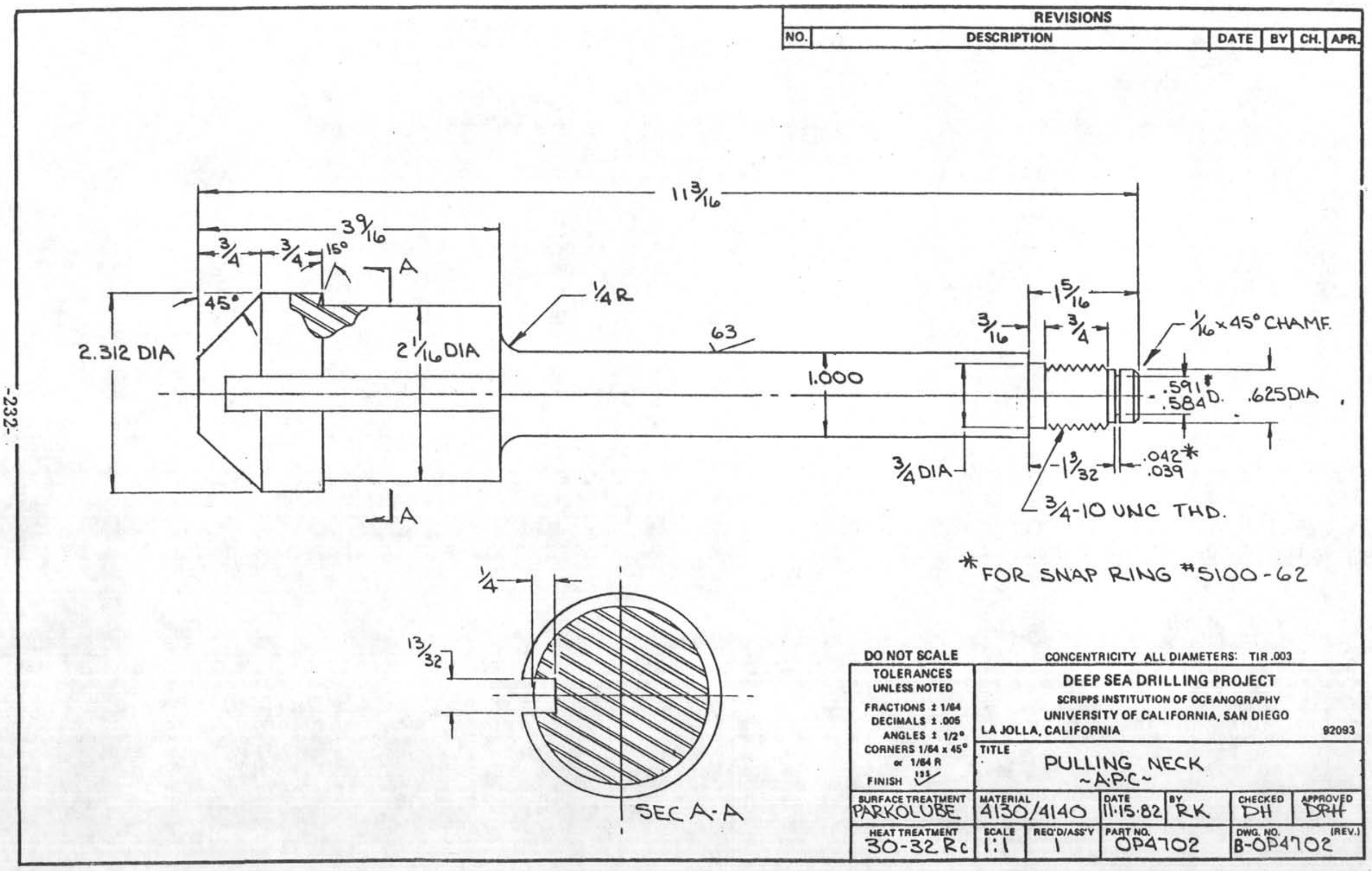




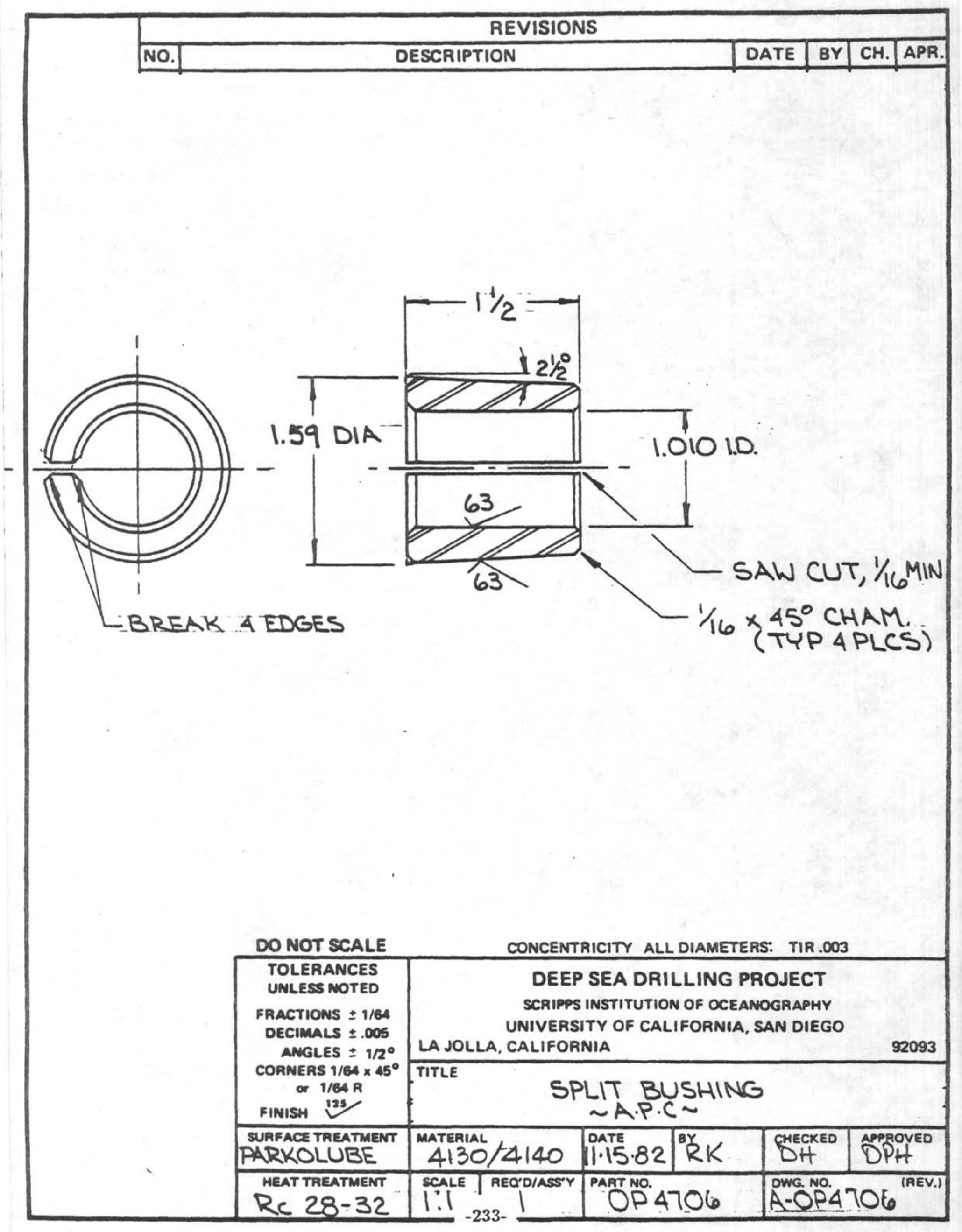




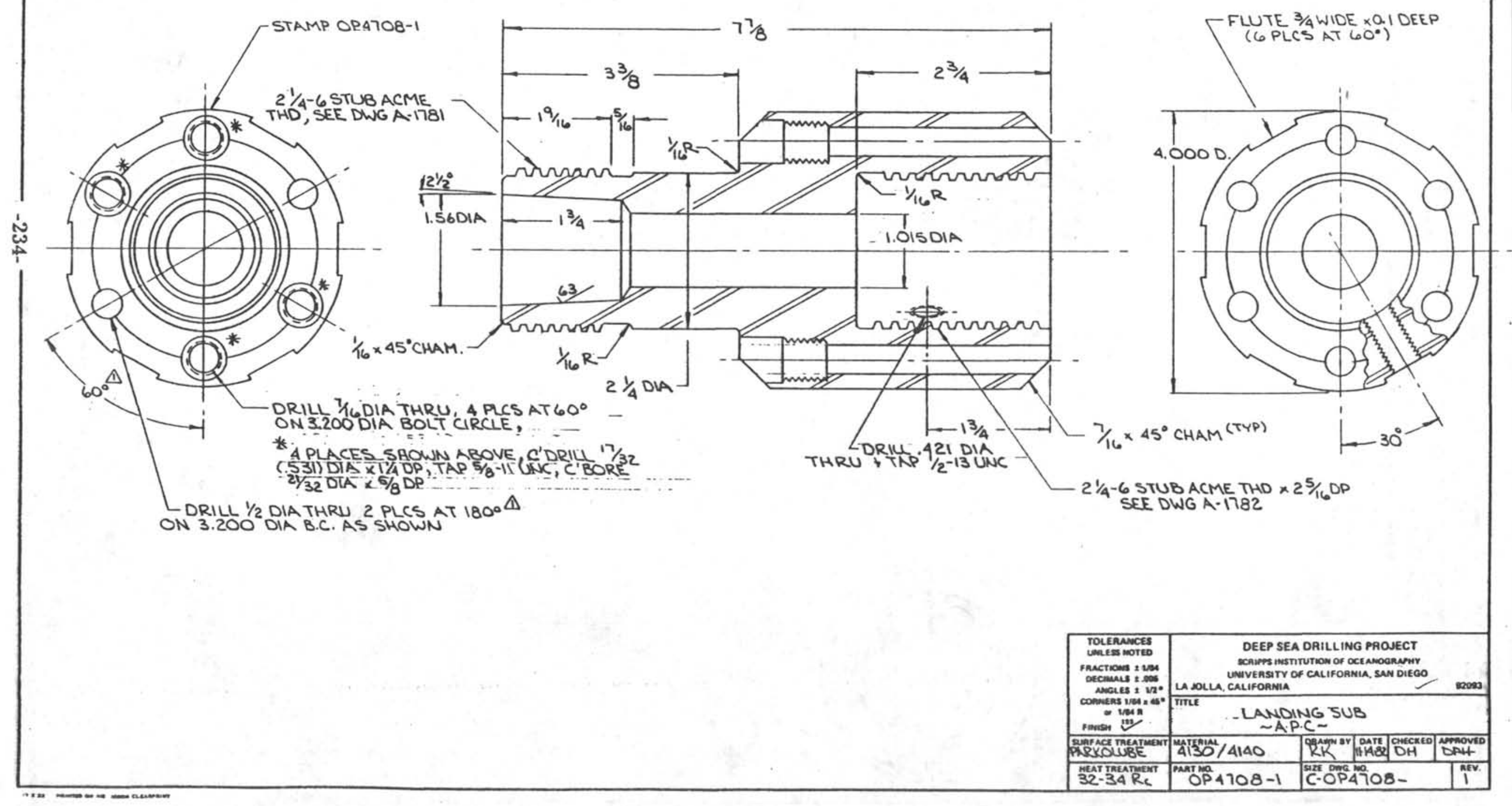




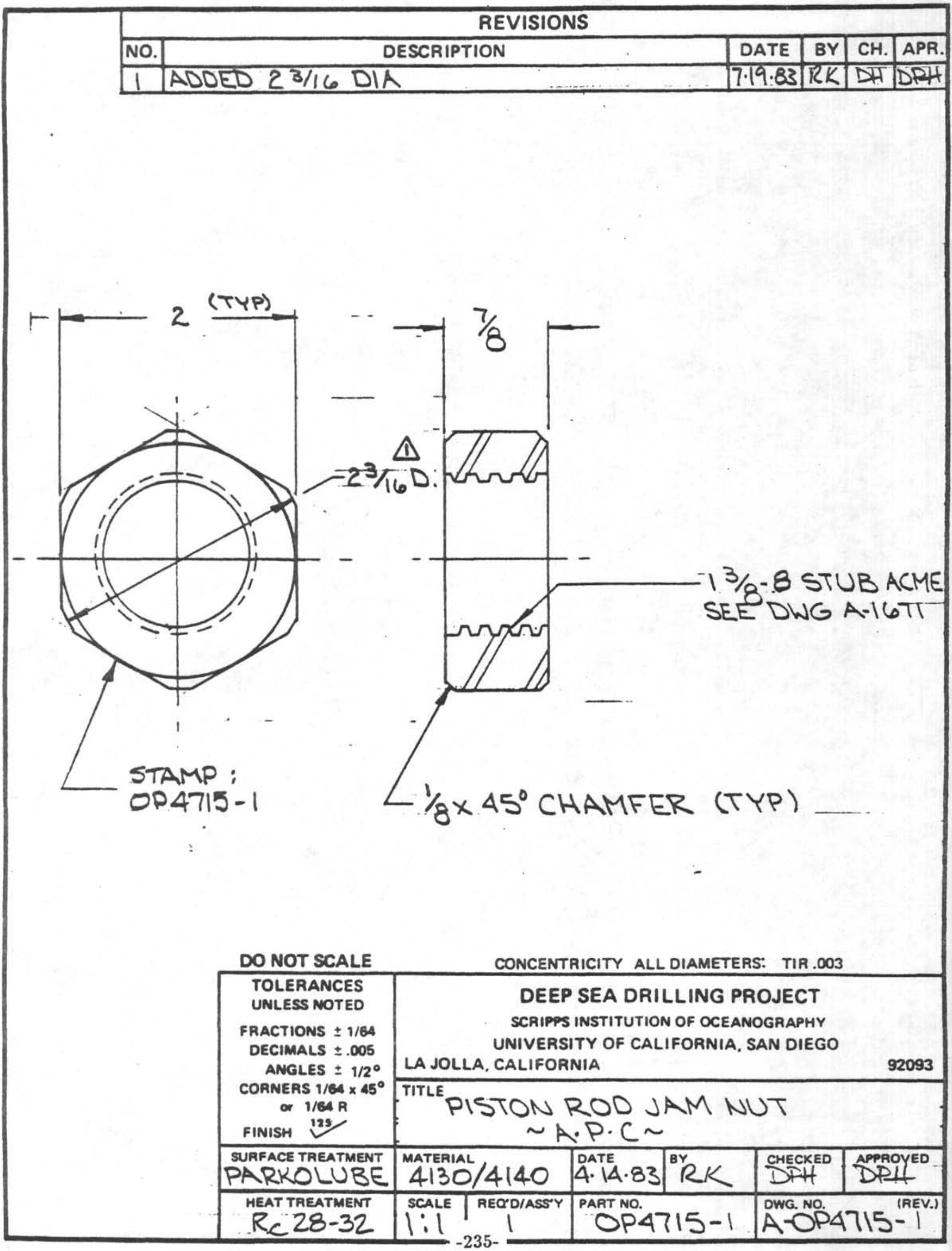



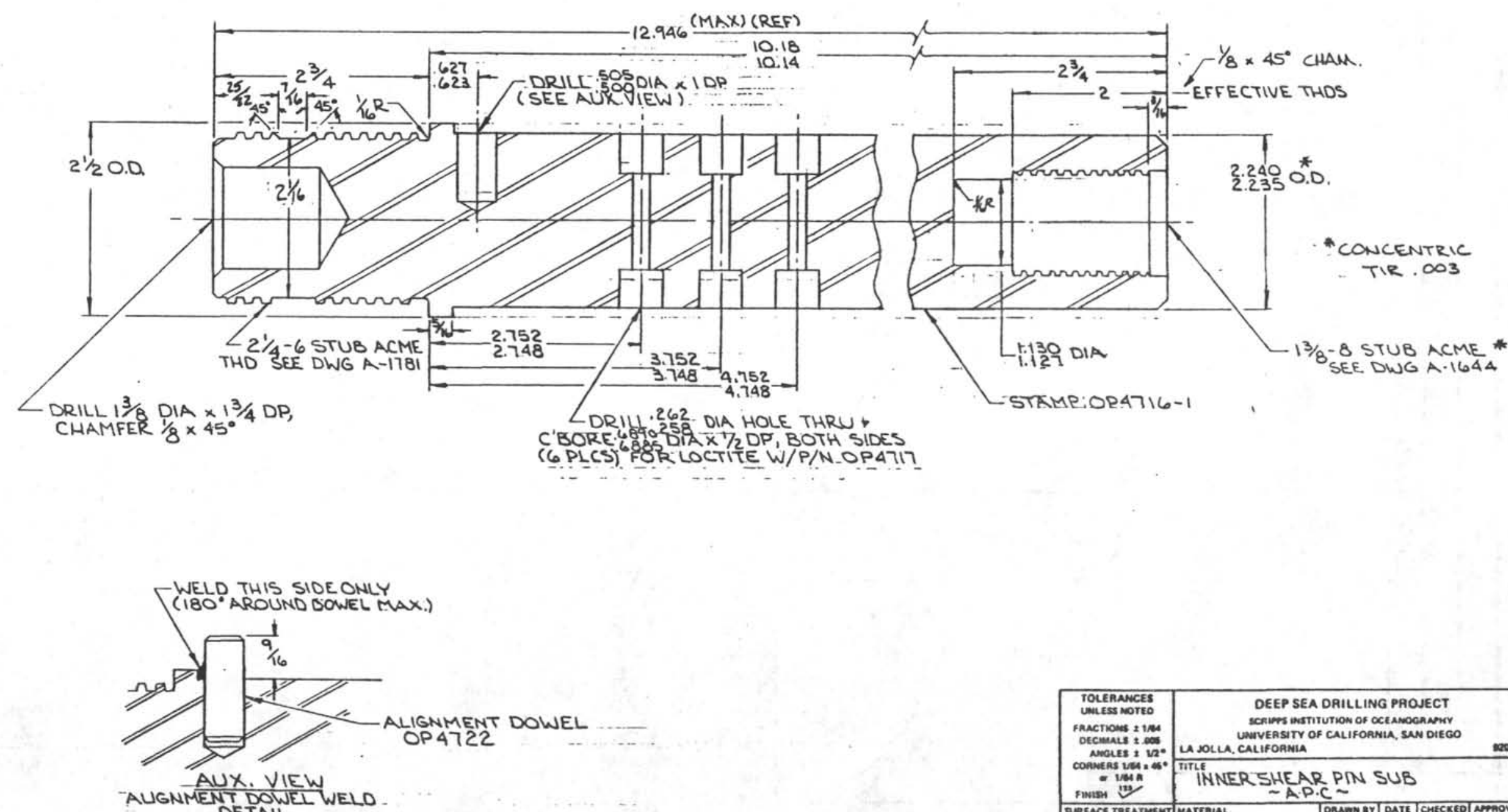

\begin{tabular}{|c|c|c|c|}
\hline \multirow{3}{*}{ 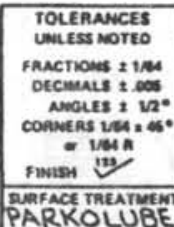 } & \multicolumn{3}{|c|}{ 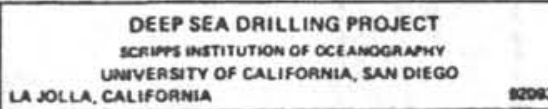 } \\
\hline & \multicolumn{3}{|c|}{ IITLERSWEAR PIN SUB } \\
\hline & $\begin{array}{l}\text { arestal } \\
4130 / 4140\end{array}$ & 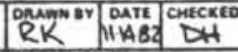 & Dimoveo \\
\hline $\begin{array}{l}\text { MEAT TEATMENT } \\
R_{C} 34.36\end{array}$ & ORT $4716-1$ & 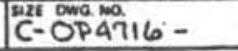 & ${ }^{\mathrm{NE}}$ \\
\hline
\end{tabular}




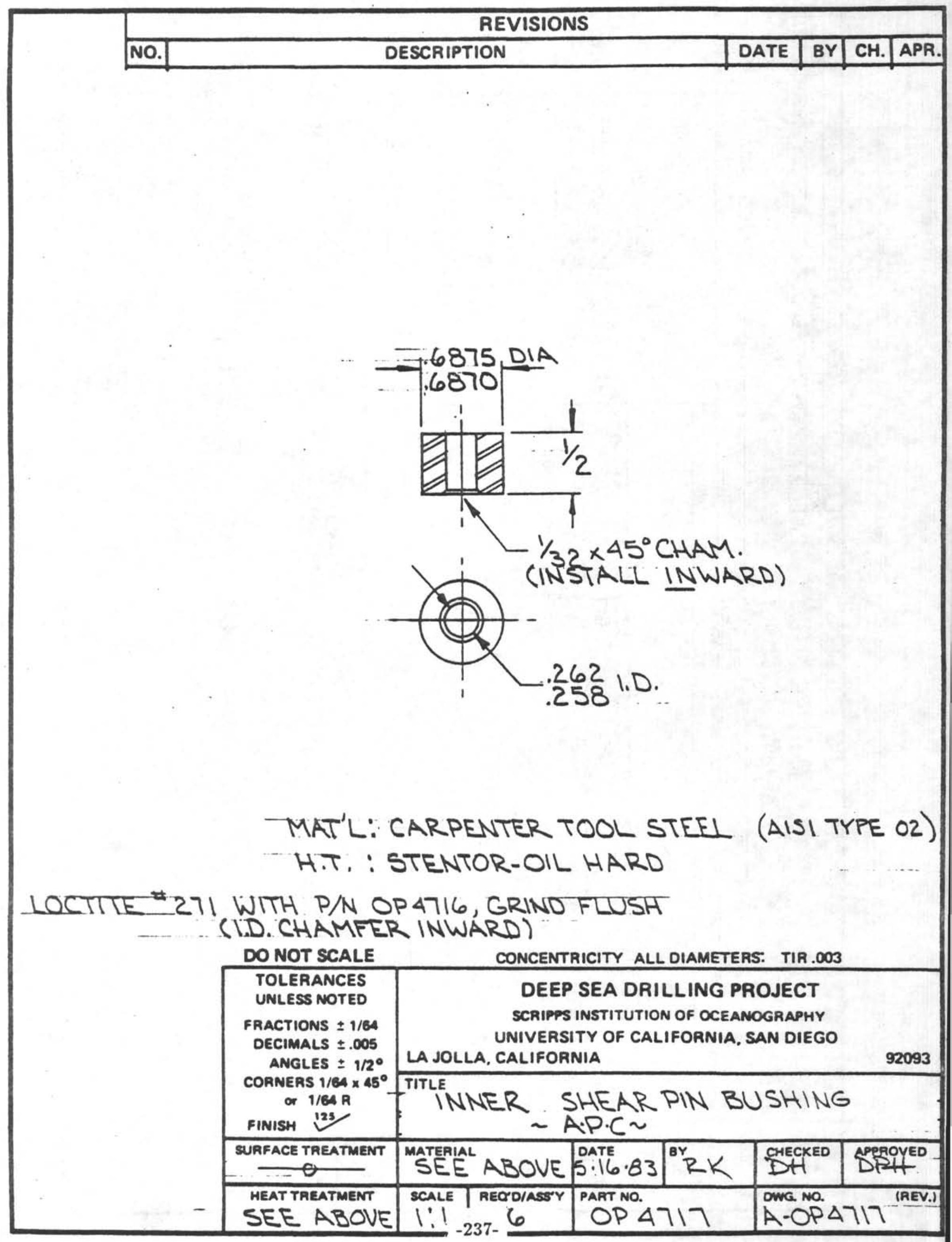




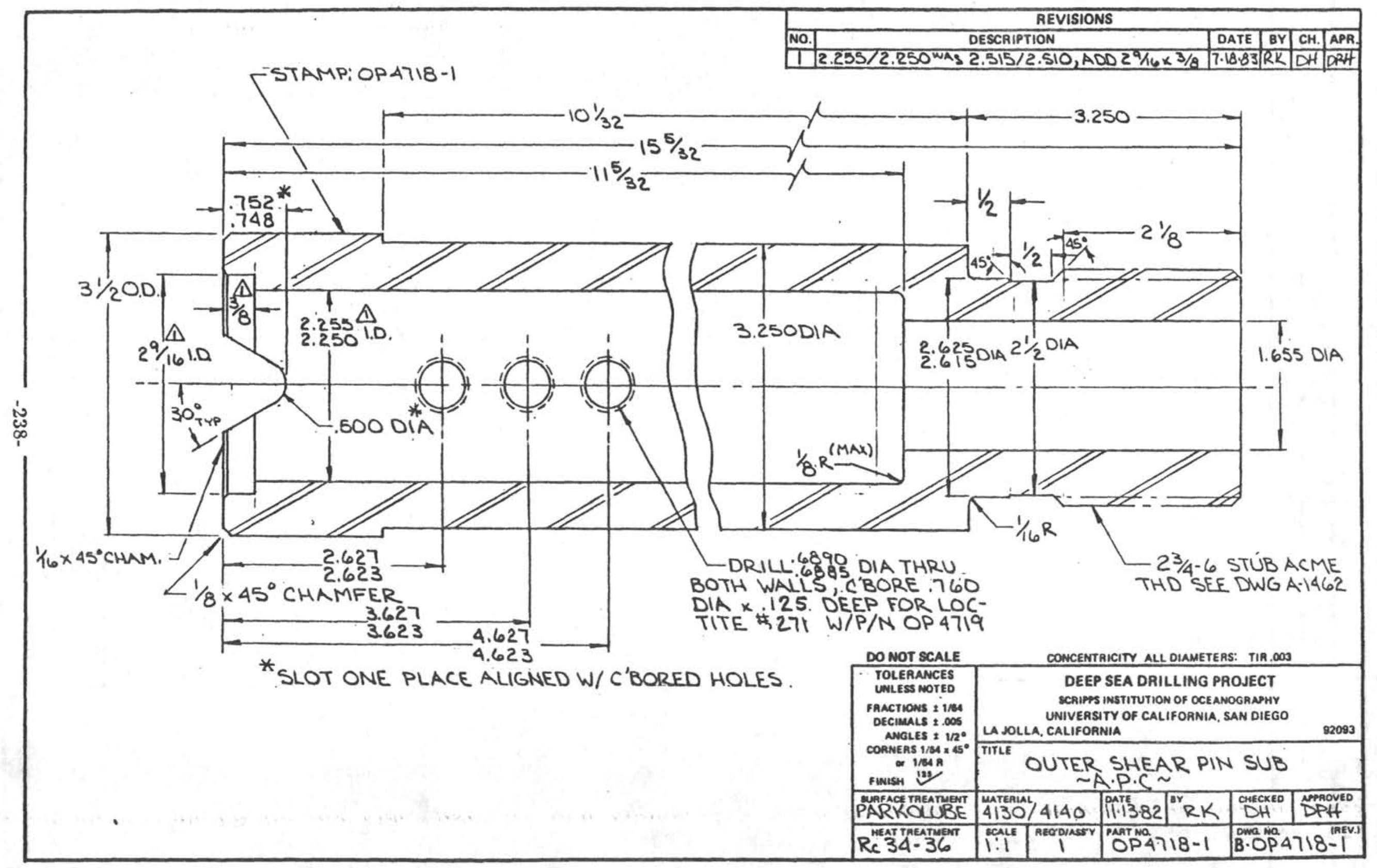




\begin{tabular}{|c|c|c|c|c|c|}
\hline \multicolumn{5}{|c|}{ REVISIONS } \\
\hline NO. & DESCRIPTION & DATE & BY & CH. & APR. \\
\hline 1 & .500 WAS .375, ADDED "SOLAR" & 7.18 .83 & RY & DH & DAH \\
\hline
\end{tabular}

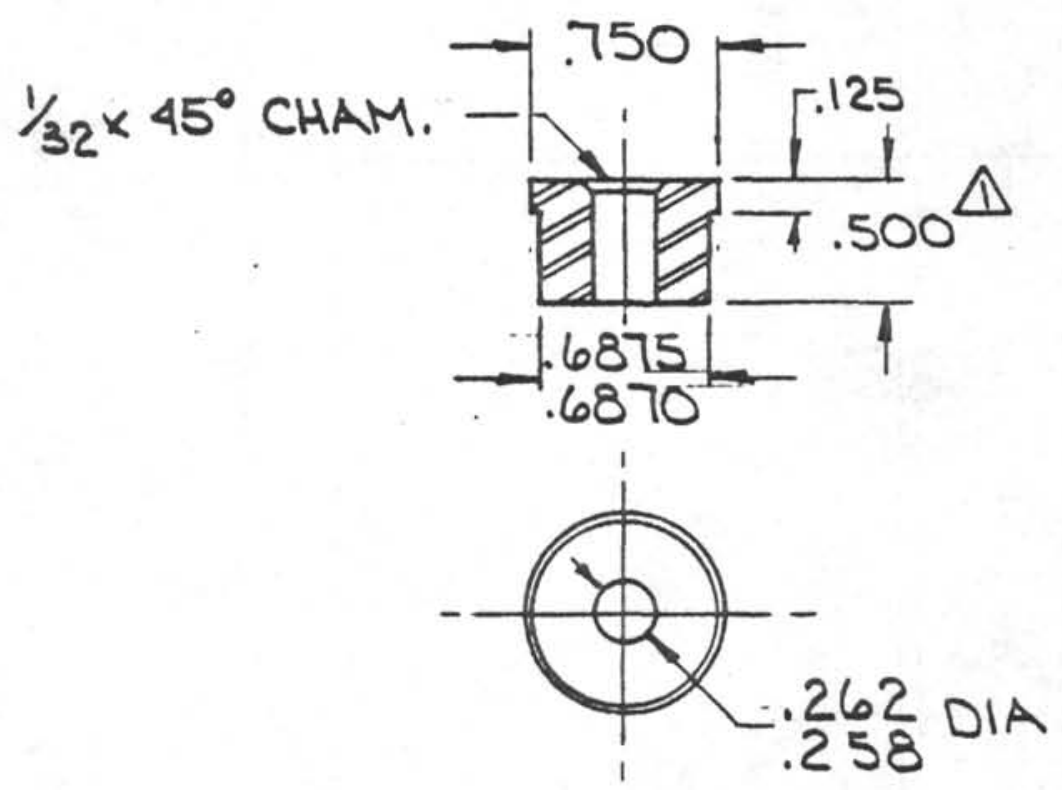

MAT'L: CARPENTER STENTOR -OIL HARD (AISI TYPE OZ) OR CARPENTER "SOLAR" TOOL STEEL.

LOCTITE "27I WITH PA OP47I8-IGRIND FLUSH

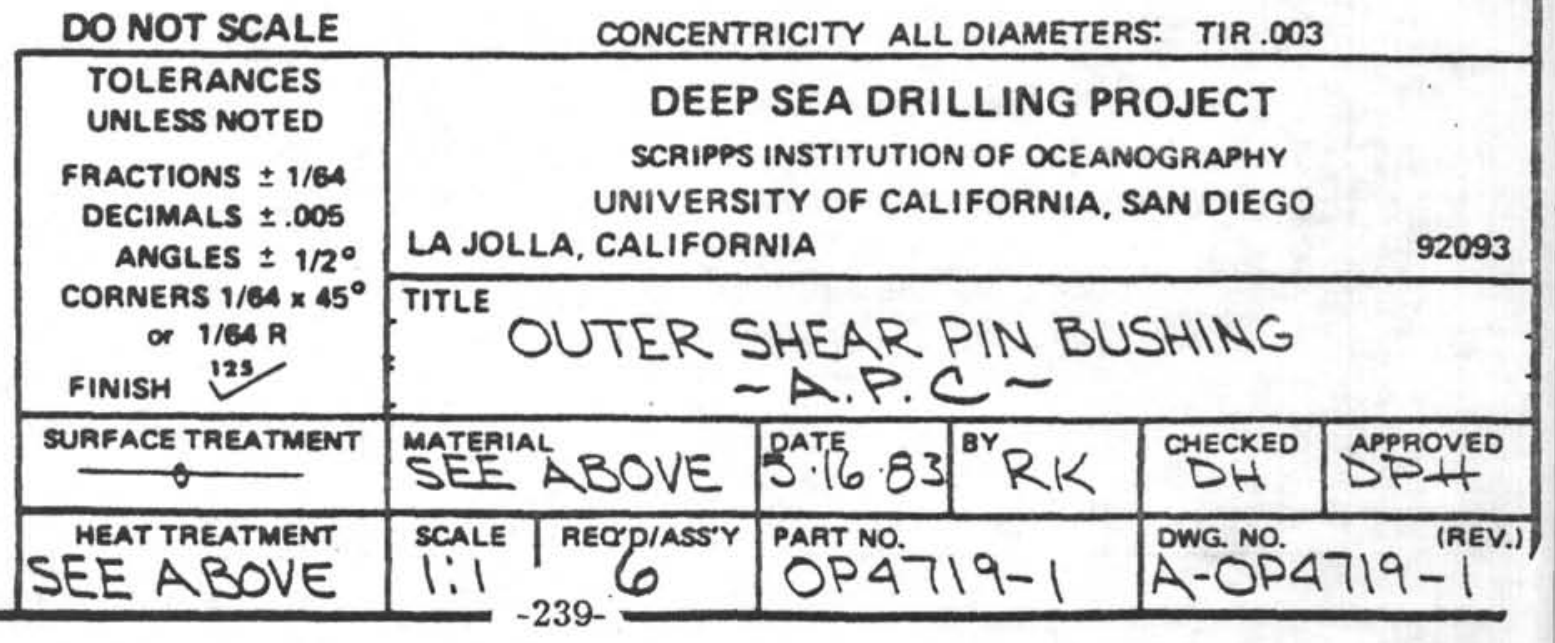




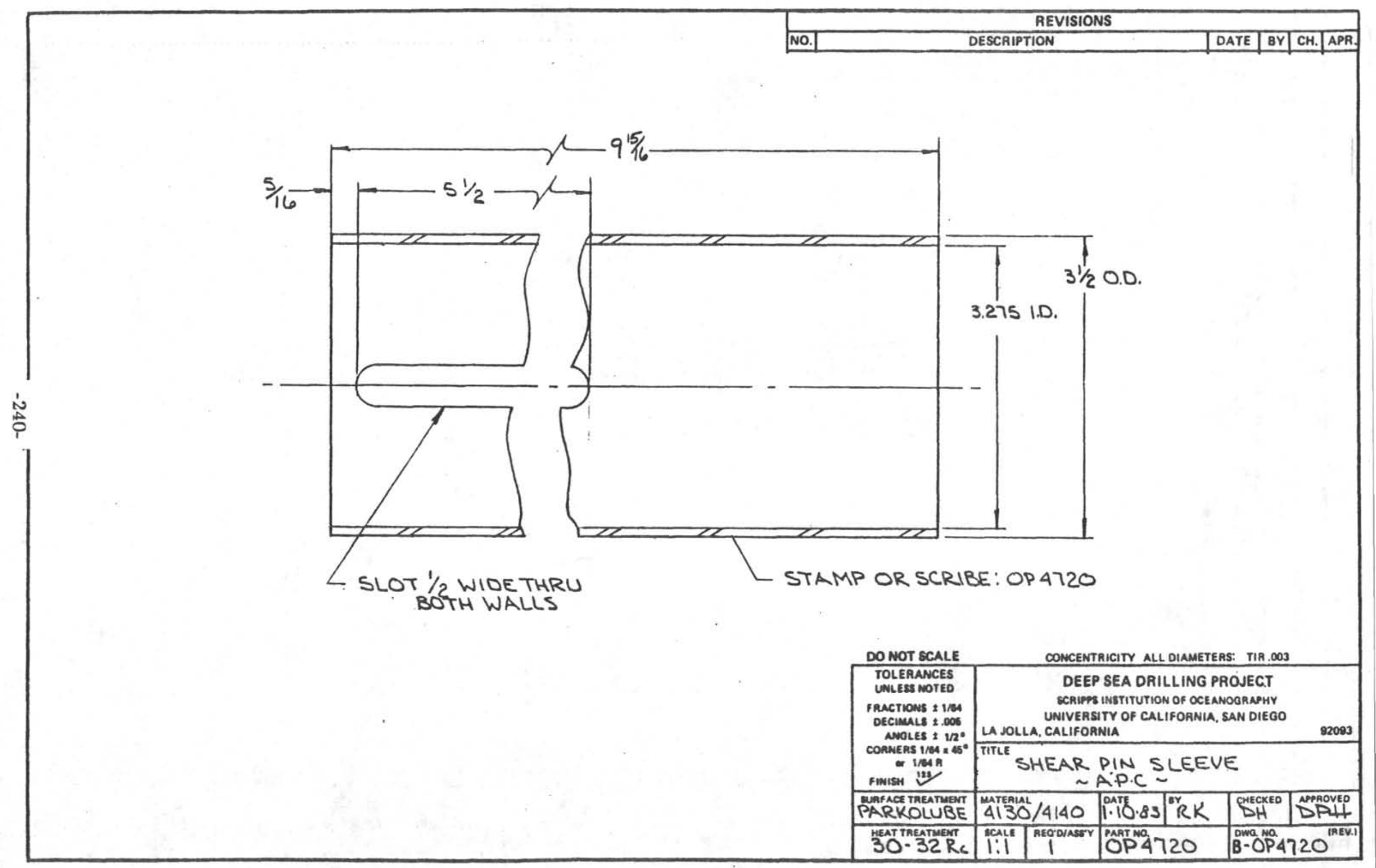




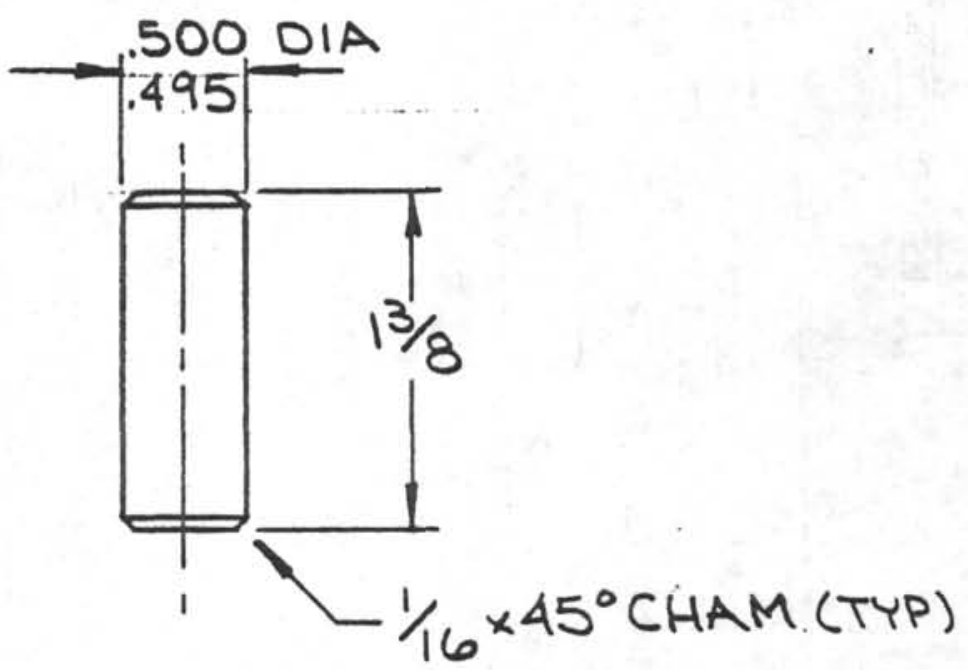

DO NOT SCALE TOLERANCES UNLESS NOTED

FRACTIONS $\pm 1 / 64$ DECIMALS \pm .005 ANGLES $\pm 1 / 2^{\circ}$ CORNERS $1 / 64 \times 45^{\circ}$ or 1/64A FINISH 125
CONCENTRICITY ALL DIAMETERS: TIR.003

\section{DEEP SEA DRILLING PROJECT}

SCRIPPS INSTITUTION OF OCEANOGRAPHY UNIVERSITY OF CALIFORNIA, SAN DIEGO

LA JOLLA, CALIFORNIA

92093 TITLE

$=$
$=$

MATERIAL SURFACE TREATMENT

HEAT TAEATMENT 34-36 Rc
4130

SCALE REO'D/ASS'Y

$1: 1$
ALIGNMENT DOWEL $\sim A \cdot P \cdot C \sim$

DATE 87
DATE 83 BY CHECKED 5.16 .83 PART NO. OP 4722 


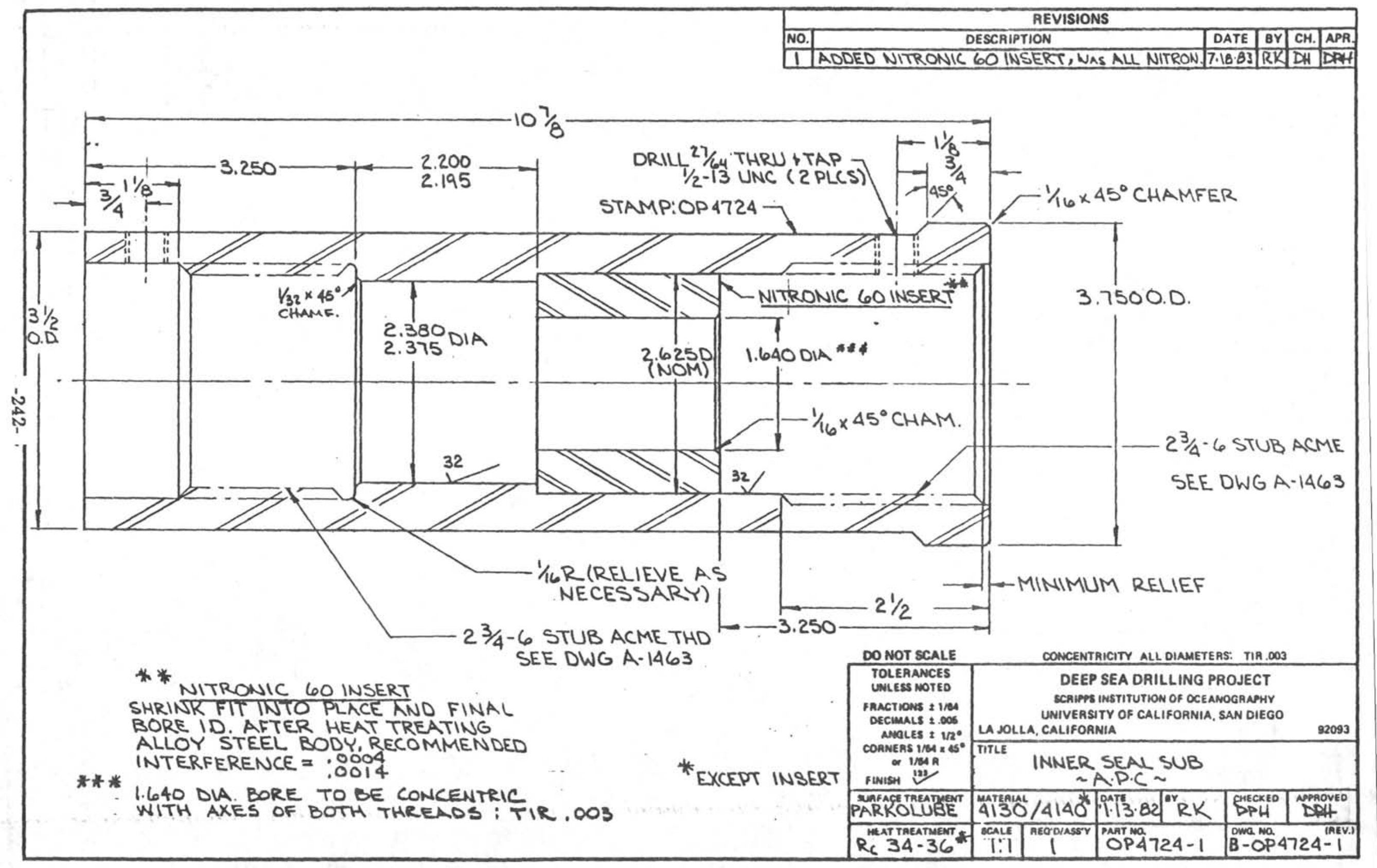




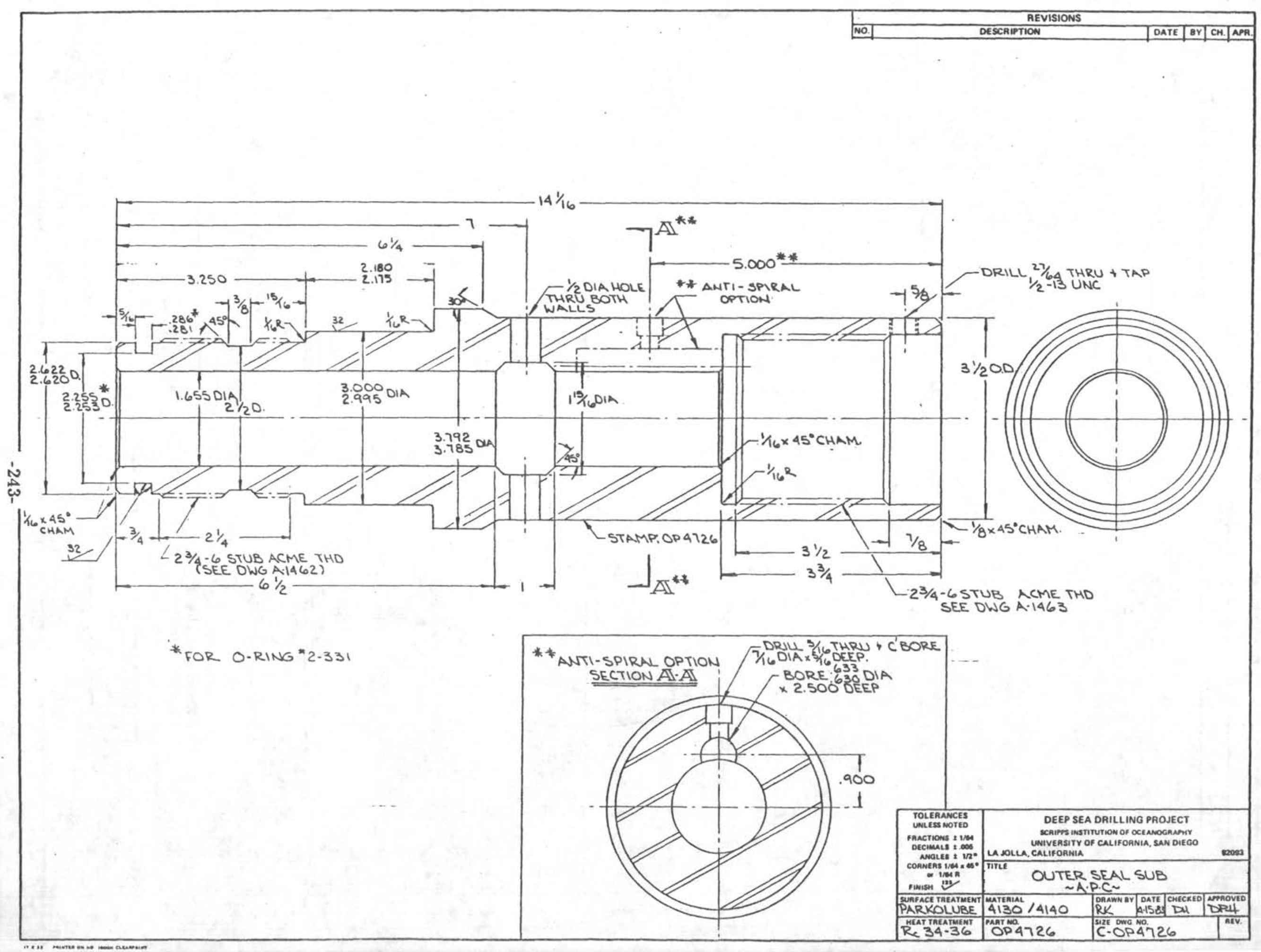




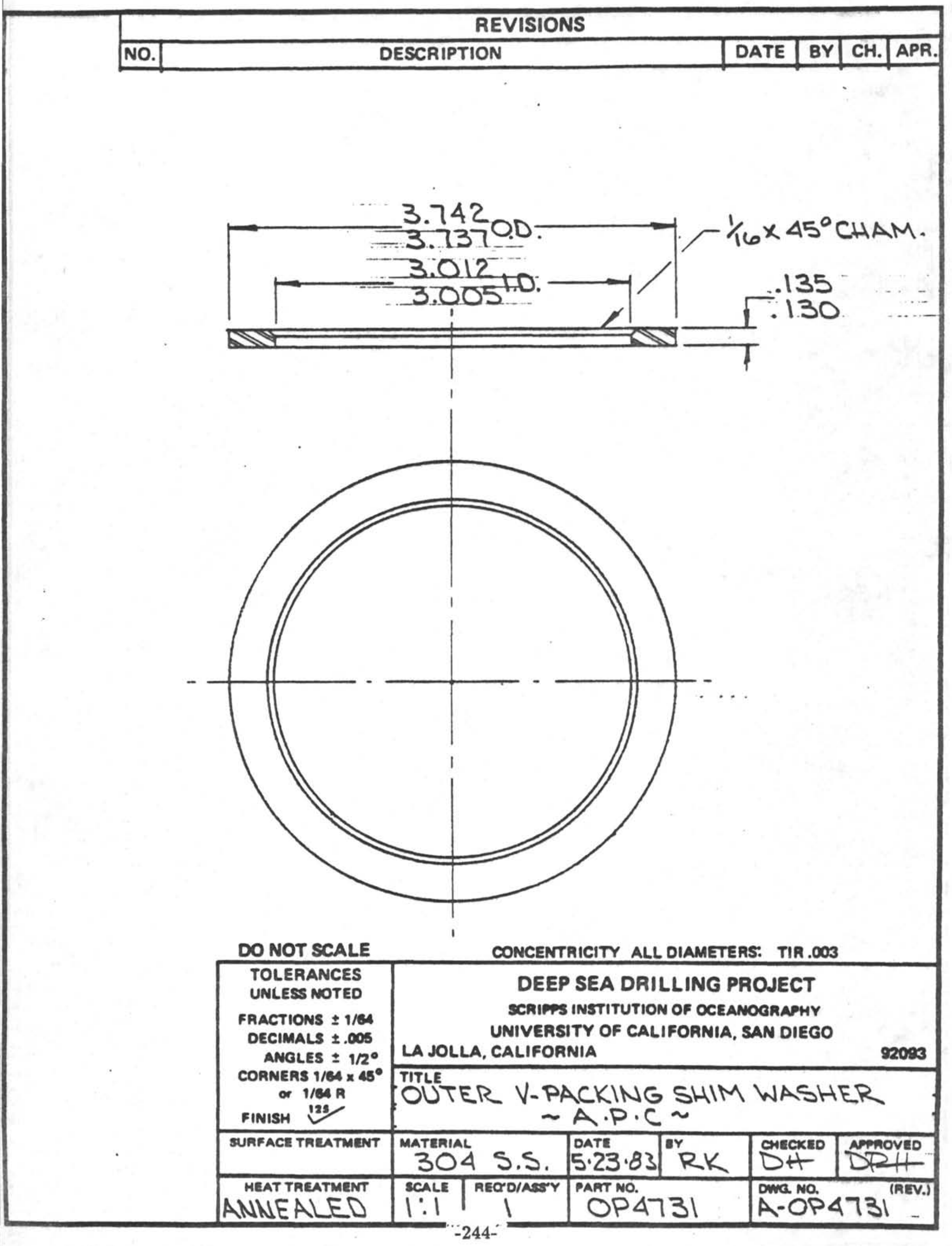




\begin{tabular}{|l|l|l|l|l|l|}
\hline \multicolumn{4}{|c|}{ REVISIONS } \\
\hline NO. & DESCRIPTION & DATE & BY & CH. & APR. \\
\hline
\end{tabular}

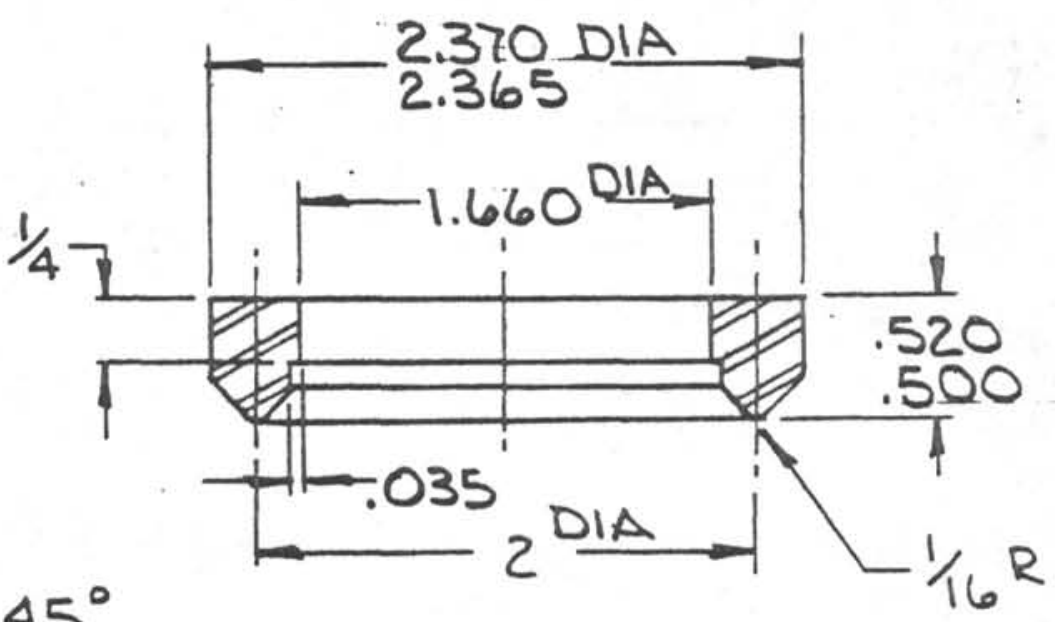

ALL ANGLES $45^{\circ}$

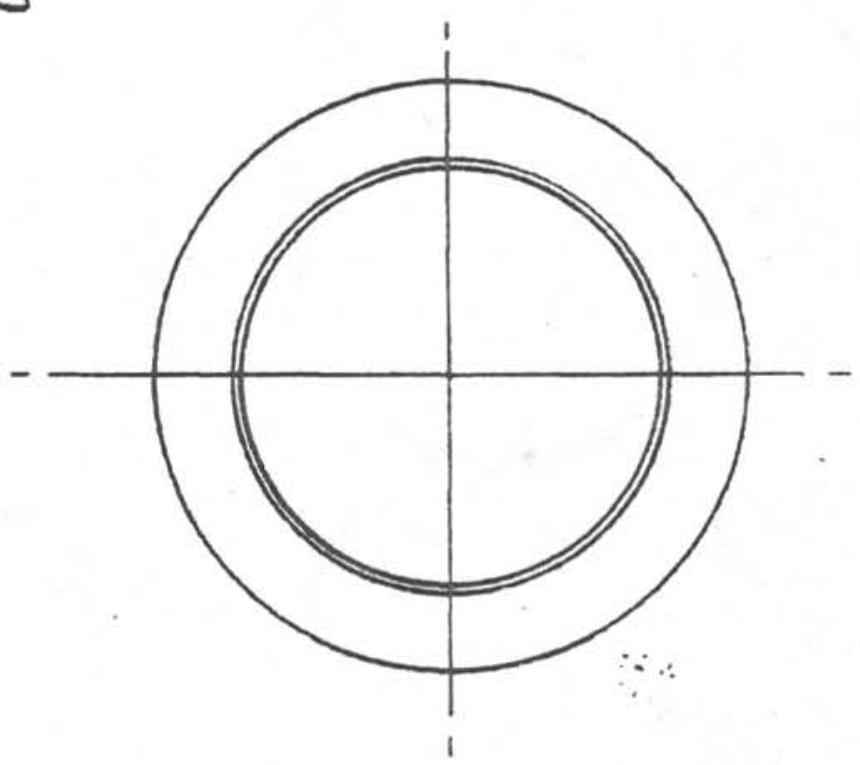

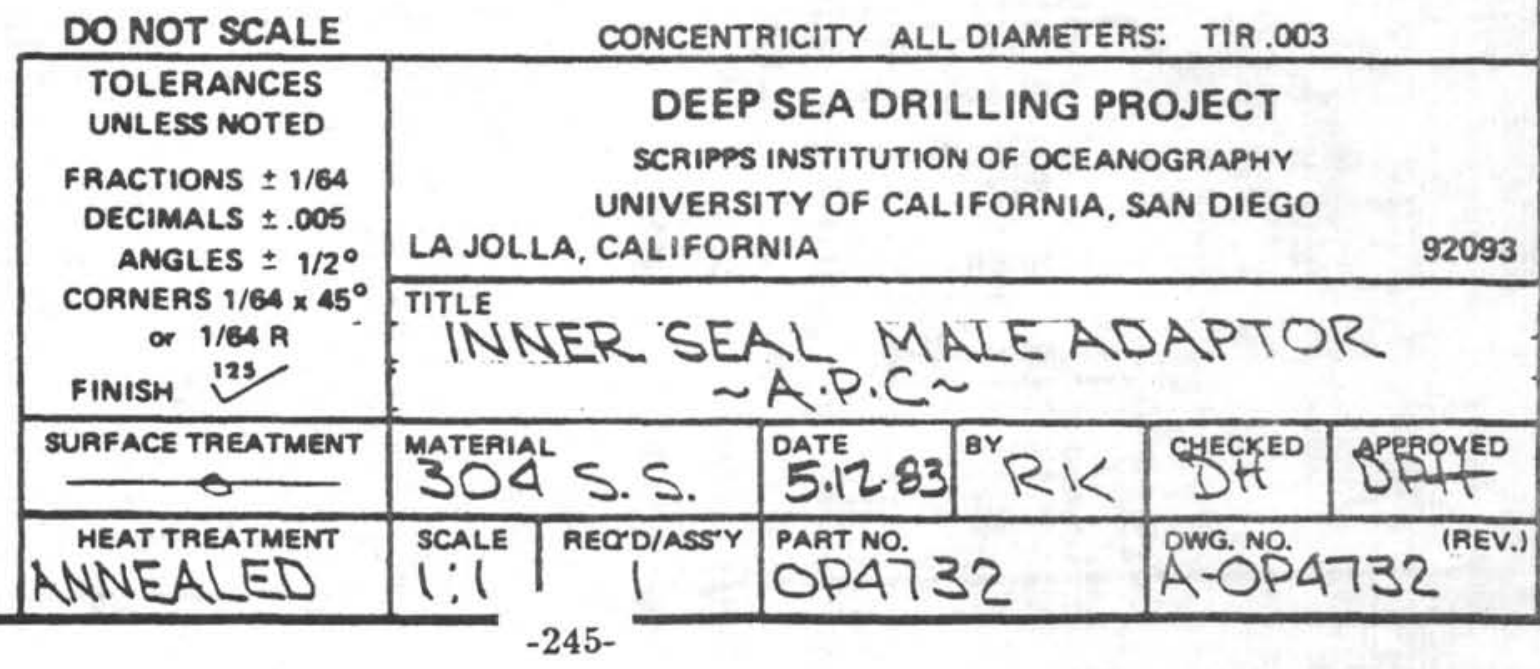




\begin{tabular}{|l|l|l|l|l|l|}
\hline NO. & DESCRIPTION & DATE & BY & CH. & APR. \\
\hline
\end{tabular}
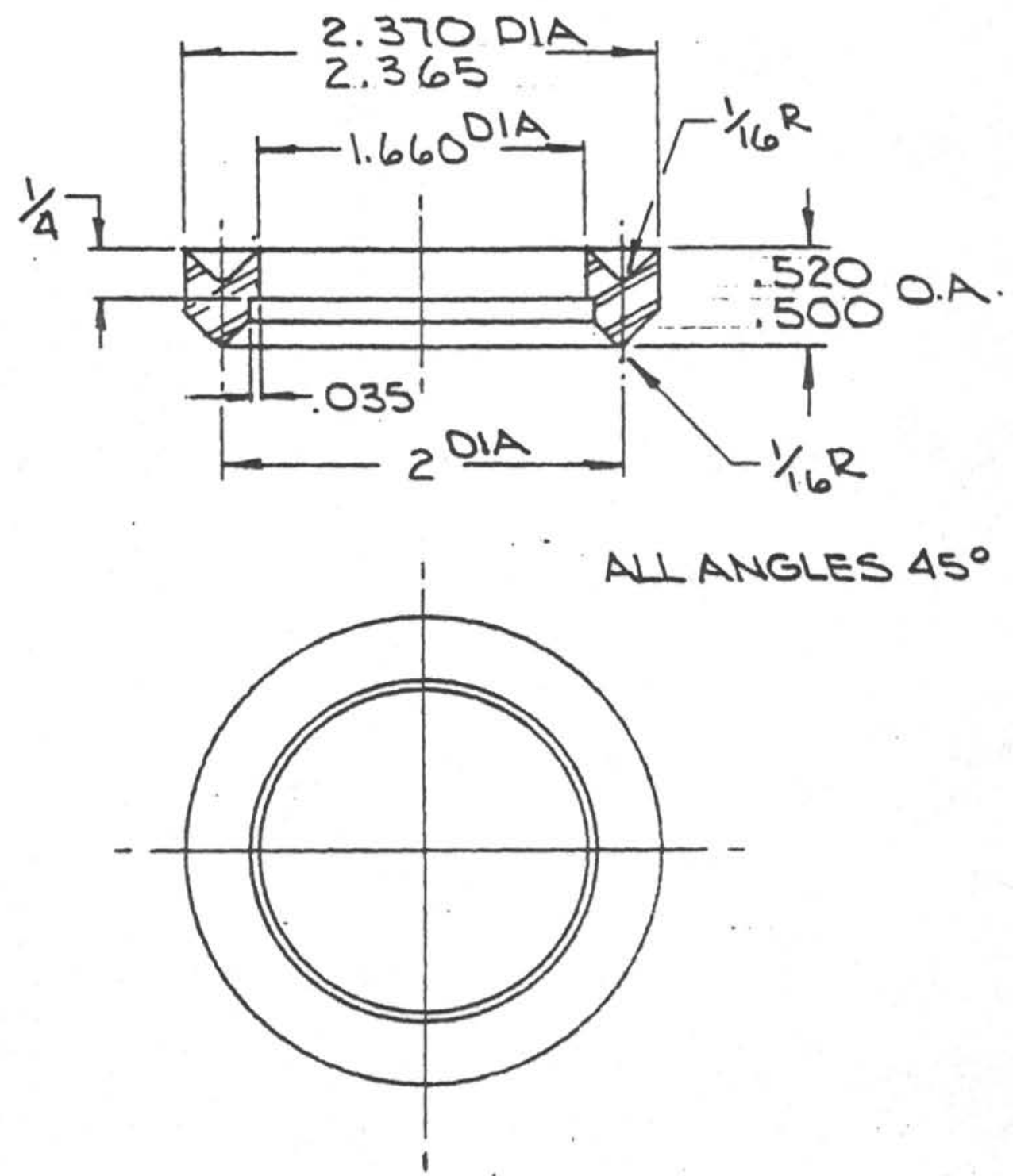

DO NOT SCALE TOLERANCES UNLESS NOTED

FRACTIONS $\pm 1 / 64$ DECIMALS \pm .005 ANGLES $\pm 1 / 2^{\circ}$ CORNERS $1 / 64 \times 45^{\circ}$ FINISH 123 SURFACE TREATMENT

HEATTEATMENT HEAT TREATMENT ANNEALED

\begin{tabular}{|c|c|c|c|}
\hline \multicolumn{5}{|c|}{ CONCENTRICITY ALL DIAMETERS: TIR.003 } \\
\hline \multirow{5}{*}{ DEEP SEA DRILLING PROJECT } \\
SCRIPPS INSTITUTION OF OCEANOGRAPHY \\
UNIVERSITY OF CALIFORNIA, SAN DIEGO
\end{tabular}




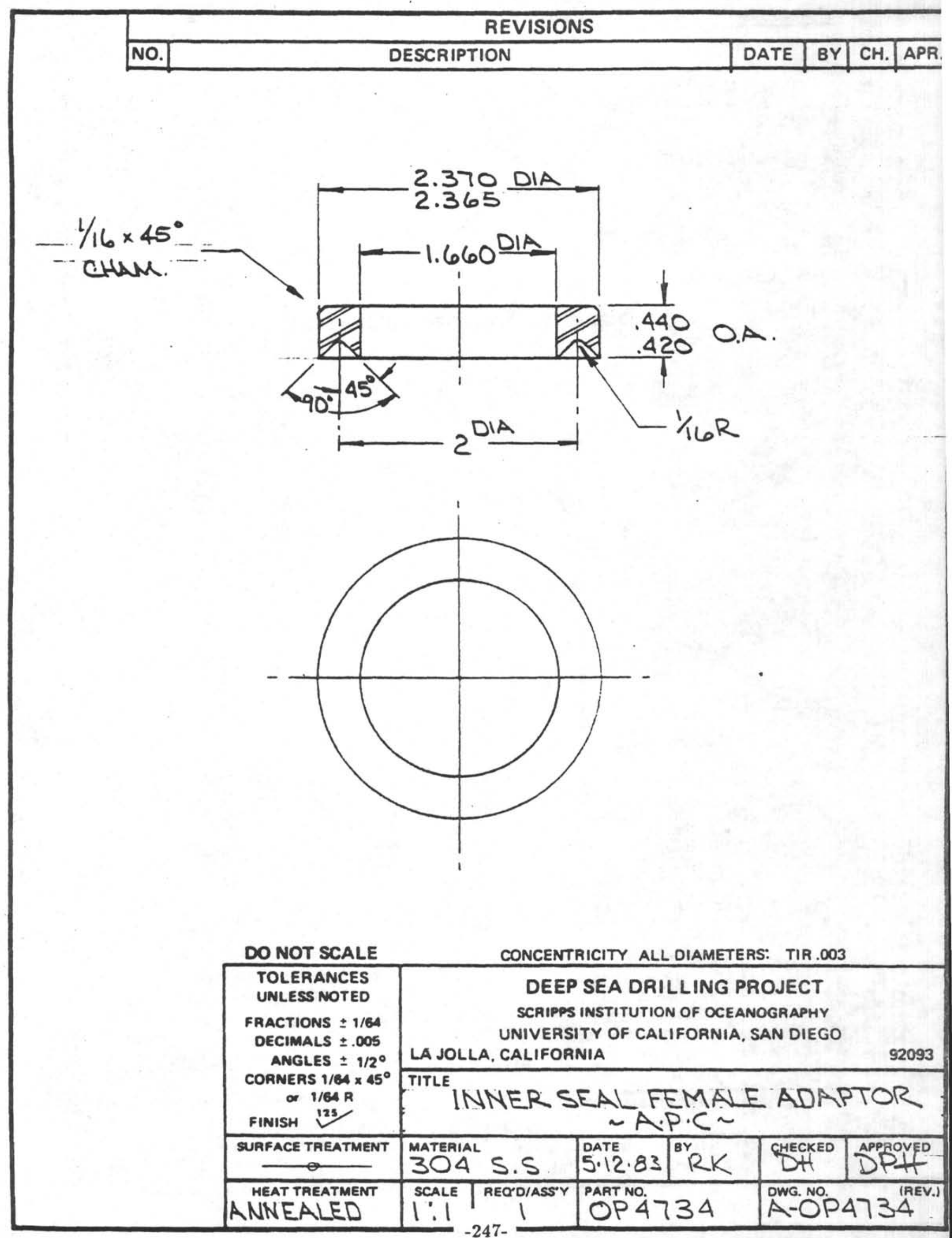




\begin{tabular}{|l|l|l|l|l|l|}
\hline NO. & DESCRIPTION & DATE & BY & CH. & APR. \\
\hline
\end{tabular}

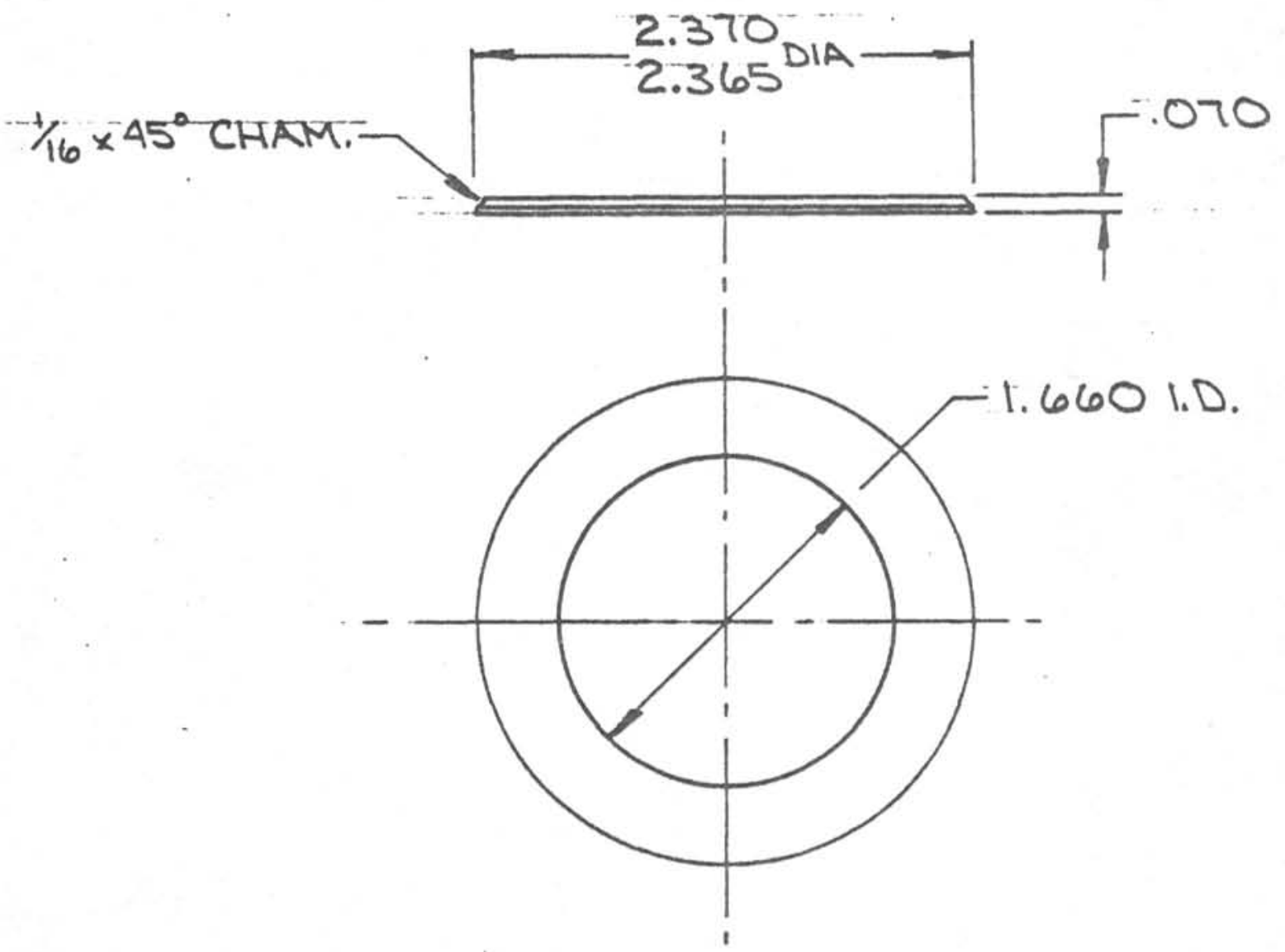

DO NOT SCALE TOLERANCES UNLESS NOTED

FRACTIONS $\pm 1 / 84$ DECIMALS \pm .005 ANGLES $\pm 1 / 2^{\circ}$ CORNERS $1 / 84 \times 45^{\circ}$ or 1/64 R

FINISH
CONCENTAICITY ALL DIAMETERS: TIR.003

\section{DEEP SEA DRILLING PROJECT}

SCRIPPS INSTITUTION OF OCEANOGRAPHY UNIVERSITY OF CALIFORNIA, SAN DIEGO

LA JOLLA, CALIFORNIA

92093

TITLE

INNER V.PACK SHIM WASHER $\sim$ A.P.C

SUAFACE TREATMENT

O

MEAT TAEATMENT

ANNEALED

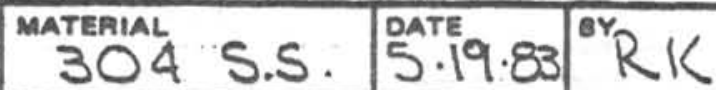
SCALE AECOD/ASSY PART NO. $1: 1$
CHECKED APROVED St OMG NO. A-OP 4735 


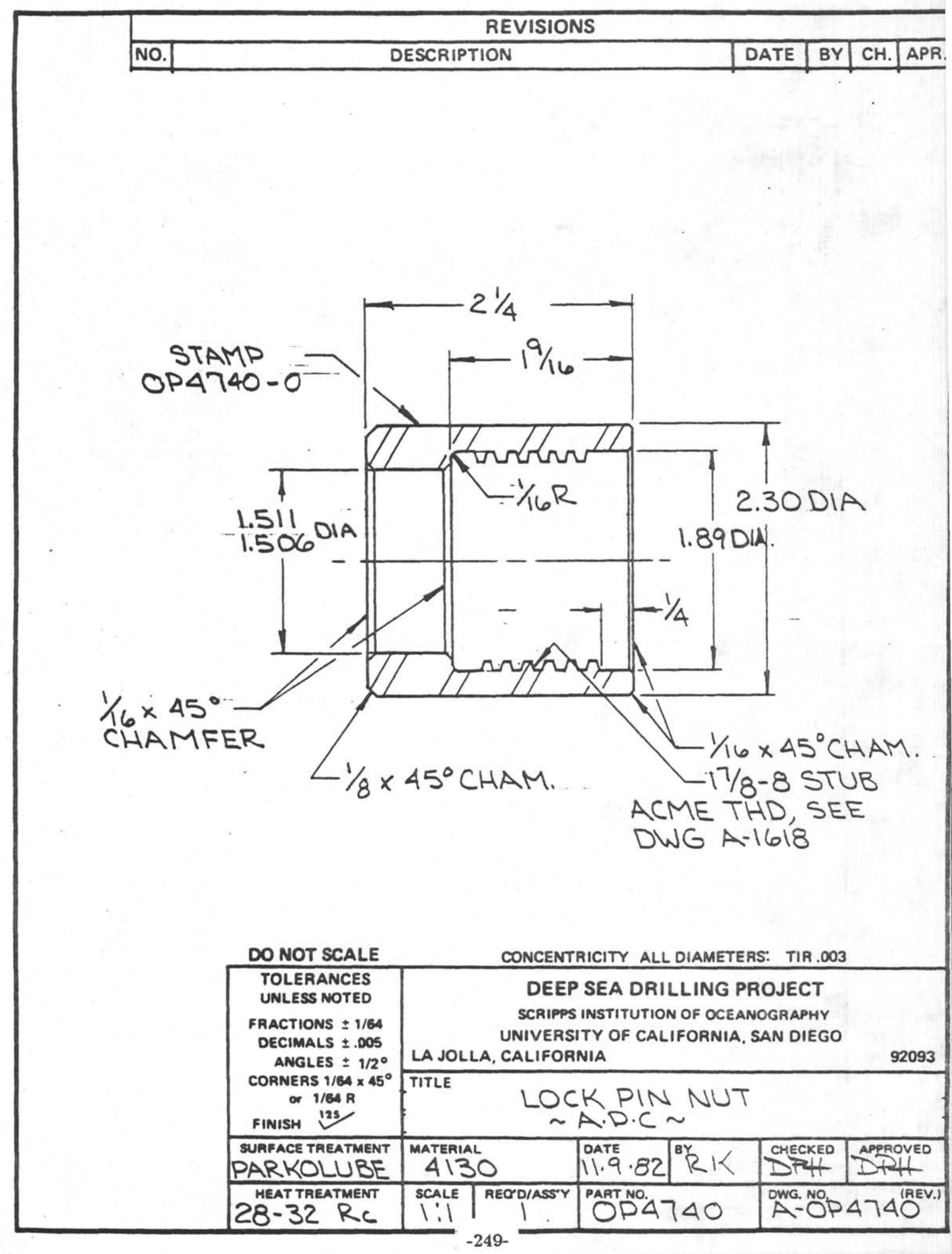




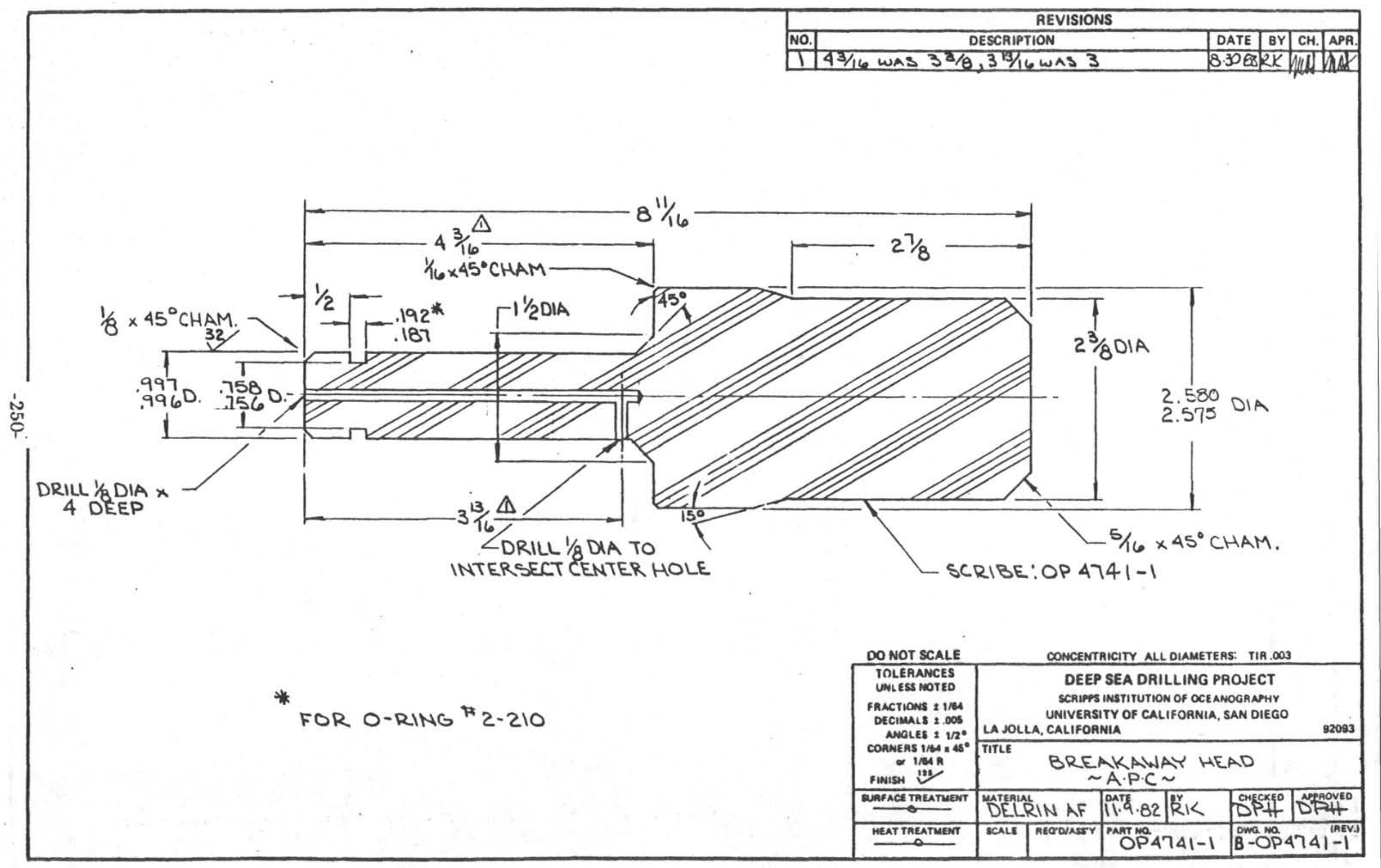




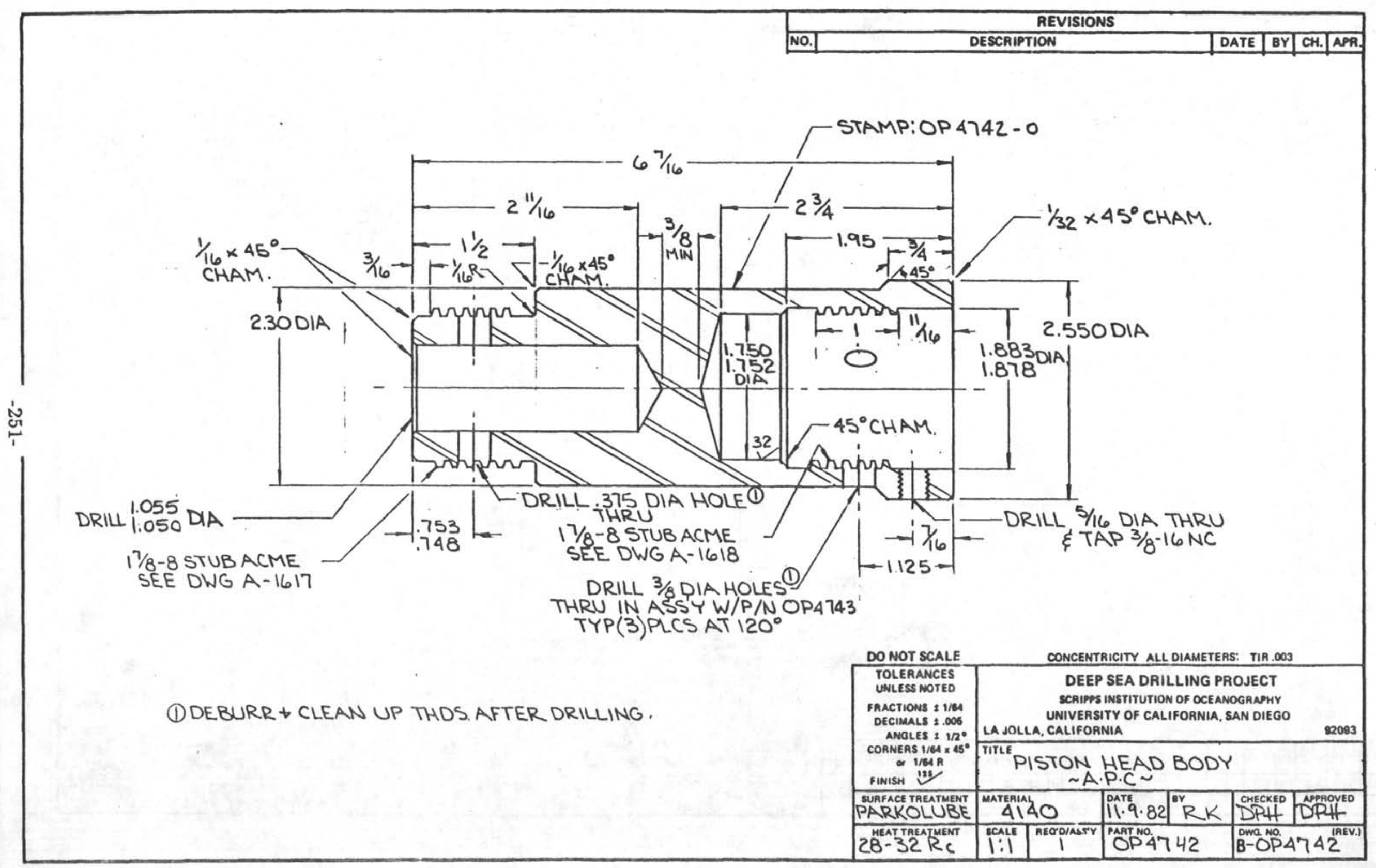



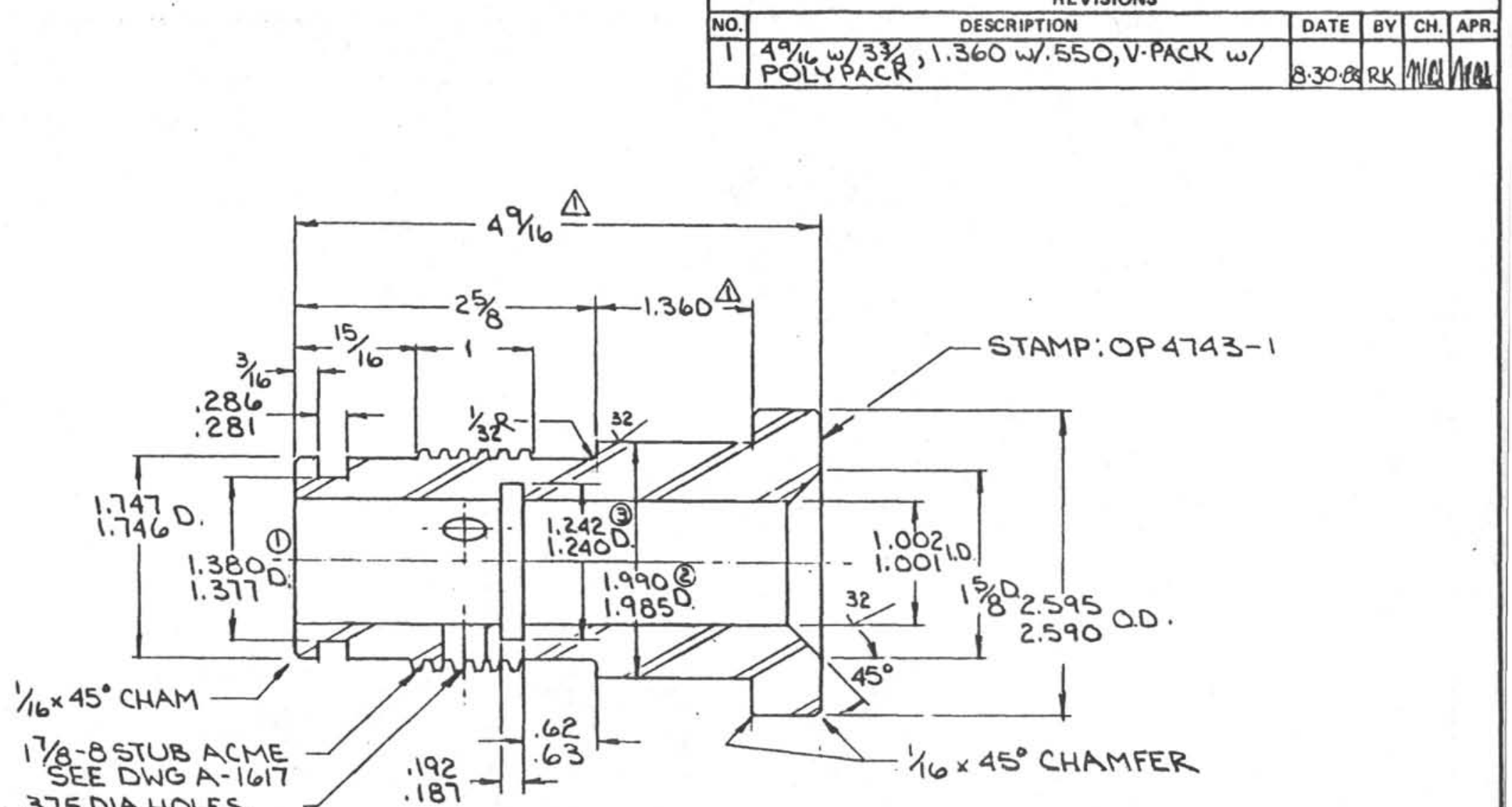

DRILL . 375 DIA HOLES

THRU IN ASS'Y W/PIN OPA742

MADE UP SNUG, 3 PLCS AT $120^{\circ}$

(1) FORO-RING 2 - 324

(5) FORORING $2-214$

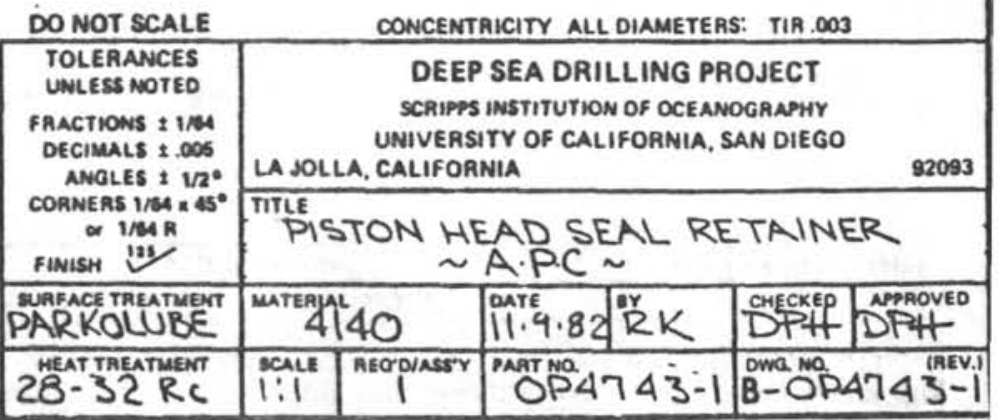




\begin{tabular}{|c|c|c|c|c|c|}
\hline \multicolumn{6}{|c|}{ REVISIONS } \\
\hline NO. & DESCRIPTION & DATE & BY & $\mathrm{CH}$. & APR \\
\hline & 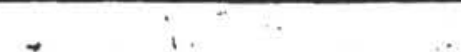 & . & $\because$ & & \\
\hline
\end{tabular}

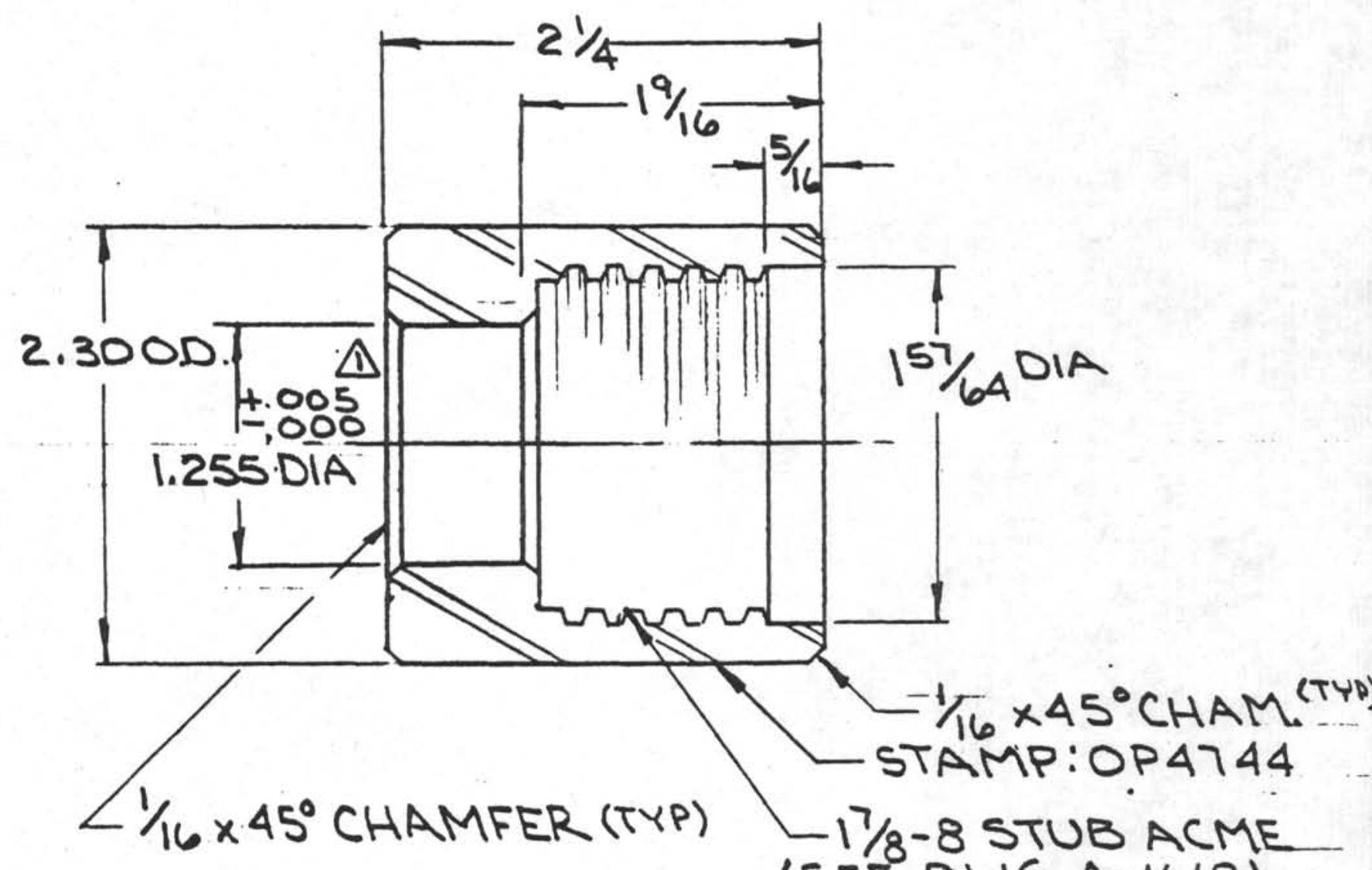

NOTE:

(SEE DWG A-1618)

RELIEVE AS NECESSARY

THIS PART REQUIREO TO ADAPT BREAKAWAT PISTON HEAD ASS'Y. (APC) TO VLHPC. IF DESIRED IT CAN BE MADE FROM EXISTING VLHPC PART "OP 4345 BY REDUCING O.D.

DO NOT SCALE TOLERANCES UNLESS NOTED

FAACTIONS $\pm 1 / 64$ DECIMALS \pm .005 ANGLES $\pm 1 / 2^{\circ}$ CORNERS $1 / 64 \times 45^{\circ}$ FINISH or 1/64 $R$ SURFACE TREATMENT PARKOLUBE HEAT TREATMENT $\operatorname{Rc} 28 \cdot .32$

.

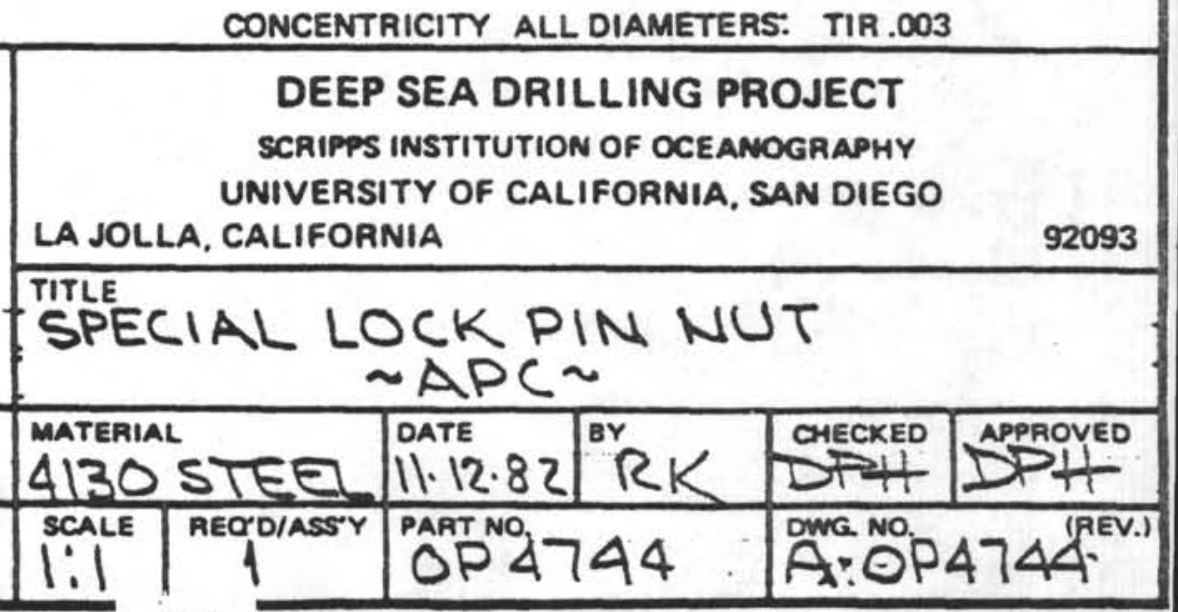




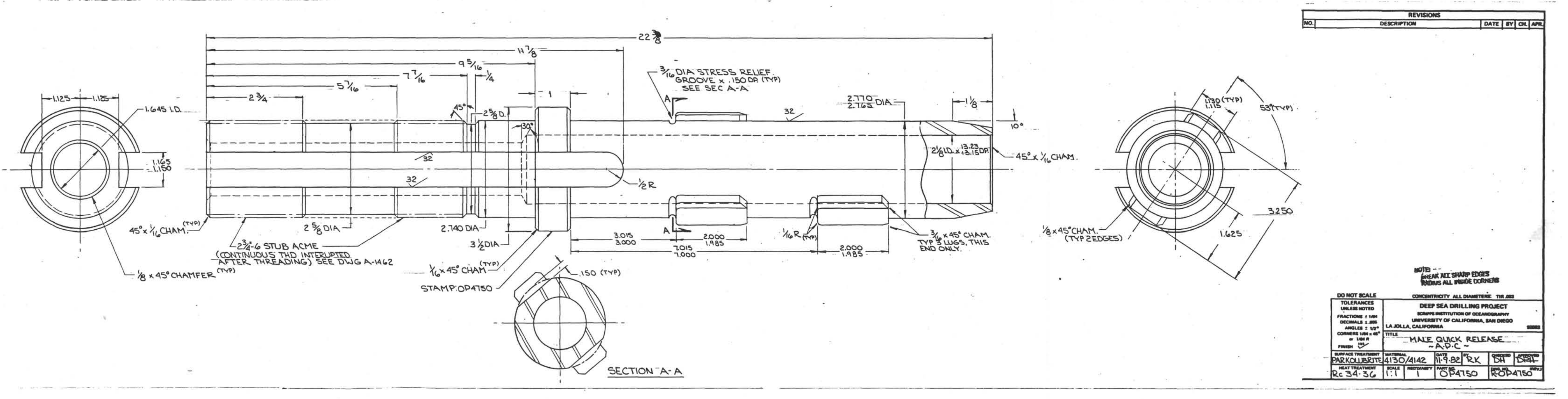




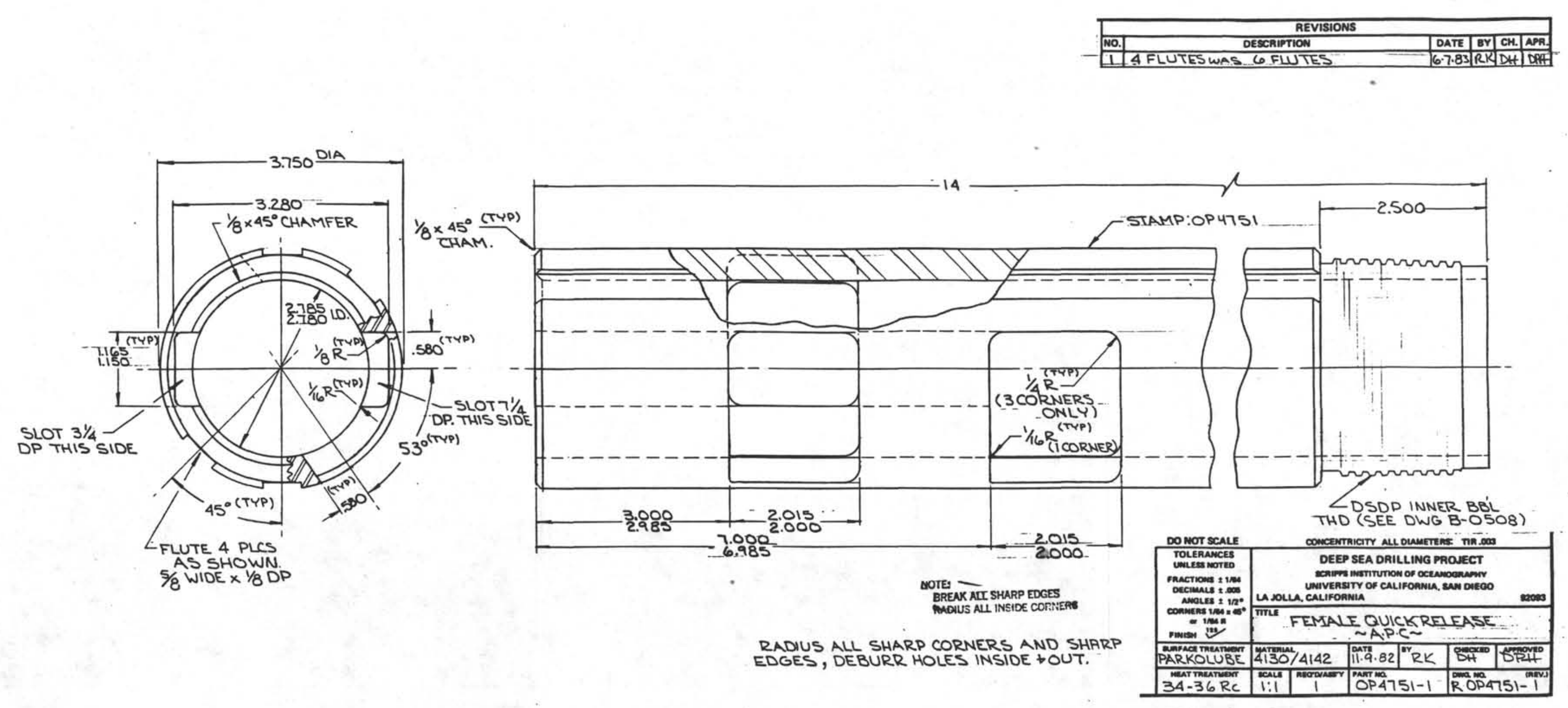




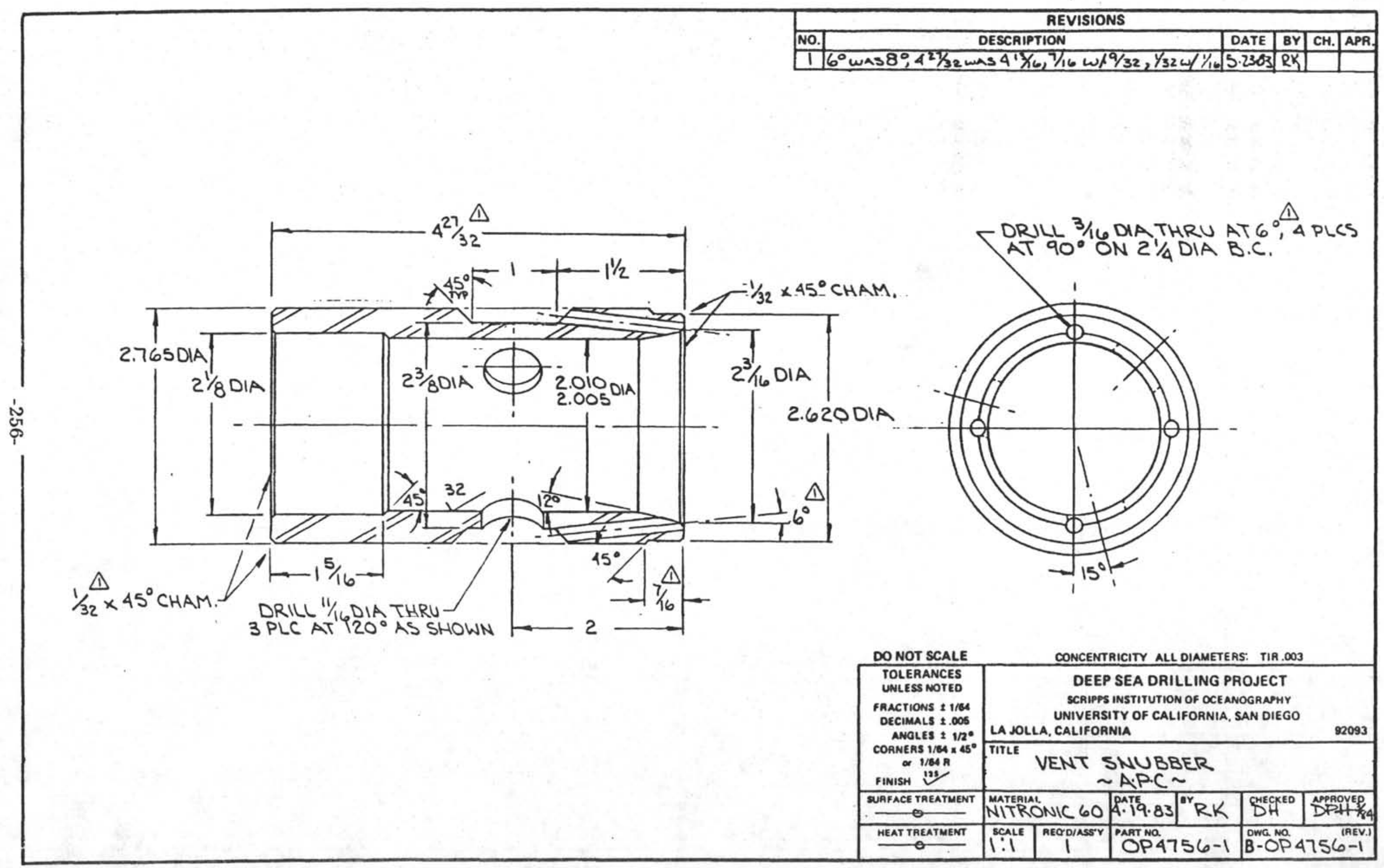




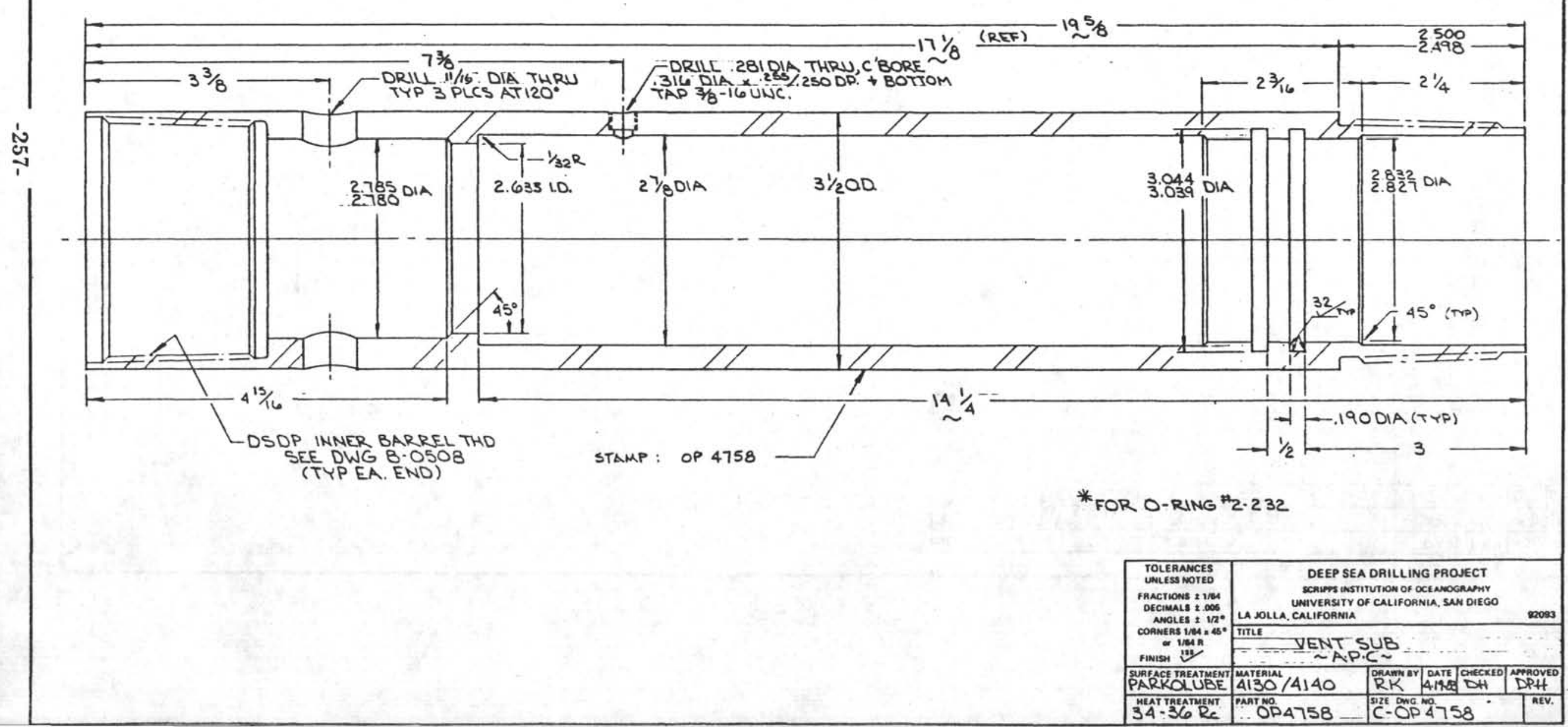




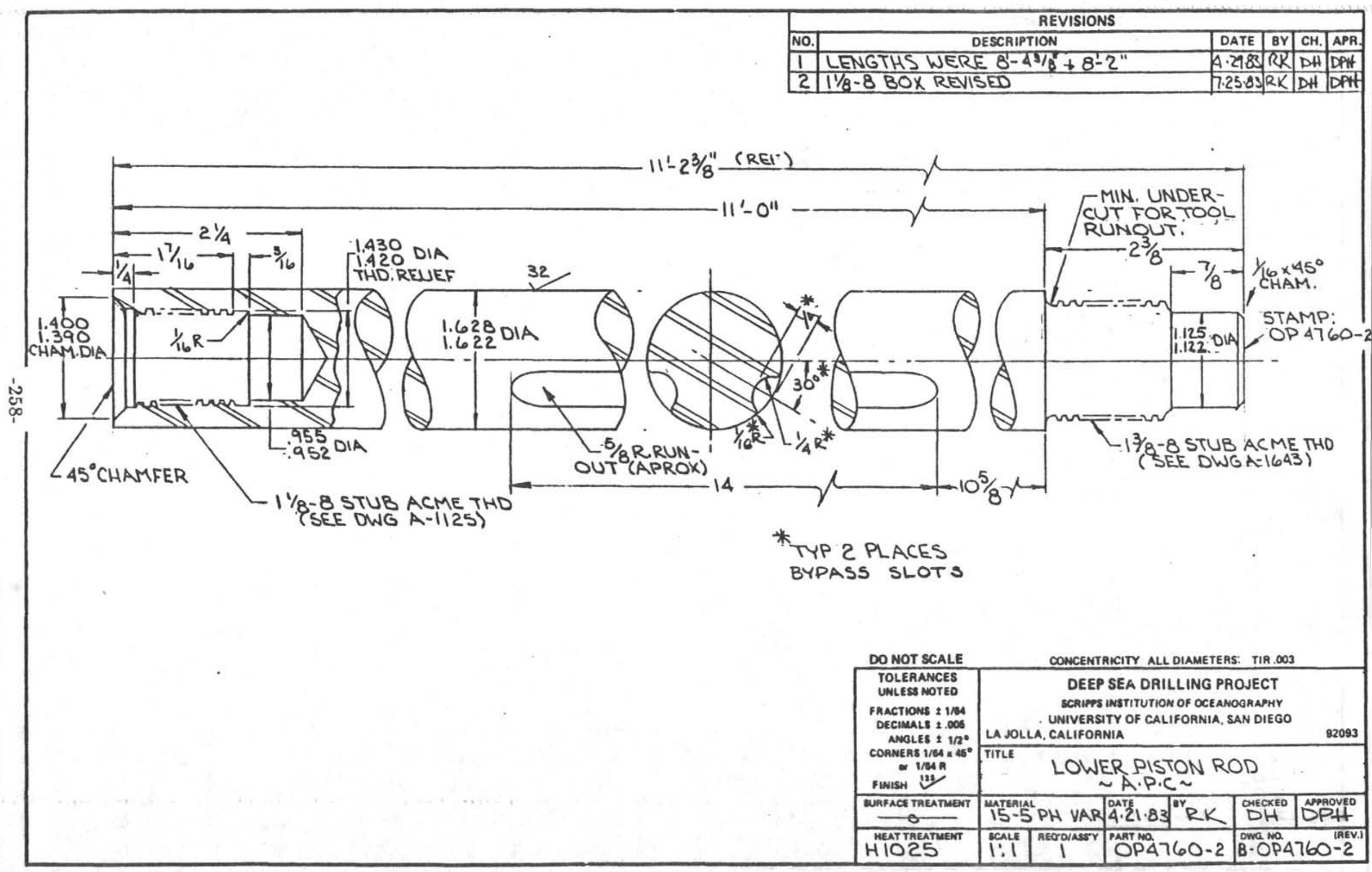




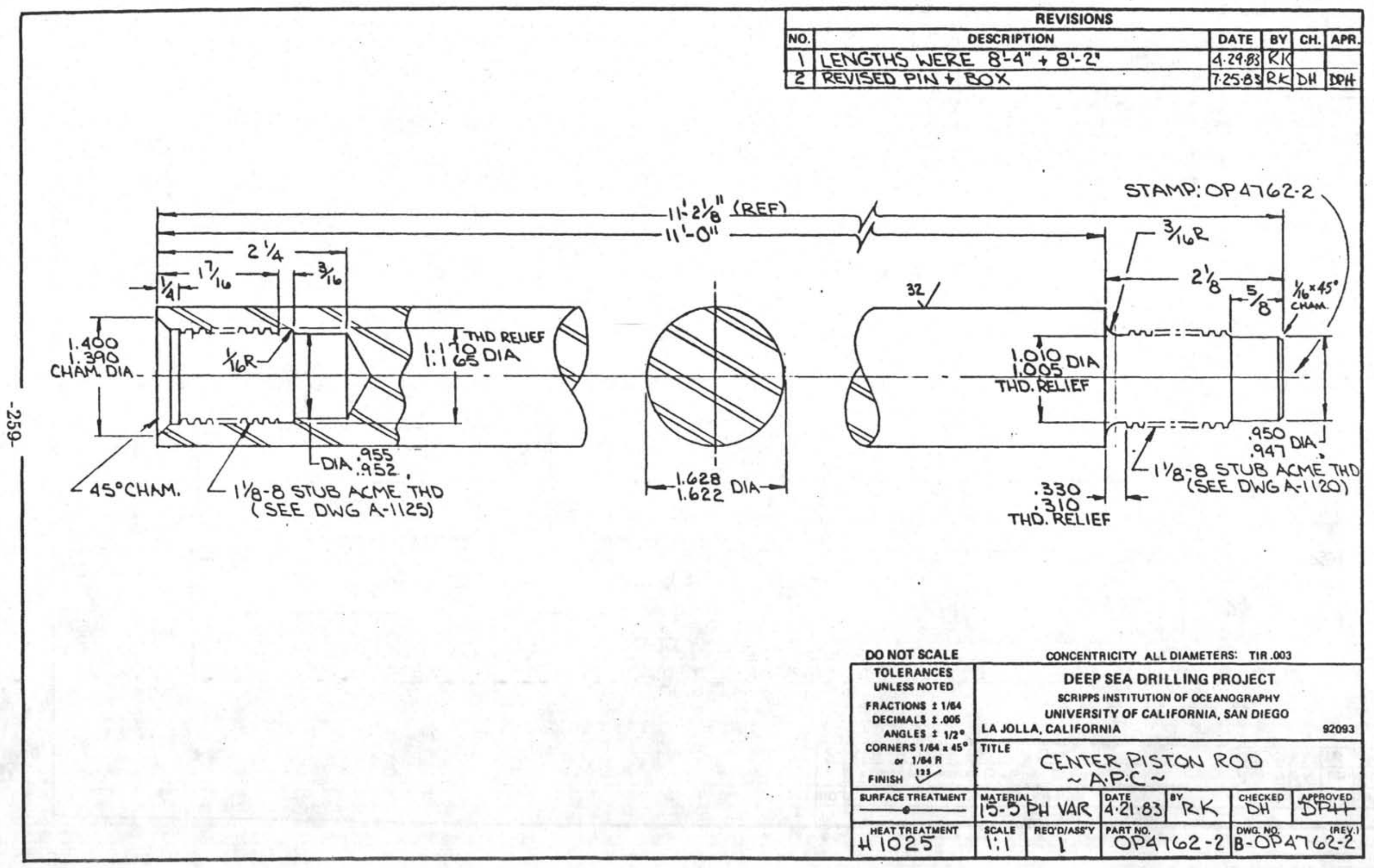




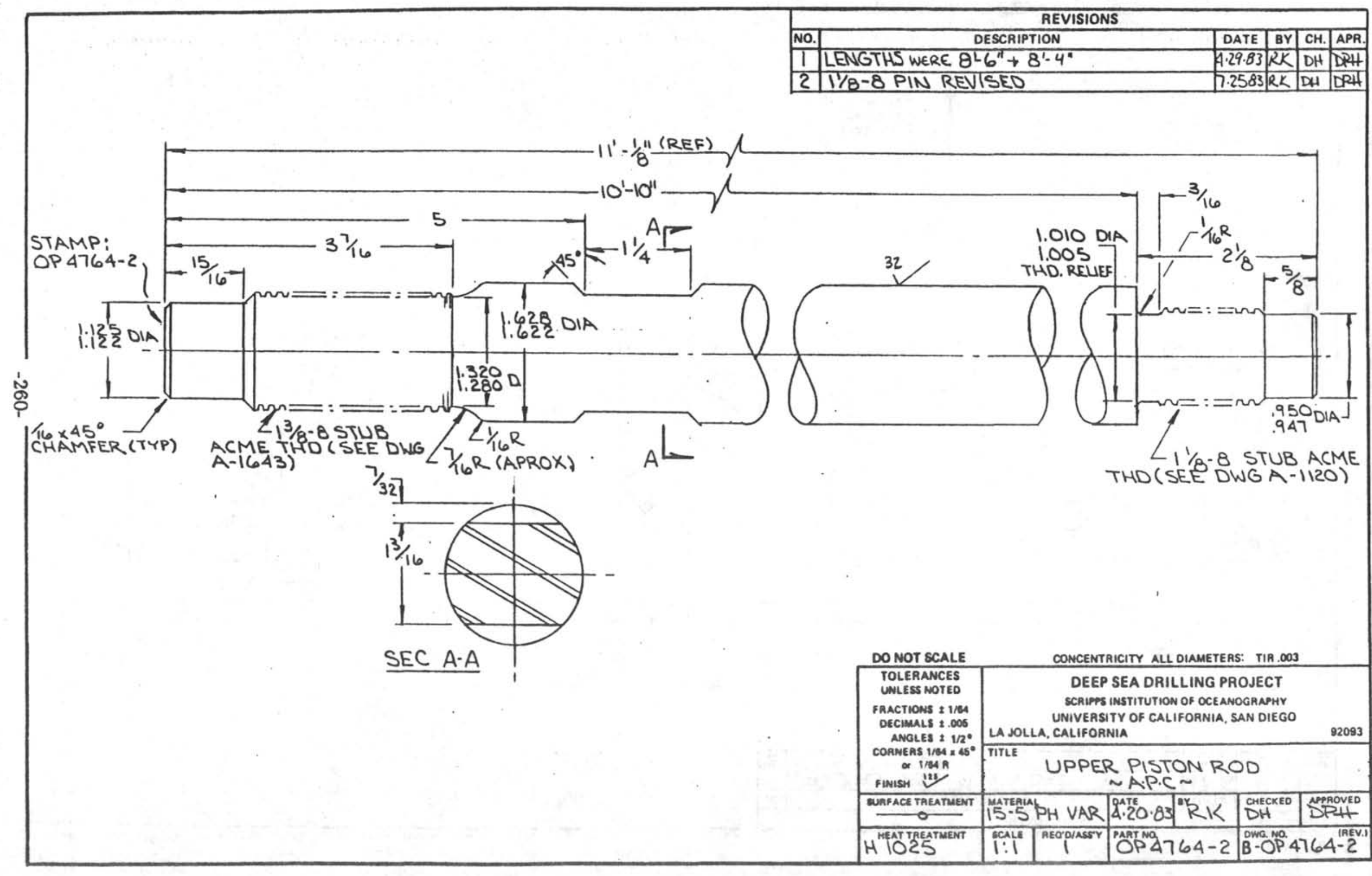




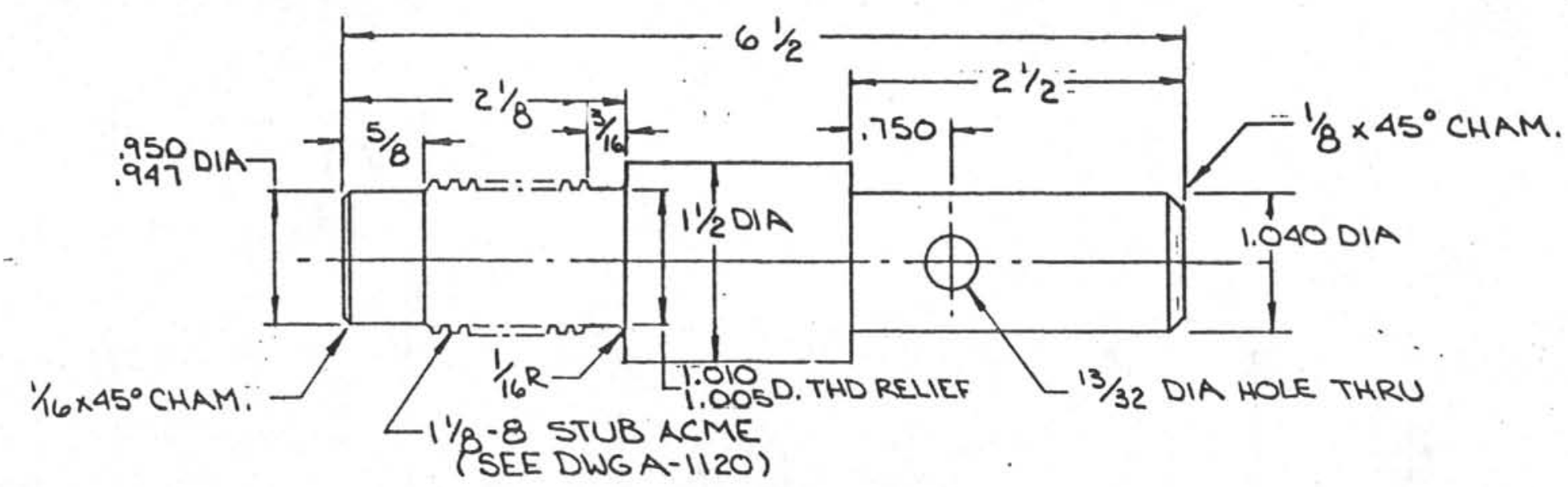

STAMP: OP 4768-1

\begin{tabular}{|c|c|c|c|c|c|}
\hline \multirow{5}{*}{$\begin{array}{l}\text { DO NOT SCALE } \\
\text { TOLERANCES } \\
\text { UNLESS NOTED } \\
\text { FAACTIONS } \$ 1 / 1 / 4 \\
\text { DECIMALS } \$: 005 \\
\text { ANGLES } \$ 1 / 2^{\circ} \\
\text { COANERS } 1 / 64 \times 45^{\circ} \\
\text { of 1/EA R } \\
\text { FINISH III }\end{array}$} & \multicolumn{5}{|c|}{ NCENTAICITY ALL DIAMETERS: TIR } \\
\hline & \multirow{3}{*}{\multicolumn{4}{|c|}{$\begin{array}{l}\text { DEEP SEA DRILLING PROJECT } \\
\text { SCAIPFS INSTITUTION OF OCEANOGAAPHY } \\
\text { UNIVERSITY OF CALIFORNIA, SAN DIEGO } \\
\text { LA JOLLA, CALIFOANIA }\end{array}$}} & \\
\hline & & & & & \\
\hline & & & & & \\
\hline & \multicolumn{5}{|c|}{$\begin{array}{l}\text { PIILE } \\
\text { PISTON ROD EXTENSION - BREAKAWAY } \\
\text { PISTON HEAD } \sim A \cdot P \cdot C \sim\end{array}$} \\
\hline & $\begin{array}{l}\text { MATEAIAL } \\
4130\end{array}$ & 4.22 .83 & & & DPPOVEO \\
\hline & SCALA AEO'OIASEYY & & & & \\
\hline
\end{tabular}




\begin{tabular}{|l|l|l|l|l|l|}
\hline NO. & DESCRIPTION & DATE & BY & CH. & APR. \\
\hline
\end{tabular}

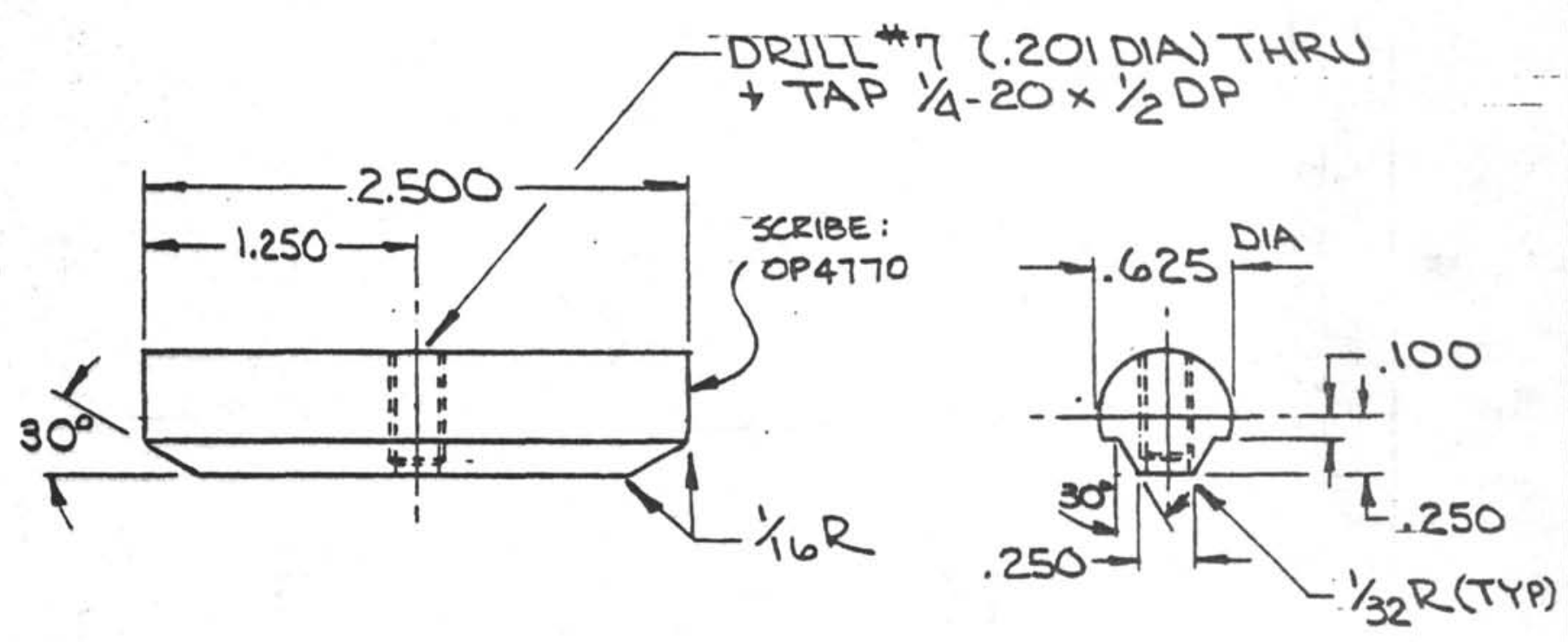

DO NOT SCALE TOLERANCES UNLESS NOTED

FAACTIONS $\pm 1 / 64$ DECIMALS \pm .005 ANGLES $\pm 1 / 2^{\circ}$ CORNERS $1 / 64 \times 45^{\circ}$ or $1 / 84 \mathrm{R}$ FINISH 125 SURFACE TREATMENT

$\longrightarrow$
HEAT TAEATMENT
CONCENTRICITY ALL DIAMETERS: TIR.003

DEEP SEA DRILLING PROJECT

SCAIPPS INSTITUTION OF OCEANOGRAPMY UNIVERSITY OF CALIFORNIA, SAN DIEGO LA JOLLA, CALIFORNIA

TITLE

ANTI-SPIRAL KEY $\sim A \cdot P C \sim$

\begin{tabular}{|c|c|c|c|c|c|}
\hline \multicolumn{2}{|c|}{ MATERIAL } & $\begin{array}{l}\text { DATE } \\
4.25 .83\end{array}$ & BY RK & CHECKED & $\begin{array}{l}\text { APPAOVED } \\
\text { DPHH }\end{array}$ \\
\hline $\begin{array}{l}\text { SCALE } \\
1: 1\end{array}$ & $\begin{array}{c}\text { AEO'D/ASSYY } \\
1\end{array}$ & $\begin{array}{l}\text { PAATNO. } \\
\text { OP } 4\end{array}$ & 0 & DW- & $\overline{\mathrm{REV} .}$ \\
\hline
\end{tabular}




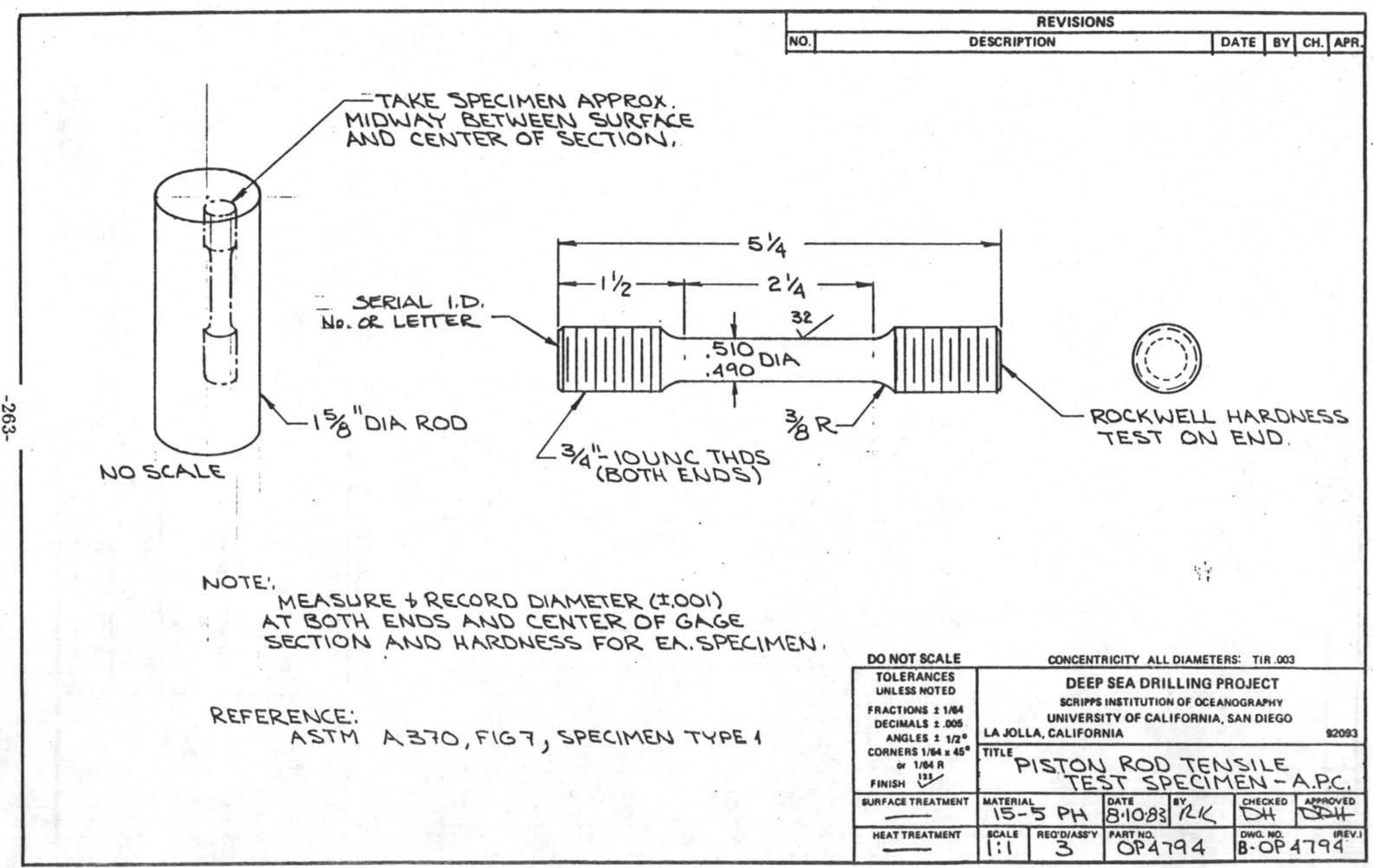



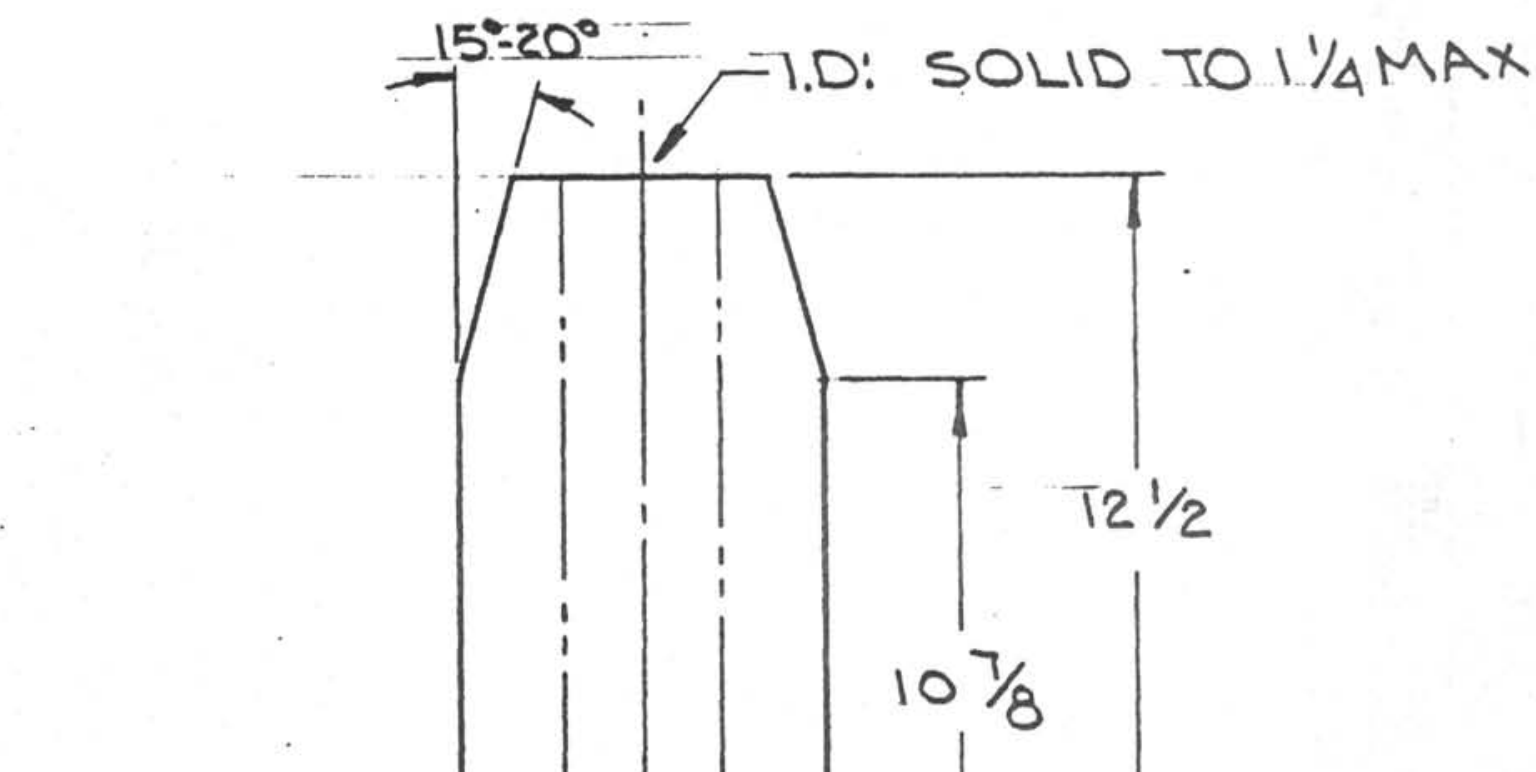
1. ASSEMBLE ONE UPPER ROD SECTION, TWO CENTER ROD SECTIONS

AND ONE LOWER ROD SECTIONS WITH THREADS MADE UP FIRMLY.

2. CUT ANTI-SPIRAL GROOVE AS SHOWN IN ASSEMBLY.

3. PART NUMBERS AS FOLLOWS:

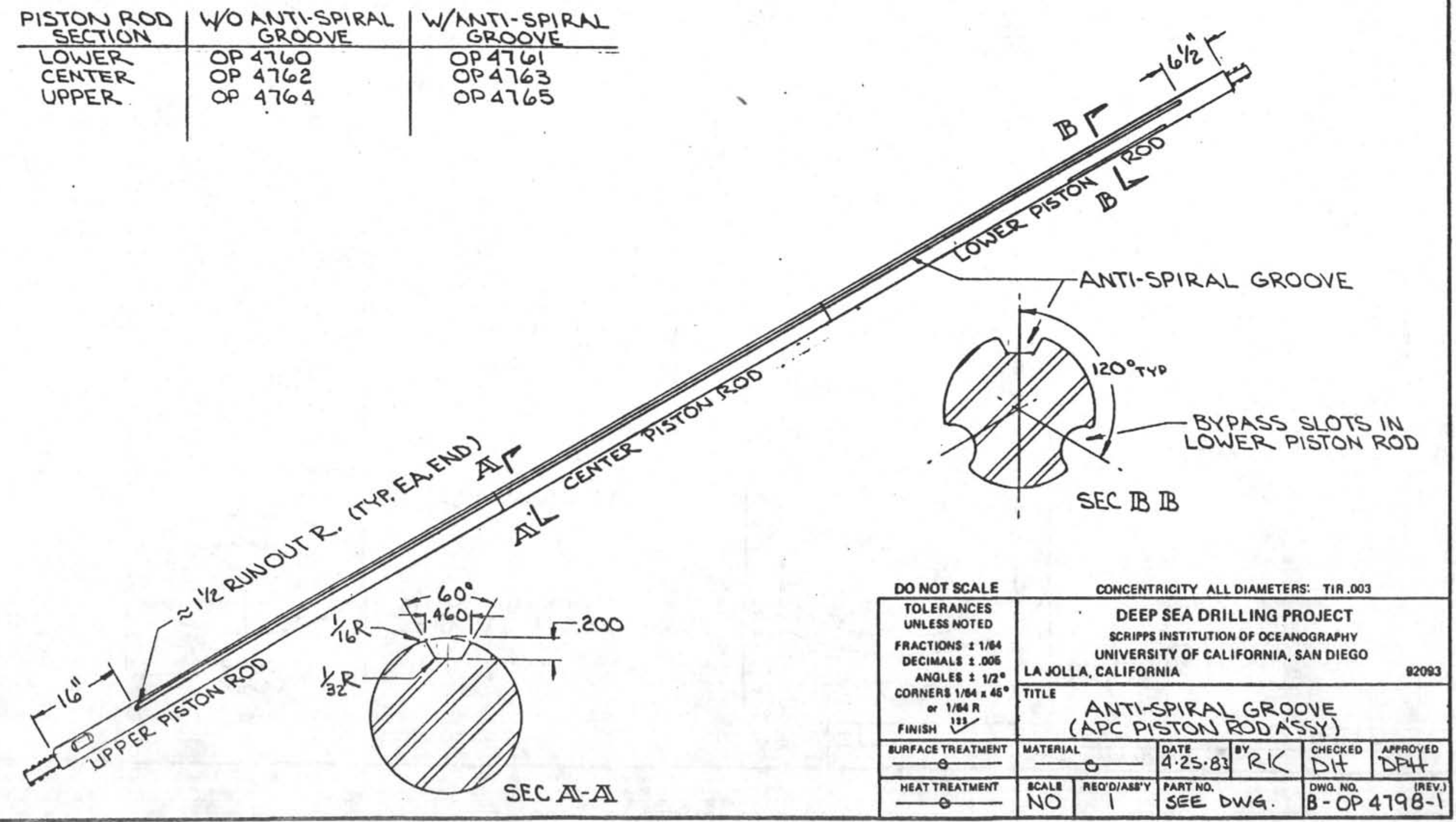




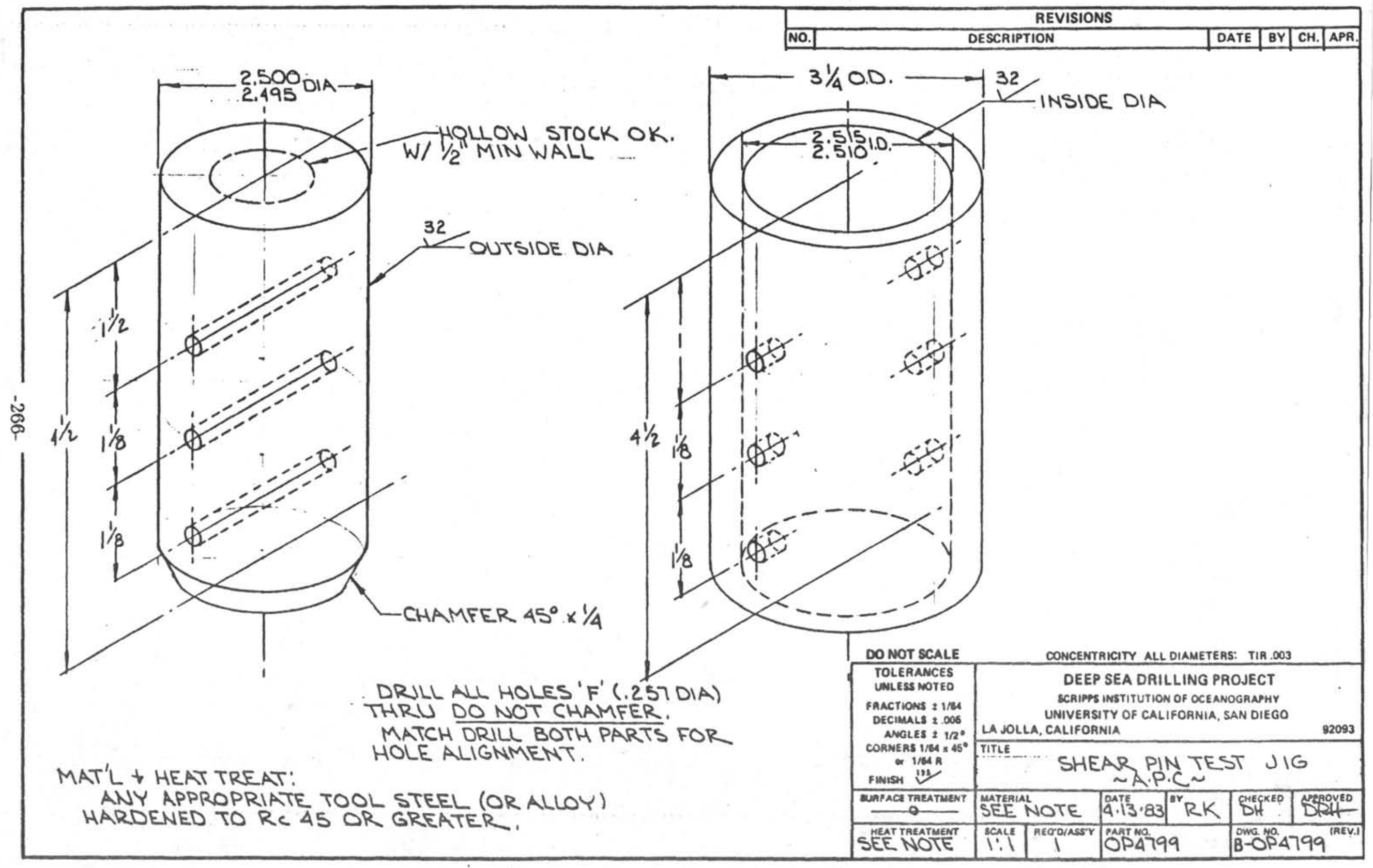




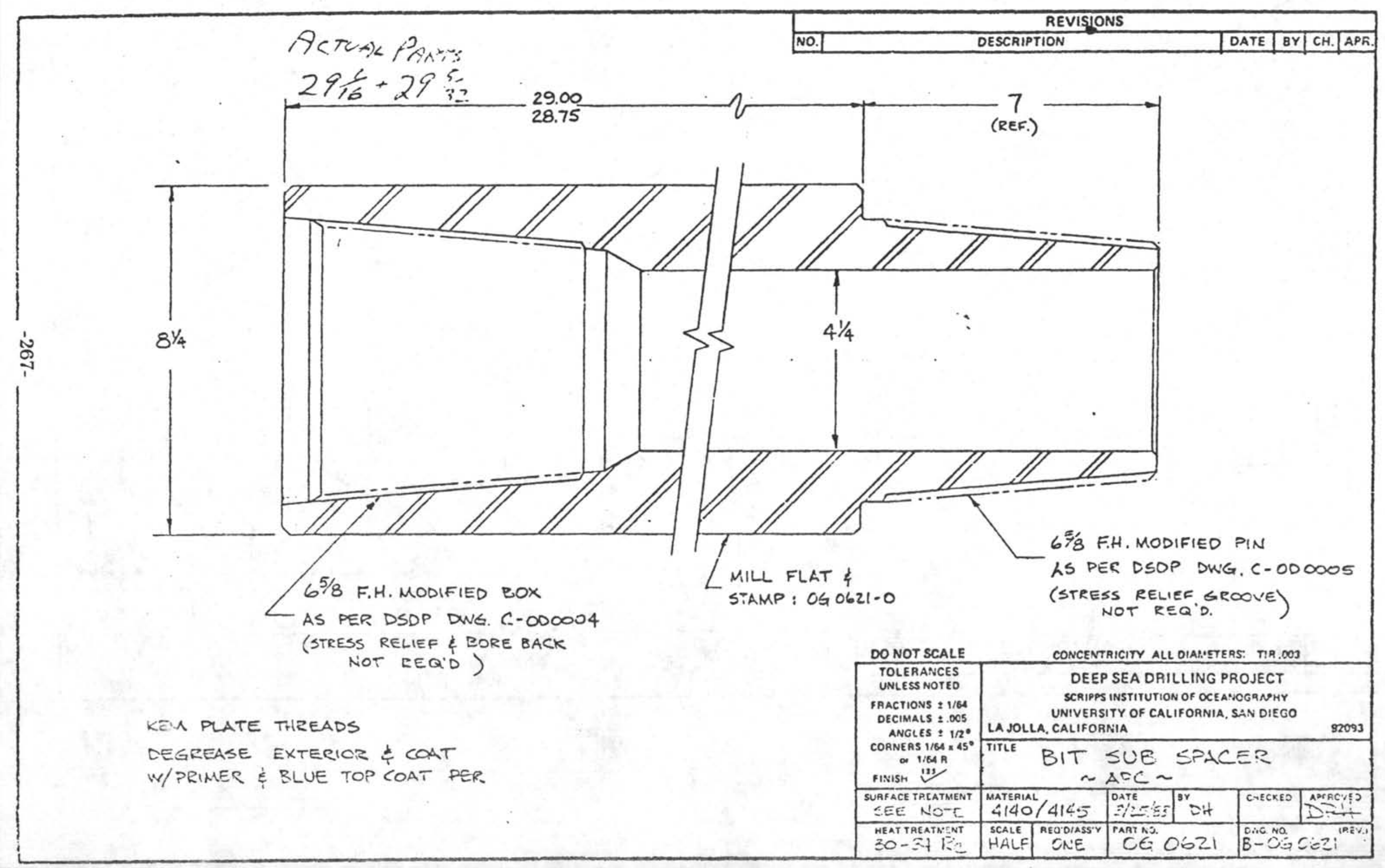




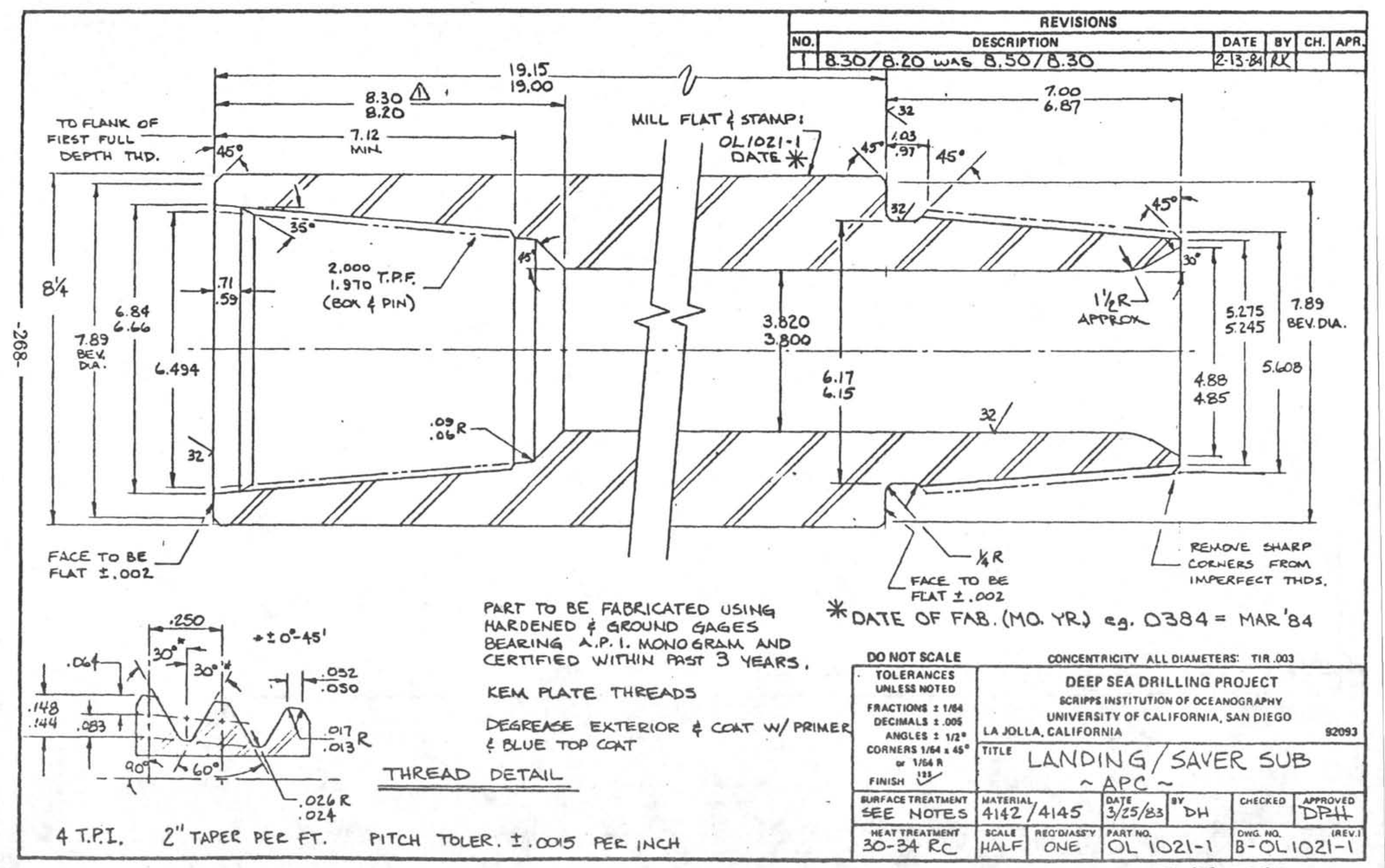




\section{SEAL BORE DRILL COLLAR SPECIFACATIONS \\ OL 1043}

Required in Hole Assembly for use with Advanced Piston Corer (APC)

Size: $8 \frac{1}{4} \pm 1 / 16^{\prime \prime}$ O.D. $\times 3.800$

$$
\text { I.D. } \times 31^{\prime}-2 \pm \frac{1}{2}{ }^{\prime \prime} \text { long, }
$$
shoulder-to-shoulder

I.D. Fin1sh: $32-64$ rms \& no steps

Materlal: Premium grade AISI 4145H Alloy Steel, fully heat treated over entire length to $285-341$ brinnel hardness.

Minimum Yield $=120,000$ psi at $1^{\prime \prime}$ below $0 . D$.

Guaranteed minimum $40 \mathrm{ft}-1 \mathrm{bs}$ Izod Impact Test

Connections: 6 5/8" Full Hole Box Up per DSDP Drwg. \#C-OD-0004

6 5/8 Full Hole Modified P1n Down (7' long)

per DSDP Drwg. \#C-OD-0005

Threads to be Hob Cut and Kemplated. Box to have Drillco Bore Back. Pin to have API Stress Relief Groove and $30^{\circ}$ I.D. chamfer x $0.8^{\prime \prime}$ deep

Provide with pressed steel box and pin thread protecters. 